ANTÔNIO CARLOS SALLARÉS DE MATTOS CARVALHO

DESENVOLVIMENTO DE PROCESSO CONTÍNUO DE COPOLIMERIZAÇÃO EM EMULSÃO EM REATOR TUBULAR 
ANTÔNIO CARLOS SALLARÉS DE MATTOS CARVALHO

\section{DESENVOLVIMENTO DE PROCESSO CONTÍNUO DE COPOLIMERIZAÇÃO EM EMULSÃO EM REATOR TUBULAR}

Tese apresentada à Escola Politécnica da Universidade de São Paulo para obtenção do Título de Doutor em Engenharia.

São Paulo

2008 


\section{DESENVOLVIMENTO DE PROCESSO CONTÍNUO DE COPOLIMERIZAÇÃO EM EMULSÃO EM REATOR TUBULAR}

Tese apresentada à Escola Politécnica da Universidade de São Paulo para obtenção do Título de Doutor em Engenharia.

Área de Concentração:

Engenharia Química.

Orientador:

Prof. Dr. Reinaldo Giudici.

São Paulo 
Este exemplar foi revisado e alterado em relação à versão original, sob responsabilidade única do autor e com a anuência de seu orientador.

São Paulo, de abril de 2008.

Assinatura do autor

Assinatura do orientador

\section{FICHA CATALOGRÁFICA}

Carvalho, Antonio Carlos Sallarés de Mattos

Desenvolvimento de processo contínuo de copolimerização em emulsão em reator tubular / A.C.S.M. Carvalho. -- São Paulo, 2008. $169 \mathrm{p}$.

Tese (Doutorado) - Escola Politécnica da Universidade de São Paulo. Departamento de Engenharia Química.

1. Polimerização 2. Reator contínuo 3. Acetato de vinila 4. Acrilato de butila I. Universidade de São Paulo. Escola Politécnica. Departamento de Engenharia Química II. t. 


\section{AGRADECIMENTOS}

Ao CNPq pela bolsa e pelos recursos de reserva técnica que tornaram possível a realização desse trabalho.

À Fundação de Amparo à Pesquisa do Estado de São Paulo - FAPESP - pelo suporte financeiro que possibilitou o projeto e a execução da adaptação física da unidade experimental utilizada.

Ao Laboratório de Computação Científica Avançada - LCCA - pela disponibilização de seus recursos computacionais mediante os quais foram feitas as simulações.

À Dow Brasil S.A. e à BASF S.A. pelo fornecimento de monômeros utilizados nos ensaios experimentais.

A todos os amigos do LSCP - Laboratório de Simulação e Controle de Processos do Departamento de Engenharia Química da USP que contribuíram direta e indiretamente para a realização deste trabalho.

Ao Prof. Reinaldo Bazito, do Instituto de Química da USP, pela sua ajuda no trabalho de caracterização do produto.

Ao Prof. Dr. Mauri Palma, pela sua valorosa contribuição no esclarecimento dos procedimentos operacionais do equipamento utilizado.

À Professora Dra. Claudia Sayer, pela sua grande ajuda e prontidão em seus esclarecimentos nos ensaios experimentais e de simulação.

Ao Prof. Dr. Reinaldo Giudici, pela sua grande atenção, disponibilidade e paciência demonstradas durante a orientação deste trabalho. 


\section{RESUMO}

Os processos industriais de polimerização em emulsão são normalmente realizados em reatores batelada ou semi batelada ou em tanques agitados contínuos (CSTR). Os reatores contínuos têm a vantagem de terem menor porte e de propiciarem melhor controle de qualidade do produto através da redução de variações de batelada a batelada. Além disso, as oscilações periódicas autosustentadas na conversão de monômero e no tamanho da partícula, que são normalmente observadas em reatores do tipo CSTR, podem ser minimizadas em reatores tubulares mediante o uso de dispositivos de mistura estáticos adequados combinados com escoamento pulsado (oscilatório).

O objetivo deste trabalho é apresentar o desenvolvimento de uma copolimerização em emulsão de acetato de vinila e acrilato de butila em uma coluna pulsada com pratos perfurados (CPPP). A fim de aumentar a sua flexibilidade operacional, a coluna é composta de 5 seções, cada uma apresentando controles independentes de alimentação lateral e temperatura. Dependendo da estratégia de alimentação de monômero, pode-se notar uma deriva de composição durante o processo de copolimerização em emulsão do acetato de vinila e acrilato de butila devido às grandes diferenças entre estes monômeros em suas razões de reatividade e nas solubilidades na fase aquosa. Neste caso, a CPPP propicia diferentes possibilidades de alimentação que permitem controlar a composição do copolímero através da alimentação do monômero mais reativo ao longo da coluna. Por esta razão, foi avaliado neste estudo o efeito do número de correntes de alimentação sobre as propriedades do polímero. Diferentes números de correntes laterais de alimentação de monômero foram empregadas nos ensaios experimentais. Diferenças na uniformidade da composição do copolímero podem ser notadas dependendo do número de correntes laterais de alimentação aplicadas em cada teste. A fim de permitir variações de temperatura, somente a temperatura de entrada das camisas de resfriamento foi fixada.

Para simular as reações foi utilizado um modelo matemático desenvolvido baseado no modelo de escoamento pistonado (plug-flow) axialmente disperso. No presente trabalho, um balanço de energia foi incluído ao modelo matemático anterior de modo que a influência de diferentes perfis de temperatura pudesse ser considerada. $O$ efeito das correntes laterais de alimentação de monômero sobre as propriedades do copolímero puderam ser previstas com suficiente precisão pelas simulações do modelo, as quais foram também validadas pelos resultados experimentais.

Com base nas simulações matemáticas, um perfil ótimo de alimentação pôde ser calculado e experimentalmente aplicado na CPPP permitindo a produção de um copolímero mais homogêneo. Os resultados também permitiram a validação do modelo matemático como uma ferramenta confiável na predição de ensaios experimentais. Além disso, as vantagens da CPPP puderam ser verificadas pelo seu desempenho adequado como reator tubular para processos contínuos de copolimerização em emulsão. Finalmente, os resultados indicaram a possibilidade de melhorias adicionais nas propriedades do polímero através do emprego de diferentes temperaturas e perfis de alimentação de outros reagentes ao longo da coluna. 


\begin{abstract}
Industrial emulsion polymerization processes are usually performed in batch or semi-batch stirred tanks, or in continuous stirred tank reactors (CSTR). Continuous reactors have the advantage of being smaller and providing a better product quality control by the reduction of the batch-to-batch variations. In addition, periodical self-sustained oscillations in monomer conversion and in particle size that are usually observed in CSTR can be minimized in tubular reactors presenting good radial mixing. Such conditions can be achieved in tubular reactors by using adequate static mixing devices combined with pulsed (oscillatory) flow.
\end{abstract}

The aim of this work is to report the development of a continuous emulsion copolymerization of vinyl acetate and butyl acrylate performed in a pulsed sieve plate column (PSPC). In order to improve its operational flexibility, the column is composed of five sections, each one presenting independent lateral feed and temperature controls. Depending on the monomer feeding strategy, a composition drift can be noticed during the emulsion copolymerization process of vinyl acetate and butyl acrylate, due to the large differences in reactivity ratios and aqueous phase solubility between these monomers. In this case, the PSPC provides different operational feeding possibilities which allow controlling the copolymer composition by feeding the more reactive monomer along the column. For this reason, in this study the effect of the number of lateral feed streams on the polymer properties was evaluated. Different numbers of lateral monomer feed streams were employed in the experimental runs. Differences in the uniformity of the copolymer composition can be noticed along the reactor depending on the number of lateral feed streams applied in each test. In order to allow temperature variations, during each reaction only the inlet temperature of the cooling jackets was fixed.

A developed mathematical model based on the axially dispersed plug-flow model was used to simulate the reactions. In the present study the energy balance was included in the mathematical model so that the influence of different temperature profiles could be taken into account. The effect of lateral monomer feed streams over the copolymer properties could be predicted with sufficient accuracy by model simulations which were also validated by the experimental results.

Based on mathematical simulations, an optimal feeding profile could be calculated and experimentally applied in the PSPC allowing the production of a more homogeneous copolymer. The results also permitted the validation of the mathematical model as a reliable tool in the prediction of experimental runs. Furthermore, the advantages of the PSPC could be verified by its adequate performance as a tubular reactor for continuous emulsion copolymerization processes. Finally, the results indicate the possibility of further improvements in other polymer properties by employing different temperature and feeding profiles of other reagents along the column. 


\section{ÍNDICE DE FIGURAS}

Figura 3.1 Coluna pulsada com pratos perfurados, em sua configuração original do trabalho de PALMA (2002).

Figura 3.2 Coluna pulsada com pratos perfurados, em sua configuração como utilizada no presente trabalho 50

Figura 3.3 Esquema da malha de controle temperatura do meio reacional 52

Figura 3.4 Tela de dados operacionais do programa de controle da CPPP. 53

Figura 3.5 Tela do programa de controle manual da CPPP 54

Figura 3.6 Exemplo de Curva de Calibração do Sistema VAc-BuA 57

Figura 3.7 Rampa de Temperatura do Forno. 58

Figura 4.1 Correlação entre o coeficiente efetivo de dispersão axial, amplitude e freqüência de pulsações, PALMA e GIUDICI (2003). 80

Figura 4.2 Volume de controle do balanço de energia para o cálculo de UA...... 82

Figura 4.3 Perfil de temperaturas da aquecida água alimentada no interior da coluna 82

Figura 4.4 Estimativa do coeficiente UA em função da freqüência de pulsação .83

Figura 5.1 Efeito no número de alimentações laterais sobre o perfil de temperatura previsto, em regime permanente 90

Figura 5.2 Efeito no número de alimentações laterais sobre o perfil de conversão previsto, em regime permanente 90

Figura 5.3 Efeito do número de alimentações laterais sobre o perfil de composição do copolímero, em regime permanente

Figura 5.4 Efeito da temperatura da água na camisa sobre o perfil de temperatura em regime permanente

Figura 5.5 Efeito da temperatura da água na camisa sobre o perfil de conversão em regime permanente

Figura 5.6 Efeito da temperatura da água na camisa sobre o perfil de composição do copolímero em regime permanente.

Figura 5.7 Efeito da amplitude de pulsação sobre o perfil de temperatura em regime permanente 
Figura 5.8 Efeito da amplitude de pulsação sobre o perfil de conversão em regime permanente

Figura 5.9 Efeito da amplitude de pulsação sobre o perfil de composição do copolímero em regime permanente 95

Figura 5.10 Efeito do tempo de residência do fluido no reator sobre o perfil de temperatura em regime permanente

Figura 5.11 Efeito do tempo de residência do fluido no reator sobre o perfil de conversão em regime permanente

Figura 5.12 Efeito do tempo de residência do fluido no reator sobre o perfil de composição do copolímero em regime permanente

Figura 5.13 Dados experimentais e resultados da simulação para o ensaio 1 101

Figura 5.14 Dados experimentais e resultados da simulação para o ensaio 1 102

Figura 5.15 Resultados da simulação para o ensaio 1 103

Figura 5.16 Distribuição das alimentações laterais de acrilato de butila usada nos ensaios 2 e 3 104

Figura 5.17 Composição, conversão e temperatura de reação em regime permanente - ensaio 2 105

Figura 5.18 Dados experimentais e resultados da simulação para o ensaio 2 ..... 106

Figura 5.19 Resultados da simulação para o ensaio 2 107

Figura 5.20 Dados experimentais e resultados da simulação para o ensaio 3 .. 108

Figura 5.21 Dados experimentais e resultados de simulação para o ensaio 3 .... 109

Figura 5.22 Resultados da simulação para o ensaio 3 110

Figura 5.23 Distribuição das alimentações laterais de acrilato de butila usada nos ensaios 4 e 5

Figura 5.24 Dados experimentais e resultados da simulação para o ensaio 4 113

Figura 5.25 Dados experimentais e resultados da simulação para o ensaio 4 114

Figura 5.26 Resultados da simulação para o ensaio 4 115

Figura 5.27 Dados experimentais e resultados da simulação para o ensaio 5 116

Figura 5.28 Dados experimentais e resultados da simulação para o ensaio 5. 117

Figura 5.29 Resultados da simulação para o ensaio 5 118

Figura 5.30 Distribuição das alimentações laterais de acrilato de butila usada no ensaio 6 
Figura 5.31 Dados experimentais e resultados da simulação para o ensaio 6 121

Figura 5.32 Dados experimentais e resultados da simulação para o ensaio 6. 122

Figura 5.33 Resultados da simulação para o ensaio 6 123

Figura 5.34 Distribuição das alimentações laterais de acrilato de butila usada nos ensaios 7 e 8 125

Figura 5.35 Dados experimentais e resultados da simulação para o ensaio 7 126

Figura 5.36 Dados experimentais e resultados da simulação para o ensaio 7 127

Figura 5.37 Dados experimentais e resultados da simulação para o ensaio 7 128

Figura 5.38 Dados experimentais e resultados da simulação para o ensaio 8. 129

Figura 5.39 Dados experimentais e resultados da simulação para o ensaio 8. 130

Figura 5.40 Resultados da simulação para o ensaio 8 131

Figura 5.41 Distribuição das alimentações laterais de acrilato de butila usada nos ensaios 9 e 10 132

Figura 5.42 Dados experimentais e resultados da simulação para o ensaio 9. 135

Figura 5.43 Dados experimentais e resultados da simulação para o ensaio 9 136

Figura 5.44 Dados experimentais e resultados da simulação para o ensaio 10 137

Figura 5.45 Dados experimentais e resultados da simulação para o ensaio 10. 138

Figura A-1 Espectro de RMN-C ${ }^{13}$ do copolímero com atribuição dos picos Dados experimentais e resultados da simulação para o ensaio 10 161

Figura A-2 Esquema do copolímero, indicando a codificação dos átomos de carbono 162

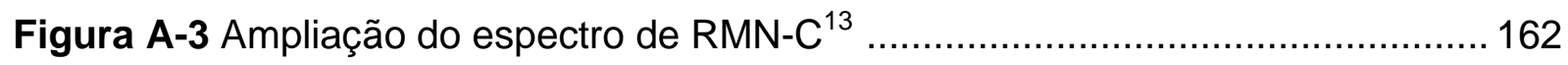

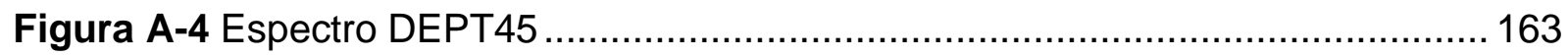

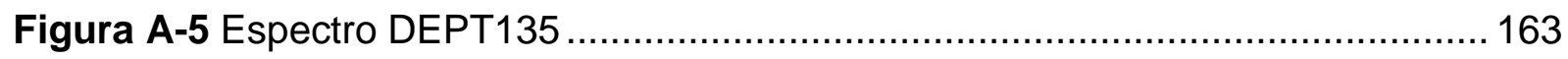

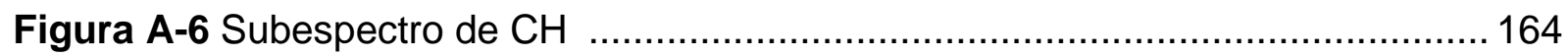

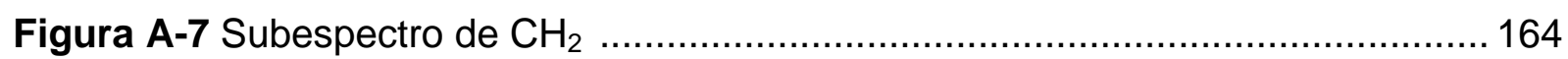

Figura A-8 Diagrama de Calorimetria Exploratória Diferencial ............................. 166 


\section{ÍNDICE DE TABELAS}

Tabela 2.1 Valores de razão de reatividade obtidos experimentalmente.................... 22

Tabela 4.1 Valores de Parâmetros Adotados nas Simulações .................................. 84

Tabela 5.1 Formulação da copolimerização VAc-BuA ........................................... 87

Tabela 5.2 Condições operacionais do caso base para o estudo de sensibilidade do

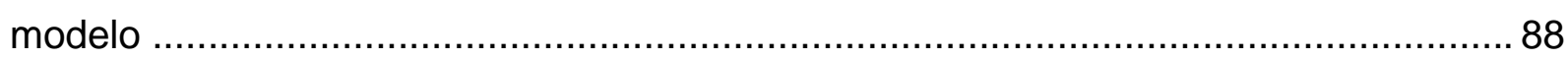

Tabela 5.3 Condições operacionais utilizadas nos ensaios experimentais................. 99

Tabela 5.4 Valores de razões de reatividade estimadas pelas equações (5.2) e (5.3) em comparação com os valores adotados no modelo ...................................... 143

Tabela 5.5 Valores de razões de reatividade obtidos experimentalmente ................. 144

Tabela A.1 Probabilidades de incidência das possíveis díades na cadeia polimérica 


\section{NOMENCLATURA}

\begin{tabular}{|c|c|c|}
\hline$A^{\prime}$ & amplitude de pulsação & $\mathrm{cm}$ \\
\hline$A$ & área de troca térmica & $\mathrm{cm}^{2}$ \\
\hline$a_{c o l}$ & altura da coluna & $\mathrm{cm}$ \\
\hline$A_{A}^{G C}$ & área correspondente ao monômero A obtida no espectro de GC & .. \\
\hline$a_{p}$ & área da superfície de uma partícula inchada de monômero & $\mathrm{cm}^{2} /$ partícula \\
\hline$a_{s}$ & área coberta por um mol de emulsificante & $\mathrm{cm}^{2} / \mathrm{mol}$ \\
\hline$C_{C}{ }^{0}$ & coeficiente de coalescência da partícula & $1 / \mathrm{s}$ \\
\hline$C_{C A}{ }^{0}$ & coeficiente de coalescência da partícula para o polímero A & $1 / \mathrm{s}$ \\
\hline$C_{C B}{ }^{0}$ & coeficiente de coalescência da partícula para o polímero B & $1 / \mathrm{s}$ \\
\hline $\mathrm{C}_{\text {feed }}$ & concentração do componente da reação na alimentação & $\mathrm{mol} / \mathrm{cm}^{3}$ \\
\hline$C_{\text {homA }}{ }^{0}$ & $\begin{array}{l}\text { coeficiente taxa de nucleação homogênea da partícula para o } \\
\text { radical } A\end{array}$ & $1 / \mathrm{s}$ \\
\hline$C_{\text {homB }}{ }^{0}$ & $\begin{array}{l}\text { coeficiente taxa de nucleação homogênea da partícula para o } \\
\text { radical B }\end{array}$ & $1 / \mathrm{s}$ \\
\hline$C_{i}$ & concentração do componente i & $\mathrm{mol} / \mathrm{cm}^{3}$ \\
\hline$C_{p}$ & calor específico da água & $\mathrm{cal} / \mathrm{g} \mathrm{s}^{\circ} \mathrm{C}$ \\
\hline$C_{p r}$ & calor específico do meio reacional & $\mathrm{cal} / \mathrm{g} \mathrm{s}^{\circ} \mathrm{C}$ \\
\hline$D_{e a}$ & coeficiente de dispersão axial & $\mathrm{cm}^{2} / \mathrm{s}$ \\
\hline $\mathrm{Dp}$ & diâmetro da partícula & $\mathrm{cm}$ \\
\hline$D_{p}$ & coeficiente de difusão de um radical nas partículas de polímero & $\mathrm{cm}^{2} / \mathrm{s}$ \\
\hline$D_{p A}$ & coeficiente de difusão do monômero A na fase polimérica & $\mathrm{cm}^{2} / \mathrm{s}$ \\
\hline$D_{p B}$ & coeficiente de difusão do monômero B na fase polimérica & $\mathrm{cm}^{2} / \mathrm{s}$ \\
\hline$d_{t}$ & diâmetro interno da coluna & $\mathrm{cm}$ \\
\hline$D_{w}$ & coeficiente de difusão na fase aquosa & $\mathrm{cm}^{2} / \mathrm{s}$ \\
\hline$D_{W A}$ & coeficiente de difusão do monômero A na fase aquosa & $\mathrm{cm}^{2} / \mathrm{s}$ \\
\hline$D_{W B}$ & coeficiente de difusão do monômero B na fase aquosa & $\mathrm{cm}^{2} / \mathrm{s}$ \\
\hline e & fator de polaridade do radical ou do monômero & .. \\
\hline$E$ & número de mols de emulsificante & $\mathrm{mol}$ \\
\hline
\end{tabular}


$[E]_{a d s} \quad$ concentração de emulsificante adsorvido nas partículas de polímero

$\mathrm{mol} / \mathrm{cm}^{2}$

$[E]^{a q} \quad$ concentração de emulsificante na fase aquosa

$\mathrm{mol} / \mathrm{cm}^{3}$

$[E]_{C M C}$ concentração micelar crítica

$\mathrm{mol} / \mathrm{cm}^{3}$

$[E]_{a d s}^{\text {sat }} \quad$ concentração de emulsificante por unidade de superfície necessária para saturar as partículas de polímero

$\mathrm{mol} / \mathrm{cm}^{2}$

$f^{\prime} \quad$ eficiência do iniciador

f freqüência de pulsação

$1 / \mathrm{s}$

$F_{M A}$ fração mássica inicial do comonômero $A$ em relação à massa total de monômero

$f_{A} \quad$ fração molar do comonômero A não reagido

$F_{A} \quad$ fração molar instantânea do comonômero A no copolímero

$f_{a b s} \quad$ eficiência de absorção de radicais da fase aquosa pelas partículas

$f_{a b s A} \quad$ eficiência de absorção de radicais $A$ da fase aquosa pelas partículas

$f_{a b s B} \quad$ eficiência de absorção de radicais $B$ da fase aquosa pelas partículas

$f_{a b s m} \quad$ eficiência de absorção de radicais da fase aquosa pelas micelas

fabsmA eficiência de absorção de radicais $A$ da fase aquosa pelas micelas

$\mathrm{f}_{\mathrm{absmB}}$ eficiência de absorção de radicais $B$ da fase aquosa pelas micelas

$f_{B}$ fração molar do comonômero B não reagido

$f_{m} \quad$ eficiência de nucleação micelar

$F_{M} \quad$ fração mássica de monômero na alimentação

$f^{m}$ abs eficiência de absorção de radicais da fase aquosa pelas micelas

Fs teor de sólidos na amostra

$F_{t} \quad$ teor de sais da alimentação

$f_{\text {void }} \quad$ fração de vazios da coluna

$h$ ' espaçamento entre os pratos da coluna

$\mathrm{cm}$

h termo de comparação de absorção/terminação

I número de mols de iniciador

mol

[I] concentração de iniciador

$\mathrm{g} / \mathrm{cm}^{3}$

$[i]_{\mathrm{j}} \quad$ concentração do monômero i na fase $\mathrm{j}$

$\mathrm{g} / \mathrm{cm}^{3}$

$j_{\text {crit }}$

comprimento de radical crítico para nucleação homogênea 
$j_{c r i t A} \quad$ comprimento crítico do radical A para a nucleação homogênea

$j_{c r i t B} \quad$ comprimento crítico do radical B para a nucleação homogênea

$j_{z}$ comprimento de radical crítico para entrada na micela ou partícula comprimento crítico do radical A para entrada na micela ou partícula comprimento crítico do radical B para entrada na micela ou partícula .. coeficiente de velocidade de dessorção taxa de dessorção de um radical coeficiente de velocidade de absorção de radicais da fase aquosa pelas partículas de polímero $\mathrm{cm}^{3} / \mathrm{mol} \mathrm{s}$

$k_{A}{ }^{d} \quad$ coeficiente de partição do monômero A entre a fase monomérica e a fase aquosa

$k_{A}{ }^{p} \quad$ coeficiente de partição do monômero A entre a fase polimérica e a fase aquosa

$k_{B}{ }^{d} \quad$ coeficiente de partição do monômero B entre a fase monomérica e a fase aquosa

$k_{B}{ }^{p} \quad$ coeficiente de partição do monômero B entre a fase polimérica e a fase aquosa

kc constante de proporcionalidade do controlador

$K_{d} \quad$ velocidade de decomposição do iniciador condutividade térmica efetiva

$\mathrm{cal} / \mathrm{s} \mathrm{cm}{ }^{\circ} \mathrm{C}$ constante de velocidade de transferência de cadeia $\mathrm{cm}^{3} / \mathrm{mol} \mathrm{s}$ constante de transferência de cadeia de radical $A$ a polímero $A$ $\mathrm{cm}^{3} / \mathrm{mol} \mathrm{s}$ constante de transferência de cadeia do radical $A$ a polímero $B$ $\mathrm{cm}^{3} / \mathrm{mol} \mathrm{s}$ constante de transferência de cadeia do radical $\mathrm{B}$ a polímero $\mathrm{A}$ $\mathrm{cm}^{3} / \mathrm{mol} \mathrm{s}$ constante de transferência de cadeia de radical $B$ a polímero $B$ $\mathrm{cm}^{3} / \mathrm{mol} \mathrm{s}$ coeficiente de partição do monômero i entre a fase monomérica e a fase aquosa

$k_{l}^{p} \quad$ coeficiente de partição do monômero i entre a fase polimérica e a fase aquosa

$k_{p} \quad$ constante de velocidade de propagação $\mathrm{cm}^{3} / \mathrm{mol} \mathrm{s}$ constante de propagação entre dois monômeros A $\mathrm{cm}^{3} / \mathrm{mol} \mathrm{s}$ constante de propagação cruzada $\mathrm{cm}^{3} / \mathrm{mol} \mathrm{s}$ $k_{p B A}$ constante de propagação cruzada $\mathrm{cm}^{3} / \mathrm{mol} \mathrm{s}$ 


\begin{tabular}{|c|c|c|}
\hline$k_{p B B}$ & constante de propagação entre dois monômeros $B$ & $\mathrm{~cm}^{3} / \mathrm{mol} \mathrm{s}$ \\
\hline$k_{t}$ & constante de velocidade de terminação & $\mathrm{cm}^{3} / \mathrm{mol} \mathrm{s}$ \\
\hline$k_{\mathrm{tAA}}$ & constante de terminação entre radicais $A$ & $\mathrm{~cm}^{3} / \mathrm{mol} \mathrm{s}$ \\
\hline$k_{t A B}$ & constante de terminação cruzada entre radicais A e B & $\mathrm{cm}^{3} / \mathrm{mol} \mathrm{s}$ \\
\hline$k_{t B B}$ & constante de terminação entre radicais $B$ & $\mathrm{~cm}^{3} / \mathrm{mol} \mathrm{s}$ \\
\hline$L$ & comprimento da coluna & $\mathrm{cm}$ \\
\hline$M$ & número de mols de monômero & mol \\
\hline$m^{\prime}$ & termo de comparação de dessorção/terminação & .. \\
\hline$m$ & vazão mássica de água alimentada na coluna & $g / s$ \\
\hline$m_{1}$ & massa da placa com gotas de hidroquinona & $g$ \\
\hline$m_{2}$ & massa da placa com gotas de hidroquinona e amostra úmida & g \\
\hline$m_{3}$ & massa da placa e amostra seca & g \\
\hline$m_{A}$ & massa de água na alimentação & $g$ \\
\hline$m_{\text {carb }}$ & massa de carbonato de cálcio na alimentação & g \\
\hline$m_{e}$ & massa de emulsificante na alimentação & $g$ \\
\hline$m_{\text {amostra }}^{G C}$ & massa da amostra & $g$ \\
\hline$m_{\mathrm{H}_{2} \mathrm{O}}^{G C}$ & massa de água da amostra & $g$ \\
\hline$m_{i}$ & massa de iniciador na alimentação & g \\
\hline$m M$ & massa de monômero na alimentação & g \\
\hline Mmic & número de micelas pelo volume da fase aquosa & micelas $/ \mathrm{cm}^{3}$ \\
\hline$m p$ & massa de polímero & $g$ \\
\hline$m t$ & massa total da alimentação & $g$ \\
\hline$[M]$ & concentração de monômero no meio reacional & $\mathrm{mol} / \mathrm{cm}^{3}$ \\
\hline$[M]_{\mathrm{aq}}$ & concentração de monômero na fase aquosa & $\mathrm{mol} / \mathrm{cm}^{3}$ \\
\hline$[M]_{\mathrm{p}}$ & concentração de monômero nas partículas & $\mathrm{mol} / \mathrm{cm}^{3}$ \\
\hline $\bar{n}$ & número médio de radicais por partícula & .. \\
\hline $\mathrm{Na}$ & número de Avogrado & .. \\
\hline$N_{\text {mic }}$ & número de micelas formadas acima da concentração micelar crítica & .. \\
\hline $\mathrm{Np}$ & número de partículas por grama de emulsão & partículas/g \\
\hline $\mathrm{Pi}$ & taxa de produção do componente i por reações & .. \\
\hline
\end{tabular}




\begin{tabular}{|c|c|c|}
\hline $\mathrm{Pe}$ & número de Peclet & .. \\
\hline$P e_{t}$ & número de Peclet térmico & .. \\
\hline$P M_{A}$ & massa molar do monômero A & $\mathrm{g} / \mathrm{mol}$ \\
\hline$P M_{B}$ & massa molar do monômero B & $\mathrm{g} / \mathrm{mol}$ \\
\hline$P M_{E}$ & massa molar do emulsificante & $\mathrm{g} / \mathrm{mol}$ \\
\hline$P M_{i}$ & massa molar do monômero i & $\mathrm{g} / \mathrm{mol}$ \\
\hline$P M_{m}$ & massa molar de monômero & $\mathrm{g} / \mathrm{mol}$ \\
\hline$P M_{w}$ & massa molar da água & $\mathrm{g} / \mathrm{mol}$ \\
\hline Q & constante de reatividade geral do monômero & .. \\
\hline$q_{e}$ & vazão na entrada do reator & $\mathrm{g} / \mathrm{s}$ \\
\hline$R$ & constante geral dos gases & $\mathrm{cal} / \mathrm{mol} \mathrm{K}$ \\
\hline$r_{A}$ & razão de reatividade do monômero A & .. \\
\hline$R_{a q}$ & concentração de radicais na fase aquosa & $\mathrm{mol} / \mathrm{cm}^{3}$ \\
\hline$r_{B}$ & razão de reatividade do monômero B & .. \\
\hline$r_{\text {col }}$ & raio interno da coluna & $\mathrm{cm}$ \\
\hline$R_{\text {ent }}$ & $\begin{array}{l}\text { concentração de radicais na fase aquosa que podem entrar nas } \\
\text { partículas de polímero }\end{array}$ & $\mathrm{mol} / \mathrm{cm}^{3}$ \\
\hline$R_{h o m}$ & taxa de nucleação homogênea & $\mathrm{cm}^{3} / \mathrm{s}$ \\
\hline$R_{\text {jcrit }}$ & $\begin{array}{l}\text { concentração de radicais com comprimento crítico } j_{\text {crit }} \text { na fase } \\
\text { aquosa }\end{array}$ & $\mathrm{mol} / \mathrm{cm}^{3}$ \\
\hline$r_{m}$ & raio de uma micela & $\mathrm{cm}$ \\
\hline$R_{\text {mic }}$ & taxas de nucleação micelar & $\mathrm{cm}^{3} / \mathrm{s}$ \\
\hline$r_{p}$ & raio de uma partícula de polímero inchada com monômero & $\mathrm{cm}$ \\
\hline$R_{p, i}$ & taxa de polimerização do monômero i & $1 / \mathrm{s}$ \\
\hline$T$ & temperatura do meio reacional & ${ }^{\circ} \mathrm{C}$ \\
\hline$t$ & tempo & $\mathrm{s}$ \\
\hline$T_{\text {feed }}$ & temperatura da alimentação na entrada da coluna & ${ }^{\circ} \mathrm{C}$ \\
\hline $\mathrm{Tg}$ & temperatura de transição vítrea do copolímero & $\mathrm{K}$ \\
\hline $\operatorname{Tg}_{1}$ & temperatura de transição vítrea do homopolímero 1 & $\mathrm{~K}$ \\
\hline $\mathrm{Tg}_{2}$ & temperatura de transição vítrea do homopolímero 2 & $\mathrm{~K}$ \\
\hline$T_{\text {in }}$ & temperatura de entrada do meio reacional na seção da coluna & ${ }^{\circ} \mathrm{C}$ \\
\hline
\end{tabular}


$T_{j} \quad$ temperatura da água na camisa de resfriamento $\quad{ }^{\circ} \mathrm{C}$

$T_{J, i n}$ temperatura de entrada da camisa $\quad{ }^{\circ} \mathrm{C}$

$T_{\text {J,out }}$ temperatura de saída da camisa $\quad{ }^{\circ} \mathrm{C}$

$T_{\text {out }}$ temperaturas de saída do meio reacional na seção da coluna $\quad{ }^{\circ} \mathrm{C}$

$U \quad$ coeficiente global de troca térmica entre o meio reacional dentro do reator e a água escoando na camisa do reator $\quad \mathrm{cal} / \mathrm{s} \mathrm{cm}^{2}{ }^{\circ} \mathrm{C}$

$u \quad$ velocidade característica do escoamento $\mathrm{cm} / \mathrm{s}$

UA coeficiente global de troca térmica multiplicado pela respectiva área cal $/ \mathrm{s}{ }^{\circ} \mathrm{C}$

$u_{z} \quad$ velocidade superficial do escoamento na direção axial $\mathrm{cm} / \mathrm{s}$

$v_{1} \quad$ fração volumétrica do monômero 1 no copolímero

$v_{2} \quad$ fração volumétrica do monômero 2 no copolímero

vaq volume total da fase aquosa $\mathrm{cm}^{3}$

$v_{d} \quad$ volume total das gotas $\mathrm{cm}^{3}$

$v_{i} \quad$ volume total do monômero i $\mathrm{cm}^{3}$

$v_{i}{ }^{\text {aq }} \quad$ volume total do monômero i na fase aquosa $\mathrm{cm}^{3}$

$v_{i}{ }^{d} \quad$ volume total do monômero i nas gotas $\mathrm{cm}^{3}$

$v_{i}^{j} \quad$ volume total do monômero i na fase j $\mathrm{cm}^{3}$

$\mathrm{v}_{\mathrm{i}}^{\mathrm{p}} \quad$ volume total do monômero i na fase polimérica $\mathrm{cm}^{3}$

$v_{j} \quad$ volume total da fase j $\mathrm{cm}^{3}$

up volume total das partículas $\mathrm{cm}^{3}$

$v_{p} \quad$ volume da fase polimérica $\mathrm{cm}^{3}$

$v_{w} \quad$ volume de água $\mathrm{cm}^{3}$

$v_{z} \quad$ velocidade superficial de escoamento do fluido na direção axial $\mathrm{cm} / \mathrm{s}$

$w_{1} \quad$ fração molar do monômero 1

$w_{2} \quad$ fração molar do monômero 2

$w_{a} \quad$ composição média em termos de fração molar de VAc no copolímero ..

$w_{A}^{G C} \quad$ fração mássica do monômero A medida na amostra de GC

$w_{B}^{G C} \quad$ fração mássica do monômero A medida na amostra de GC

$\mathrm{X}_{\mathrm{BuA}} \quad$ composição de BuA no final de cada seção

$X_{M} \quad$ conversão global de monômero 
$\underline{X} \quad$ vetor das concentrações dos diferentes componentes

$\mathrm{g} / \mathrm{cm}^{3}$

$\underline{x}_{\text {feed }} \quad$ vetor das concentrações dos componentes na corrente de alimentação

$\mathrm{g} / \mathrm{cm}^{3}$

xgel função de efeito gel

$X_{\mathrm{A}}^{\text {global }}$ conversão global do monômero A

X conversão global dos monômeros

$\mathrm{X}_{\mathrm{sp}} \quad$ set-point para ajuste composição de BuA no final de cada seção

$Y_{A} \quad$ Fração mássica de VAc no copolímero

Z $\quad$ posição ao longo da direção axial

$\mathrm{cm}$

$\beta_{m} \quad$ probabilidade de um radical na fase aquosa reagir por propagação ou por terminação

$\gamma \quad$ número de mols de emulsificante por micela

$\mathrm{mol} / \mathrm{micela}$

$\Delta \mathrm{F} \quad$ variação da vazão de monômero

$\mathrm{g} / \mathrm{s}$

$\Delta H_{p i} \quad$ variação de entalpia de polimerização do monômero i

$\mathrm{cal} / \mathrm{mol}$

$\Delta H_{A} \quad$ variação de entalpia de polimerização do acetato de vinila

$\mathrm{cal} / \mathrm{mol}$

$\Delta H_{B} \quad$ variação de entalpia de polimerização do acrilato de butila

$\mathrm{cal} / \mathrm{mol}$

$\varphi_{\mathrm{A}} \quad$ coeficiente angular da curva de calibração de GC

$\rho \quad$ densidade do meio reacional

$\mathrm{g} / \mathrm{cm}^{3}$

$\rho_{i} \quad$ densidade do monômero i

$\mathrm{g} / \mathrm{cm}^{3}$

$\rho_{m A} \quad$ densidade do monômero A

$\mathrm{g} / \mathrm{cm}^{3}$

$\rho_{m B} \quad$ densidade do monômero B

$\mathrm{g} / \mathrm{cm}^{3}$

$\rho_{\text {pol }} \quad$ densidade do copolímero formado

$\mathrm{g} / \mathrm{ml}$

$\rho_{p A} \quad$ densidade do homopolímero A

$\mathrm{g} / \mathrm{cm}^{3}$

$\rho_{p B} \quad$ densidade do homopolímero B

$\mathrm{g} / \mathrm{cm}^{3}$

$\rho_{w} \quad$ densidade da água

$\mathrm{g} / \mathrm{cm}^{3}$

$\rho^{*} \quad$ coeficiente da velocidade total de absorção de radicais da fase aquosa pela fase polimérica

$\tau_{\delta} \quad$ constantes de tempo derivativo do controlador

S

$\tau_{\mathrm{I}} \quad$ constantes de tempo integral do controlador 
$\psi \quad$ soma das taxas de propagação e terminação dos radicais na fase aquosa e das taxas de absorção pelas micelas e partículas

$\omega_{\mathrm{A}}^{\mathrm{GC}}$ fração mássica do monômero A medido pelo GC no frasco 


\section{Abreviaturas}

ABS resina acrilonitrila-butadieno-estireno.

BuA acrilato de butila.

CFD Fluido Dinâmica Computacional.

CMC concentração micelar crítica.

CPPP Coluna Pulsada de Pratos Perfurados.

CRP Coluna Pulsada com Recheio.

CSTR Reator Contínuo de Tanque Agitado.

DEPT Distortionless Enhancement by Polarization Transfer (Intensificação sem Distorção por Transferência de Polarização).

DSC Differential Scanning Calorimetry (Calorimetria Exploratória Diferencial).

DTP distribuição de tamanhos de partícula.

DTR distribuição de tempos de residência.

GC Cromatografia Gasosa.

PPM partes por milhão.

PSPC Pulsed Sieved Plate Column.

PVOH poli(álcool vinílico).

PVAc poli(acetato de vinila).

PVC poli(cloreto de vinila).

RBS resina butadieno-estireno.

RMN Ressonância Magnética Nuclear.

SLS lauril sulfato de sódio.

TMS tetrametilsilano.

VAc acetato de vinila. 


\section{SUMÁRIO}

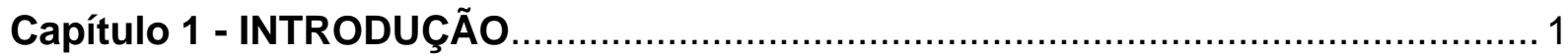

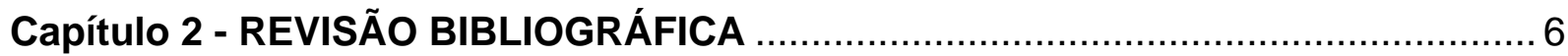

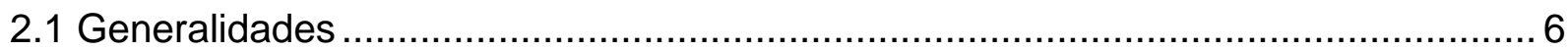

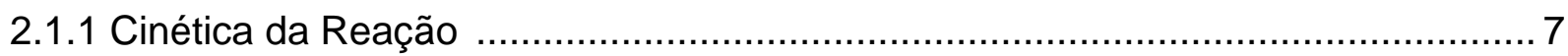

2.1.2 Teorias Clássicas dos Mecanismos da Polimerização em Emulsão .................... 11

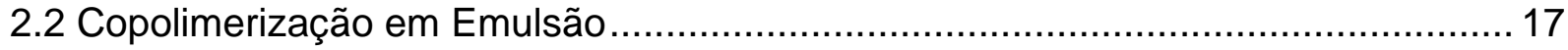

2.3 Tipos de Reatores Utilizados em Polimerização em Emulsão .............................. 24

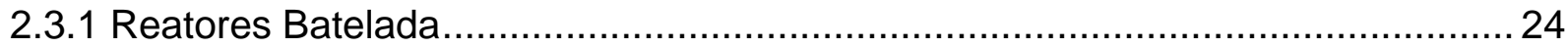

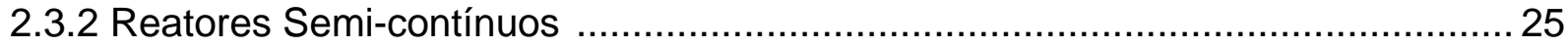

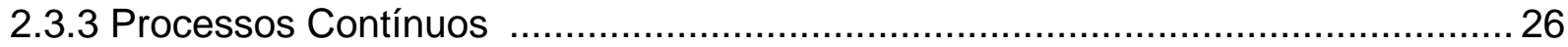

2.3.3.1 Reatores Contínuos de Tanque Agitado (CSTR) ........................................ 26

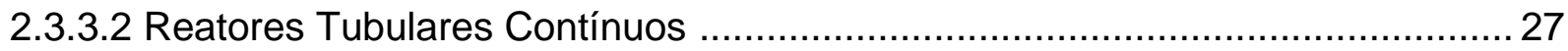

2.3.3.3 Reatores Tubulares Contínuos com Reciclo .............................................. 28

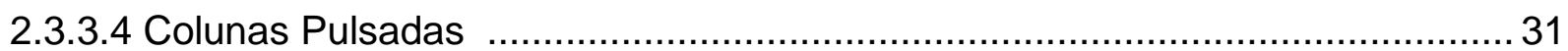

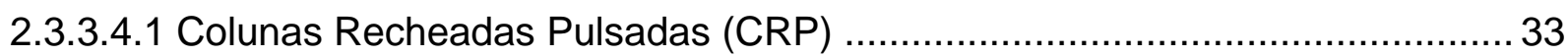

2.3.3.4.2 Colunas Pulsadas com Pratos Perfurados (CPPP) .................................... 38

2.3.3.4.3 Produção de sementes em Colunas Pulsadas ....................................... 45

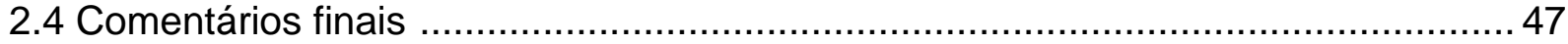

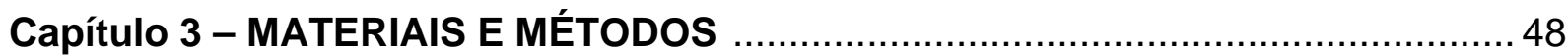

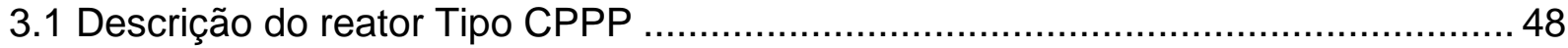

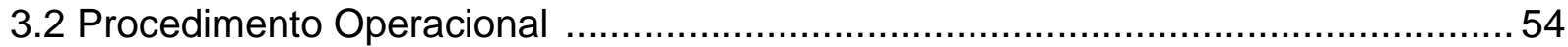

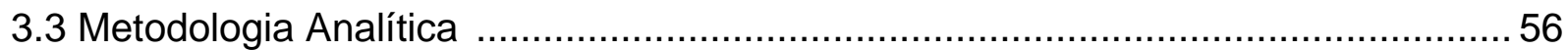

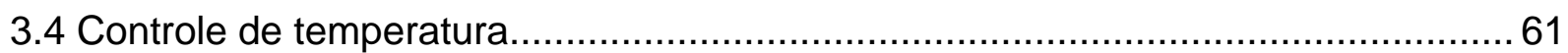

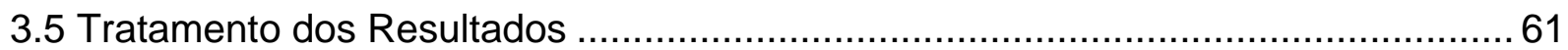

Capítulo 4 - DESENVOLVIMENTO DO MODELO MATEMÁTICO .......................... 62 
4.1 Mecanismo Cinético de Copolimerização 63

4.2 Modelagem dos Mecanismos Característicos da Polimerização em Emulsão 64

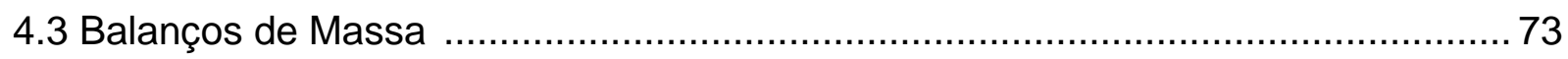

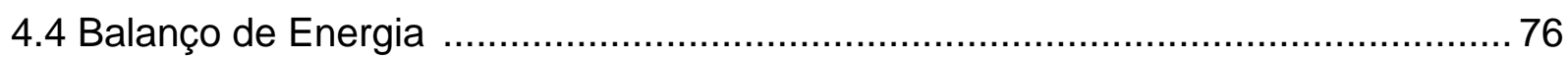

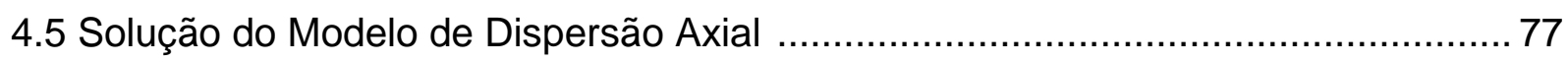

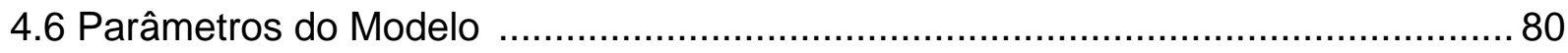

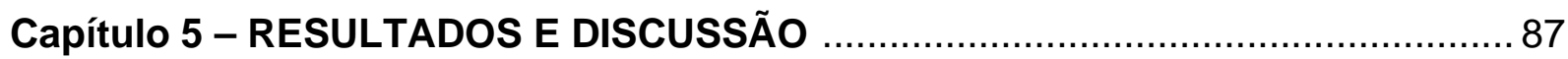

5.1. Análise de Sensibilidade Paramétrica do Modelo ........................................... 87

5.1.1 Estudo do Efeito do Número de Alimentações Laterais ................................... 89

5.1.2 Estudo do Efeito da Temperatura da Água de Resfriamento ............................ 91

5.1.3 Estudo do Efeito da Amplitude de Pulsação ..................................................... 93

5.1.4 Estudo do efeito do tempo de residência ....................................................... 96

5.2 Resultados Experimentais e Comparação com as Simulações ............................. 98

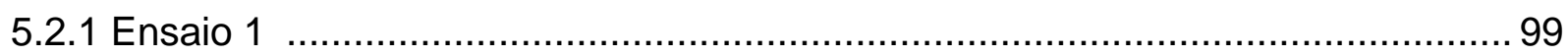

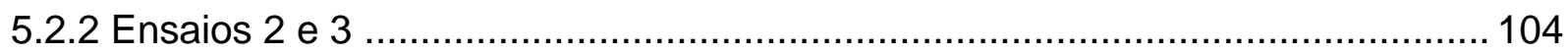

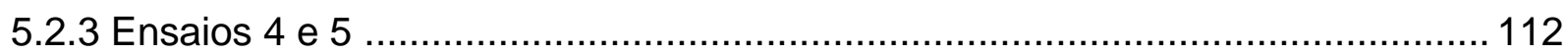

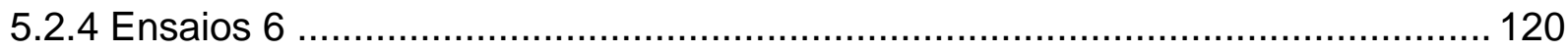

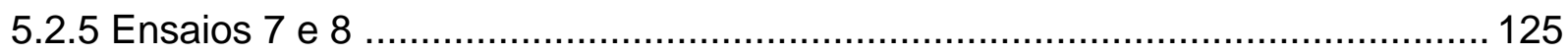

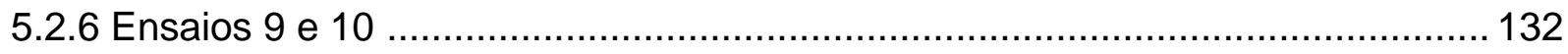

5.3 Análise das Possíveis Fontes de Imprecisão dos Resultados ........................... 140

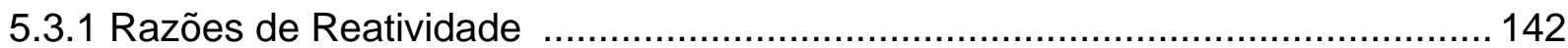

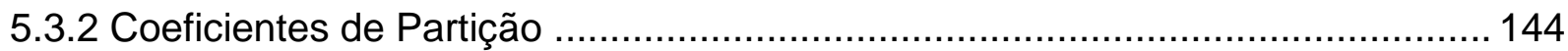

5.3.3 Área Específica Coberta por Emulsificante ................................................. 145

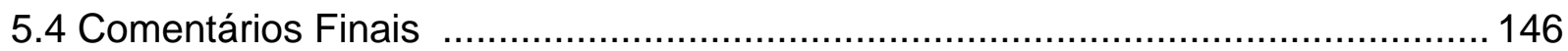

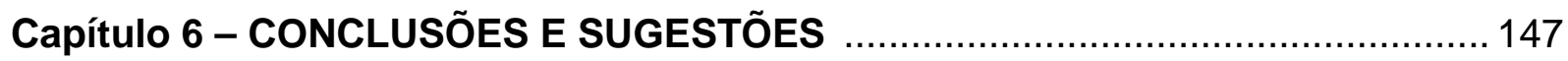

6.1 Conclusões dos Resultados Obtidos ..................................................... 147

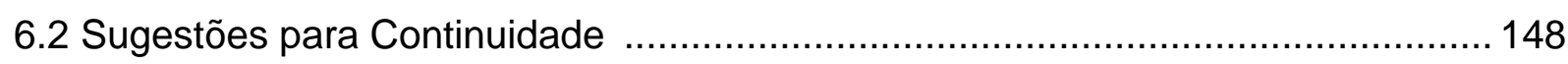


REFERÊNCIAS BIBLIOGRÁFICAS 150

APÊNDICE A1 - Caracterização do Produto Final 160

APÊNDICE A2 - Trabalhos Publicados pelo Autor Relacionados com a Presente Tese 


\section{Capítulo 1 - INTRODUÇÃO.}

A polimerização em emulsão é um processo que ocorre via radicais livres, onde o polímero se forma como partículas dispersas em um meio aquoso. Os constituintes básicos são o monômero, emulsificante, iniciador (solúvel em água) e água. Em um processo típico em batelada, o monômero inicialmente está disperso em forma de gotículas em emulsão, estabilizadas pelo emulsificante, e também está dissolvido parcialmente na fase aquosa, onde ocorre a formação de radicais livres. Os radicais formados na fase aquosa crescem e podem entrar em micelas, o que leva à formação de novas partículas de polímero (nucleação micelar), ou entrar nas partículas poliméricas já existentes, que crescem de tamanho ao longo da reação. Dependendo do sistema, partículas podem ser formadas também por precipitação dos radicais oligoméricos que crescem na fase aquosa até um tamanho tal que se tornam insolúveis em água (nucleação homogênea), ou por coagulação destas partículas primárias assim formadas (nucleação homogênea coagulativa). O monômero consumido nas partículas poliméricas é reposto a partir do monômero presente nas gotas. Portanto, trata-se de um processo de natureza heterogênea que envolve uma série de reações químicas e de fenômenos de transferência de massa que ocorrem simultaneamente. O produto resultante da reação é constituído de polímero disperso em forma coloidal numa fase contínua aquosa formando um látex.

Devido à natureza aquosa da fase dispersante, os processos de polimerização em emulsão apresentam uma série de vantagens, em comparação com outros tipos de processos de polimerização (em massa, em solução), tais como (GILBERT, 1995):

- $\quad$ menor energia e investimento para agitação e bombeamento;

- maior facilidade no processo de eliminação de calor;

- melhor manuseio do produto e melhor segurança do processo;

- em muitos casos podem ser alcançadas altas taxas de velocidade de reação e, simultaneamente, altos pesos moleculares devido à natureza heterogênea do processo; 
- pode ser realizada a altas conversões, minimizando problemas com monômero residual e maximizando a eficiência do processo;

- possibilidade de obtenção de partículas estruturadas do tipo core-shell, o que gera diferentes características morfológicas do produto final e aumenta as possibilidades de aplicação do produto.

A polimerização em emulsão também apresenta algumas limitações que podem ser as seguintes:

- O produto final apresenta uma grande quantidade de impurezas constituídas a partir dos aditivos, do emulsificante e da decomposição do iniciador. Dependendo da aplicação do produto final, estes compostos podem comprometer a qualidade do polímero formado ou encarecer o seu processo de purificação.

- Se o produto final for constituído de polímero seco, a remoção do meio dispersante passa a ser necessária, encarecendo o processo de fabricação.

- Por se tratar de uma reação desenvolvida em meio heterogêneo e envolvendo mecanismos cinéticos complexos, a polimerização em emulsão constitui-se em um processo difícil de ser entendido e, portanto, de ser controlado.

- Devido ao tipo de regime de escoamento do meio reacional ou à instabilidade do sistema coloidal, podem ocorrer algumas incrustações nas superfícies de troca térmica, reduzindo a eficiência do controle de temperatura.

- Requer maior volume reacional para produzir a mesma quantidade de polímero do que em uma polimerização em massa.

As características da polimerização em emulsão justificam o fato dela ser uma das técnicas de polimerização mais empregadas na indústria. A importância econômica da polimerização em emulsão é mais do que evidente se for considerada a enorme 
variedade de produtos obtidos a partir deste processo. Entre tais produtos podem ser citados diversos tipos de tintas, adesivos, PVOH, PVC, ABS, RBS etc. Além disso, entre 40 e 50\% dos processos industriais de polimerização por radicais livres são realizados em emulsão (GILBERT, 1995). Na segunda guerra mundial, o desenvolvimento da polimerização em emulsão em larga escala visava principalmente a substituição da borracha natural.

Atualmente, a demanda mundial de polímeros, baseada neste tipo de processo, é estimada em cerca de 25 milhões de toneladas/ano (8 milhões de toneladas base seca). Dessa quantidade, $23 \%$ são destinados à indústria do papel e papelão, 20\% para tintas e revestimentos, $25 \%$ para adesivos e vedantes e $9 \%$ para fabricação de carpetes (VAN HERK, 2005).

Os processos industriais de polimerização em emulsão são normalmente realizados em reatores de tipo tanque agitado em batelada (ou semibatelada) ou em contínuo (CSTR). Os reatores semibatelada são empregados quando é necessária uma maior flexibilidade da produção e quando são produzidas somente quantidades relativamente pequenas de polímero. Reatores contínuos têm a vantagem de apresentarem menor porte e de propiciarem melhor controle de qualidade do produto com especificações mais rígidas pela redução de variações de batelada a batelada, menor geração de poluentes e menores custos de produção. Por outro lado, os reatores contínuos de mistura perfeita (CSTR) podem ainda exibir oscilações periódicas e auto-sustentadas de conversão e tamanho de partículas (ARAÚjO et al., 1998), e de modo particular para monômeros parcialmente solúveis em água como o acetato de vinila, tal como é verificado por KIPARISSIDES et al. (1980) e OHMURA et al. (1998), devido a golpes de renucleação de partículas de polímero. Oscilações similares podem também ocorrer em reatores tubulares operados com altas taxas de reciclo, também chamados de reator "loop", ABAD et al. (1994), ARAúJO (1999), ARAÚJO et al. (1998), ARAújo et al. (1999), ARAÚjO et al. (2000), ARAÚJO et al. (2001). Estas oscilações podem ser minimizadas em reatores tubulares contínuos sem reciclo. Devido à alta relação entre a superfície de troca térmica e o volume do meio reacional, o reator tubular contínuo, seja 
com reciclo ou de passagem simples, se apresenta como uma alternativa vantajosa em relação aos processos com tanque agitado. Por isso, têm-se desenvolvido reatores tubulares com reciclo (ABAD et al., 1994; ARAÚJO, 1999) e mais recentemente as colunas pulsadas. Nos reatores com reciclo (loop) o depósito de polímero nas paredes é evitado com o uso de altas taxas de reciclo (altas vazões de recirculação); nos reatores tubulares com passagem única, sem reciclo como é o caso da CPPP, isto é evitado com o uso de dispositivos internos e com o uso de escoamento pulsado.

No presente trabalho é estudado o desenvolvimento de um processo contínuo de copolimerização em emulsão em reator tubular com escoamento pulsado, e com dispositivos internos do tipo pratos perfurados, chamada de coluna pulsada de pratos perfurados (CPPP). Este trabalho dá seguimento a uma linha de pesquisa iniciada com o desenvolvimento de processo de homopolimerização na CPPP (PALMA, 2002).

No presente trabalho, tal reator tubular é estudado para conduzir reações de copolimerização em emulsão. O sistema estudado, envolvendo os comonômeros acetato de vinila e acrilato de butila, foi escolhido por se tratar de um copolímero de interesse industrial, e também, e especialmente, por se tratar de um par de monômeros com grandes diferenças de razão de reatividade, por isso com forte tendência de ocorrer a indesejada deriva (desvio) de composição. Neste sistema o monômero mais reativo tende a ser incorporado preferencialmente nas cadeias poliméricas, e se não houver um adequado controle do processo, cadeias poliméricas com grandes diferenças de composição serão formadas, prejudicando as propriedades do polímero produzido. Assim, objetiva-se desenvolver o processo contínuo em reator tubular para um caso-teste em que o controle da composição do copolímero é especialmente difícil.

O trabalho foi desenvolvido tanto no aspecto experimental, realizando-se ensaios no reator CPPP sob diferentes condições experimentais, como também no aspecto de modelagem matemática do processo. Neste sentido, foram realizados o aperfeiçoamento e testes de validação de um modelo matemático previamente desenvolvido no grupo para o processo de polimerização na CPPP (PALMA et al., 
2001a; SALLARÉS et al., 2004; SAYER et al., 2001a; SAYER et al., 2001b; SAYER et al., 2002a; SAYER et al., 2002b; SAYER e GIUDICI, 2002a; SAYER e GIUDICI, 2002b), bem como a inclusão do balanço de energia no modelo, permitindo dessa forma prever também o efeito de variações no perfil de temperatura ao longo do reator sobre o processo.

A presente tese está assim organizada. No Capítulo 2 é apresentada uma revisão da literatura sobre os assuntos de interesse para o trabalho, tais como os aspectos fundamentais de polimerização em emulsão e copolimerização, e uma análise dos trabalhos já realizados sobre uso de reatores tubulares para processos de polimerização em emulsão. No Capítulo 3 é apresentado o equipamento experimental e os procedimentos utilizados nos ensaios e a metodologia analítica empregada no estudo experimental. No Capítulo 4 apresenta-se o modelo matemático desenvolvido para o processo de copolimerização em emulsão de acetato de vinila e acrilato de butila em reator tubular com dispersão axial, incluindo as modificações introduzidas no presente trabalho, relativas ao balanço de energia. No Capítulo 5 são apresentados e discutidos os resultados experimentais obtidos, bem como sua comparação com as previsões do modelo matemático. Finalmente no Capítulo 6 são apresentadas as conclusões e contribuições deste trabalho, e algumas recomendações para futuros trabalhos neste linha de pesquisa, em continuidade ao presente trabalho. 


\section{Capítulo 2 - REVISÃO BIBLIOGRÁFICA.}

Neste capítulo serão revisados os fenômenos e mecanismos envolvidos no processo de polimerização em emulsão, particularmente da copolimerização em emulsão do acetato de vinila e acrilato de butila. Serão apresentados também os tipos de reatores que podem ser utilizados na polimerização em emulsão e de modo especial serão descritos os trabalhos já realizados na coluna pulsada com pratos perfurados (CPPP).

\subsection{Generalidades.}

Os constituintes básicos de uma reação de polimerização em emulsão são o monômero, emulsificante, iniciador e água. As descrições de cada ingrediente vem a seguir.

\section{Monômero}

O monômero, dependendo da sua solubilidade em água, está dissolvido em diferentes proporções tanto na fase aquosa quanto nas partículas de polímero e nas gotas. As gotas de monômero são estabilizadas por moléculas de emulsificante e atuam como reservatórios de monômero no decorrer da polimerização. A distribuição do monômero entre as fases do meio reacional, também definida pelo seu coeficiente de partição, depende da sua solubilidade em água e da temperatura em que a reação é conduzida.

\section{Emulsificante}

O emulsificante, também denominado surfatante, é um tensoativo que proporciona a emulsão das partículas poliméricas em água e das gotas de monômero, estabilizandoas. Quando a concentração de emulsificante na fase aquosa excede a CMC (concentração micelar crítica) a tensão superficial do meio aquoso mantém-se constante e ocorre a formação de agregados de moléculas de emulsificante chamados 
micelas. Essas características se devem ao fato das moléculas de emulsificante apresentarem um segmento hidrofílico e outro hidrófobo em suas cadeias carbônicas. Conforme a natureza química de seu grupo hidrofílico o emulsificante pode ser classificado em aniônico, catiônico, anfótero e não iônico.

\section{$\underline{\text { Iniciador }}$}

O iniciador normalmente é solúvel em água e se decompõe na fase aquosa formando radicais livres. Normalmente a eficiência de formação de radicais capazes de iniciar uma nova cadeia polimérica não é completa devido à ocorrência de reações secundárias que geram compostos não ativos e, também, devido a limitações difusionais destas moléculas em meio aquoso, ocorre a neutralização mútua de uma fração dos mesmos radicais formados pela decomposição do iniciador.

\section{Outros Ingredientes}

Alguns dos aditivos mais freqüentemente empregados em pequenas quantidades na polimerização em emulsão são os inibidores presentes no monômero comercial (a fim de evitar a polimerização prematura dos monômeros durante seu transporte e armazenamento), os agentes de transferência de cadeia que são adicionados com a finalidade de controlar o peso molecular das cadeias poliméricas, e os agentes tamponantes utilizados para estabilizar o $\mathrm{pH}$ do meio reacional.

\subsubsection{Cinética da Reação}

Apesar de seu amplo uso, a polimerização em emulsão é um processo difícil de ser representado devido ao seu complexo mecanismo cinético. O principal motivo desta dificuldade é a ocorrência de várias fases no reator, e os fenômenos de transferência de massa entre as diversas fases. Portanto, a modelagem cinética correspondente requer o detalhamento de complexos fenômenos físicos e químicos descritos na ciência que estuda os colóides e as reações de polimerização. 


\section{Reações Químicas}

A reação de polimerização em emulsão se desenvolve através dos mecanismos de polimerização por radicais livres que estão descritos a seguir.

1- Iniciação

Consiste na decomposição do iniciador I e a adição do radical R $\bullet$ formado com a primeira unidade monomérica.

$$
\begin{array}{lll}
\mathrm{I} & \rightarrow & 2 \mathrm{R} \bullet \\
\mathrm{R} \bullet+\mathrm{M} & \rightarrow & \mathrm{R}_{1}
\end{array}
$$

Conforme mencionado anteriormente, os dois radicais $\mathrm{R} \bullet$, também reagem entre si devido a fatores difusionais, e este aspecto é levado em conta na eficiência do iniciador. Além disso, o radical livre formado pode reagir com impurezas ou com inibidores formando um composto não ativo.

\section{2- Propagação}

Esta é a etapa de crescimento da cadeia polimérica em que os radicais $\mathrm{R}$ reagem sucessivamente com as unidades monoméricas $M$.

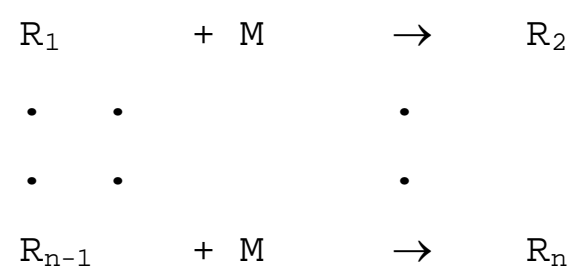

Normalmente, considera-se que a constante da taxa de propagação independe do tamanho da cadeia ativa. A propagação pode ocorrer tanto no interior das partículas 
como também, até certo ponto, na fase aquosa. Para monômeros mais solúveis em água, a extensão da propagação na fase aquosa tende a ser maior. Em sistemas com radicais e monômeros menos solúveis em água, a propagação ocorre primordialmente no interior das partículas poliméricas.

\section{3- Terminação}

A etapa de terminação gera cadeias poliméricas inativas. A terminação ocorre através de dois tipos diferentes de reação envolvendo dois radicais $\mathrm{R}$ e formando uma ou duas cadeias poliméricas mortas $P$ :

\section{a- Combinação}

$\mathrm{Na}$ reação de combinação de dois radicais, uma nova ligação química é formada conectando as duas cadeias em crescimento e formando uma única cadeia morta.

$$
R_{j} \quad+R_{n} \rightarrow P_{j+n}
$$

\section{b- Desproporcionamento}

Nesta reação um dos dois radicais seqüestra um átomo de hidrogênio de outra cadeia ativa em crescimento, formando duas cadeias inativas ou mortas. O carbono receptor do átomo de hidrogênio termina saturado enquanto que a terminação correspondente ao carbono da outra cadeia passa então a ter uma dupla ligação com o carbono adjacente.

$$
R_{j} \quad+R_{n} \rightarrow P_{j}+P_{n}
$$

A taxa de terminação também pode ser limitada por fatores difusionais envolvendo as cadeias poliméricas. 
Uma vez que a difusividade das cadeias depende de seus respectivos tamanhos e também da viscosidade do "locus" de polimerização, a velocidade de terminação varia conforme o teor de polímero no "locus" de reação e com os pesos moleculares alcançados.

4- Transferência de cadeia ao Monômero

O radical polimérico reage com uma molécula de monômero gerando uma cadeia polimérica inativa e um radical monomérico.

$$
\mathrm{R}_{\mathrm{j}} \quad+\mathrm{M} \quad \rightarrow \quad \mathrm{P}_{\mathrm{j}} \quad+\mathrm{R}_{1}
$$

\section{5- Transferência de cadeia a Moléculas Pequenas}

As moléculas pequenas neste caso podem ser agentes de transferência de cadeia, solvente, iniciador ou mesmo impurezas. $O$ radical polimérico reage com a molécula $X$ produzindo uma molécula de polímero inativo e um radical $X \bullet$ que pode, ou não, reagir com outra molécula de monômero ou polímero.

$$
\mathrm{R}_{\mathrm{j}} \quad+\mathrm{X} \quad \rightarrow \quad \mathrm{P}_{\mathrm{j}} \quad+\mathrm{X} \bullet
$$

6- Transferência de cadeia ao Polímero.

$$
\mathrm{R}_{\mathrm{j}} \quad+\mathrm{P}_{\mathrm{n}} \rightarrow \mathrm{P}_{\mathrm{j}} \quad+\mathrm{R}_{\mathrm{n}}
$$

Todas as reações de transferência entre radicais livres e qualquer outro tipo de molécula não alteram a quantidade de radicais livres no meio reacional. A principal influência das reações de transferência é observada principalmente nos valores dos pesos moleculares das cadeias poliméricas obtidas. 


\section{$\underline{\text { Transferência de Massa }}$}

Além das reações químicas, ocorrem também processos simultâneos de transferência de massa entre as fases. A importância de cada um destes mecanismos vai depender das características do sistema a ser estudado. Os mecanismos mais significativos de transferência de massa são os seguintes:

- transferência de radicais livres entre a fase aquosa e as partículas (entrada e saída de radicais das partículas);

- transferência de radicais livres entre a fase aquosa e as micelas;

- transferência de monômero entre a fase aquosa e as micelas;

- transferência de monômero entre a fase aquosa e as partículas poliméricas em crescimento;

- transferência de monômero entre as gotas de monômero e a fase aquosa;

- transferência de emulsificante entre micelas e a fase aquosa;

- transferência de emulsificante entre partículas poliméricas em crescimento e a fase aquosa.

\subsubsection{Teorias Clássicas dos Mecanismos da Polimerização em Emulsão}

Nesta seção estão descritas resumidamente as principais teorias clássicas dos mecanismos da polimerização em emulsão. Estas teorias consideram o processo de polimerização em emulsão dividido em três intervalos:

- intervalo I: nucleação das partículas (caracterizado pela presença de micelas);

- intervalo II: crescimento das partículas na presença de monômero (caracterizado pela ausência de micelas e presença de gotas de monômero);

- intervalo III: esgotamento do monômero (caracterizado pela ausência de micelas e pela ausência de gotas de monômero). 


\section{$\underline{\text { Teoria qualitativa de Harkins }}$}

A primeira descrição qualitativa da polimerização em emulsão é a de Harkins (1947) cuja teoria se aplica a monômeros pouco solúveis em água e onde a concentração de emulsificante está acima da CMC. As principais hipóteses assumidas nesta teoria são as seguintes:

- A principal função das gotas de monômero é a de atuar como reservatório.

- As micelas são o lugar principal de formação de partículas.

- O principal local de polimerização são as partículas de polímero.

- Uma pequena parte das partículas formadas ocorre na fase aquosa sendo esta quantidade cada vez mais desprezível à medida que a reação progride.

- O crescimento das partículas poliméricas aumenta a área superficial total e o consumo de tensoativo.

- A nucleação é finalizada com o desaparecimento das micelas.

- O consumo de monômero pela reação conduz ao desaparecimento das gotas de monômero após a eliminação das micelas.

Com base nestas considerações, os mecanismos da cinética de polimerização em emulsão estão descritos em três intervalos em função do tempo de reação em um reator de batelada.

Intervalo I.

É a primeira etapa da reação, conhecida por nucleação durante a qual são geradas novas partículas de polímero. O iniciador presente na fase aquosa se decompõe formando radicais livres que se propagam crescendo na fase aquosa até alcançarem um determinado tamanho, tornando-se insolúveis em água sendo capturados pelas micelas, transformando-as também em partículas de polímero (nucleação micelar). A probabilidade de ocorrer a nucleação das gotas de monômero é muito pequena. Isto ocorre graças à grande diferença de tamanho entre as gotas (1000 - 10000nm) e as 
partículas (50 - 300nm) e das micelas (10nm). Conseqüentemente, a relação superfície I volume das partículas e das micelas é muito maior que a das gotas. Depois de formada, a partícula cresce até que outro radical livre entre na mesma e termine o radical polimérico que está em crescimento. A partícula volta a crescer somente com a entrada de um novo radical.

Devido à saturação de emulsificante no meio aquoso, esta fase da reação é caracterizada pela tensão superficial constante do meio reacional e pela presença de micelas. Também, o intervalo I é marcado pelo crescimento do número de partículas conduzindo a altas velocidades de conversão.

À medida que novas partículas se formam e crescem, a superfície total de polímero disperso em meio aquoso aumenta, requerendo que novas moléculas de emulsificante migrem da fase aquosa para as partículas o que, por sua vez, reduz o número de micelas até que elas finalmente desapareçam. As micelas desaparecem tanto devido à nucleação micelar (que transforma micelas em partículas de polímero) como pela dissolução de micelas para fornecer emulsificante para estabilizar a crescente área das partículas poliméricas em crescimento.

Intervalo II

O segundo intervalo é iniciado com o fim da nucleação de novas partículas (desaparecimento das micelas) e corresponde à fase de crescimento das partículas poliméricas. Durante este período as moléculas de monômero migram das gotas de monômero através da fase aquosa para as partículas de polímero, onde a concentração de monômero permanece constante até o esgotamento total das gotas de monômero. Como a concentração de monômero se mantém constante e o número de partículas não é alterado, a taxa de polimerização permanece constante durante essa fase.

Intervalo III 
A terceira e última etapa começa com o desaparecimento das gotas de monômero e com a conseqüente diminuição da concentração de monômero no interior das partículas poliméricas. O monômero restante passa a ser consumido reduzindo a taxa de reação e aumentando a viscosidade do meio polimérico. Por outro lado, em algumas situações, a terminação entre radicais livres dentro das partículas pode se tornar limitada pela difusão, o que pode propiciar o aumento do número de radicais por partícula e, eventualmente dessa forma, aumentar a taxa de reação apesar da menor concentração de monômero (efeito Trommsdorff ou efeito gel). A conversão do monômero restante no interior das partículas também conduz a uma redução do tamanho das mesmas partículas uma vez que a densidade do polímero formado é maior que a do monômero consumido.

\section{Teoria quantitativa de Smith-Ewart}

A teoria de Harkins constituiu-se no primeiro passo para o entendimento que o principal local onde a polimerização ocorre é dentro das partículas. Além disso, contribuiu para o entendimento básico da função desempenhada pelas principais espécies químicas, presentes nas diferentes fases do meio reacional, e seu envolvimento nos vários mecanismos da polimerização em emulsão.

Adotando as mesmas hipóteses adotadas anteriormente, a teoria de Smith-Ewart foi a primeira a descrever quantitativamente a teoria de Harkins e tenta prever a taxa de reação em função das concentrações dos principais componentes do sistema. Assim sendo, considera-se também desprezível qualquer polimerização na fase aquosa ou nas gotas de monômero. A taxa global de polimerização é definida como produto da velocidade de reação em cada partícula pelo número total de partículas:

$$
R_{p}=k_{p}[M]_{p} \bar{n} \frac{N_{p}}{N_{a}}
$$

Onde:

$\bar{n} \quad$ representa o número médio de radicais por partícula; 
$N_{p} \quad$ representa o número total de partículas;

$\mathrm{Na}$ representa o número de Avogrado;

$k_{p} \quad$ representa a constante de propagação;

$[M]_{p} \quad$ representa a concentração de monômero nas partículas.

Portanto, para a correta aplicação da equação acima, foram desenvolvidos modelos para o balanço de radicais e monômeros no interior das partículas. Em tais modelos são consideradas as taxas de entrada, saída e de consumo de radicais em cada partícula. Com essa finalidade, Smith e Ewart (1948) trataram quantitativamente a teoria de Harkins para três casos limitantes:

Caso 1 - O número médio de radicais por partícula é muito menor que 0,5. A taxa de saída de radicais das partículas poliméricas é muito maior que a sua taxa de entrada.

Caso 2 - O número médio de radicais por partícula é aproximadamente igual a 1/2. Neste caso admite-se que a taxa de saída de radicais nas partículas poliméricas seja desprezível e que a taxa de entrada seja muito menor que a taxa de terminação.

Caso 3 - O número médio de radicais por partícula é muito maior que 0,5. Supõe-se que a taxa de entrada de radicais nas partículas poliméricas é muito maior que a taxa de terminação.

As teorias clássicas apresentam, entretanto, discrepâncias importantes ao tentar prever a polimerização de sistemas compostos por certos monômeros tais como o acetato de vinila devido às suas características físico-químicas particulares, tais como a maior solubilidade em água e a conseqüente possibilidade de nucleação homogênea adicionalmente à micelar. 


\section{Nucleação Homogênea e Nucleação Coagulativa}

O mecanismo da nucleação homogênea também pode ser responsável pelo processo de formação de partículas (GILBERT, 1995). Pelo mecanismo da nucleação homogênea, a cadeia polimérica dos radicais gerados pela decomposição do iniciador na fase aquosa cresce pela reação de propagação com os monômeros dissolvidos em fase aquosa. A terminação destes radicais também pode ocorrer na fase aquosa. Os radicais oligoméricos então podem se tornar insolúveis em fase aquosa quando um comprimento de cadeia crítico é alcançado. O radical oligomérico hidrofóbico então colapsa conformando-se numa cadeia compacta, de modo a reduzir o contato com as moléculas de água, e constituindo-se em um núcleo de partícula na fase aquosa. Essa etapa é seguida pela formação de partículas primárias mediante a floculação de núcleos de partículas relativamente instáveis e pela adsorção de moléculas de surfatante sobre a superfície dessas novas partículas. As partículas primárias passam então a absorver moléculas de monômero dissolvidas na fase aquosa possibilitando que novos radicais poliméricos cresçam por propagação em seu interior.

A fase de nucleação das partículas controla o tamanho médio e a distribuição dos tamanhos das partículas do produto final (CHERN, 2006). Com base nesse fato, LICHTI et al., 1983, estudaram a evolução em seus estágios iniciais da distribuição dos tamanhos de partícula (DTP) de poliestireno, obtidas com o emprego de lauril sulfato de sódio em concentrações acima da CMC, de modo a determinar os mecanismos de formação e de crescimento destas partículas. Os dados obtidos neste estudo não puderam ser ajustados a mecanismos de uma simples etapa, tanto para a nucleação micelar como para a nucleação homogênea. Por outro lado, verificou-se que estes mesmos resultados poderiam ser ajustados assumindo-se que a etapa de coagulação das partículas primárias, talvez formadas por nucleação homogênea, determinasse os processos de nucleação e de entrada de radicais livres em partículas maduras de látex. Deste modo, sugeriu-se que a nucleação homogênea de oligômeros na fase aquosa produz pequenas partículas primárias, com características coloidais, nas quais ocorre a reação de polimerização a uma velocidade baixa. Estas partículas primárias coagulam 
umas com as outras para produzir partículas de látex. Estas mesmas partículas primárias podem coagular também com partículas de látex e contribuir para o processo de entrada de radicais. As versões do modelo que explicitamente consideram a etapa de coagulação às vezes são denominadas de "nucleação homogêneo-coagulativa" (GILBERT, 1995), nucleação homogênea coagulativa (TAUER e KÜHN, 1995) ou nucleação coagulativa (VAN HERK, 2005).

\subsection{Copolimerização em Emulsão}

As propriedades dos materiais poliméricos dependem da distribuição dos pesos molares e do grau de ramificação de suas cadeias poliméricas. Nos processos da polimerização em emulsão, a distribuição de tamanho das partículas também é um fator importante a ser controlado dependendo do tipo de aplicação do produto. No caso específico da copolimerização, certas propriedades, tais como a temperatura de transição vítrea e o módulo de elasticidade, estão intensamente relacionadas à distribuição dos comonômeros na seqüência de unidades monoméricas da cadeia de polímero formado.

\section{Mecanismo cinético da copolimerização por radicais livres}

Se considerarmos que a reatividade de um radical polimérico depende apenas da unidade monomérica na qual se encontra o centro ativo (modelo terminal) e, também, que a reatividade deste radical independe do tamanho de sua cadeia, a propagação da copolimerização seria caracterizada por quatro etapas de propagação. Além das taxas de propagação, também são consideradas quatro taxas de transferência de cadeia aos monômeros e ao polímero. As constantes de propagação cruzadas, $k_{p A B}$ e $k_{p B A}$, são determinadas através das razões de reatividade dos monômeros.

$$
\mathrm{A}_{\mathrm{n}-1}+\mathrm{A} \stackrel{k_{p A A}}{\longrightarrow} \quad \mathrm{A}_{\mathrm{n}}
$$




$$
\begin{array}{llll}
\mathrm{A}_{\mathrm{n}-1} & +\mathrm{B} & \stackrel{k_{p A B}}{\longrightarrow} & \mathrm{B}_{\mathrm{n}} \\
\mathrm{B}_{\mathrm{n}-1}+\mathrm{A} & \stackrel{k_{p B A}}{\longrightarrow} & \mathrm{A}_{\mathrm{n}} \\
\mathrm{B}_{\mathrm{n}-1} & +\mathrm{B} & \stackrel{k_{p B B}}{\longrightarrow} & \mathrm{B}_{\mathrm{n}}
\end{array}
$$

Definem-se as razões de reatividade $r_{A}$ e $r_{B}$ como sendo as razões entre as constantes de propagação calculadas por:

$$
\begin{aligned}
& r_{A}=\frac{k_{p A A}}{k_{p A B}} \\
& \mathrm{r}_{B}=\frac{k_{p B B}}{k_{p B A}}
\end{aligned}
$$

A razão de reatividade $r_{A}$ representa a preferência do radical $A_{n-1}$, com centro ativo na unidade monomérica $A$, para reagir com o monômero $A$ em relação ao monômero $B$. De modo análogo, a razão de reatividade $r_{B}$ representa a preferência do radical $B_{n-1}$, com centro ativo na unidade monomérica $B$, para reagir com o monômero $B$ em relação ao monômero A.

$\mathrm{Na}$ representação do mecanismo que define a composição do copolímero formado, considera-se que a reatividade dos radicais é determinada pela natureza da última unidade monomérica do radical, conforme o modelo último (ou terminal) de MAYO e LEWIS (1944). Neste caso, a adição de um comonômero à cadeia de um determinado radical é definida pela razão de reatividade entre este comonômero e a última unidade monomérica da cadeia deste radical. Seguindo o modelo último, a equação (2.4) estabelece a relação entre a fração molar instantânea $F_{A}$ do comonômero A presente no copolímero formado, e as frações molares $f_{A}$ e $f_{B}$ dos comonômeros $A$ e $B$ não reagidos, presentes na fase em que ocorre a reação, de acordo com suas respectivas razões de reatividade. 


$$
F_{A}=\frac{r_{A} f_{A}^{2}+f_{A} f_{B}}{r_{A} f_{A}^{2}+2 f_{A} f_{B}+r_{B} f_{B}^{2}}
$$

\section{Deriva de Composição}

Uma característica da copolimerização é a deriva de composição. Ela é uma conseqüência da diferença entre a composição instantânea do copolímero formado e a composição total de monômeros consumidos, de acordo com a equação (2.4). Esta diferença é determinada pela razão de reatividade dos comonômeros (cinética da reação) e pela relação entre as concentrações dos comonômeros presentes nas partículas. Estas concentrações são determinadas pela partição (relação de equilíbrio) das quantidades dissolvidas de cada comonômero nas diferentes fases do sistema heterogêneo. Por esta razão, a relação entre as concentrações presentes nas partículas, ou na fase aquosa, pode diferir também da proporção existente entre as quantidades totais dos comonômeros alimentados no reator à medida que a conversão aumenta.

A deriva de composição é um fenômeno que contribui para a heterogeneidade da cadeia do copolímero formado, ampliando a distribuição da composição ou a distribuição dos tamanhos das seqüências de unidades monoméricas da cadeia polimérica. Esta situação pode induzir à formação de um copolímero muito heterogêneo e pode ter uma influência significativa sobre o comportamento mecânico e térmico, a processabilidade e a aplicação do produto final.

A formação de um copolímero heterogêneo ocorre quando as cadeias formadas inicialmente apresentam uma composição muito diferente das cadeias obtidas no final da reação. Neste caso, as cadeias iniciais podem vir a ser imiscíveis com o restante do polímero formado e ocorre então uma separação de fases na partícula polimérica. Por este motivo, os copolímeros heterogêneos apresentam as propriedades dos polímeros de que são formados, por exemplo podem apresentar duas temperaturas de transição 
vítrea. Já os copolímeros homogêneos normalmente apresentam propriedades físicas que são características de um novo polímero como, por exemplo, somente uma temperatura de transição vítrea, de valor intermediário entre as temperaturas de transição vítrea dos dois respectivos homopolímeros.

\section{$\underline{\text { Copolimerização em emulsão de acetato de vinila e acrilato de butila }}$}

Copolímeros com diferentes composições podem apresentar propriedades distintas das do homopolímero, p.ex. a temperatura de transição vítrea (Tg) . Para explorar esta possibilidade, usualmente a copolimerização é realizada com monômeros cujos respectivos homopolímeros apresentam grande diferença na $\mathrm{Tg}$. O homopolímero poli(acetato de vinila) tem $\mathrm{Tg}$ ao redor de $28^{\circ} \mathrm{C}$, enquanto que a $\mathrm{Tg}$ do homopolímero poli(acrilato de butila) é da ordem de $-55^{\circ} \mathrm{C}$. Assim a incorporação de acrilato de butila no copolímero VAc-BuA provoca uma diminuição da temperatura de transição vítrea do polímero (ERBIL, 1996). Neste caso, as propriedades adesivas do produto são melhoradas com o aumento do grau de homogeneidade na composição do copolímero formado (CHUJO et al., 1969). Este tipo de látex tem uma extensa margem de aplicação em segmentos dos mercados de tintas e adesivos devido a suas propriedades físicas e reológicas. No entanto, o mecanismo de copolimerização de Vac e BuA mostra um desvio considerável em relação à teoria clássica da polimerização em emulsão devido às características particulares do VAc e do BuA. A solubilidade do VAc é relativamente alta em água, 2,4\% em fração mássica (DIMITRATOS et al.,1989), e por isso favorece a nucleação homogênea do VAc em água competindo com a nucleação micelar. O número de radicais por partícula pode variar entre 1 e 7 para composições de 20 a 100\% de BuA (KONG et al., 1988). Por outro lado, em copolimerizações em batelada o número de radicais por partícula começa alto, para baixas conversões, porém decresce para valores inferiores a 0,5 após o consumo total de BuA (KONG et al., 1988).

Como as razões de reatividade entre esses dois comonômeros são bem diferentes, a deriva de composição nos processos tipo batelada é inevitável. Portanto, especialmente 
neste caso, a modelagem e o controle dos processos semi-batelada e contínuo de copolimerização passaram a ter grande importância. Neste sentido, o trabalho de CHUJO et al. (1969) é o primeiro a verificar as importantes diferenças nas propriedades finais dos copolímeros de acetato de vinila e acrilato de butila, obtidos a partir de métodos distintos de adição dos monômeros. Mais tarde, nos trabalhos de PICHOT et al. (1981), EL-AASSER et al. (1983) e MISRA et al. (1983), foram verificadas outras importantes diferenças em propriedades mecânicas, morfológicas e coloidais do látex produzido nos modos batelada e semi-contínuo. Concluiu-se que, devido à grande diferença de reatividade existente entre estes comonômeros, a composição do copolímero era influenciada pelas taxas de adição dos monômeros. Chegou-se também à conclusão de que as polimerizações operadas em modo semi-batelada apresentam melhor controle sobre o grau de homogeneidade da composição do copolímero do que nas polimerizações realizadas em batelada. No modo batelada, as partículas formadas durante os primeiros estágios da reação apresentam uma estrutura do tipo núcleocasca ("core-shell"). A parte interna ("core"), é composta principalmente por BuA enquanto que a parte exterior ("shell") é composta por VAc.

No trabalho de MISRA et al. (1979), verificou-se que o tamanho das partículas é determinado pela composição do copolímero quando o processo é realizado no modo semi-batelada, sendo que isso não se verifica no caso do modo batelada. O tamanho e a distribuição das partículas variaram com a proporção entre as quantidades dos comonômeros alimentados assim como com seus respectivos modos operacionais de alimentação. Partículas menores eram obtidas em copolímeros de maior quantidade de BuA incorporada em suas cadeias e também obtidos a partir de processos em modo semi-batelada.

Nos anos seguintes, os mecanismos cinéticos envolvidos nos processos de copolimerização em emulsão de acrilato de butila e acetato de vinila foram intensivamente estudados e descritos por VANDERHOFF (1985), DELGADO et al. (1986), KONG et al. (1988). A copolimerização em miniemulsão de VAc e BuA também foi estudada por DELGADO et al. (1988), DELGADO et al. (1989) e DELGADO et al. 
(1990). Dentre os trabalhos realizados com copolimerização em emulsão existem discrepâncias significativas dos valores empregados de razão de reatividade do BuA e VAc. Na tabela 2.1 apresentam-se valores aplicados a copolimerizações em emulsão de VAc e BuA.

Tabela 2.1 Valores de razão de reatividade obtidos experimentalmente.

\begin{tabular}{|l|c|c|c|}
\hline referência & $\mathbf{r}_{\mathbf{B}}$ (BuA) & $\mathbf{r}_{\mathbf{A}}$ (VAc) & Temperatura $\left(^{\circ} \mathbf{C}\right.$ ) \\
\hline NIKOLAEV et al. (1969) & 5,529 & 0,0388 & 50 \\
\hline CHUJO et al. (1969) & 8 & 0 & 68,4 \\
\hline PICHOT et al. (1981) & 5,5 & 0,04 & 60 \\
\hline DELGADO (1986) & 6,35 & 0,037 & ----- \\
\hline KONG et al. (1988) & 7,2 & 0,08 & 60 \\
\hline BATAILLE e BOURASSA (1989) & 10,67 & 0,024 & 60 \\
\hline
\end{tabular}

A variação dos resultados obtidos pode ser explicada pela precisão do método adotado para a sua determinação (BATAILLE e BOURASSA, 1989). Esta variação também pode ser atribuída ao uso de dados de composição dos copolímeros em cálculos de razões de reatividade sem que tenha sido considerada a influência da partição dos monômeros (DUBÉ e PENLIDIS, 1995). Os dados cinéticos obtidos por KONG et al. (1988), mostram que o BuA reage a taxas similares às observadas em sua homopolimerização. Já o VAc apresenta uma reatividade mais baixa se comparada à sua homopolimerização até que todo o BuA seja consumido. A partir daí, a velocidade de reação do VAc cresce rapidamente.

No caso da copolimerização em emulsão de VAc e BuA, a diferença de solubilidade relativa dos comonômeros em água é outro fator importante que define a composição final do copolímero (LOVELL e EL-AASSER, 1997). Os coeficientes de partição dos comonômeros definem a distribuição das quantidades dos mesmos nas fases monomérica, aquosa e polimérica do meio reacional. Portanto, ficam definidas assim as concentrações de cada comonômero em cada uma dessas fases e isto se reflete na composição final do produto (GUGLIOTTA et al., 1995; ARMITAGE et al.,1994). Até 
recentemente, foram estudados diferentes modelos e realizadas determinações experimentais para os coeficientes de partição de sistemas de monômeros em látex, entre os quais de VAc e BuA a $65^{\circ} \mathrm{C}$ (HILLER, 2004). Neste caso, também foi discutida a influência da temperatura sobre os valores dos coeficientes de partição em geral. A partir dos valores dos coeficientes de partição obtidos, ficou evidente que a concentração de acetato de vinila na partícula polimérica é aproximadamente 10 vezes mais alta que na fase aquosa. Como a solubilidade em água do acrilato de butila é muito baixa, 0,16\% em fração mássica (DIMITRATOS et al.,1989), o seu coeficiente de partição no látex correspondente é muito alto. A concentração de BuA medido nas partículas era aproximadamente 140 vezes maior que na fase aquosa.

Em alguns trabalhos publicados sobre a copolimerização em emulsão de VAc e BuA, foi empregada a técnica da ressonância nuclear magnética NMR para a determinação da composição do copolímero formado (BATAILLE e BOURASSA, 1989; BRITTON et al., 2001; PICHOT et al., 1981). Observou-se que esta técnica apresenta alta sensibilidade ao efeito da micro-estrutura molecular. Por isso, o efeito da seqüência de unidades de monômeros na cadeia polimérica sobre o espectro pode comprometer as medidas quantitativas. Ou seja, a NMR pode determinar espectros mais nítidos sobre cadeias de copolímeros seqüenciados em bloco do que dos seqüenciados aleatoriamente (VAN HERK, 2005). Recentemente, BRITTON et al. (2001) também empregaram ${ }^{13} \mathrm{C}-\mathrm{NMR}$ na determinação do grau de ramificação e da distribuição da seqüência de copolímeros de VAc e BuA obtidos a partir da copolimerização em emulsão num processo do tipo semi-batelada. Nesse trabalho chegou-se à conclusão de que existe um efeito sinergético que induz a uma maior formação de ramificações na copolimerização de VAc e BuA do que nas suas respectivas homopolimerizações. Além disso, verificou-se que os radicais com terminação ativa de VAc tendem a realizar transferência de cadeia preferencialmente com unidades monoméricas de BuA e de maneira mais efetiva que os próprios radicais com terminação ativa de BuA.

Outra técnica de caracterização bastante empregada para a avaliação do grau de homogeneidade do copolímero formado é a determinação da temperatura de transição 
vítrea, Tg. Devido à grande diferença de $\mathrm{Tg}$ entre os homopolímeros correspondentes aos comonômeros $\left(\mathrm{BuA}=-55^{\circ} \mathrm{C} ;\right.$ VAc $\left.=28^{\circ} \mathrm{C}\right)$ (BRANDRUP \& IMMERGUT, 1989) as diferentes composições do copolímero também determinam diferentes temperaturas de transição vítrea (BURAC, 1998). Neste caso, a formação da estrutura "core-shell" da partícula pode ser facilmente verificada com a observação de duas temperaturas de transição vítrea que são correspondentes aos polímeros presentes nas duas fases das partículas.

\subsection{Tipos de reatores utilizados em polimerização em emulsão.}

Nas polimerizações em emulsão, os tipos de reatores empregados podem operar nos modo batelada, semi-contínuo (ou semi-batelada) e contínuo. O tipo de reator mais comum é o de tipo tanque agitado operando em modo semi-contínuo.

\subsubsection{Reatores Batelada}

São usados industrialmente, apresentam alta flexibilidade e são bastante empregados em escala piloto e de bancada pela sua simplicidade e baixo custo operacional, além de poderem alcançar altas taxas de conversão. Porém, apresentam algumas desvantagens:

- Impossibilidade do controle das propriedades do polímero.

- Baixa produtividade industrial considerando os tempos de carga, descarga e limpeza.

- Dificuldade no controle de temperatura.

- Variação de qualidade entre diferentes bateladas.

No caso de copolimerizações, quanto maior a diferença entre as razões de reatividade dos monômeros maior será o desvio de composição dos copolímeros produzidos. 


\subsubsection{Reatores Semi-contínuos}

Uma das principais vantagens dos processos de polimerização em semi-batelada, em relação aos de batelada convencionais, é a possibilidade de se estabelecer um controle de adição de reagente de modo a se obter taxas adequadas de conversão e de remoção de calor compatíveis e um controle adequado da composição, entre outras propriedades do copolímero. Nos reatores semi-batelada, uma parte dos reagentes, denominada carga inicial, é inicialmente carregada no reator e o restante das quantidades da formulação passa a ser continuamente alimentada durante um determinado período de tempo após o início da reação. As copolimerizações conduzidas no modo semi-batelada, também denominadas semi-contínuas, podem ser executadas de acordo com algumas estratégias elaboradas para a adição de monômeros.

Uma das estratégias seria, por exemplo, a adição contínua de um monômero ou de uma mistura de monômeros, podendo esta adição ser previamente emulsificada ou não. Este processo pode ser realizado de modo que a taxa de adição de reagentes seja maior que a taxa de reação, deixando o meio reacional saturado com monômeros, ou, de modo oposto, em condições de escassez. Em condições de escassez, a taxa de adição dos monômeros é menor que a máxima taxa de reação que seria alcançada se o meio reacional estivesse saturado com todos os monômeros. Para este caso, devido à baixa taxa de adição dos monômeros, um regime intermediário é atingido de modo que a taxa de reação dos monômeros adicionados passa a ser igual à sua taxa de adição, controlando também dessa forma a composição do copolímero formado (DIMITRATOS et al., 1989). Também pode ser empregado o processo de composição controlada. Neste tipo de controle a adição é feita a partir de um perfil ótimo de adição em função do tempo. O controle pode ser feito a partir de medições em linha, tais como pela espectroscopia NIR, pela espectroscopia Raman, ou pela calorimetria, ou baseados em modelos que relacionam a composição do copolímero com a conversão da reação. 
A principal desvantagem deste modo operacional é a sua relativa baixa produtividade em relação ao processo em batelada. Esta limitação pode ser compensada com o uso de reatores maiores.

\subsubsection{Processos Contínuos.}

São os mais adequados para minimizar os tempos gastos na carga, descarga e limpeza do equipamento além de eliminarem as variações de qualidade entre diferentes lotes dos processos batelada. Porém, apresentam algumas desvantagens. Distribuições de tamanho e morfologias específicas de partícula, dependendo do caso, podem ser mais difíceis de serem obtidas em processos contínuos. Processos de produção em menores quantidades de produtos de diferentes qualidades ("grades") que requerem mudanças freqüentes de condições operacionais também podem ser desvantajosas de se realizar em reatores contínuos.

\subsubsection{Reatores Contínuos de Tanque Agitado (CSTR)}

Os reatores CSTR têm grande aplicação como equipamento para pesquisa e desenvolvimento de estudos cinéticos. Certas situações experimentais podem ocorrer muito rapidamente em processos operados em modo batelada ou semi-batelada enquanto que, em um reator do tipo CSTR, tais condições podem ser alcançadas e medidas em regime permanente (LOVELL e EL-AASSER, 1997). As outras vantagens são as mesmas que são inerentes a qualquer processo contínuo. Porém, em processos de polimerização em emulsão os reatores CSTR podem apresentar oscilações autosustentadas (RAWLINGS e RAY, 1987) causadas pela alta velocidade de nucleação que, por sua vez, é muito sensível a variações na concentração de emulsificante e eletrólitos, tornando mais difícil o controle do número de partículas. O uso de um reator tubular, onde a nucleação poderia ser mais bem controlada, associado em série ao tanque CSTR, pode ser uma maneira de minimizar essas oscilações, (LOVELL e ELAASSER, 1997; PIIRMA, 1982). Além disso, as distribuições de tamanhos de partículas 
e de pesos moleculares tendem a ser mais largas devido às distribuições de tempos de residência serem largas em CSTR. Geralmente, estas distribuições podem vir a ser mais estreitas se também for aplicada uma associação de tanques agitados em série operando continuamente. As desvantagens na partida também podem ser minimizadas adotando-se algumas estratégias como, por exemplo, iniciar o processo a partir de produto final de outros lotes de produção (LOVELL e EL-AASSER, 1997).

\subsubsection{Reatores Tubulares Contínuos}

Um estudo clássico das características dos reatores tubulares em polimerização em emulsão são os trabalhos publicados por PAQUET e RAY (1994a) (1994b), onde a modelagem matemática feita se ajusta satisfatoriamente aos dados experimentais obtidos para as homopolimerizações de metacrilato de metila e estireno alimentados a $30 \%$ de volume reacional. No trabalho desenvolvido por estes autores (PAQUET e RAY, 1994a), foram feitas comparações do desempenho entre os reatores CSTR, batelada e tubular analisando-se a conversão e a distribuição de tamanhos de partículas. Além disso, realizou-se um estudo do efeito das pulsações sobre a distribuição de tamanhos de partícula. Os resultados obtidos demonstraram que o reator tubular com escoamento pulsado apresenta um melhor desempenho em relação ao CSTR, o qual apresenta menores conversões e distribuições de tamanho de partículas mais largas. Além disso, como processo contínuo, o reator tubular com escoamento pulsado também representa uma alternativa viável ao processo batelada.

Além de apresentarem as mesmas vantagens que os reatores do tipo CSTR, por causa do modo contínuo de operação, os reatores tubulares também apresentam outras vantagens quando comparados com os de tipo CSTR, tais como:

- maior flexibilidade operacional;

- redução de perdas durante paradas, partidas e mudanças de "grade" devido aos períodos de regime transiente mais curtos; 
- controle de temperatura mais eficiente devido às altas áreas de troca térmica em relação ao volume de reação;

- menor tempo de residência e, portanto, menor volume de reação requerido;

- distribuição de tamanhos de partícula mais estreita no caso de emulsões;

- pesos moleculares e taxas de reação melhor controlados devido ao controle de temperatura e alimentação de reagentes em pontos determinados do reator.

Como principais desvantagens temos as seguintes:

- são menos flexíveis que os reatores semi-batelada quanto à alimentação de reagentes;

- número reduzido de estudos experimentais e teóricos;

- a emulsão pode se desestabilizar;

- $\quad$ pode ocorrer a formação de depósito de polímero nas paredes.

Estas desvantagens podem ser minimizadas através da introdução de maior número de alimentações laterais de reagentes, de pulsos no escoamento e do emprego de altas taxas de reciclo do meio reacional. Bons resultados foram obtidos recentemente na estabilidade dos látices produzidos com teores de sólidos acima de $30 \%$ do volume do meio reacional para processos de copolimerização em emulsão de MMA, metacrilato de metila, e BuA aplicando-se uma alimentação lateral deste monômero em um reator tubular helicoidal (OUZINEB et al., 2004).

\subsubsection{Reatores Tubulares Contínuos com Reciclo.}

Neste tipo de reator, parte do efluente do reator é recirculada para junto da corrente de alimentação de reagentes. Caso a taxa de recirculação seja muito alta, o comportamento do processo passa a se aproximar ao de um CSTR, alargando conseqüentemente a distribuição dos tempos de residência e de tamanhos de partículas. Além disso, em virtude dessa semelhança com o comportamento de um reator CSTR, em determinadas condições específicas, são produzidas oscilações que 
podem se tornar auto-sustentadas. Estas oscilações são caracterizadas por golpes de renucleação de partículas causados pela instabilidade no controle do número de partículas e da concentração de emulsificante.

O reator tubular contínuo com reciclo pode ser usado de modo vantajoso para a obtenção de altas taxas de conversão. Isto é possível porque altas taxas de transporte de calor são atingidas devido às características geométricas do reator. Devido a essa vantagem os efeitos das características operacionais desse tipo de reator vêm sendo estudados, (ABAD et al., 1995a; ABAD et al., 1995b; ABAD et al., 1995c; ARAÚJO et al., 1998; ARAÚJO et al.,1999; ARAÚjO et al., 2000; ARAÚJO et al., 2001).

O estudo da copolimerização em emulsão de acetato de vinila e acrilato de butila, conduzido em um reator tubular contínuo com reciclo, foi realizado por POORMAHDIAN e BATAILLE (2000). Nesse trabalho foram avaliados os efeitos das condições operacionais sobre a conversão, tamanho de partículas e composição do copolímero formado. Foram avaliadas diferentes velocidades de escoamento e diferentes composições dos monômeros alimentados. A partir daí conclui-se que a quantidade de acrilato de butila alimentada e a velocidade de escoamento influenciavam fortemente a distribuição do tamanho de partículas e a composição do copolímero, podendo-se evitar a alta deriva de composição característica de reatores batelada. Determinaram-se também velocidades ótimas de escoamento onde eram alcançadas máximas taxas de conversão. Estas velocidades variam de acordo com a composição dos monômeros alimentados.

LEE et al. (1990) estudaram o efeito do tempo de residência médio sobre a performance de um reator tubular contínuo com reciclo e verificaram um aumento seguido de uma queda nos valores tanto da conversão de monômero como da concentração de partículas na etapa transiente, até alcançar o regime permanente, e cujas amplitudes aumentavam com o incremento do tempo médio de residência. Estas amplitudes podem ser minimizadas utilizando-se diferentes estratégias de partida. No trabalho realizado por $A B A D$ et al. (1994) verificou-se que a melhor estratégia para o 
reator contínuo com reciclo estudado era o arranque do processo com o reator carregado com um látex produzido a partir de uma polimerização prévia.

Na investigação realizada por ARAÚJO et al. (1999) foi estudado o efeito de várias condições experimentais (temperatura, tempo de residência e concentração de iniciador) sobre o desempenho do processo contínuo de copolimerização de acetato de vinila e Veova $10^{\circledR}$ em emulsão conduzida num reator tubular com reciclo. Os resultados deste estudo mostraram que, para este tipo de processo, não podem ser alcançados simultaneamente desempenhos ótimos de produção e de qualidade do produto. Neste caso, deve-se alcançar uma relação ótima entre qualidade do produto e a taxa de produção do processo. ARAÚJO et al. (2001) também determinaram as condições ótimas de operação de modo a aumentar não só a taxa de conversão do processo como também a qualidade do produto obtido. Tais condições, que não devem ser as mesmas que são aplicadas no início do processo, estão relacionadas a um regime pseudo-estacionário, no qual altas taxas de conversão são obtidas com baixos tempos de residência, baixas temperaturas e baixas concentrações de iniciador.

Em um estudo sobre o efeito do regime de escoamento sobre a polimerização em emulsão em um reator tubular com reciclo, realizado por ROLLIN et al. (1977) foram realizadas polimerizações isotérmicas em emulsão de estireno empregando-se concentrações de emulsificante próximas à concentração micelar crítica, CMC. Verificou-se que a taxa de polimerização alcançou valores máximos na fase de transição entre regimes de escoamento laminar e turbulento. Neste caso, do mesmo modo que na polimerização em emulsão em batelada, a turbulência excessiva do escoamento da emulsão aumenta a área superficial das gotas de monômero, as quais passam a deslocar emulsificante do meio dispersante, diminuindo a formação de micelas e a taxa de conversão. Por outro lado, a baixa turbulência do meio reacional pode limitar a taxa de reação no reator tubular devido a fatores difusionais. Já nas polimerizações em emulsão em batelada, a queda na taxa de conversão com a baixa agitação se deve à coalescência excessiva das gotas de monômero com a conseqüente segregação de fases. 
No trabalho de PAQUET e RAY (1994a) destaca-se a importância do regime turbulento para manter uma mistura eficiente da emulsão. Por outro lado o regime turbulento excessivo pode causar a coagulação de emulsões fracamente estabilizadas. O regime laminar em reatores tubulares, sem recheios ou anteparos internos, se caracteriza pela ausência de mistura radial, afetando o transporte de calor e de massa do meio reacional e podendo causar também a coalescência de gotas de monômero, separando-as da fase dispersante. Esta segregação pode ser responsável pela possível formação de coágulos em pontos de estagnação do escoamento, tais como locais de amostragem no interior do reator.

O estudo do efeito do recheio em uma polimerização em emulsão de metil metacrilato, conduzida em modo descontínuo com reciclo num reator tubular com duas seções, a primeira seção com reciclo, realizado por FAN et al. (2005) indicou que o recheio do tipo Sulzer SMXL ajuda a manter a estabilidade da emulsão favorecendo o controle de temperatura. Esta conclusão confirma o resultado do estudo anterior feito no mesmo equipamento sem reciclo, (FAN et al., 2003) indicando que escoamentos próximos ao do tipo pistonado podem ser obtidos na presença de homogenizadores estáticos tais como os do tipo de recheio utilizado. Portanto, os inconvenientes ocasionados por uma distribuição de tempos de residência larga, tais como os obtidos no CSTR, podem ser evitados neste caso.

\subsubsection{Colunas Pulsadas.}

As colunas pulsadas podem ser de dois tipos: colunas pulsadas com pratos perfurados (CPPP) e colunas com recheio pulsadas (CRP). Em ambos os casos, as pulsações causam turbulências suficientes para dificultar a deposição das partículas de polímero nas paredes e nos internos do reator, evitando entupimentos e incrustações, além de propiciar uma boa mistura radial para o transporte de calor. Em trabalhos anteriores do grupo (CARVALHO et al., 2005; CARVALHO et al., 2006a; CARVALHO et al., 2006b; CARVALHO et al., 2006c; PALMA, 2002; PALMA e GIUDICI, 2001; 
PALMA e GIUDICI, 2003; PALMA et al., 2001a; PALMA et al., 2001b; SALLARÉS et al., 2004; SAYER e GIUDICI, 2002a; SAYER e GIUDICI, 2002b; SAYER et al., 2002a; SAYER et al., 2002b), foi estudado o uso da coluna pulsada com pratos perfurados (CPPP) para a realização de reações de homopolimerização de acetato de vinila e de copolimerização de acetato de vinila e acrilato de butila em emulsão. Neste caso, as pulsações produzidas no meio reagente evitam não só a formação de depósitos, decorrentes da desestabilização da emulsão, como também gradientes radiais de temperatura e de concentração. A dispersão axial também pode ser variada através da amplitude e da freqüência dos pulsos (HOEDEMAKERS, 1990; MEULDIJK, 1992; PAQUET e RAY, 1994a, 1994b; SHOLTENS, 2002; PALMA e GIUDICI, 2003).

Mesmo assim, os reatores contínuos de coluna pulsada, cujas qualidades já foram mencionadas anteriormente, ainda não são empregados para processos de polimerização por emulsão em escala industrial. Isto se deve ao desenvolvimento relativamente recente deste tipo de reator para polimerizações em emulsão (HOEDEMAKERS et al.,1989).

Os efeitos da aplicação do escoamento pulsado ao meio reacional sobre a distribuição dos tempos de residência foram descritos por MACKLEY et al. (1996) confirmando a possibilidade de se obter um escoamento próximo ao pistonado, plugflow, com tempos de residência altos em um comprimento relativamente curto de um reator tubular pulsado com anteparos. O escoamento pulsado em tubos com anteparos permite melhorar as características do meio reacional, tais como os graus de mistura e de transporte de massa e de calor. Uma das características do escoamento pulsado em um tubo com anteparos é a possibilidade da mudança da distribuição dos tempos de residência de modo independente da velocidade média de escoamento. No trabalho de STONESTREET e VAN DER VEEKEN (1999) foram obtidas relações ótimas entre os regimes de escoamento oscilatório e o escoamento médio, em um reator tubular pulsado com anteparos, a fim de se obter a distribuição de tempos de residência mais próxima ao de um escoamento pistonado. NI e PEREIRA (2000) também realizaram estudos experimentais para a análise da distribuição de tempos de residência e 
determinação da dispersão axial. Os resultados obtidos mostraram a possibilidade da obtenção do escoamento contínuo pistonado em um tubo com anteparos no intervalo de velocidade média caracterizado pelo regime laminar. OLAYIWOLA e WALZEL (2007) também determinaram condições ótimas de transferência de calor em um duto aletado, com velocidades médias de escoamento moderadas. Neste trabalho, estudando-se o efeito das pulsações sobre a taxa de troca de calor, os autores obtiveram um coeficiente de transferência de calor 2,4 vezes maior que o alcançado no escoamento não-pulsado. Chegou-se também à conclusão de que, à medida que a velocidade média de escoamento aumenta, o efeito das pulsações sobre o transporte de calor passa a ser cada vez menor.

A simulação mais completa dos perfis de escoamento em um tubo com anteparos foi realizada pela primeira vez por $\mathrm{NI}$ et al. (2002), mediante dinâmica dos fluidos computacional, CFD. A validação do modelo obtido com os dados experimentais permite representar escoamentos simétricos e assimétricos do meio reacional abrindo possibilidades de estudo da influência desses perfis sobre outras características do processo neste tipo de reator.

Recentemente, MARÍN et al. (2006a), MARÍN et al. (2006b), propuseram um novo tipo de reator tubular, não pulsado, com anteparos inclinados. O modelo matemático desenvolvido para representar o funcionamento contínuo do reator proposto foi simulado empregando o método dos volumes finitos. Foram analisados os desempenhos do reator para a polimerização em emulsão de estireno assumindo-se o escoamento laminar pistonado do meio reacional. Concluiu-se que a presença de anteparos produz um efeito positivo sobre a viscosidade e o número de partículas do produto final.

\subsection{Colunas Recheadas Pulsadas (CRP)}

O primeiro processo contínuo de polimerização em emulsão em uma CRP foi desenvolvido e patenteado por HOEDEMAKERS et al. (1988), no Departamento de 
Química e Engenharia Química da Universidade de Tecnologia de Eindhoven. A coluna, feita de vidro, tinha altura de $5 \mathrm{~m}$ e diâmetro de $0,05 \mathrm{~m}$ e era dividida em 5 seções de 1 metro de comprimento cada uma. Cada seção estava equipada com camisa para água de resfriamento para controle independente de temperatura. Foram utilizados anéis de Raschig como elementos de recheio, dispostos aleatoriamente ao longo da coluna, cada um com comprimento de $10 \mathrm{~mm}$, diâmetro externo de $9 \mathrm{~mm}$ e diâmetro interno de $7 \mathrm{~mm}$. Um pulsador estava montado na base da coluna. O sistema também dispunha de um tanque para pré mistura de onde o meio reagente era enviado a um préaquecedor, antes e alimentar a coluna pela sua base. De acordo com os inventores, verificou-se a possibilidade de realizar polimerizações em emulsão de acetato de vinila de modo a evitar oscilações na conversão e reduzir consideravelmente o nível de incrustações. Outros trabalhos, realizados pelo mesmo grupo, deram seqüência a este estudo inicial (MAYER et al., 1994; MAYER et al., 1996; MEULDIJK et al., 2001; MEULDIJK, 1992; MEULDIJK e GERMAN, 1999; SHOLTENS et al., 2001a; SHOLTENS et al., 2001b; SHOLTENS et al., 2001c; SHOLTENS, 2002; HOEDEMAKERS et al.,1989; HOEDEMAKERS, 1990; VAN DEN BOOMEN, 1996; VAN DEN BOOMEN, 1999).

O principal fator responsável pela operação estável da CRP é a dispersão axial. Na polimerização em emulsão de acetato de vinila, realizada em uma CRP, a oscilação da conversão e do número médio de partículas em função do tempo foi totalmente suprimida com valores de coeficiente de dispersão axial de até $3 \mathrm{~cm}^{2} / \mathrm{s}$, MEULDIJK (1992).

\section{Homopolimerização em Emulsão em uma CRP}

Os trabalhos que serão mencionados nesta seção descrevem a homopolimerização em emulsão do estireno e do acetato de vinila. O estudo da homopolimerização em emulsão destes dois monômeros em uma CRP foi inicialmente descrito por HOEDEMAKERS et al. (1988). 
A polimerização em emulsão do estireno em uma CRP foi realizada por HOEDEMAKERS (1990) onde os resultados de conversão e de número total de partículas, obtidos com a coluna operando em regime permanente, foram analisados em função da posição de tomada da amostra, do tempo de residência, das pulsações e do tipo de recheio da coluna. Em termos de distribuição de tempos de residência, o desempenho da coluna foi comparado a dois casos extremos que correspondem aos processos realizados em CSTR e em batelada. A partir desses resultados, concluiu-se que as pulsações influenciam na distribuição do tempo de residência das partículas e na conversão da reação na coluna. Deste modo, para baixas pulsações e altas velocidades intersticiais do meio reacional, o comportamento do processo na coluna se aproxima ao processo do tipo batelada quanto ao número e distribuição de tamanhos de partículas, às taxas de conversão e aos pesos moleculares. Para altas pulsações, o comportamento do processo se aproximava mais ao de um reator CSTR. No caso de baixas velocidades intersticiais, onde a taxa de reação e o número de partículas cai ligeiramente, o desempenho da CRP ainda é superior ao de um ou mais (2 a 3) reatores CSTR associados em série. As pulsações, porém, não alteraram significativamente a distribuição de pesos moleculares do polímero formado.

Verificou-se também que a coluna operou de modo estável durante ensaios de mais de 10 horas. Além disso, as distribuições de tamanhos de partículas da CRP foram mais estreitas do que as obtidas em um ou mais reatores CSTRs (2 a 3) associados em série e operando nas mesmas condições. O efeito do grau de dispersão axial sobre a conversão e a distribuição dos tamanhos de partículas é determinado, principalmente, durante o primeiro estágio da polimerização, na seção da coluna onde ocorre a etapa de nucleação das partículas, na presença de gotas de monômero no meio reacional. O grau de dispersão axial também está associado ao tipo de recheio da coluna que, por esse motivo, também influencia no desempenho do processo na coluna.

MAYER et al. (1994) estudaram o efeito de altas frações mássicas de monômero na formulação de polimerização de estireno no processo batelada e nos processos contínuos CSTR e na CRP. Foram utilizadas alimentações com frações mássicas de 
monômero de 0,47 para os ensaios na CRP. Foram avaliados a conversão, o número de partículas e o comportamento reológico do látex obtido. A partir desse estudo concluiu-se que o número de partículas nucleadas na CRP depende consideravelmente da distribuição de tempos de residência, a qual depende do grau de pulsação. Os valores do número de partículas na CRP são inferiores aos do processo batelada e superiores ao do processo CSTR. Portanto, a velocidade de pulsação constitui-se numa poderosa ferramenta para o controle da distribuição dos tamanhos de partícula e, conseqüentemente, das características reológicas do produto final. Para as concentrações de monômero empregadas, não foram verificadas incrustações durante os ensaios. Também, ficou demonstrado que na CRP pode ser produzido um látex com a mesma quantidade de polímero que no reator batelada porém com viscosidade mais baixa, devido à diferença na distribuição de tamanhos de partícula.

Em outro trabalho destes mesmos autores (MAYER et al., 1996) foi desenvolvido um modelo matemático que representa a produção de sementes em regime permanente. $A$ equação que descreve a taxa de nucleação das partículas foi derivada a partir de dados obtidos em processo batelada. A CRP utilizada é a mesma que a dos trabalhos anteriores, porém com uma altura de $1 \mathrm{~m}$. A relação entre o diâmetro dos anéis de Raschig, utilizados como recheio, e o diâmetro da coluna foi de 0,2, de modo a garantir um escoamento fácil através da coluna. A corrente de saída, localizada no topo da CRP, está conectada a um reator CSTR onde as micelas existentes se dissolvem, mantendo constante o número de partículas do meio reacional. Os resultados desse trabalho mostraram que o número de partículas do final do período de nucleação diminui com o aumento da dispersão axial. Também verificou-se que tanto o número de partículas como a conversão, logo na entrada do reator, aumentam com o aumento da dispersão axial.

A polimerização em emulsão do acetato de vinila também foi realizada em uma CRP de modo estável devido à limitação da dispersão axial (MEULDIJK et al., 1992). A CRP utilizada por MEULDIJK et al. (1992) tinha diâmetro de 0,05 $\mathrm{m}$ e altura de 5,1 m. Estava recheada com anéis de Raschig com diâmetro de 0,01 m; porosidade do leito de 0,73; 
era equipada com jaqueta para água de resfriamento e seis pontos de amostragem. A freqüência de pulsação, do pulsador montado na base, foi variada de 0,87 a 3,5 Hz com amplitude constante de 0,014 $\mathrm{m}$. Estes autores determinaram valores de coeficientes de dispersão axial e dados, em regime permanente, de conversão de monômero e número de partículas ao longo da coluna e em função da freqüência de pulsação. Foram obtidos valores de conversões de monômero de cerca de 50\% e de 90\% para tempos de residência médios de 30 a 90 minutos, respectivamente. As oscilações de conversão foram eliminadas, embora tenham observado que a concentração de partículas oscilava entre $1,2 \times 10^{20}$ e $1,8 \times 10^{20}$ partículas $/ \mathrm{m}^{3}$ de látex para um tempo de residência médio de 30 minutos. Esta oscilação foi completamente eliminada para um tempo de residência médio de 90 minutos, mantendo-se a mesma pulsação.

A influência da dispersão axial sobre a conversão e a concentração de partículas foi medida para um tempo de residência médio de 30 minutos e obtiveram conversão variando de cerca de 59\% a 50\% para coeficientes de dispersão axial de 0,84 e 3,0 $\mathrm{cm}^{2} / \mathrm{s}$, respectivamente. A influência da dispersão axial foi maior sobre a concentração de partículas, que variaram de $3,0 \times 10^{20}$ a $2,0 \times 10^{20}$ partículas $/ \mathrm{m}^{3}$, para coeficientes de dispersão axial variando de 0,8 a $3,0 \mathrm{~cm}^{2} / \mathrm{s}$, respectivamente. Aparentemente, a dispersão axial limitada teve pouca influência sobre o grau de conversão e a taxa de reação. Porém o número de partículas foi evidentemente afetado.

\section{Copolimerização em Emulsão em uma CRP}

No trabalho de VAN DEN BOOMEN et al. (1996) a CRP foi utilizada como etapa para produção contínua de partículas sementes para o processo de copolimerização de estireno e acrilato de metila. Uma associação de reatores em série, composta pela coluna e mais três tanques CSTR, operou em regime permanente. O produto formado pelo processo contínuo realizado nesta associação de reatores apresentou uma distribuição trimodal de composições. Neste caso, o motivo do emprego da CRP na primeira etapa do processo se deve à sua capacidade particular de produzir partículas monodispersas. 
Em outro trabalho destes mesmos autores (VAN DEN BOOMEN et al., 1999) foi investigado o desempenho de uma CRP alimentada com sementes de poliestireno. A partir da copolimerização de estireno e acrilato de metila, verificou-se que o copolímero formado apresentava uma distribuição mais estreita em sua composição intermolecular se o monômero mais reativo, neste caso o estireno, for alimentado lateralmente em algumas posições ao longo da coluna. Para o sistema composto por esses dois monômeros, somente 3 alimentações laterais já foram suficientes para suprimir o efeito da deriva de composições.

\subsection{Colunas Pulsadas com Pratos Perfurados (CPPP).}

O processo de polimerização em emulsão realizado na CPPP apresenta importantes vantagens sobre o processo realizado na CRP devido à uniformidade de seu escoamento e maior mistura radial favorecendo ainda mais a remoção de calor (PALMA, 2002). Além disso, a CRP possui regiões estagnadas que favorecem a coagulação do polímero. A remoção e a limpeza do feixe de pratos perfurados na CPPP são muito mais simples do que a remoção e a limpeza do recheio na CRP (MEULDIJK, 1992; SHOLTENS, 2002).

Assim como na CRP, a dispersão axial é um dos parâmetros mais importantes na utilização da CPPP como reator de polimerização em emulsão frente ao reator batelada e ao CSTR, já que o seu comportamento corresponderia a uma combinação destes dois tipos de reatores (PALMA, 2002; PALMA e GIUDICI, 2003). Além disso, para baixos valores do coeficiente de dispersão axial, é possível aproximar o comportamento do escoamento da CPPP ao de um reator tubular ideal e, como conseqüência, realizar a polimerização em emulsão com alta conversão de monômero, eliminando as oscilações de conversão observadas no reator do tipo CSTR (PALMA, 2002). A dispersão axial pode ser expressa pelo adimensional número de Peclet axial, definido por: 


$$
P e=\frac{u L}{D_{e a}}
$$

onde $u$ é a velocidade característica do escoamento e $L$ é o comprimento da coluna. Em um reator tubular ideal (escoamento pistonado ou "plug-flow") o coeficiente de dispersão axial é nulo, ou $P e=\infty$, enquanto que em um reator CSTR ideal o coeficiente de dispersão axial é infinito, ou $P e=0$. O coeficiente de dispersão axial $D_{e a}$ é dimensionalmente análogo ao coeficiente de difusão molecular, porém considera outros mecanismos relacionados ao transporte convectivo de massa além da difusividade molecular. Portanto, trata-se de um parâmetro efetivo que representa todos os fatores relacionados com a dispersão.

O estudo do efeito de condições operacionais (freqüência e amplitude de pulsação) e de parâmetros geométricos (espaçamento entre pratos) sobre a dispersão axial na CPPP foi realizado por PALMA e GIUDICI (2003). Neste trabalho, os autores determinaram o valor do coeficiente de dispersão axial a partir do ajuste do modelo de dispersão a dados de distribuição de tempos de residência (DTR) do escoamento no reator. Estes dados foram obtidos a partir de 213 ensaios realizados com água a $20{ }^{\circ} \mathrm{C}$, abrangendo uma faixa operacional de 0 a $4,5 \mathrm{~Hz}$ de freqüência de pulsação, de 5 a 25 mm de amplitude de pulsação, de 3,8 a 11,8 L/h de vazão e espaçamento entre os pratos de 25, 50 e $100 \mathrm{~mm}$. Adicionalmente, foram realizados 39 ensaios de escoamento pulsado empregando soluções aquosas de poli(álcool vinílico) a $25^{\circ} \mathrm{C}$, em diferentes concentrações de modo a obter valores de viscosidades entre 1,4 e 10,0 cP. Nos ensaios com viscosidade de 1cP, foram utilizados água destilada e traçador consistindo de solução aquosa de azul de metileno a $1 \%$ à temperatura de $20{ }^{\circ} \mathrm{C}$. Nos ensaios com soluções de poli(álcool vinílico), o traçador utilizado consistiu em uma solução de azul de metileno a 1\% em solução de água destilada e álcool polivinílico. 0 equipamento utilizado era uma coluna pulsada de vidro com pratos perfurados, composta por três seções de 800 mm de comprimento e 39,6 mm de diâmetro interno. Os pratos eram de aço inoxidável com 39 furos de $3 \mathrm{~mm}$ de diâmetro em arranjo triangular resultando numa área livre de 22,3 \%. Entre a primeira e segunda seção foi instalada a sonda de amostragem de um espectrofotômetro digital, modificado para 
trabalhar em linha com o processo. A injeção de traçador foi feita em forma de pulso na base da coluna.

Os resultados destes ensaios demonstraram que a dispersão axial aumenta com a amplitude e a freqüência das pulsações. O efeito do espaçamento entre os pratos também depende da velocidade de pulsação. Nos ensaios realizados sem pulsação obteve-se um valor máximo de dispersão axial para um valor intermediário de espaçamento entre os pratos, indicando a incidência de um comportamento mais complexo no transporte de massa axial, provavelmente relacionado a mudanças no regime de escoamento do fluido. Os resultados também mostram que a dispersão axial diminui com o espaçamento entre os pratos e aumenta com o aumento da viscosidade para o espaçamento de $25 \mathrm{~mm}$. Para os espaçamentos de 50 e $100 \mathrm{~mm}$, o efeito da viscosidade na dispersão axial foi considerado desprezível no intervalo de valores considerado. Os coeficientes de dispersão obtidos, equivalentes a valores de Peclet entre 2,5 e 70, demonstraram a possibilidade de ajuste do escoamento da CPPP de modo a que ela opere de maneira similar aos reatores do tipo "plug-flow" e CSTR. A partir dos mesmos dados, também foram realizadas regressões lineares entre dois grupos adimensionais, $D_{e d} /(u h)$ e $A f / u$, onde A representa a amplitude e $f$ a freqüência das pulsações. Para todos os espaçamentos entre os pratos estabelecidos foram obtidos coeficientes de correlação linear satisfatórios entre estes dois grupos adimensionais.

O modelo de reator tubular com dispersão axial utilizado por PALMA e GIUDICI (2001) e PALMA (2002) para representar o comportamento da CPPP é dado por:

$$
\frac{\partial C_{i}}{\partial t}=-u_{z} \frac{\partial C_{i}}{\partial z}+D_{e a} \frac{\partial^{2} C_{i}}{\partial z^{2}}+P_{i}
$$

Onde:

$C_{i}$ representa a concentração do componente i;

$D_{e a}$ é o coeficiente efetivo de dispersão axial; 
$u_{z}$ é velocidade superficial do escoamento na direção axial;

t é a variável tempo;

z é a variável de posição axial ao longo do comprimento do reator;

$P_{i}$ é a taxa de produção do componente i por reações, que para o caso do ensaio de DTR é igual a zero.

SCHOLTENS et al. (2001a) realizaram ensaios para o estudo da mistura axial em uma CPPP de aço inoxidável, com diâmetro interno de $49,5 \mathrm{~mm}$, altura de $5 \mathrm{~m}$. A área livre relativa dos pratos era 34\% e o espaçamento entre pratos de $9 \mathrm{~mm}$. Trabalharam com amplitudes de 0 e $35 \mathrm{~mm}$ e freqüências de pulsação de 1 a 3,5 Hz. Na determinação da mistura axial utilizaram a técnica de injeção de tipo pulso de solução de $\mathrm{NaCl}$ na base da coluna. A medição da condutividade elétrica do meio foi feita a 2,035 m abaixo do topo da coluna. Para o tratamento dos resultados usou-se o mesmo modelo de dispersão axial. Os coeficientes de dispersão axial obtidos foram similares aos encontrados por HOEDEMAKERS (1990) no estudo da dispersão axial em uma CRP recheada com anéis de Raschig.

SCHOLTENS (2002) estudou a dispersão axial em uma CPPP utilizando um modelo de tanques agitados com retro-mistura. Esse modelo supõe que a mistura na coluna é representada por uma série de tanques agitados ideais. Neste caso, o número de tanques é o parâmetro que descreve a mistura no escoamento. No modelo de tanques agitados, considerando retro-mistura, há dois parâmetros ajustáveis: o número de tanques e a fração de retro-mistura do escoamento. A retro-mistura é um parâmetro ajustável e não necessariamente tem significado físico. Os valores de coeficientes de dispersão axial na CPPP, obtidos por SCHOLTENS (2002), estão contidos no intervalo de 0,2 a $6 \mathrm{~cm}^{2} / \mathrm{s}$.

\section{$\underline{\text { Homopolimerização em Emulsão em uma CPPP }}$}

O processo contínuo de polimerização em emulsão do acetato de vinila em uma CPPP em aço inoxidável e encamisado foi realizado por PALMA (2002) medindo-se a 
conversão e a distribuição de tamanhos de partículas (DTP), na saída do reator em regime transiente e permanente, e também ao longo do reator em regime permanente. Verificou-se que as condições operacionais (tempo médio de residência e grau de dispersão axial) influenciam várias características do produto como a conversão, tamanho médio e concentração de partículas, porém, não influencia significativamente a viscosidade da emulsão produzida para a formulação da reação de polimerização e as condições operacionais estudadas. Nesse trabalho mostrou-se ser possível obter altas conversões em tempos médios de residência da ordem, ou mesmo inferiores, aos do processo em batelada e atingir regime permanente de operação em um a dois tempos de residência. A CPPP pode operar estavelmente por pelo menos seis horas, sem perturbações nas vazões de alimentação, na freqüência e na amplitude de pulsação. Não foram observadas oscilações auto-sustentadas de conversão de monômero e de concentração de partículas. As características do produto em termos de tamanho médio e de concentração de partículas podem ser manipuladas através da dispersão axial e do tempo espacial do escoamento no reator variando-se a amplitude de pulsação e vazão.

SAYER et al. (2001a,b) desenvolveram e validaram experimentalmente um modelo matemático para a simulação dinâmica do processo de polimerização em emulsão de VAc em uma CPPP. Neste modelo foram representados os mecanismos de nucleação homogênea além da nucleação micelar e de coagulação, característicos da polimerização em emulsão do VAc. O processo na CPPP está representado por um modelo de dispersão axial que permite a simulação em uma ampla faixa de condições operacionais. O método das linhas foi utilizado para discretizar as equações diferenciais parciais de segunda ordem, que representam o balanço de cada componente envolvido na reação em função do tempo e ao longo da altura da coluna. Os resultados demonstraram que, devido à alta solubilidade do VAc na fase aquosa, a nucleação homogênea é significativa e a nucleação das partículas não está limitada somente à entrada na base da coluna, onde a concentração de emulsificante encontra-se acima da CMC. Conseqüentemente, a concentração de partículas aumenta ao longo de quase toda a altura da coluna. À medida que o número de partículas aumenta, a 
concentração de emulsificante na fase aquosa diminui, estabilizando as partículas na emulsão. O modelo foi adequadamente ajustado aos dados experimentais, sendo também usado para simular diferentes procedimentos de partida e mostrando ser uma ferramenta útil na previsão de reações em diferentes condições experimentais.

\section{Copolimerização em Emulsão em uma CPPP}

Assim como no caso da CRP, a copolimerização em emulsão conduzida em uma CPPP foi estudada para os casos em que os pares de monômeros apresentam diferenças consideráveis de solubilidade em água e de reatividade entre si, ocasionando uma dificuldade adicional no controle da homogeneidade do copolímero formado.

SHOLTENS et al. (2001a) estudaram a copolimerização do estireno e acrilato de metila em uma CPPP com o objetivo de verificar a influência da distribuição de tempos de residência na distribuição pré-definida de composições intermoleculares do copolímero formado. Foram comparados os resultados obtidos pelo processo semibatelada e o conduzido, de modo contínuo, em uma CPPP alimentada pela base com os dois monômeros, com sementes de poliestireno e lateralmente com uma corrente de acrilato de metila e duas de estireno. Durante o processo semi-batelada, a adição de monômero foi realizada por injeção em forma de pulso em quantidades e em determinados tempos de reação, de modo equivalente à seqüência, à posição e às vazões das alimentações laterais empregadas na CRP. Em ambos os casos, foram obtidas distribuições bimodais na composição do copolímero formado, porém o processo na CRP apresentou uma pequena quantidade de produto formado com composições intermediárias entre as duas médias principais. A essa pequena diferença de resultados se atribui o efeito da dispersão axial na coluna.

De modo análogo, outra comparação entre o processo de copolimerização em emulsão de estireno e acrilato de metila conduzido em semi-batelada e o equivalente em modo contínuo, realizado em uma CPPP com 3 alimentações laterais, foi 
investigada por SCHOLTENS et al. (2001c). Em ambos os processos, o número de partículas pôde ser melhor controlado devido à alimentação de látex com sementes na etapa de início da reação, evitando a nucleação de partículas. Para base de comparação entre os dois tipos de processo, foram escolhidos dois modos operacionais equivalentes de alimentação de monômero, de maneira a ser obtida uma distribuição de composições bimodal e outra em bloco no copolímero formado em cada processo. A adição de monômero durante o processo semi-batelada, foi realizada por injeção em forma de pulso em determinadas quantidades e em três instantes de tempo determinados da reação. De modo equivalente, na CPPP foram mantidos a seqüência, o tempo espacial e a quantidade de monômero adicionada ao meio reacional através das correspondentes posições e vazões das alimentações laterais. Para a obtenção da distribuição de composições bimodal, os procedimentos operacionais adotados na alimentação de monômero foram similares aos realizados por SHOLTENS et al. (2001a). Neste caso, o monômero da primeira adição, ou corrente alimentada, é o acrilato de metila e nas outras duas adições o monômero é o estireno.

No caso da distribuição em bloco de composições, as três alimentações de monômero, na CPPP, correspondiam somente às de estireno. Já para o processo em semi-batelada, a alimentação de estireno foi feita de forma contínua de acordo com um perfil de adição calculado em função do tempo. Para a obtenção da distribuição em bloco de composições, a composição deve variar de modo controlado em função da conversão da reação. No caso da CPPP, o baixo número de alimentações laterais representou um fator limitante para o controle da distribuição de concentrações que apresentou um perfil multimodal. Para minimizar este problema, os autores recomendam que se aumente a dispersão axial, através da troca de recheio ou do aumento de espaçamento entre os pratos, além de incrementar o número de pontos de alimentação lateral ao longo da coluna.

Para a copolimerização em emulsão dos mesmos comonômeros em uma CPPP, SCHOLTENS (2002) também analisou o efeito do incremento do número de alimentações laterais no controle da distribuição de composições do copolímero 
formado em diferentes condições de pulsação mediante o uso de modelagem matemática. Os resultados obtidos permitiram concluir que a CPPP pode produzir copolímeros homogêneos em altas taxas de conversão, com um número limitado de correntes laterais de alimentação de monômero, desde que sejam aplicadas condições apropriadas de pulsação intensa. Os experimentos realizados na CPPP também demonstraram que a distribuição de composições do copolímero depende muito do grau de dispersão axial aplicado na coluna. Finalmente, para o controle da distribuição de composições do copolímero formado, concluiu-se que o número requerido de alimentações laterais na CPPP, operando com velocidades de pulsações apropriadas, deveria estar entre 5 e 10, de modo que ela pudesse apresentar a mesma flexibilidade operacional que um processo semi-batelada.

SAYER e GIUDICI (2002) estudaram via simulação a viabilidade do emprego da CPPP na copolimerização em emulsão de acetato de vinila e acrilato de butila. Para isso foi usado um modelo dinâmico rigoroso de reações de copolimerização em emulsão em um reator tubular com dispersão axial. Foram determinadas as condições operacionais ótimas para conversão e composição em tempos de residência relativamente curtos. Observou-se que as reações de copolimerização destes dois monômeros são mais lentas que as suas respectivas reações de homopolimerização. Isto se deve à grande diferença de reatividade entre os dois comonômeros. Também devido essa diferença de reatividade, existe a dificuldade em produzir um copolímero homogêneo. Essa limitação pode ser minimizada através do emprego de alimentações laterais do monômero mais reativo ao longo da coluna.

\subsection{Produção de Sementes em Colunas Pulsadas}

Muitos processos industriais de polimerização em emulsão empregam a adição de sementes no meio reacional a fim de ajustar o número de partículas desejado. Tanto o número como a distribuição de tamanho das partículas são características definidas pela etapa de nucleação. Esta primeira etapa do processo ocorre principalmente na região inferior da coluna pulsada e sofre influência da distribuição de tempos de 
residência (HOEDEMAKERS, 1990). Portanto, devido às baixas velocidades de escoamento, a altura requerida da coluna para esta etapa do processo deve ser menor do que a que é necessária para a obtenção de uma conversão completa, quando somente se utiliza a coluna como único reator do processo.

Assim como no trabalho de VAN DEN BOOMEN et al. (1996) também foi realizada por MEULDIJK et al. (2001) o estudo da polimerização em emulsão em um sistema de reatores contínuos. O sistema considerado estava dividido em duas partes. A primeira parte corresponde à produção de sementes, realizada em uma CPPP, e a segunda parte consiste na conversão final do meio reacional, realizada em uma associação de um ou mais tanques em série. Os resultados obtidos mostraram que a concentração e a distribuição de tamanho das partículas no produto formado na CPPP, operando com escoamento próximo ao pistonado, não eram significativamente diferentes das obtidas através do processo batelada iniciado sem o uso de sementes, o que viabiliza a CRP como um sistema apropriado para a produção de sementes.

SCHOLTENS et al. (2001b) também estudaram a produção de sementes de poliestireno a $85{ }^{\circ} \mathrm{C}$ em uma CPPP. Neste caso foi utilizada uma coluna pulsada de aço inoxidável, dividida em 5 seções com $1 \mathrm{~m}$ de comprimento e $5 \mathrm{~cm}$ de diâmetro interno. Cada seção continha 100 pratos perfurados de aço inoxidável com furos de $3 \mathrm{~mm}$ de diâmetro e superfície livre de 35\%. O número de Peclet empregado, $P e=189$, indicou um comportamento pistonado no escoamento do meio reacional. Através do cálculo do número total de partículas e do balanço de emulsificante, verificou-se que para um tempo de residência médio de 20 minutos, o período de nucleação terminava quando a conversão alcançada equivalia a 26\%, a 0,68 m a partir da base da coluna. Com esse comprimento obtido recalcula-se o número de Peclet na zona de nucleação e obtém-se o valor de 26 que, ainda assim, é suficientemente alto para que o processo de nucleação das partículas não seja afetado, confirmando também resultados obtidos por HOEDEMAKERS (1990). Portanto, devido a esse comportamento pistonado do escoamento no interior da coluna, as características do látex formado se aproximam bastante às do produto obtido em processo batelada. 


\subsection{Comentários finais.}

Da apreciação da literatura, observa-se que um dos primeiros estudos detalhados de reatores tubulares para polimerização em emulsão foi realizado por Feldon et al. (1955) e que mais recentemente, dois grupos de pesquisa estudaram de modo mais sistemático o uso destes reatores. O grupo da Universidade de Eindhoven (Holanda) desenvolveu inicialmente um reator tubular com recheio, CRP (com recheio de anéis de Raschig), estudando diversos aspectos tais como caracterização do escoamento e da mistura axial por experimentos de distribuição de tempos de residência, reações de homopolimerização e de copolimerização.

O grupo da USP propôs inicialmente o uso de novo tipo de internos, os pratos perfurados, a partir da adaptação de uma coluna pulsada de pratos perfurados CPPP (usada previamente em estudos de extração líquido-líquido) para uso como reator tubular contínuo de polimerização. As vantagens deste novo tipo de dispositivo interno promotor de mistura (agindo de modo similar a um misturador estático) em relação ao recheio de anéis de Raschig são bastante significativas, especialmente em termos de apresentar menor área de contato parede-fluido (o que dificulta a deposição de polímero), e de apresentar mais facilidade de limpeza. O próprio grupo de Eindnhoven, após ter tomado conhecimento deste novo tipo de dispositivo interno, passou a adotá-lo em seus estudos, substituindo o recheio convencional de anéis de Raschig (embora seus trabalhos continuassem chamando de CRP a CPPP).

O grupo da USP, dentro do qual o presente trabalho foi desenvolvido, também realizou estudos de caracterização fluidodinâmica via distribuição de tempos de residência (PALMA e GIUDICI, 2003), estudos de homopolimerização em emulsão na CPPP (PALMA, 2002), de modelagem matemática do processo (SAYER e GIUDICI, 2002a; SAYER e GIUDICI, 2002b; SAYER et al., 2002a; SAYER et al., 2002b) e de copolimerização em emulsão (CARVALHO et al., 2005; CARVALHO et al., 2006a; CARVALHO et al., 2006b; CARVALHO et al., 2006c; SALLARÉS et al., 2004), sendo estes dois últimos assuntos o tema do presente trabalho. 


\section{Capítulo 3 - MATERIAIS E MÉTODOS.}

Neste Capítulo apresenta-se o equipamento utilizado nos ensaios experimentais, as modificações nele introduzidas, o procedimento experimental e as técnicas analíticas utilizadas.

\subsection{Descrição do Reator Tipo CPPP.}

A coluna pulsada de pratos perfurados (CPPP) utilizada no presente trabalho foi originalmente construída durante o trabalho de PALMA (2002), sobre a qual foram introduzidas modificações necessárias para o presente estudo, e que permitem maior flexibilidade operacional.

As figuras 3.1 e 3.2 mostram os esquemas da CPPP original (PALMA, 2002) e da fase atual, respectivamente.

A CPPP foi originalmente construída com 5 seções de aço inoxidável cada uma com $1000 \mathrm{~mm}$ de comprimento e $40 \mathrm{~mm}$ de diâmetro interno. Os pratos são de aço inoxidável, cada um com 39 furos de $3 \mathrm{~mm}$ em arranjo triangular, resultando numa área livre de 22,3\% em cada prato. Os pratos são sustentados por uma haste central de 5 $\mathrm{mm}$ de diâmetro, coaxial com o tubo do reator. O espaço entre os pratos pode ser regulado por espaçadores, mas nos ensaios realizados no presente trabalho este espaçamento foi fixado em $50 \mathrm{~mm}$, resultando num volume livre de 95,7\% do reator. 


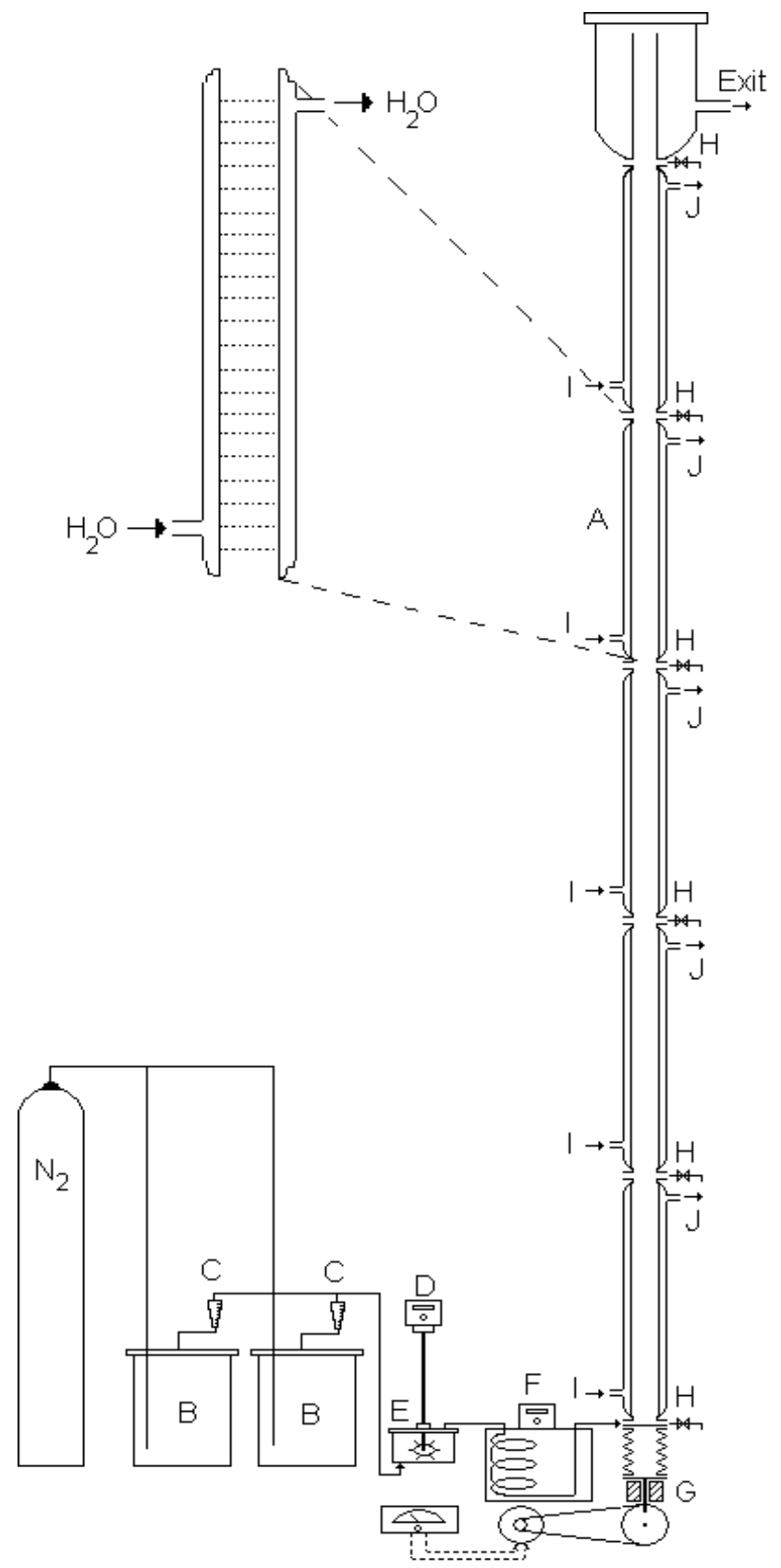

$\begin{array}{llll}\text { A } & \text { Coluna (reator) } & \text { F } & \text { pre-aquecedor } \\ \text { B } & \text { tanques de alimentação } & \text { G } & \text { pulsador } \\ \text { C } & \text { medidor de vazão } & \text { H } & \text { pontos de amostragem } \\ \text { D } & \text { agitador } & \text { I } & \text { entradas da camisa } \\ \text { E } & \text { pre-misturador } & \mathrm{J} & \text { saídas da camisa }\end{array}$

Figura 3.1 - Coluna pulsada com pratos perfurados, em sua configuração original do trabalho de PALMA (2002). 


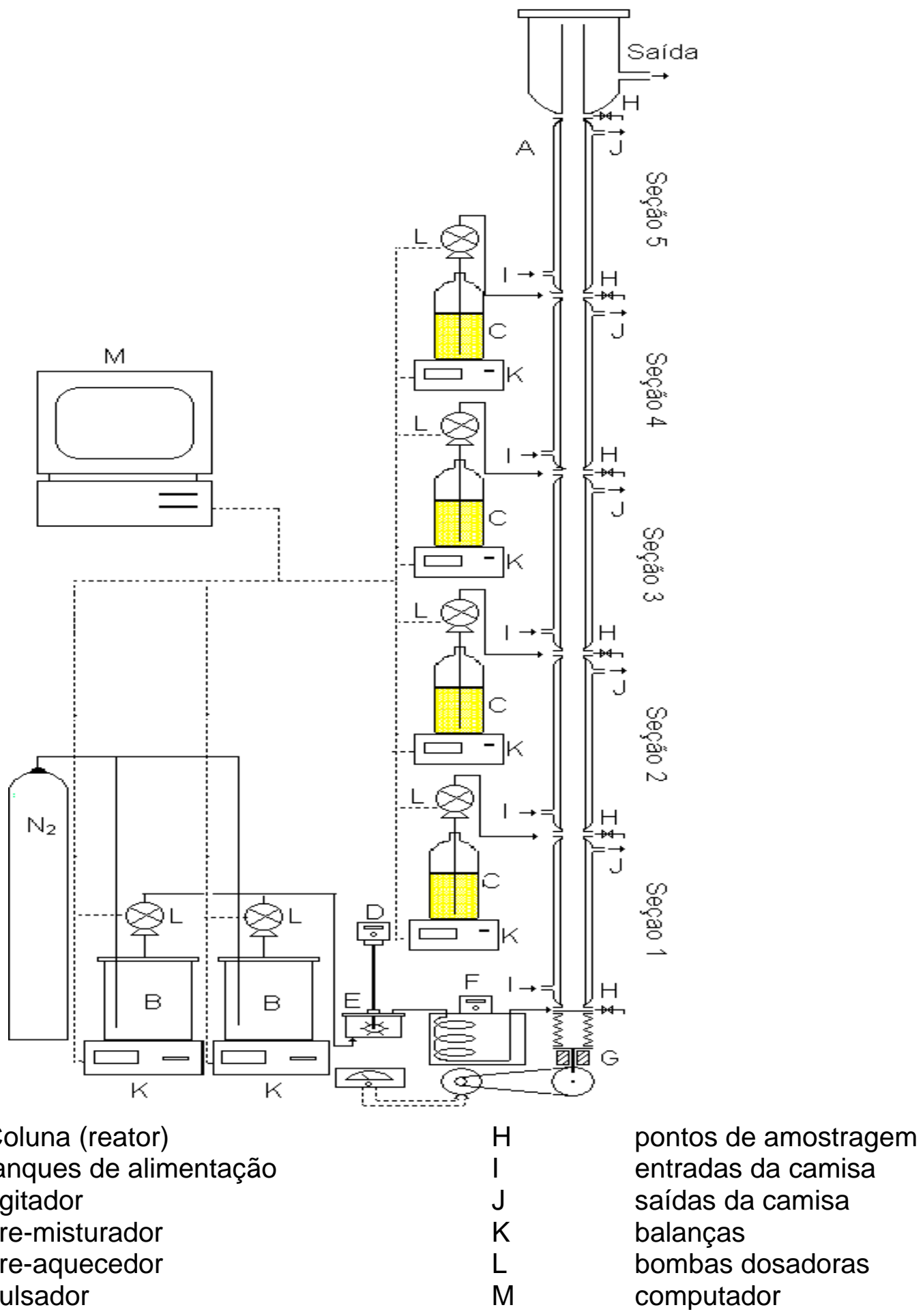

Figura 3.2 - Coluna pulsada com pratos perfurados, em sua configuração como utilizada no presente trabalho. 
Para evitar possível perda de estabilidade da emulsão e minimizar possível formação de depósitos de polímero nas paredes do reator, uma pulsação é sobreposta ao escoamento axial. O pulsador se encontra na base da coluna, sendo formado por um dispositivo tipo fole acionado por uma biela que está excentricamente ligada a um disco acionado por um motor elétrico. A amplitude da movimentação do fole pode ser variada alterando-se o ponto de ligação excêntrico no disco, e a freqüência de pulsação pode ser variada pela alteração da velocidade do motor elétrico. A amplitude e a freqüência podem ser ajustadas, respectivamente, nas faixas de 5 a $25 \mathrm{~mm}$ e de 0,2 a 3,5 Hz. A pulsação provê uma boa agitação local, reduz os gradientes radiais, define o grau de mistura axial, e ajuda a evitar a perda de estabilidade da emulsão e, conseqüentemente, o entupimento do reator.

Em relação ao equipamento original, a coluna apresenta atualmente um controle automático e independente de alimentação e de temperatura para cada uma de suas seções. Essa flexibilidade adicional permite o melhor estudo do efeito dessas variáveis operacionais sobre as propriedades do polímero tais como, composição, conversão, distribuição de tamanhos de partículas, de pesos moleculares, etc.

Os monômeros, além de outros reagentes tais como agentes de transferência de cadeia, podem ser alimentados não só na base da coluna como também em outros 4 pontos ao longo da coluna. O sistema de aquisição e controle de dados é responsável pelo controle e armazenamento dos dados de decréscimo de peso dos reagentes nas balanças. Esses dados entram na malha de controle de um sistema PID que, com o auxílio de um computador, atua ajustando a vazão das bombas dosadoras. Já o sistema de controle de temperatura atua a partir de 5 controladores PID independentes instalados em um painel de controle.

Na figura 3.3 está representado o sistema de controle de temperatura de uma única seção, onde $T_{J, \text { out }}$ é a temperatura de saída da camisa, $T_{J, i n}$ é a temperatura de entrada da camisa e $T_{\text {in }}$ e $T_{\text {out }}$ são respectivamente as temperaturas da entrada e de saída do meio reacional. Trata-se de um sistema de controle em cascata, onde um controlador 
escravo atua para controlar a temperatura de entrada da água na camisa da seção, recebendo como "set-point" a indicação dada por um controlador mestre colocado em cascata. Cada controlador estabelece a freqüência de abertura e de fechamento de duas válvulas solenóides, uma para água fria e outra para água quente, e o sinal da temperatura da mistura entre essas duas correntes, na entrada da camisa da seção, é enviado ao controlador para ser comparado com o set-point estabelecido. Ao longo do trabalho verificou-se que era mais conveniente operar este sistema com o controlador escravo apenas, desativando o controlador mestre. Desse modo evitam-se oscilações observadas possivelmente devido à instabilidade causada pela exotermia da reação, associada ao tempo excessivo de resposta da temperatura de reação na saída da seção, e causada possivelmente pela sintonia inapropriada dos parâmetros do controlador.

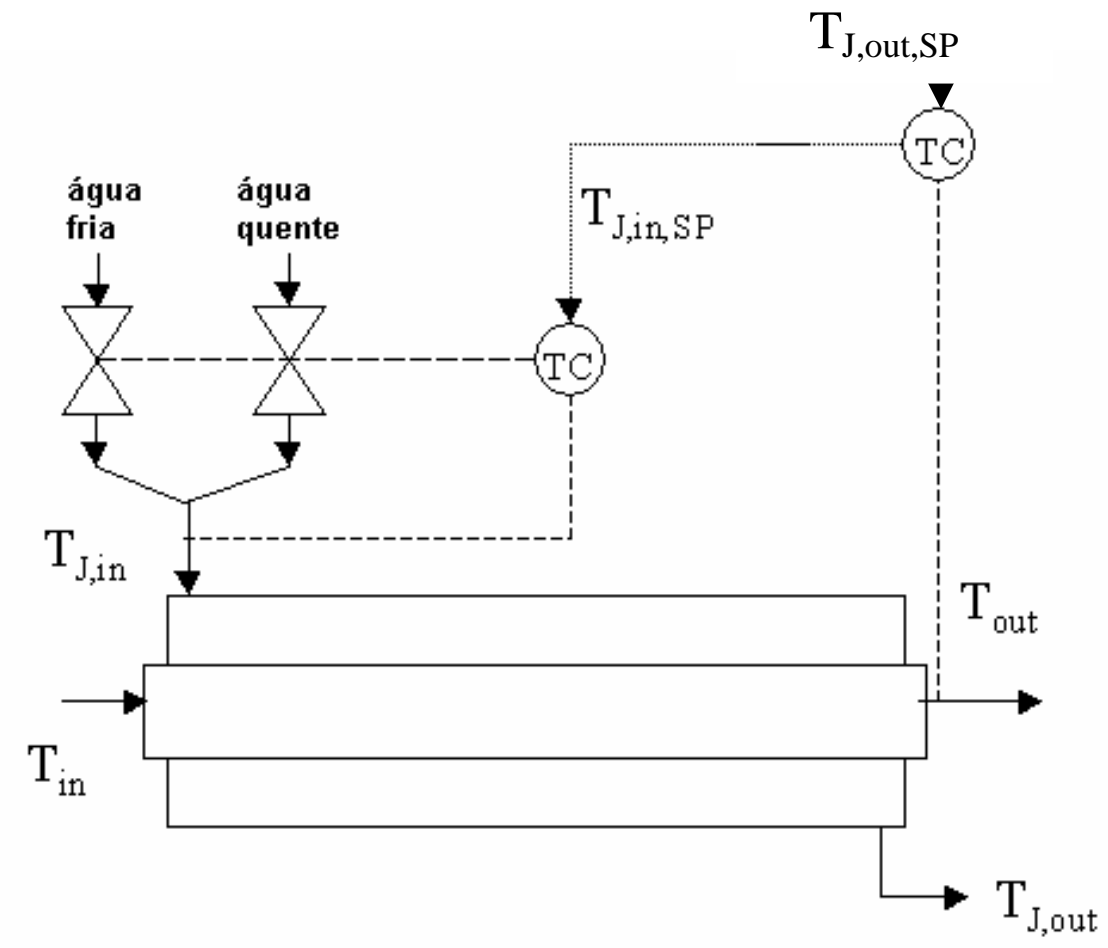

Figura 3.3. Esquema da malha de controle temperatura do meio reacional. 
O set-point da temperatura dos controladores é estabelecido, juntamente com os valores dos demais parâmetros operacionais, na receita do programa do sistema de controle da reação, instalado no computador. O valor do set-point também pode ser alterado diretamente na tela do computador durante a execussão do programa da reação.

Nas Figuras 3.4 e 3.5 estão apresentadas duas telas ilustrativas do sistema de controle e de aquisição de dados do reator.

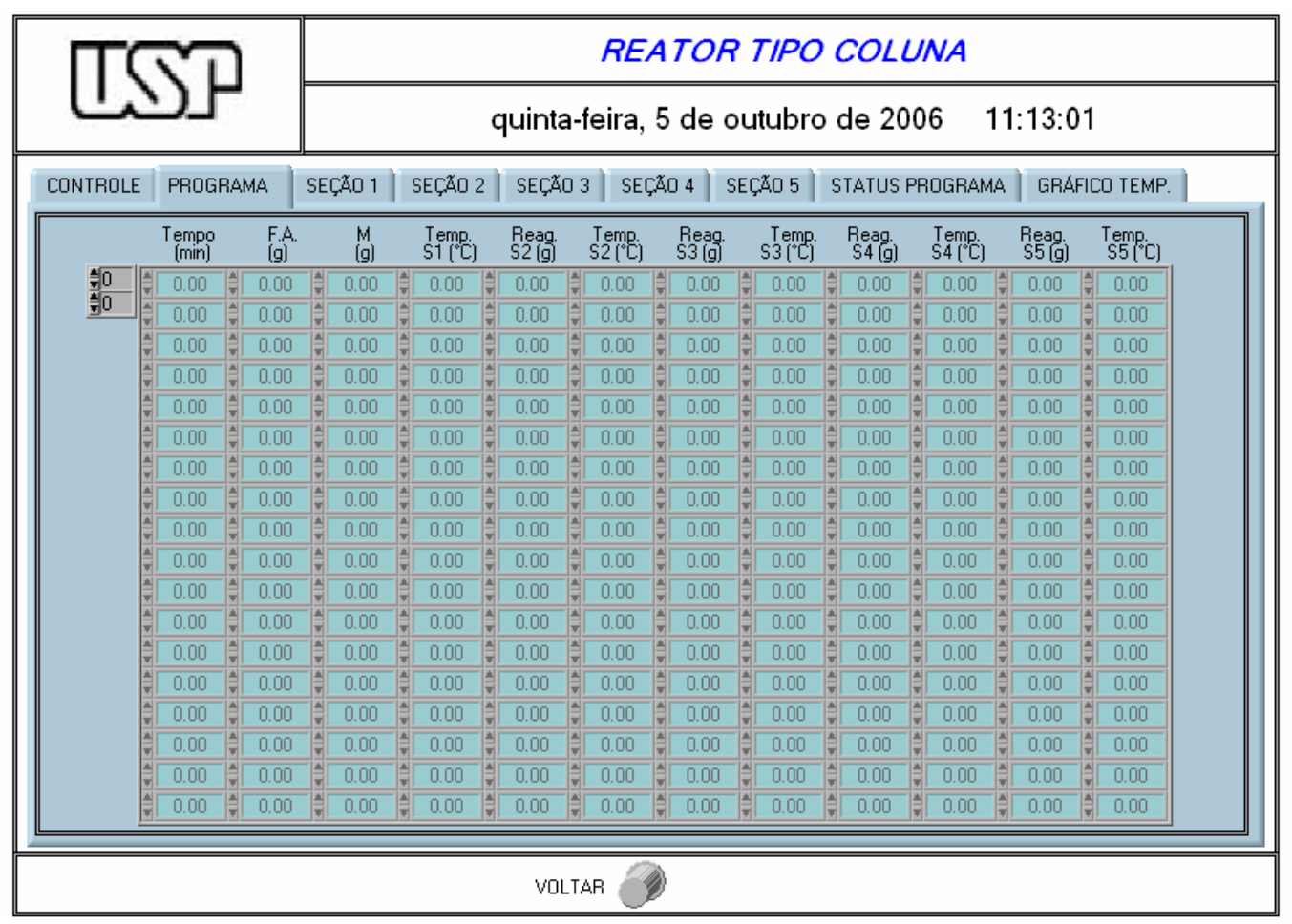

Figura 3.4 Tela de dados operacionais do programa de controle da CPPP. 


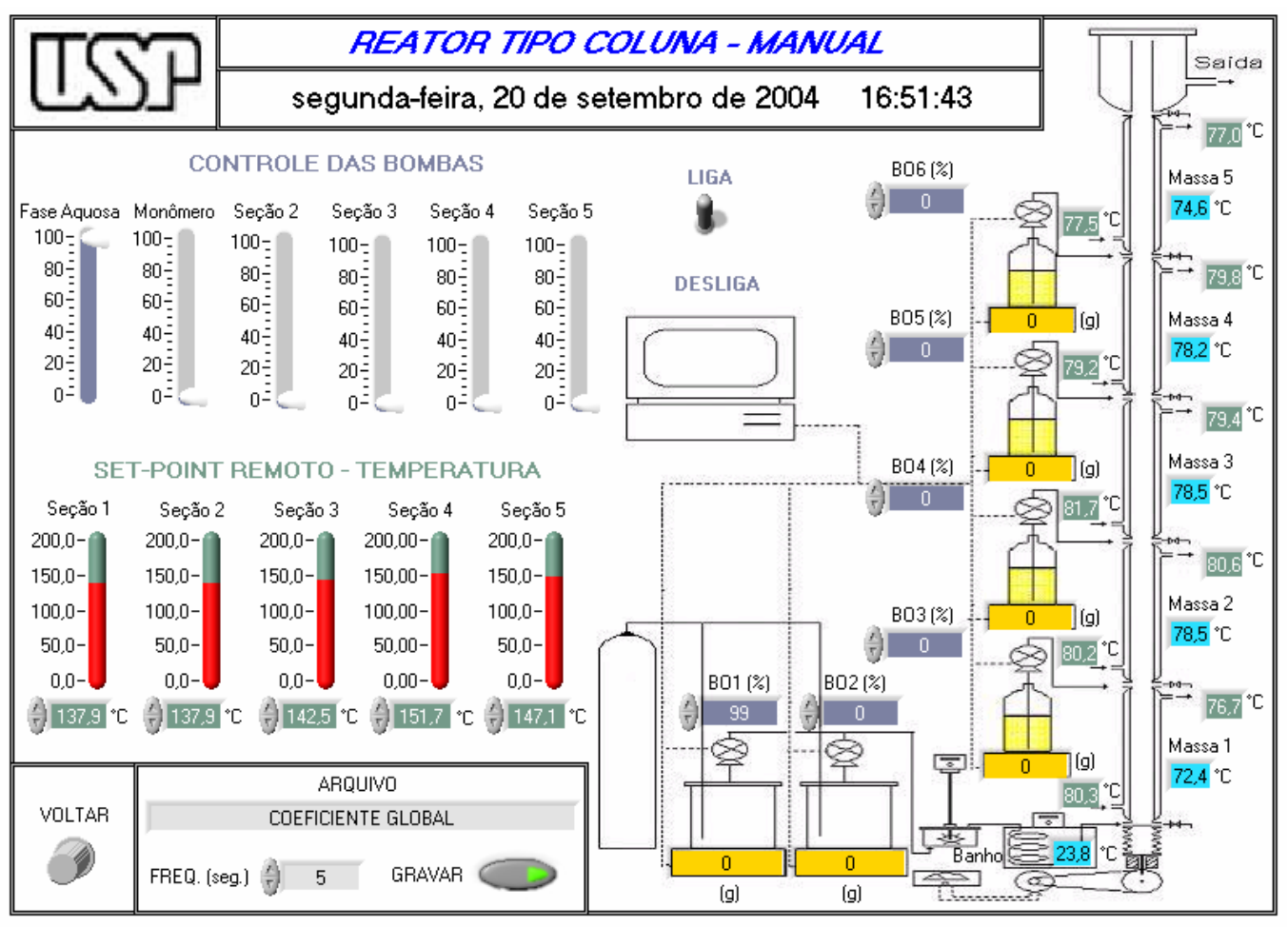

Figura 3.5. Tela do programa de controle manual da CPPP.

\subsection{Procedimento Operacional}

O procedimento de partida das reações contínuas consiste em encher a coluna com água destilada e aquecê-la até que ela atinja a temperatura da reação estabelecida. Os reagentes são alimentados em dois tipos de correntes distintas. Uma corrente, alimentada pela base, consiste na fase aquosa e contém o iniciador, o emulsificante e o agente tamponante. As demais correntes alimentam a coluna com a fase monomérica conforme estabelecido no programa do ensaio a ser realizado. No nosso caso, a corrente de monômero alimentada pela base consiste numa mistura de acetato de vinila e acrilato de butila. As correntes laterais consistem somente de acrilato de butila pelo fato deste monômero ser o mais reativo. Os tanques contendo os reagentes são previamente inertizados com nitrogênio para evitar a inibição da reação pela presença de oxigênio dissolvido no meio reacional. Também, antes da partida da reação, o tanque de pré-aquecimento deve estar preparado de modo que a temperatura 
estabelecida seja alcançada pelo meio reacional proveniente do tanque de agitação, onde a emulsão é criada a partir das correntes que alimentam a base da coluna.

A coleta de dados e o acompanhamento da evolução do desempenho do processo, realizado durante a operação da coluna, são efetuados através de retiradas periódicas das amostras nos pontos indicados $\mathrm{H}$ na figura 3.2. Também, no final de cada seção e próximo aos pontos de amostragem, existem furos rosqueados para futura adaptação de uma sonda de infravermelho próximo (NIR) com cabo de fibra ótica, permitindo a possibilidade futura de monitoração em linha do processo, não utilizada no presente trabalho. 


\subsection{Metodologia Analítica.}

\section{Conversão global dos monômeros.}

As medidas de conversão global foram realizadas através do método de gravimetria. Para a determinação da conversão por gravimetria são coletadas amostras com volume de 10 a $15 \mathrm{ml}$ em recipientes previamente pesados de folha de alumínio com forma e tamanho de placas de Petri, as quais já devem conter algumas gotas de solução aquosa de hidroquinona a $1 \%$ em massa, que inibe a reação de polimerização. As amostras então são repesadas e colocadas em estufa a $90{ }^{\circ} \mathrm{C}$ e ali mantidas até que as suas massas se tornem constantes, até a evaporação total da fase líquida, constituída de monômero e água. A massa de sólidos não poliméricos, que deve ser considerada no cálculo da conversão, é constituída pela massa de iniciador e emulsificante. Portanto, após a secagem, as amostras são pesadas novamente à temperatura ambiente para a avaliação do grau de conversão da reação no instante da coleta da amostra. O cálculo da conversão global da reação é dado pelas seguintes equações:

$$
\begin{aligned}
& X_{M}=\text { conversão global }=(F s-F t) / F_{M} \\
& F s=\text { teor de sólidos na amostra }=\left(m_{3}-m_{1}\right) /\left(m_{2}-m_{1}\right) \\
& m_{1}=\text { massa da placa }+ \text { gotas de hidroquinona } \\
& m_{2}=\text { massa da placa }+ \text { gotas de hidroquinona }+ \text { amostra úmida } \\
& m_{3}=\text { massa da placa }+ \text { amostra seca } \\
& F_{t}=\text { teor de sais da alimentação }=\left(m_{i}+m_{c a r b}+m_{e}\right) / m_{t} \\
& m_{t}=\text { massa da alimentação }=m_{A}+m_{M}+m_{i}+m_{c a r b}+m_{e} \\
& m_{A}=\text { massa de água na alimentação. } \\
& m_{M}=\text { massa de monômero na alimentação. } \\
& m_{i}=\text { massa de iniciador na alimentação. } \\
& m_{e}=\text { massa de emulsificante na alimentação. } \\
& m_{c a r b}=\text { massa de carbonato de cálcio na alimentação. } \\
& F_{M}=\text { fração de monômero na alimentação }=m_{M} / m_{t}
\end{aligned}
$$




\section{Composição do copolímero.}

A medida da evolução da composição de copolímero nas reações de copolimerização de acetato de vinila e acrilato de butila em emulsão na CPPP foi feita a partir de medidas dos teores de monômeros residuais por cromatografia gasosa. $\mathrm{O}$ equipamento utilizado é um cromatógrafo gasoso (GC - 17A - Shimadzu) com amostrador automático tipo headspace (HSS 4A - Shimadzu) e com detector de ionização de chamas (FID). As amostras retiradas do reator são recolhidas em frascos contendo algumas gotas de solução de hidroquinona a 1\% e transferidos para recipientes que são selados com tampa de borracha revestida com teflon e lacre de alumínio. Os frascos são posteriormente colocados no amostrador headspace do cromatógrafo a gás.

O cromatograma é caracterizado por uma série de picos cujas áreas se relacionam linearmente com a massa do componente. Na figura 3.6 apresenta-se um exemplo de curva de calibração, de onde se obteve a relação entre a área e a fração mássica de monômero na emulsão, a partir das amostras preparadas com látex isento de monômero e quantidades conhecidas de monômero.

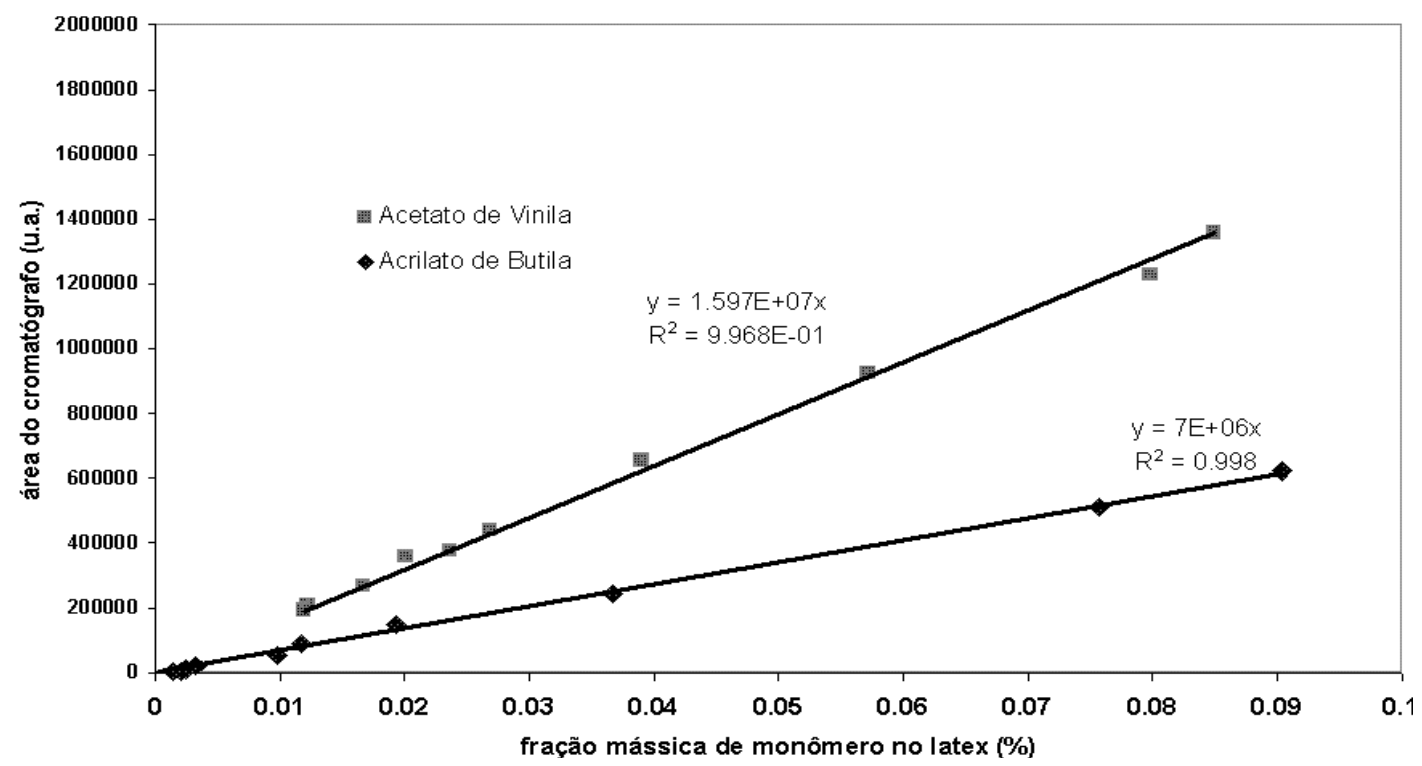

Figura 3.6 Exemplo de Curva de Calibração do Sistema VAc-BuA 
As condições de operação do equipamento são as seguintes:

- gás de arraste: hélio;

- temperatura do vial: $70{ }^{\circ} \mathrm{C}$ (tempo: 20 minutos);

- temperatura da seringa: $80{ }^{\circ} \mathrm{C}$;

- temperatura inicial do forno: $40{ }^{\circ} \mathrm{C}$;

- temperatura do injetor: $240{ }^{\circ} \mathrm{C}$;

- temperatura do detector FID: $260{ }^{\circ} \mathrm{C}$;

- split 1:10;

- tempo de análise: 13 minutos;

- coluna DB-5 (5\% de Fenil e 95\% de polimetil siloxano, comprimento de $30 \mathrm{~m}$, diâmetro interno 0,25 $\mathrm{mm}$ e espessura do filme $0,25 \mu \mathrm{m}$ ).

A figura 3.7 apresenta a programação de temperatura da coluna cromatográfica durante a análise.

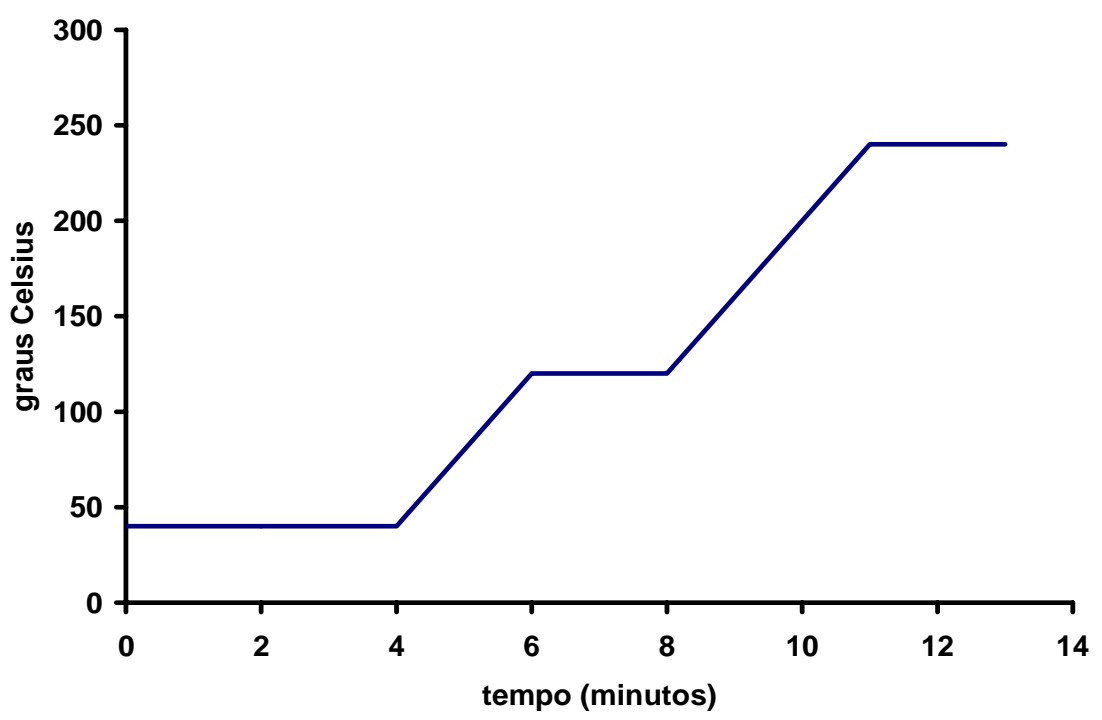

Figura 3.7 Rampa de Temperatura do Forno.

A composição molar acumulada do polímero é calculada a partir das medidas da análise gravimétrica e das obtidas por GC, cromatografia gasosa. A seqüência de cálculos para a composição mássica do copolímero é dada pelas seguintes equações: 


$$
\begin{aligned}
& \omega_{A}^{G C}=\frac{A_{A}^{G C}}{\varphi_{A}} \\
& w_{A}^{G C}=\omega_{A}^{G C} *\left(\frac{m_{H_{2} O}^{G C}+m_{\text {amostra }}^{G C}}{\left.m_{\text {amostra }}^{G C}\right)}\right) \\
& X_{A}^{\text {global }}=\frac{F_{M A} * F_{M}-w_{A}^{G C}}{F_{M A} * F_{M}} \\
& X=\frac{F_{M}-w_{A}^{G C}-w_{B}^{G C}}{F_{M}} \\
& Y_{A}=\frac{X_{A}^{\text {global }}}{X}
\end{aligned}
$$

onde,

$F_{M}$ é a fração mássica de monômero no meio reacional antes da reação;

$X$ é a conversão global dos monômeros;

$X_{A}^{\text {global }}$ é a conversão global do monômero A;

$F_{M A}$ é a fração mássica inicial do comonômero $A$ em relação à massa total de monômero;

$w_{A}^{G C}$ é a fração mássica do monômero A medida na amostra;

$w_{B}^{G C}$ é a fração mássica do monômero $B$ medida na amostra;

$m_{\text {amostra }}^{G C}$ é a massa da amostra;

$m_{\mathrm{H}_{2} \mathrm{O}}^{\mathrm{GC}}$ é massa de água da amostra;

$\omega_{A}^{G C}$ é a fração mássica do monômero A medido pelo GC no frasco;

$\varphi_{A}$ é o coeficiente angular da curva de calibração;

$A_{A}^{G C}$ é a área correspondente ao monômero A obtida no espectro;

$Y_{A}$ é a fração mássica de VAc no copolímero. 


\section{Tamanho médio das partículas}

A determinação do tamanho das partículas foi feita pelo método de espalhamento dinâmico de luz (também chamado de espectroscopia de correlação de fótons) empregando-se um aparelho Coulter N4 Plus equipado com lâmpada laser He-Ne de $10 \mathrm{~mW}$, de comprimento de onda 632,8 nm. Este aparelho analisa tamanhos de partículas em amostras diluídas de emulsões ou suspensões para partículas com diâmetros variando na faixa entre $3 \mathrm{~nm}$ e $3000 \mathrm{~nm}$. A amostra recolhida do reator, estabilizada com algumas gotas de solução de hidroquinona a 1\%, é diluída com água destilada e transferida para a cubeta, a qual é introduzida no aparelho para a análise. A medição do tamanho médio da partícula é feita pela difração dinâmica da luz sobre as partículas dispersas em um fluido. Considerando-se o conceito do movimento Browniano das partículas em um fluido, a velocidade de difusão das mesmas é influenciada, principalmente, pela viscosidade e temperatura do fluido e pelo tamanho da partícula. O princípio de funcionamento do equipamento baseia-se na incidência de um feixe de luz sobre uma cubeta contendo a amostra. Esta luz pode ser espalhada e captada em diversos detectores em ângulos estabelecidos. A amostra deve ser suficientemente diluída para que não ocorra espalhamentos múltiplos.

\section{Concentração de partículas ou Número de partículas por grama de emulsão.}

O número de partículas por grama de emulsão é obtido a partir do diâmetro médio medido, da densidade estimada do copolímero e da conversão obtida até o momento de tomada da amostra.

$$
N p=\frac{6 X F M}{\pi(D p)^{3} \rho_{\text {pol }}}
$$

onde,

$N p$ é o número de partículas por grama de emulsão;

FM é a fração mássica de monômero no meio reacional antes da reação;

$X$ é a conversão global dos monômeros; 
$\rho_{\text {pol }}$ é a densidade do copolímero formado $(\mathrm{g} / \mathrm{ml})$;

Dp é o diâmetro da partícula (cm).

\subsection{Controle de Temperatura.}

Com o objetivo de minimizar possíveis oscilações de temperatura nas seções do reator nas quais as taxas de reação são mais elevadas, adotou-se o controle da temperatura da entrada da camisa ao invés do controle da temperatura do meio reacional. Ou seja, na prática operou-se "desligando" o sistema de controle em cascata apresentado na figura 3.3. O controlador "mestre" da temperatura do reator foi desligado e operou-se apenas com o controlador "escravo", fornecendo o "set-point" desejado para a temperatura da entrada da água na camisa. Uma das principais características das reações de polimerização em emulsão é a elevada taxa de reação deste processo que é exotérmico. Portanto, o calor gerado em determinadas regiões destas seções dificulta o controle de temperatura da reação. Portanto, esse procedimento operacional conduz a uma redução muito significativa da amplitude das oscilações tanto das temperaturas de entrada das camisas, como das temperaturas do meio reacional em cada uma das cinco seções do reator.

\subsection{Tratamento dos Resultados.}

Os resultados obtidos experimentalmente foram comparados aos obtidos pela simulações com um modelo matemático que é baseado em balanços de massa para cada componente (monômeros, emulsificante, iniciador, número de partículas, água) e balanço de energia, de acordo com modelo de escoamento com dispersão axial. O desenvolvimento do modelo é descrito em detalhes no Capítulo 4. 


\section{Capítulo 4 - DESENVOLVIMENTO DO MODELO MATEMÁTICO}

Neste capítulo é apresentado o modelo matemático utilizado para simular o processo de copolimerização em emulsão de acetato de vinila e acrilato de butila no reator tubular CPPP. O desenvolvimento usou como base o modelo previamente elaborado nos trabalhos de SAYER e GIUDICI (2002a) e SAYER et al. (2002b), no qual foram consideradas as seguintes hipóteses:

- As concentrações dos monômeros, nas partículas poliméricas, gotas de monômero e fase aquosa se encontram em equilíbrio termodinâmico;

- A quantidade de polímero formada na fase aquosa é desprezível;

- A formação de partículas pode ocorrer por nucleação micelar e homogênea;

- A coalescência das partículas depende da concentração de iniciador e de emulsificante adsorvido nas partículas de polímero;

- Partículas poliméricas são esféricas e todas apresentando o mesmo tamanho (população monodispersa);

- O efeito gel é insignificante nas reações estudadas de copolimerização de acetato de vinila e acrilato de butila em emulsão;

- É utilizada a hipótese de estado pseudo-estacionário para os radicais;

- As constantes cinéticas independem do comprimento de cadeia;

- As constantes cinéticas na fase aquosa são as mesmas da fase polimérica;

- A reatividade dos radicais é determinada pela última unidade monomérica (modelo último ou terminal);

- Os radicais provenientes da etapa de iniciação ou de etapas de transferência de cadeia para monômero apresentam as mesmas reatividades.

- Reações isotérmicas (esta hipótese foi relaxada no presente trabalho com a inclusão do balanço de energia no modelo);

- Mistura radial é perfeita;

- Velocidade axial é constante;

- Mistura axial no reator tubular CPPP é representada por um coeficiente de dispersão. 


\subsection{Mecanismo Cinético de Copolimerização.}

O mecanismo cinético utilizado no modelo para representar as reações de copolimerização em emulsão considera as seguintes reações: iniciação, propagação, transferência de cadeia a monômeros, a moléculas pequenas e a polímero, e terminação de radicais por combinação e por desproporcionamento. Deste modo, denotando por I o iniciador, R• os radicais fragmentos do iniciador, A e B os comonômeros, $A_{n}$ e $B_{n}$ os radicais poliméricos de tamanho $n$ com unidade terminal do tipo $A$ e do tipo $B$, respectivamente, $P_{n}$ o polímero morto de tamanho $n, X$ e $X \bullet$ as moléculas pequenas ou agente de transferência de cadeia e o respectivo radical resultante, as etapas cinéticas consideradas no modelo de copolimerização em emulsão podem ser descritas na forma:

1- Iniciação

$$
\begin{aligned}
& \mathrm{I} \quad \rightarrow 2 \mathrm{R} \bullet \\
& \mathrm{R} \bullet+\mathrm{A} \rightarrow \mathrm{A}_{1} \\
& \mathrm{R} \bullet+\mathrm{B} \rightarrow \mathrm{B}_{1}
\end{aligned}
$$

\section{2- Propagação}

$$
\begin{aligned}
& A_{n-1}+A \rightarrow A_{n} \\
& A_{n-1}+B \rightarrow B_{n} \\
& B_{n-1}+A \rightarrow A_{n} \\
& B_{n-1}+B \rightarrow B_{n}
\end{aligned}
$$

3- Transferência de cadeia para monômero

$$
\begin{aligned}
& A_{j}+B \rightarrow P_{j}+B_{1} \\
& B_{j}+B \rightarrow P_{j}+B_{1} \\
& B_{j}+A \rightarrow P_{j}+A_{1} \\
& A_{j}+A+P_{j}+A_{1}
\end{aligned}
$$


4- Transferência de cadeia para moléculas pequenas

$$
\begin{aligned}
& \mathrm{A}_{j}+\mathrm{X} \rightarrow \mathrm{P}_{j}+\mathrm{X}_{\bullet} \\
& \mathrm{B}_{j}+\mathrm{X} \rightarrow \mathrm{P}_{\mathrm{j}}+\mathrm{X} \bullet
\end{aligned}
$$

5- Transferência ao polímero

$$
\begin{aligned}
& A_{j}+P_{n} \rightarrow P_{j}+A_{n} \\
& A_{j}+P_{n} \rightarrow P_{j}+B_{n} \\
& B_{j}+P_{n} \rightarrow P_{j}+A_{n} \\
& B_{j}+P_{n} \rightarrow P_{j}+B_{n}
\end{aligned}
$$

\section{6- Terminação}

$$
\begin{aligned}
& A_{j}+A_{n} \rightarrow P_{j}+P_{n} \\
& A_{j}+A_{n} \rightarrow P_{j+n} \\
& B_{j}+A_{n} \rightarrow P_{j}+P_{n} \\
& B_{j}+A_{n} \rightarrow P_{j+n} \\
& A_{j}+B_{n} \rightarrow P_{j}+P_{n}
\end{aligned}
$$

\subsection{Modelagem dos Mecanismos Característicos da Polimerização em Emulsão}

A cinética química da reação de copolimerização, cujos mecanismos estão descritos acima, são comuns a todos tipos de processo onde ela pode ser desenvolvida (massa, solução, suspensão ou emulsão). No caso particular da polimerização em emulsão, as características do produto formado também estão determinadas pelo transporte de massa entre as fases que constituem o meio reacional e pelas relações de equilíbrio termodinâmico. 
A modelagem matemática dos mecanismos de nucleação e das relações de equilíbrio associadas (partições de monômero e emulsificante), além das resultantes determinações do número médio de radicais e da taxa de coalescência das partículas, estão representadas a seguir:

\section{$\underline{\text { Nucleação Micelar }}$}

A taxa de nucleação micelar é dada por:

$$
R_{\text {mic }}=k^{m}{ }_{\text {abs }} R_{\text {ent }} N_{\text {mic }}
$$

onde $R_{\text {ent }}$ é a concentração de radicais na fase aquosa que podem entrar nas partículas de polímero, calculadas pela Eq. (4.26) e $k^{m}{ }_{a b s}$ é a constante cinética de entrada de radicais da fase aquosa nas micelas:

$$
k^{m}{ }_{a b s}=4 \pi D_{w} r_{m} f^{m}{ }_{a b s} N a
$$

onde $D_{w}, r_{m}$ e $f_{a b s}^{m}$ representam, respectivamente, o coeficiente de difusão na fase aquosa, o raio de uma micela e a eficiência de entrada de radicais da fase aquosa pelas micelas.

A variável $N_{\text {mic }}$ é o número de micelas formadas quando a concentração de emulsificante na fase aquosa $[E]^{\text {aq }}$ se encontra acima da concentração micelar crítica $(\mathrm{CMC})$ :

$$
N_{\text {mic }}=M_{\text {mic }} v_{a q}
$$

onde $M_{\text {mic }}$ é o número de micelas por volume da fase aquosa, calculado pela Eq. (4.12) ou pela Eq. (4.13), dependendo da presença de um excesso de emulsificante. $v_{p}$ e $v_{a q}$ são, respectivamente, os volumes das fases polimérica e aquosa. 


\section{Nucleação homogênea}

A taxa de nucleação homogênea é dada por:

$$
R_{\text {hom }}=C_{\text {hom }}{ }^{0} k_{p}[M]_{a q} R_{j c r i t} v_{a q} N a
$$

onde $c_{h o m}{ }^{0}$ é o coeficiente de nucleação homogênea e $k_{p}[M]_{a q} R_{j c r i t}$ é a taxa de propagação na fase aquosa.

A variável $R_{\text {jcrit }}$ é a concentração de radicais com comprimento crítico $j_{\text {crit }}$ na fase aquosa, calculada, conforme descrito pela Eq. (4.25).

\section{Coalescência das partículas}

Visando evitar o uso de relações complexas como as extensões do modelo DLVO (Derjaguin-Landau-Verwey-Overbeek) que envolvem um número significativo de parâmetros desconhecidos (GILBERT, 1995, ARAÚJO et al., 2000), uma equação simples, que apenas considera a concentração de iniciador na fase aquosa, dado que elevadas concentrações de sais aumentam a taxa de coalescência (MELIS et al., 2000), foi usada quando a concentração de emulsificante adsorvido nas partículas de polímero, $[E]_{\mathrm{ads}}$, estava abaixo da concentração de emulsificante necessária para saturar as partículas de polímero, $[E]_{a d s}^{s a t}$. A taxa de coalescência é considerada proporcional ao quadrado da concentração de partículas $(N p)$ e a constante de cinética de coalescência é dada por:

$$
C_{c}=c_{c}^{0} \sqrt{I N a}
$$

onde $I$ é a concentração de iniciador na fase aquosa e $c_{c}{ }^{0}$ é o único parâmetro de ajuste. Quando a concentração de emulsificante adsorvido nas partículas de polímero é 
igual a concentração de emulsificante necessária para saturar a superfície das partículas de polímero a taxa de coalescência é igual a zero.

\section{Partição de Emulsificante entre a fase Aquosa e as Superfícies.}

Como as gotas de monômero são muito maiores que as partículas de polímero e, conseqüentemente, no conjunto possuem área superficial muito menor, a quantidade de emulsificante adsorvido nas gotas de monômero pode ser considerada desprezível. Assim, a quantidade total de emulsificante está distribuída entre a fase aquosa, as micelas (se presentes) e as partículas de polímero:

$$
E=[E]^{a q} v_{a q}+\gamma M_{m i c} v_{a q}+a_{p} N_{p}[E]_{a d s}
$$

onde $[E]^{a q}$ é a concentração de emulsificante na fase aquosa, $\gamma$ é o número de moles de emulsificante por micela e $[E]_{a d s}$ é a concentração de emulsificante adsorvido nas partículas de polímero. A variável $\gamma$ pode ser expressa por:

$$
\gamma=\frac{4 \pi r_{m}^{2}}{f_{m} a_{s}}
$$

onde $f_{m}$ é a eficiência de nucleação micelar e $a_{s}$ é a área coberta por um mol de emulsificante. $a_{p}$ é a área superficial de uma partícula de polímero inchada com monômero:

$$
a_{p}=4 \pi r_{p}^{2}
$$

$r_{p}$ é o raio de uma partícula de polímero inchada com monômero:

$$
r_{p}=\sqrt[3]{\frac{3 v_{p} / N_{p}}{4 \pi}}
$$


As variáveis $[E]^{a q},[E]_{a d s}$ e $M_{\text {mic }}$ devem ser calculadas para dois casos distintos:

Caso 1: se houver excesso de emulsificante, a concentração de emulsificante na fase aquosa é igual à concentração micelar crítica, $\mathrm{CMC}$; a concentração de emulsificante adsorvido nas partículas é igual à concentração de saturação e o excesso de emulsificante formará micelas:

$$
\begin{aligned}
& {[E]^{a q}=[E]_{C M C}} \\
& {[E]_{a d s}=[E]_{a d s}^{\text {sat }}=\frac{1}{a_{s}}} \\
& M_{\text {mic }}=\frac{\left(E-a_{p} N_{p}[E]_{a d s}^{s a t}-[E]_{C M C} v_{a q}\right)}{\gamma v_{a q}}
\end{aligned}
$$

Caso 2: se não há excesso de emulsificante, não ocorre a formação de micelas. Admite-se que o emulsificante se distribuirá preferencialmente para as partículas de polímero, estabilizando-as:

$$
M_{\text {mic }}=0
$$

Se a concentração de emulsificante é suficiente para saturar as partículas de polímero:

$$
[E]_{a d s}=[E]_{a d s}^{s a t}
$$

e $[E]^{\mathrm{aq}}$ é calculado por:

$$
[E]^{a q}=\frac{\left(E-a_{p} N_{p}[E]_{a d s}^{\text {sat }}\right)}{v_{a q}}
$$

Se a concentração de emulsificante não é suficiente para saturar as partículas de polímero: 
$[E]^{a q}=0$

$[E]_{a d s}=\frac{E}{a_{p} N_{p}}$

\section{Número Médio de Radicais por Partícula}

O método da expansão em frações continuadas sugerido por UGELSTAD et al. (1967) foi utilizado para calcular o número médio de radicais por partícula de polímero $\bar{n}$ :

$$
\bar{n}=\frac{1}{2} \frac{h^{2} / 4}{m^{\prime}+0+\frac{h^{2} / 4}{m^{\prime}+1+\frac{h^{2} / 4}{m^{\prime}+2+\ldots}}}
$$

onde $h$ e $m^{\prime}$ ' são, respectivamente, os termos de comparação absorção/terminação e dessorção/terminação:

$$
\begin{aligned}
& h=\left(\frac{8 \rho^{*}}{k_{t} \text { xgel }}\right)^{\frac{1}{2}} \\
& m^{\prime}=\frac{k N a v_{p}}{k_{t} \text { xgel } N_{p}}
\end{aligned}
$$

$\rho^{*}$ é o coeficiente da taxa total de entrada de radicais da fase aquosa pela fase polimérica:

$$
\begin{gathered}
k_{a b s}=4 \pi D_{w} r_{p} N a f_{a b s} \\
\rho^{*}=k_{a b s} \frac{R_{e n t} N a v_{p}}{N_{p}}
\end{gathered}
$$


onde $R_{\text {ent }}$ é a concentração de radicais na fase aquosa que podem entrar nas partículas de polímero e que é calculada pelas equações apresentadas a seguir:

$$
\begin{aligned}
& \Psi=k_{p}[M]_{a q}+k_{a b s} \frac{N_{p}}{v_{a q} N a}+k_{a b s}^{m} \frac{N_{m i c}}{v_{a q} N a}+k_{t} R_{a q} \\
& R_{1}=\left(\frac{\frac{2 I f^{\prime} k_{d}}{v_{a q}}+\frac{k \bar{n} N_{p}}{v_{a q} N a}}{k_{p}[M]_{a q}+k_{t} R_{a q}}\right) \\
& R_{j c r i t}=R_{1}\left(\frac{k_{p}[M]_{a q}}{k_{p}[M]_{a q}+k_{t} R_{a q}}\right)^{\left(j_{e}-2\right)}\left(\frac{k_{p}[M]_{a q}}{\Psi}\right)^{\left(j_{c r i t}-j_{e}\right)} \\
& R_{e n t}=R_{1}\left(\frac{k_{p}[M]_{a q}}{k_{p}[M]_{a q}+k_{t} R_{a q}}\right)^{\left(j_{z}-2\right)} \sum_{j=j_{z}}^{j c r i t-1}\left(\frac{k_{p}[M]_{a q}}{\Psi}\right)^{\left(j-j_{z}+1\right)} \\
& R_{a q}=R_{1}\left[1+\sum_{j=2}^{j_{z}-1}\left(\frac{k_{p}[M]_{a q}}{k_{p}[M]_{a q}+k_{t} R_{a q}}\right)^{(j-1)}\right]+R_{e n t}
\end{aligned}
$$

onde $R_{a q}$ é a concentração de radicais na fase aquosa, $j_{z}$ e $j_{c r i t}$ são os comprimentos de cadeia cinéticos críticos para entrada dos radicais nas micelas e nas partículas de polímero e para nucleação homogênea (GILBERT, 1995), que dependem da solubilidade do monômero na fase aquosa, $k_{t} R_{a q}$ e $k_{p}[M]_{a q}$ são as taxas de terminação e propagação na fase aquosa, $f$ 'é a eficiência de formar radicais pela decomposição do iniciador e $k$ é o coeficiente da taxa de saída de radicais das partículas de polímero:

$$
k=k_{f}[M]_{p} \frac{k_{0 m}}{\left(k_{0 m} \beta_{m}+k_{p}[M]_{p}\right)}
$$

onde $k_{0 m}$ e $\beta_{m}$ são a taxa de saída de um radical monomérico e a probabilidade de um radical na fase aquosa reagir por propagação ou por terminação: 


$$
\begin{gathered}
k_{0 m}=\frac{3 \frac{D_{w}}{r_{p}^{2} k_{m}^{p}}}{2 \frac{D_{w}}{D_{p} k_{m}{ }^{p}}+1} \\
\beta_{m}=\frac{\left(k_{p}[M]_{w}+k_{t} R_{a q}\right)}{(\psi)}
\end{gathered}
$$

onde $D_{p}$ é o coeficiente de difusão de um radical nas partículas de polímero em $\mathrm{cm}^{2} / \mathrm{s}$.

O cálculo do número médio de radicais por partícula polimérica $(\bar{n})$ é realizado de forma iterativa:

1 - arbitra-se um valor inicial para $\bar{n}$;

2 - calculam-se o coeficiente das taxas de absorção de radicais da fase aquosa e de terminação;

3 - arbitra-se um valor inicial para $R_{a q}$;

4 - calcula-se Equações (4.23) a (4.27) até convergência de $R_{a q}$;

5 - calcula-se $\bar{n}$, Equação (4.18);

6 - compara-se $\bar{n}$ calculado com seu valor anterior. Se o erro estiver dentro da tolerância, pode ser finalizado o cálculo; senão, volta-se ao passo 2 com o novo valor de $\bar{n}$.

\section{Partição de Monômero}

O cálculo iterativo das concentrações de monômero $(I=A$ ou $B)$ nas diferentes fases (fase aquosa (aq), gotas de monômero ( $d$ ) e partículas de polímero $(p)$ ) presentes nas reações de polimerização em emulsão foi realizado pelo procedimento proposto por OMl et al. (1985). Utilizando-se os coeficientes de partição, definidos por: 


$$
\begin{aligned}
& \mathrm{k}_{\mathrm{i}}^{\mathrm{d}}=\frac{\mathrm{v}_{\mathrm{i}}^{\mathrm{d}} / \mathrm{v}_{\mathrm{d}}}{v_{\mathrm{i}}^{\mathrm{aq}} / \mathrm{v}_{\mathrm{aq}}} \\
& k_{i}^{p}=\frac{v_{i}^{p} / v_{p}}{v_{i}^{a q} / v_{a q}}
\end{aligned}
$$

podem-se explicitar os volumes de monômero $i$ nas gotas $\left(v_{i}^{d}\right)$ e na fase aquosa $\left(v_{i}^{\text {aq }}\right)$ :

$$
\begin{aligned}
& v_{i}^{d}=\frac{v_{d}}{v_{p}} \frac{k_{i}^{d}}{k_{i}^{p}} v_{i}^{p} \\
& v_{i}^{a q}=\frac{v_{a q}}{v_{p}} \frac{1}{k_{i}^{p}} v_{i}^{p}
\end{aligned}
$$

Além disso, conhecendo-se o volume total do monômero $i\left(v_{i}\right)$, tem-se que:

$v_{i}=v_{i}^{d}+v_{i}^{p}+v_{i}^{a q}$

e substituindo as Equações (4.33) e (4.34) na Equação (4.35) chega-se a:

$$
v_{i}^{p}=\frac{v_{i}}{1+\frac{v_{a q}}{v_{p} k_{i}^{p}}+\frac{v_{a q} k_{i}^{d}}{v_{p} k_{i}^{p}}}
$$

Por outro lado, os volumes totais das gotas $\left(v_{d}\right)$, da fase aquosa $\left(v_{a q}\right)$ e das partículas $\left(v_{p}\right)$ são calculados por:

$$
\begin{aligned}
& v_{d}=\sum_{i=1}^{2} v_{i}^{d} \\
& v_{a q}=\sum_{i=1}^{2} v_{i}^{a q}+v_{w} \\
& v_{p}=\sum_{i=1}^{2} v_{i}^{p}+v_{p o l}
\end{aligned}
$$


Onde, $v_{w}$ é o volume de água e $v_{p o l}$ é o volume de copolímero.

Portanto, conhecidos $v_{i}, v_{p o l}, v_{w}, k_{i}^{d}$ e $k_{l}^{p}$, podem-se calcular $v_{i}^{d}, v_{i}^{a q}$ e $v_{l}^{p}$ através do seguinte algoritmo iterativo:

1- Arbitram-se valores iniciais de $v_{d}, v_{a q}$ e $v_{p}$;

2- calcula-se $v_{1}^{p}$ com a Equação (4.36);

3- calculam-se $v_{i}^{d}$ e $v_{i}^{a q}$ com as Equações (4.33) e (4.34);

4- calculam-se novos valores de $v_{d}$, $v_{a q}$ e $v_{p}$ com as Equações (4.37), (4.38) e (4.39);

5- Volta-se ao passo 1 até $v_{d}, v_{a q}$ e $v_{p}$ convergirem.

Conhecidos os volumes de cada monômero em cada uma das fases (j), as suas concentrações são calculadas da seguinte forma:

$$
[i]_{j}=\frac{v_{i}^{j}}{v_{j}} \frac{P M_{i}}{\rho_{i}}
$$

\subsection{Balanços de Massa}

Os balanços de massa para os diferentes componentes do sistema no reator CPPP foram escritos usando o modelo de dispersão axial, cuja forma geral é:

$$
\frac{\partial C_{i}}{\partial t}+v_{z} \frac{\partial C_{i}}{\partial z}-D_{e a} \frac{\partial^{2} C_{i}}{\partial z^{2}}=\operatorname{Taxa}_{\text {geração }}-\text { Taxa }_{\text {consumo }}
$$

onde $C_{i}$ representa a concentração do componente e $\operatorname{Taxa}_{\text {geração }}$ e $\operatorname{Taxa}_{\text {consumo }}$ são as correspondentes taxas de produção e de consumo do componente considerado, $v_{z}$ é a velocidade superficial de escoamento do fluido e $D_{e a}$ é o coeficiente efetivo de dispersão axial, $t$ é o tempo e z é a posição ao longo da direção axial. 
No reator tubular tipo CPPP, o escoamento pulsado (oscilatório) causa um certo grau de mistura axial. No modelo de dispersão axial, este efeito é considerado através do coeficiente efetivo de dispersão axial, o qual depende das condições do escoamento. PALMA e GIUDICI (2003) realizaram ensaios de distribuição de tempos de residência no reator CPPP e determinaram o coeficiente de dispersão axial para diferentes condições de operação em função da freqüência e da amplitude das pulsações, do espaçamento entre as placas perfuradas, da vazão, e da viscosidade do meio. As correlações empíricas obtidas por PALMA e GIUDICI (2003) foram usadas no presente trabalho para determinar o coeficiente efetivo de dispersão axial, como será apresentado no item 4.6.

As condições de contorno do modelo de dispersão axial utilizadas no presente trabalho foram as clássicas condições de contorno de DANCKWERTS (1953):

$$
\begin{aligned}
& \left.C\right|_{z=0}=C_{\text {feed }}+\left.\frac{D_{e a}}{v_{z}} \frac{\partial C}{\partial z}\right|_{z=0} \\
& \left.\frac{\partial C}{\partial z}\right|_{z=L}=0
\end{aligned}
$$

Considerando as hipóteses e as etapas cinéticas anteriormente apresentadas, as equações de balanço de massa para cada componente considerado para reações contínuas de polimerização em emulsão na CPPP podem ser explicitadas como apresentado a seguir:

a) Número de partículas de polímero $\left(N_{p}\right)$ :

$$
\frac{\partial N_{p}}{\partial t}+v_{z} \frac{\partial N_{p}}{\partial z}-D e a \frac{\partial^{2} N_{p}}{\partial z^{2}}=R_{\text {mic }}+R_{\mathrm{hom}}-C_{c}\left(N_{p}\right)^{2}
$$

onde $v_{z}$ é a velocidade axial e Dea é o coeficiente de dispersão axial em $\mathrm{cm}^{2} / \mathrm{s}$ : 


$$
\begin{aligned}
& v_{z}=\frac{q_{e}}{\left(\pi r_{\text {col }}^{2} f_{\text {void }}\right)} \\
& \text { Dea }=v_{z} \frac{a_{\text {col }}}{P e}
\end{aligned}
$$

onde $q_{e}$ é a vazão na entrada do reator em $\mathrm{g} / \mathrm{s}, r_{c o l}$ e $a_{c o l}$ são, respectivamente, o raio e o comprimento da CPPP em $\mathrm{cm}$ e $f_{\text {void }}$ é a fração de vazios da CPPP. Pe é o número de Peclet e $R_{\text {mic }}$ e $R_{\text {hom }}$ representam as taxas de nucleação micelar e homogênea e $c_{c}\left(N_{p}\right)^{2}$ representa a taxa de coalescência das partículas de polímero.

b) Iniciador (I, moles):

$$
\frac{\partial I}{\partial t}+v_{z} \frac{\partial I}{\partial z}-D e a \frac{\partial^{2} I}{\partial z^{2}}=-I k_{d}
$$

c) Emulsificante ( $E$, moles):

$$
\frac{\partial E}{\partial t}+v_{z} \frac{\partial E}{\partial z}-D e a \frac{\partial^{2} E}{\partial z^{2}}=0
$$

d) Monômero ( $M$, moles):

$$
\frac{\partial M}{\partial t}+v_{z} \frac{\partial M}{\partial z}-\operatorname{Dea} \frac{\partial^{2} M}{\partial z^{2}}=-\frac{\bar{n} N_{p}}{N a}\left(k_{p}[M]_{p}+k_{f}[M]_{p}\right)
$$

onde $[M]_{\mathrm{p}}$ é a concentração de monômero nas partículas de polímero.
e) Polímero $\left(m_{p}, g\right)$ : 
$\frac{\partial m_{p}}{\partial t}+v_{z} \frac{\partial m_{p}}{\partial z}-\operatorname{Dea} \frac{\partial^{2} m_{p}}{\partial z^{2}}=\frac{\bar{n} N_{p}}{N a} k_{p}[M]_{p} P M_{m}$

f) Água $\left(v_{w}, \mathrm{~cm}^{3}\right)$ :

$$
\frac{\partial v_{w}}{\partial t}+v_{z} \frac{\partial v_{w}}{\partial z}-D e a \frac{\partial^{2} v_{w}}{\partial z^{2}}=0
$$

\subsection{Balanço de Energia}

De modo análogo à equações de balanço de massa, também foi desenvolvido o balanço diferencial de energia para a coluna.

$$
\rho C_{p r} \frac{\partial T}{\partial t}+\rho C_{p r} v_{z} \frac{\partial T}{\partial z}-k_{e f} \frac{\partial^{2} T}{\partial z^{2}}=\sum_{i=A, B}\left(-\Delta H_{p, i}\right) R_{p, i}-U \frac{4}{d_{t}}\left(T-T_{J}\right)
$$

onde:

$\rho$ e $C_{p r}$ são respectivamente a densidade e calor específico do meio reacional;

$v_{z}$ é a velocidade axial do meio reacional;

$T$ é a temperatura do meio reacional;

$k_{e f}$ é condutividade térmica efetiva;

$U$ é o coeficiente global de troca térmica entre o meio reacional dentro do reator e a água escoando na camisa do reator;

$T_{j}$ é a temperatura da água na camisa de resfriamento;

$T_{\text {feed }}$ é a temperatura de alimentação do meio reacional na entrada da coluna;

$\Delta H_{p i}$ é a variação de entalpia de polimerização do monômero $i$;

$R_{p, i}$ é a taxa de polimerização do monômero $i$; 
$d_{t}$ é o diâmetro da coluna.

As respectivas condições de contorno axiais tipo DANCKWERTS (1953) para equação (4.52) são:

$$
\begin{aligned}
& \left.T\right|_{z=0}=T_{\text {feed }}+\left.\frac{k_{e f}}{\rho C_{p} v_{z}} \frac{\partial \underline{T}}{\partial z}\right|_{z=0} \\
& \left.\frac{\partial T}{\partial z}\right|_{z=L}=0
\end{aligned}
$$

O valor do coeficiente global de transferência de calor $U$ com a camisa foi determinado experimentalmente para diferentes condições, como descrito no item 4.6. O valor da condutividade térmica axial efetiva foi estimado a partir do ajuste dos resultados do modelo aos resultados experimentais, na forma do número adimensional número de Peclet térmico, definido por.

$$
P e_{t}=\frac{\rho C_{p} v_{z} L}{k_{e f}}
$$

\subsection{Solução do modelo de dispersão axial}

O conjunto de equações diferenciais de balanço de massa (4.41), (4.47), (4.48), (4.49), (4.50) e (4.51) e suas respectivas condições de contorno, pode ser descrito compactamente na forma vetorial

$$
\begin{gathered}
\frac{\partial \underline{x}}{\partial t}+v_{z} \frac{\partial \underline{x}}{\partial z}-D_{e a} \frac{\partial^{2} \underline{x}}{\partial z^{2}}=\underline{\operatorname{Taxa}}_{\text {geração }}-\underline{\operatorname{Taxa}}_{\text {consumo }} \\
\left.\underline{x}\right|_{z=0}=\underline{x}_{f e e d}+\left.\frac{D_{e a}}{v_{z}} \frac{\partial \underline{x}}{\partial z}\right|_{z=0} \\
\left.\frac{\partial \underline{x}}{\partial z}\right|_{z=L}=0
\end{gathered}
$$


onde:

$\underline{x}$ representa o vetor das concentrações dos diferentes componentes;

$\underline{X}_{f e e d}$ representa o vetor das concentrações dos componentes na corrente de alimentação;

$L$ é a altura da coluna (comprimento total do reator tubular).

$v_{\mathrm{z}}$ é velocidade do escoamento axial;

$D_{e a}$ é o coeficiente efetivo de dispersão axial, o qual é usualmente expresso na forma do adimensional número de Peclet, definido por

$$
P e=\frac{v_{z} L}{D_{e a}}
$$

O método das linhas foi usado para resolver as equações diferenciais parciais de segunda ordem. Através deste procedimento o domínio axial $0 \leq z \leq L$ é discretizado em pontos igualmente espaçados e as derivadas primeira e segunda na direção axial são aproximadas por fórmulas de diferenças finitas. Desta forma, cada uma das equações diferenciais parciais, Eq. (4.56), é convertida em um conjunto de equações diferenciais ordinárias na forma:

$$
\frac{d \underline{x}_{i}}{d t}=\left[D_{e a}\left(\frac{\underline{x}_{i+1}-2 \underline{x}_{i}+\underline{x}_{i-1}}{(\Delta z)^{2}}\right)-v_{z}\left(\frac{\underline{x}_{i+1}-\underline{x}_{i-1}}{2 \Delta z}\right)\right]+\underline{\operatorname{Taxa}}_{\text {geração }, i}-\underline{\operatorname{Taxa}}_{\text {consumo }, i}
$$

onde o índice $i$ representa a numeração dos pontos de discretização distribuídos ao longo da direção axial. De modo análogo, substituindo as derivadas que aparecem nas condições de contorno, Eq. (4.57) e (4.58), pelas fórmulas de diferenças finitas, resulta:

$$
\begin{aligned}
& \underline{x}_{1}=\frac{4 \underline{x}_{2}-\underline{x}_{3}+2(\Delta z / L) P e \underline{x} f e e d}{2(\Delta z / L) P e+3} \\
& \underline{x}_{N D+2}=\frac{4 \underline{x}_{N D+1}-\underline{x}_{N D}}{3}
\end{aligned}
$$


onde $N D$ é o número de pontos internos e $\Delta z$ é a distância entre os pontos de discretização:

$$
\Delta z=\frac{L}{N D+1}
$$

O balanço de energia é também discretizado do mesmo modo resultando as seguintes equações:

$$
\begin{aligned}
\rho C_{p} \frac{d T_{i}}{d t} & =\left[k_{e f}\left(\frac{T_{i+1}-2 T_{i}+T_{i-1}}{(\Delta z)^{2}}\right)-\rho C_{p} v_{z}\left(\frac{T_{i+1}-T_{i-1}}{2 \Delta z}\right)\right] \\
& +\left(-\Delta H_{p A}\right) R_{p A, i}+\left(-\Delta H_{p B}\right) R_{p B, i}-U \frac{4}{d_{t}}\left(T_{i}-T_{J}\right)
\end{aligned}
$$

com condições de contorno:

$$
\begin{aligned}
& T_{1}=\frac{4 T_{2}-T_{3}+2(\Delta z / L) P e_{t} T_{\text {feed }}}{2(\Delta z / L) P e_{t}+3} \\
& T_{N D+2}=\frac{4 T_{N D+1}-T_{N D}}{3}
\end{aligned}
$$

O modelo desenvolvido foi implementado em um programa em linguagem FORTRAN e o sistema de equações algébrico-diferenciais foi resolvido pelo pacote computacional DASSL (PETZOLD, 1982). Todas as simulações foram realizadas com ND=90 pontos internos ao longo da direção axial, sendo que este número foi determinado a partir de simulações prévias de modo que os resultados não fossem afetados pelo número de pontos de discretização. 


\subsection{Parâmetros do Modelo}

\section{Coeficiente efetivo de dispersão axial}

O valor do coeficiente efetivo de dispersão axial $D_{e a}$ foi estimado por uma correlação empírica desenvolvida no mesmo equipamento por PALMA e GIUDICI (2003), em função do valor da freqüência e da amplitude de pulsação, para o espaçamento entre os pratos $h^{\prime}=50 \mathrm{~mm}$ usado nos ensaios. A seguinte equação empírica envolvendo o coeficiente efetivo de dispersão axial, a amplitude $A^{\prime}$ e a freqüência de pulsação $f$ e a velocidade de escoamento $v_{z}$ foi obtida por PALMA e GIUDICI (2003):

$\frac{D_{e a}}{v_{z} h^{\prime}}=0,049 \frac{A^{\prime} f}{v_{z}}+0,953$

e está apresentada na figura 4.1.

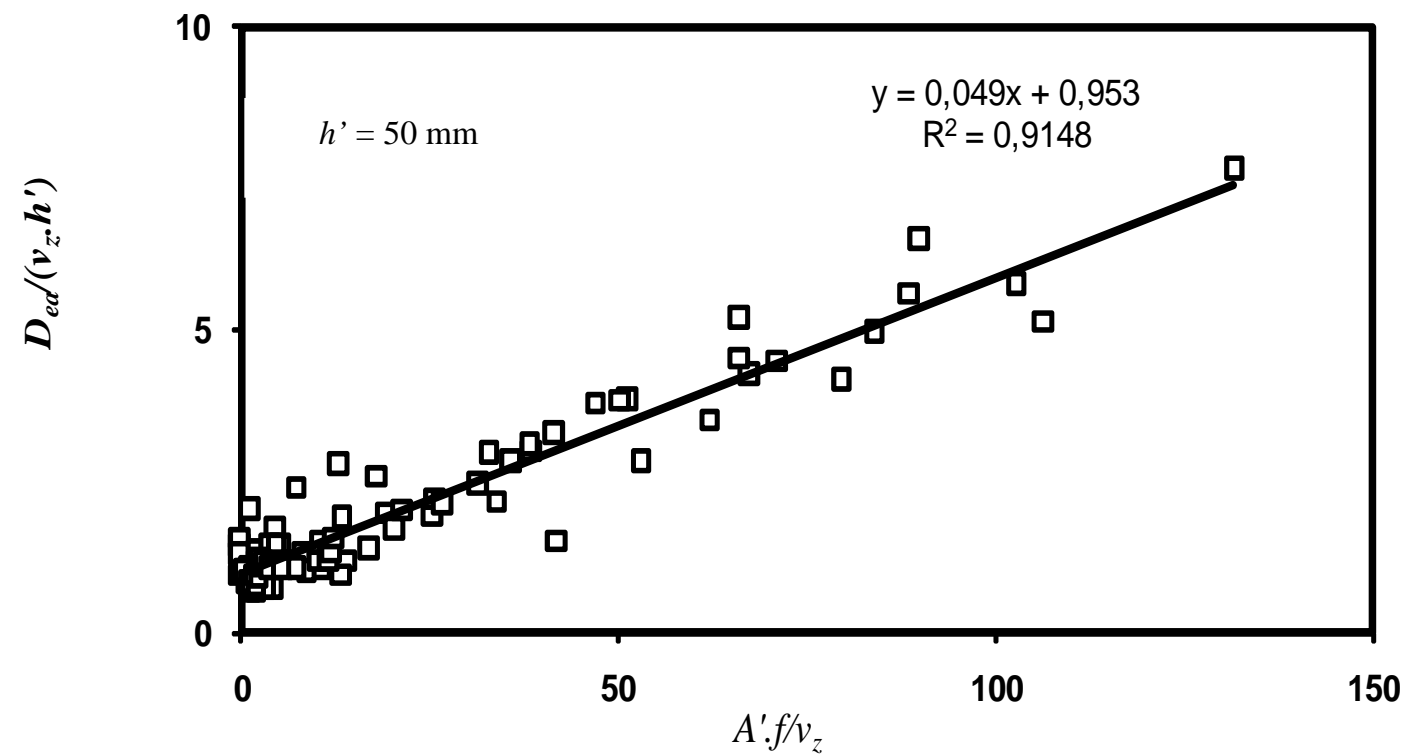

Figura 4.1. Correlação entre o coeficiente efetivo de dispersão axial, amplitude e freqüência de pulsações, PALMA e GIUDICI (2003). 


\section{Coeficiente global de transferência de calor}

Para a obtenção de uma primeira estimativa do coeficiente UA (coeficiente global de troca térmica multiplicado pela respectiva área) foram realizados alguns testes na coluna com água nos quais foi alimentada água fria a partir da primeira seção, e usando uma vazão constante de água quente pelas camisas. A temperatura de entrada da água quente nas camisas foi mantida constante. Esse teste foi realizado para diferentes freqüências de pulsações.

Uma vez obtidos os dados de temperaturas na entrada e na saída da água no reator e da água na camisa e de vazão da água alimentada, o valor de UA pode ser determinado a partir de um balanço de energia na primeira seção da coluna, de acordo com a equação (4.61) e conforme ilustrado na Figura 4.2:

$$
\begin{aligned}
& m C_{p}\left(T_{\text {in }}-T_{\text {out }}\right)=U A \frac{\left(T_{\text {in }}-T_{J, \text { in }}\right)-\left(T_{\text {out }}-T_{J, \text { out }}\right)}{\ln \left(\frac{\left(T_{\text {in }}-T_{J, \text { in }}\right)}{\left(T_{\text {out }}-T_{J, \text { out }}\right)}\right)} \\
& \underbrace{-}--\frac{T_{l m}}{-}-\longrightarrow
\end{aligned}
$$

Onde:

$T_{J \text {,out }}$ é a temperatura de saída da camisa;

$T_{J, \text { in }}$ é a temperatura de entrada da camisa;

$T_{\text {in }}$ é a temperatura da entrada do meio reacional;

$T_{\text {out }}$ é a temperatura de saída do meio reacional;

$\Delta T_{l m}$ é a média logarítmica de temperaturas;

$m$ é a vazão mássica de água alimentada na coluna;

$A$ é a área de troca térmica;

$C_{p}$ é o calor específico da água. 


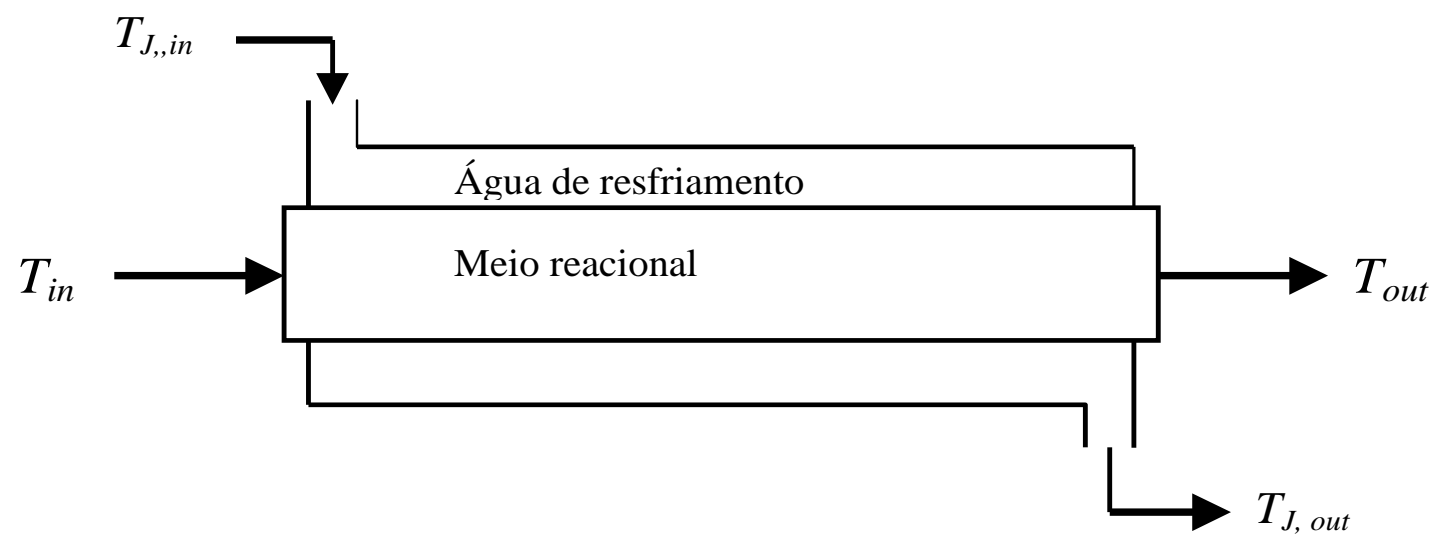

Figura 4.2. Volume de controle do balanço de energia para o cálculo de UA.

Equação 8

Em todos os testes, a temperatura da água alimentada, $T_{j, i n}$, atingiu um valor bem próximo ao da água da camisa nas 3 últimas seções da coluna (80 $\left.{ }^{\circ} \mathrm{C}\right)$, conforme mostrado na figura 4.3.

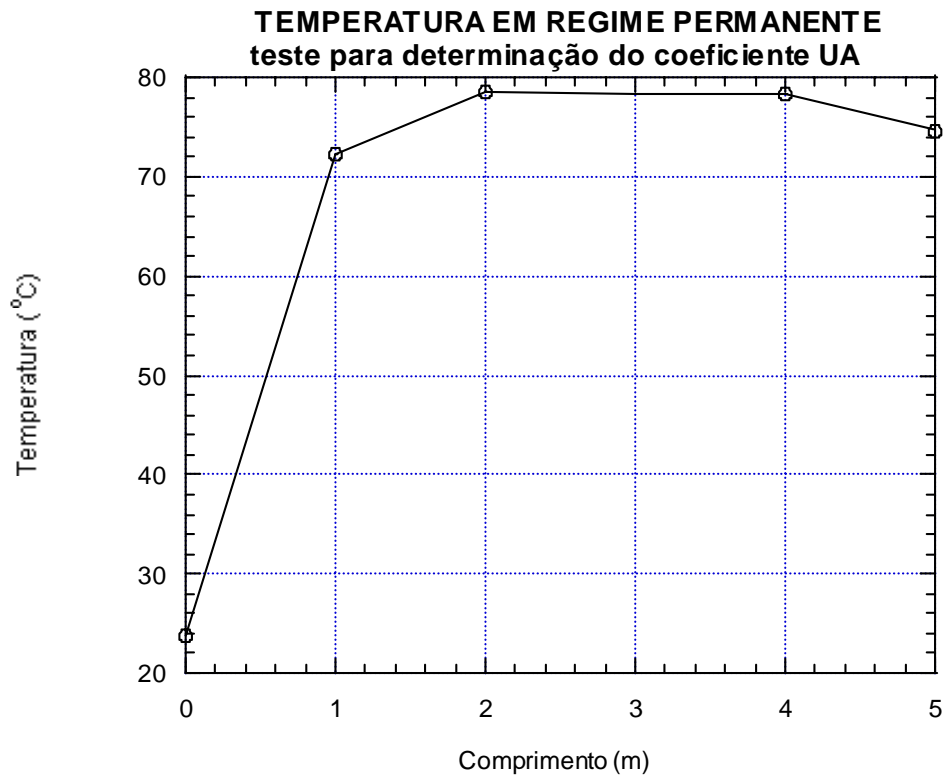

Figura 4.3. Perfil de temperaturas da água no interior da coluna.

Nota-se que a equação (4.61) admite que escoamento no reator é do tipo "plug-flow", uma simplificação (despreza-se nesta análise o efeito da dispersão axial). Por isso, os valores de $U$ assim obtidos são apenas indicativos, servindo para uma estimativa 
preliminar. Além disso, diferenças de viscosidade durante a polimerização não são levadas em conta nestes valores de UA obtidos usando apenas água como fluido que escoa no reator.

Na figura 4.4 são apresentados os valores obtidos da UA em função da freqüência de pulsação do escoamento oscilatório. Observa-se que o aumento da freqüência de pulsação causa um aumento do coeficiente de troca de calor.

Estes valores serviram de estimativa inicial para o valor do coeficiente global de transferência de calor entre o fluido dentro do reator e o fluido na camisa, sendo o valor final ajustado aos dados experimentais dos ensaios.

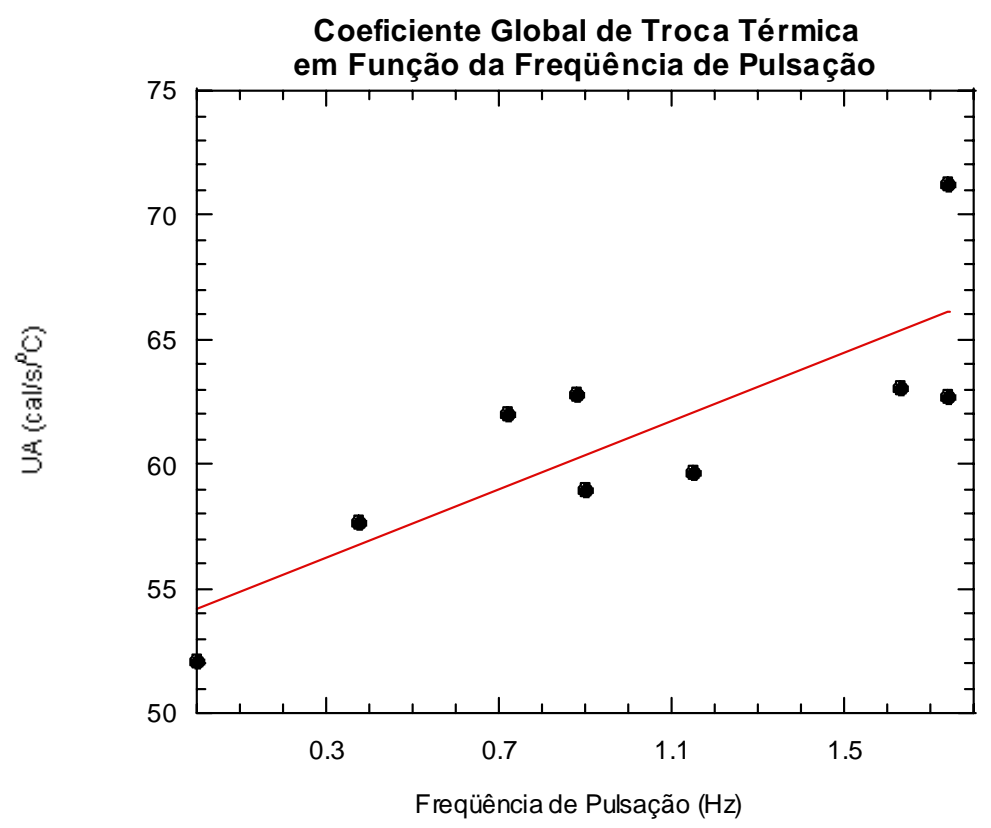

Figura 4.4. Estimativa do coeficiente UA em função da freqüência de pulsação.

\section{Condutividade térmica efetiva axial}

O valor da condutividade térmica axial efetiva foi estimado a partir do ajuste dos resultados do modelo aos resultados experimentais. Como estimativa inicial deste parâmetro, poder-se-ia considerar a analogia entre os transportes de calor e de massa axial no reator, causados pelos mesmos fenômenos de agitação impostos no sistema 
pela pulsação do fluxo de fluido. Segundo esta analogia o adimensional número de Peclet axial de massa $\left(P e=v_{z} L / D_{e}\right)$ seria igual ao adimensional número de Peclet axial térmico $\left(P e_{t}=\rho C_{p} v_{z} L / k_{e f}\right)$. No entanto, é necessário lembrar que além dos mecanismos de transporte associados ao movimento do fluido, existe ainda, no caso da transferência de calor, o mecanismo de condução de calor axial pelas paredes do reator e pela haste coaxial de sustentação dos pratos perfurados. Por isso, espera-se um valor de condutividade térmica axial efetiva $k_{e f}$ maior que o avaliado pela analogia $P e_{t}=P e$. Isto implica que, na prática, $P e_{t}<P e$. Por esta razão, o valor de $k_{e f}$ foi ajustado aos dados experimentais de cada ensaio tratado.

\section{$\underline{\text { Parâmetros cinéticos e propriedades físicas e químicas }}$}

A Tabela 4.1 apresenta os valores dos parâmetros, constantes cinéticas e grandezas físicas utilizadas no modelo, e suas respectivas fontes.

Tabela 4.1 Valores de Parâmetros Adotados nas Simulações.

\begin{tabular}{llll}
\hline Parâmetro & Valor & Unidade & Fonte: \\
\hline$k_{d}$ & $1,8 \times 10^{17} \exp [-34100 /(R T)]$ & $1 / \mathrm{s}$ & RAWLINGS e RAY, 1988 \\
$k_{p A A}$ & $1,44544 \times 10^{10} \exp [-2489,65 / T]$ & $\mathrm{cm}^{3} / \mathrm{mol} \mathrm{s}$ & HUTCHINSON et al., 1995 \\
$k_{p B B}$ & $2,73 \times 10^{9} \exp [-6300 /(R T)]$ & $\mathrm{cm}^{3} / \mathrm{mol} \mathrm{s}$ & MCKENNA et al., 1995 \\
$k_{p A B}$ & $\mathrm{k}_{\mathrm{pAA}} / r_{\mathrm{A}}$ & $\mathrm{cm}^{3} / \mathrm{mol} \mathrm{s}$ & \\
$k_{p B A}$ & $\mathrm{k}_{\mathrm{pBB}} / r_{B}$ & $\mathrm{~cm}^{3} / \mathrm{mol} \mathrm{s}$ & \\
$k_{f A A}$ & $2,43 \times 10^{-5} \mathrm{k}_{\mathrm{pAA}}$ & $\mathrm{cm}^{3} / \mathrm{mol} \mathrm{s}$ & CHATTERJEE et al., 1977 \\
$k_{f B B}$ & $1,9 \times 10^{-4} \mathrm{k}_{\mathrm{pBB}}$ & $\mathrm{cm}^{3} / \mathrm{mol} \mathrm{s}$ & BRANDRUP e IMMERGUT, 1989 \\
$k_{f A B}$ & $\mathrm{k}_{\mathrm{fAA}} / r_{\mathrm{A}}$ & $\mathrm{cm}^{3} / \mathrm{mol} \mathrm{s}$ & \\
$k_{f B A}$ & $\mathrm{k}_{\mathrm{fBB}} / r_{B}$ & $\mathrm{~cm}^{3} / \mathrm{mol} \mathrm{s}$ & \\
$k_{\mathrm{tAA}}$ & $5,255 \times 10^{9} \exp [-884 / \mathrm{T}]$ & $\mathrm{cm}^{3} / \mathrm{mol} \mathrm{s}$ & BAAD et al., 1982 \\
$k_{t B B}$ & $1,6794 \times 10^{7} \exp [-2800 /(\mathrm{RT})]$ & $\mathrm{cm}^{3} / \mathrm{mol} \mathrm{s}$ & MCKENNA et al., 1995 \\
$k_{\mathrm{tAB}}$ & $k_{\mathrm{tAA}}$ & $\mathrm{cm}^{3} / \mathrm{mol} \mathrm{s}$ &
\end{tabular}




\begin{tabular}{|c|c|c|c|}
\hline Parâmetro & Valor & Unidade & Fonte: \\
\hline$r_{m}$ & $2,5 \times 10^{-7}$ & $\mathrm{~cm}$ & MIN e RAY, 1978 \\
\hline$[E]_{C M C}$ & $2,43 \times 10^{-6}$ & $\mathrm{~mol} / \mathrm{cm}^{3}$ & UNZUETA e FORCADA, 1997 \\
\hline$D_{W A}$ & $1,1 \times 10^{-5}$ & $\mathrm{~cm}^{2} / \mathrm{s}$ & MIN e RAY, 1978 \\
\hline$D_{W B}$ & $1,0 \times 10^{-5}$ & $\mathrm{~cm}^{2} / \mathrm{s}$ & GARDON, 1969 \\
\hline$D_{p A}$ & $1,1 \times 10^{-6}$ & $\mathrm{~cm}^{2} / \mathrm{s}$ & MIN e RAY, 1978 \\
\hline$D_{p B}$ & $1,0 \times 10^{-7}$ & $\mathrm{~cm}^{2} / \mathrm{s}$ & GARDON, 1969 \\
\hline$f_{a b s A}$ & $1,947 \times 10^{-2}$ & - & valor ajustado \\
\hline$f_{a b s B}$ & $5,9 \times 10^{-5}$ & - & valor ajustado \\
\hline$f_{a b s m A}$ & $0,15 \times 10^{-5}$ & - & valor ajustado \\
\hline$f_{a b s m B}$ & $1,0 \times 10^{-8}$ & - & valor ajustado \\
\hline$c_{C A}{ }^{0}$ & $1,2 \times 10^{-27}$ & $1 / \mathrm{s}$ & valor ajustado \\
\hline$c_{c B}{ }^{0}$ & 0,0 & $1 / \mathrm{s}$ & SAYER e GIUDICI (2002a) \\
\hline$C_{\text {homA }}{ }^{0}$ & $3,0 \times 10^{-3}$ & $1 / \mathrm{s}$ & SAYER e GIUDICI (2002a) \\
\hline$C_{\text {homB }}{ }^{0}$ & $1,0 \times 10^{-5}$ & $1 / \mathrm{s}$ & SAYER e GIUDICI (2002a) \\
\hline$j_{\text {critA }}$ & 16 & - & GILBERT, 1995 \\
\hline$j_{c r i t B}$ & 8 & - & GILBERT, 1995 \\
\hline$j_{z A}$ & 8 & - & GILBERT, 1995 \\
\hline$j_{z B}$ & 1 & - & GILBERT, 1995 \\
\hline$P M_{A}$ & 86,09 & $\mathrm{~g} / \mathrm{mol}$ & BRANDRUP e IMMERGUT, 1989 \\
\hline$P M_{B}$ & 128,17 & $\mathrm{~g} / \mathrm{mol}$ & BRANDRUP e IMMERGUT, 1989 \\
\hline$P M_{E}$ & 288,38 & $\mathrm{~g} / \mathrm{mol}$ & BRANDRUP e IMMERGUT, 1989 \\
\hline$P M_{w}$ & 18,01 & $\mathrm{~g} / \mathrm{mol}$ & PERRY e CHILTON, 1980 \\
\hline$\rho_{m A}$ & 0,933 & $\mathrm{~g} / \mathrm{cm}^{3}$ & BRANDRUP e IMMERGUT, 1989 \\
\hline$\rho_{m B}$ & 0,8 & $\mathrm{~g} / \mathrm{cm}^{3}$ & BRANDRUP e IMMERGUT, 1989 \\
\hline$\rho_{p A}$ & 1,13 & $\mathrm{~g} / \mathrm{cm}^{3}$ & ARAÚJO et al., 2000 \\
\hline$\rho_{p B}$ & 0,933 & $\mathrm{~g} / \mathrm{cm}^{3}$ & BRANDRUP e IMMERGUT, 1989 \\
\hline$\rho_{w}$ & 1,028 & $\mathrm{~g} / \mathrm{cm}^{3}$ & PERRY e CHILTON, 1980 \\
\hline$k_{A}{ }^{d}$ & 34,7 & - & GARDON, 1969 \\
\hline
\end{tabular}




\begin{tabular}{llll}
\hline Parâmetro & Valor & Unidade & Fonte: \\
\hline$k_{B}{ }^{d}$ & 705,0 & - & UNZUETA e FORCADA, 1997 \\
$k_{A}{ }^{p}$ & 28,0 & - & valor ajustado \\
$k_{B}{ }^{p}$ & 460,0 & - & UNZUETA e FORCADA, 1997 \\
$a_{s}$ & {$\left[39,3 w_{a}+26,5\left(1,0-w_{a}\right)\right] N a \times 10^{-16}$} & $\mathrm{~cm}^{2} / \mathrm{mol}$ & ajuste \\
$r_{A}$ & 0,04 & - & PICHOT et al. (1981) \\
$r_{B}$ & 4,7 & - & valor ajustado \\
$\Delta H_{A}$ & $-2,0895 \times 10^{4}$ & $\mathrm{cal} / \mathrm{mol}$ & BRANDRUP e IMMERGUT, 1989 \\
$\Delta H_{B}$ & $-1,5439 \times 10^{4}$ & $\mathrm{cal} / \mathrm{mol}$ & BASF, 2003 \\
$P e t$ & 7,0 & - & valor ajustado \\
$U A$ & 68,0 & $\mathrm{cal} / \mathrm{s} \mathrm{K}$ & valor estimado \\
$C_{\mathrm{pr}}$ & 1,0 & $\mathrm{cal} / \mathrm{g} \mathrm{K}$ & valor ajustado \\
$R$ & 1,987 & $\mathrm{cal} / \mathrm{mol} \mathrm{K}$ & PERRY e CHILTON, 1980 \\
$P e$ & 61,6 & - & valor calculado \\
$x g e l$ & 1,0 & - & assumido por hipótese \\
\hline
\end{tabular}

Continuição da tabela 4.1 


\section{5 - RESULTADOS E DISCUSSÃO.}

Neste capítulo estão apresentados os resultados experimentais dos ensaios realizados no reator CPPP e sua comparação com os obtidos nas simulações com o modelo. Todos os resultados aqui reportados referem-se a condições do processo operando em regime permanente.

Foi realizado o estudo da variação paramétrica das variáveis operacionais do processo, através da simulação com o modelo matemático, de modo a verificar o grau de sensibilidade do processo em relação a estas variáveis. Esta análise de sensibilidade é apresentada a seguir. O modelo foi previamente ajustado aos dados experimentais. Na sequência, estão representados os resultados experimentais dos ensaios realizados e sua respectiva comparação com os resultados simulados (validação do modelo matemático), e das condições operacionais ótimas previstas pela simulação do mesmo modelo. Finalmente, é apresentada uma discussão dos possíveis fatores que interferiram na precisão dos resultados obtidos, tanto os experimentais como os simulados.

\subsection{Análise de Sensibilidade Paramétrica do Modelo.}

Os parâmetros operacionais escolhidos para este estudo de sensibilidade são o número de alimentações laterais do comonômero mais reativo (acrilato de butila, BuA), a temperatura da água que entra na camisa de resfriamento, a amplitude de pulsação (que define o grau de dispersão axial) e o tempo de residência. Em todas as simulações foram consideradas as mesmas proporções entre os reagentes, empregadas nos ensaios experimentais, conforme mostrado na Tabela 5.1.

Tabela 5.1 Formulação da copolimerização VAc-BuA.

\begin{tabular}{lll}
\hline Reagentes & Função & fração mássica \\
\hline Acetato de vinila (VAc) & Comonômero & 0,1596 \\
Acrilato de butila (BuA) & Comonômero & 0,0282 \\
Água & Meio dispersante & 0,8069 \\
Lauril sulfato de sódio & Emulsificante & 0,0024 \\
Persulfato de sódio & Iniciador & 0,0029 \\
\hline
\end{tabular}


Nos resultados das simulações que representam o efeito da variação do número de correntes de alimentação lateral, a quantidade total de BuA alimentada é igualmente distribuída entre a corrente de alimentação do fundo da coluna e as correntes laterais dispostas ao longo da coluna. Em todos os casos o comonômero menos reativo (acetato de vinila, VAc) é alimentado exclusivamente pelo fundo da coluna. Para o caso de duas alimentações laterais, as correntes laterais alimentam a base das seções 2 e 3 . No caso de três alimentações laterais, são alimentadas as bases das seções 2, 3 e 4. E com quatro alimentações laterais, as seções 2, 3, 4 e 5 são alimentadas pelas respectivas bases.

Os efeitos das variações paramétricas estão representados em função dos resultados simulados de temperatura e conversão global de reação e pela composição acumulada do copolímero formado ao longo da coluna operando em regime permanente. As condições operacionais do caso base, escolhido para a comparação de todos os efeitos estudados, estão representadas na Tabela 5.2. Cada uma das condições foi variada individualmente, mantendo-se as demais condições fixas e iguais às mostradas na Tabela 5.2 .

Tabela 5.2 - Condições operacionais do caso base para o estudo de sensibilidade do modelo.

\begin{tabular}{ll}
\hline Tempo de residência & $30 \mathrm{~min}$ \\
Temperaturas das camisas & $55^{\circ} \mathrm{C}$ \\
Número de alimentações laterais & 4 \\
Amplitude de pulsação & $18 \mathrm{~mm}$ \\
Freqüência de pulsação & $2,1 \mathrm{~Hz}$ \\
Número de Peclet $(P e)$ & 61,6 \\
Número de Peclet térmico $\left(P e_{t}\right)$ & 7,0 \\
Coeficiente global de traca térmica multiplicado pela área $(U A)$ & $72,0 \mathrm{cal} / \mathrm{s}^{\circ} \mathrm{C}$ \\
\hline
\end{tabular}




\subsubsection{Estudo do Efeito do Número de Alimentações Laterais.}

Os resultados de simulação representados nas figuras 5.1, 5.2 e 5.3 são referentes à avaliação do efeito do número de alimentações laterais do monômero mais reativo acrilato de butila - e indicam que as características da unidade experimental permitem controlar a composição do copolímero através de uma melhor distribuição da alimentação lateral do monômero mais reativo. Aumentando o número de alimentações laterais (ou seja, distribuindo mais equilibradamente o monômero mais reativo ao longo da coluna) é possível obter uma composição de copolímero mais uniforme ao longo do reator, reduzindo a deriva de composição causada pela diferença entre as razões de reatividade dos monômeros. Ao mesmo tempo, quando se distribue melhor o monômero mais reativo, a elevação de temperatura ao longo do comprimento do reator é também mais moderada, bem como a variação de conversão é mais suave.

Nos casos em que o número de alimentações laterais é menor, as taxas de reação tendem a valores maiores nas primeiras seções. Isso se deve à maior concentração do monômero BuA na entrada do reator e ao fato de haver uma grande diferença entre as razões de reatividade destes dois comonômeros. Neste caso, se não houver alimentação lateral de acrilato de butila, este comonômero, por ser o mais reativo, tende a reagir preferencialmente com os radicais poliméricos em crescimento, seja quando a unidade monomérica terminal for de acetato de vinila, seja quanto for de acrilato de butila. Já nos casos em que BuA é alimentado de modo mais distribuído ao longo da coluna, criam-se estados de escassez de BuA (menores concentrações de BuA tendem a compensar sua maior reatividade em relação ao VAc), nos quais a homogeneidade das cadeias poliméricas pode ser melhor controlada. Pelas comparações feitas na figura 5.2, verifica-se que o número de correntes laterais teve um efeito inverso sobre a conversão global dos reagentes, sendo alcançadas conversões maiores no interior da coluna nas reações nas quais foram empregadas menor número de correntes laterais. A conversão final do produto é praticamente a mesma, exceto para o caso das 4 alimentações laterais. Além disso, pode-se verificar que a distribuição da alimentação lateral do monômero mais reativo também altera a distribuição da geração de calor de 
reação ao longo da coluna. Em relação à composição do copolímero, esta se mantém mais uniforme à medida em que são adicionadas mais correntes laterais de alimentação do monômero mais reativo.

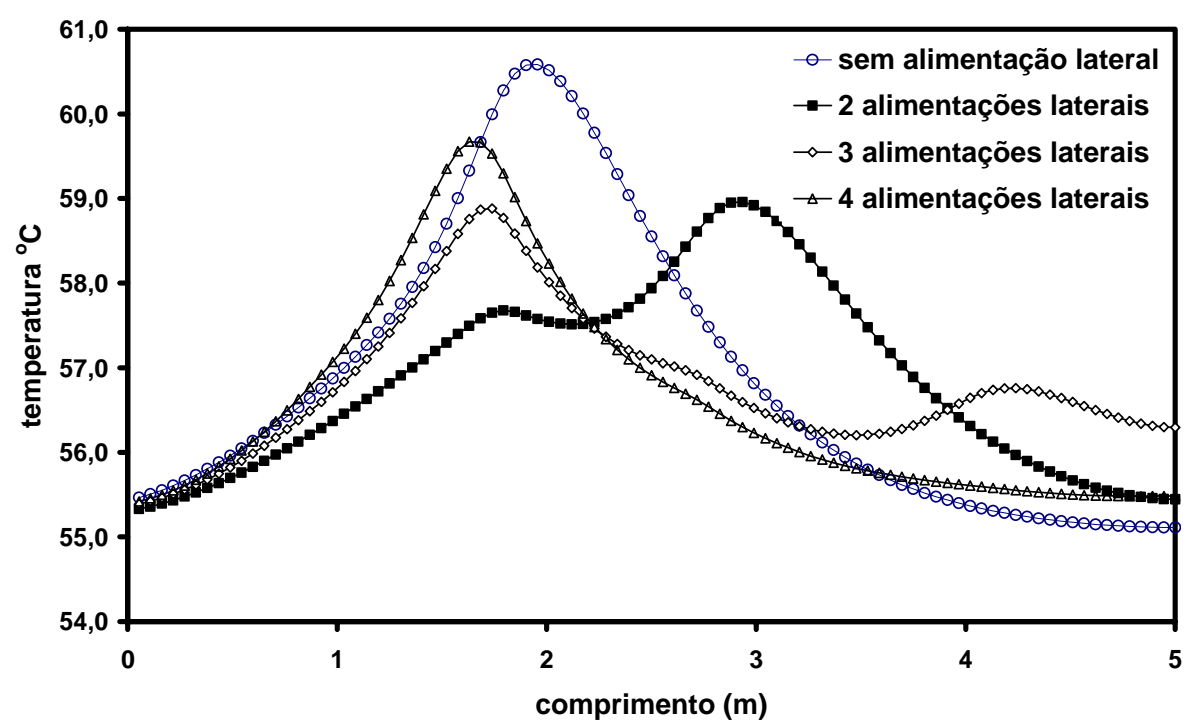

Figura 5.1 Efeito do número de alimentações laterais sobre o perfil de temperatura previsto pelo modelo, em regime permanente.

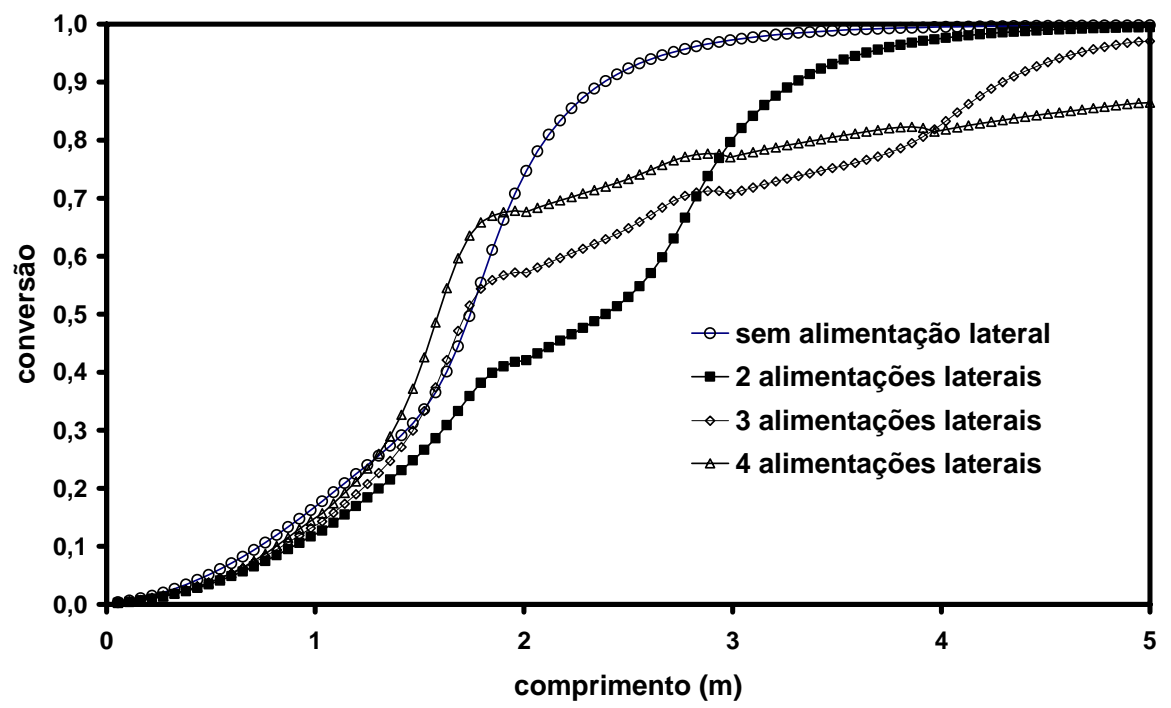

Figura 5.2 Efeito do número de alimentações laterais sobre o perfil de conversão previsto pelo modelo, em regime permanente. 


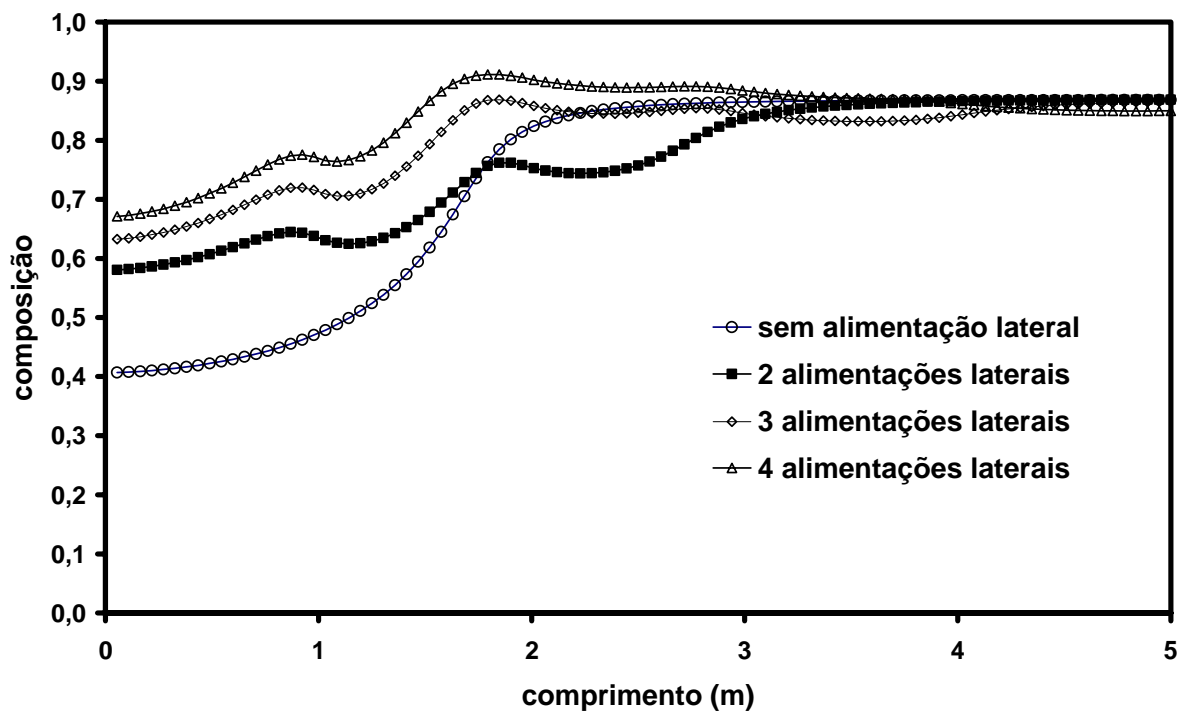

Figura 5.3 Efeito do número de alimentações laterias sobre o perfil de composição do copolímero previsto pelo modelo, em regime permanente.

\subsubsection{Estudo do Efeito da Temperatura da Água de Resfriamento.}

Os resultados de simulação apresentados nas figuras 5.4, 5.5 e 5.6 mostram que o desempenho global da reação é fortemente determinado pela temperatura da água na camisa de resfriamento da coluna. O efeito do aumento da temperatura da camisa nas seções 1 e 2 ocasiona o aumento das constantes de propagação dos comonômeros, aumentando a velocidade de polimerização e a taxa de calor gerado pela reação. As temperaturas máximas de reação são alcançadas nas seções onde respectivamente ocorrem as maiores taxas de reação.

A partir da análise da figura 5.6, verifica-se que a composição do copolímero formado também pode ser influenciada pelo controle de temperatura da água nas camisas.

A diminuição da velocidade de polimerização no final da coluna poderia ser evitada ou parcialmente compensada através do uso de temperaturas mais elevadas na camisa de resfriamento das últimas seções da coluna. 


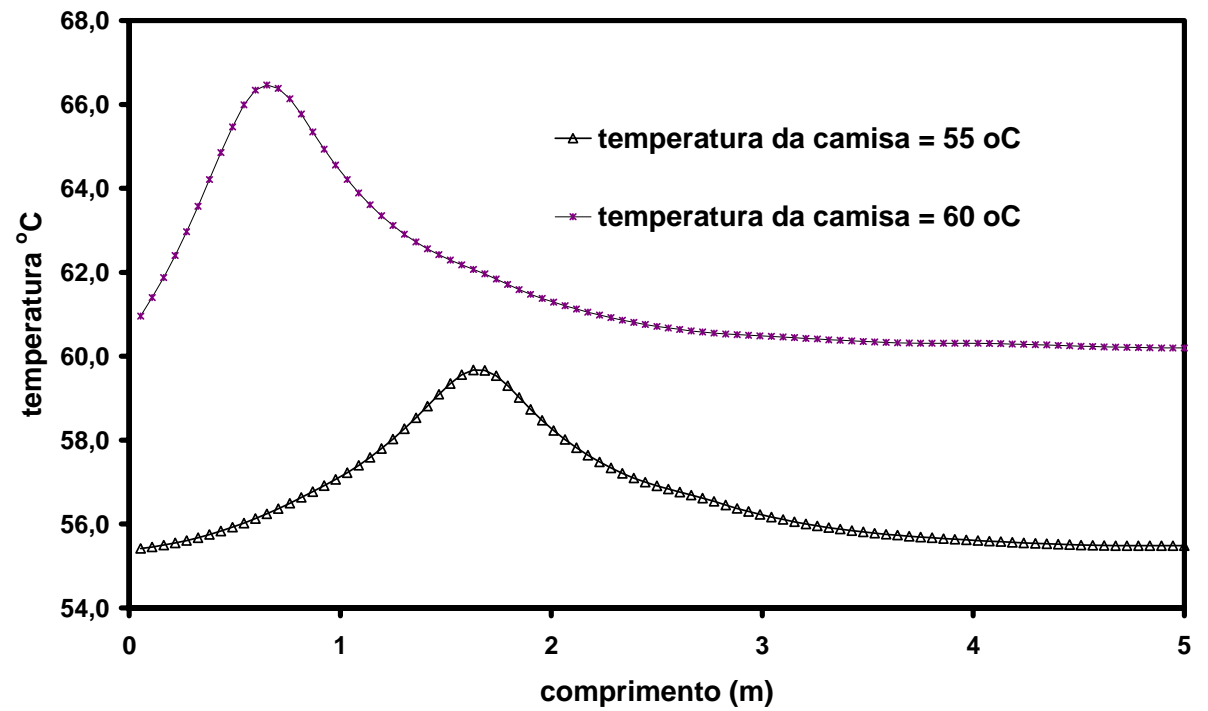

Figura 5.4. Efeito da temperatura da água na camisa sobre o perfil de temperatura em regime permanente, previsto pelo modelo.

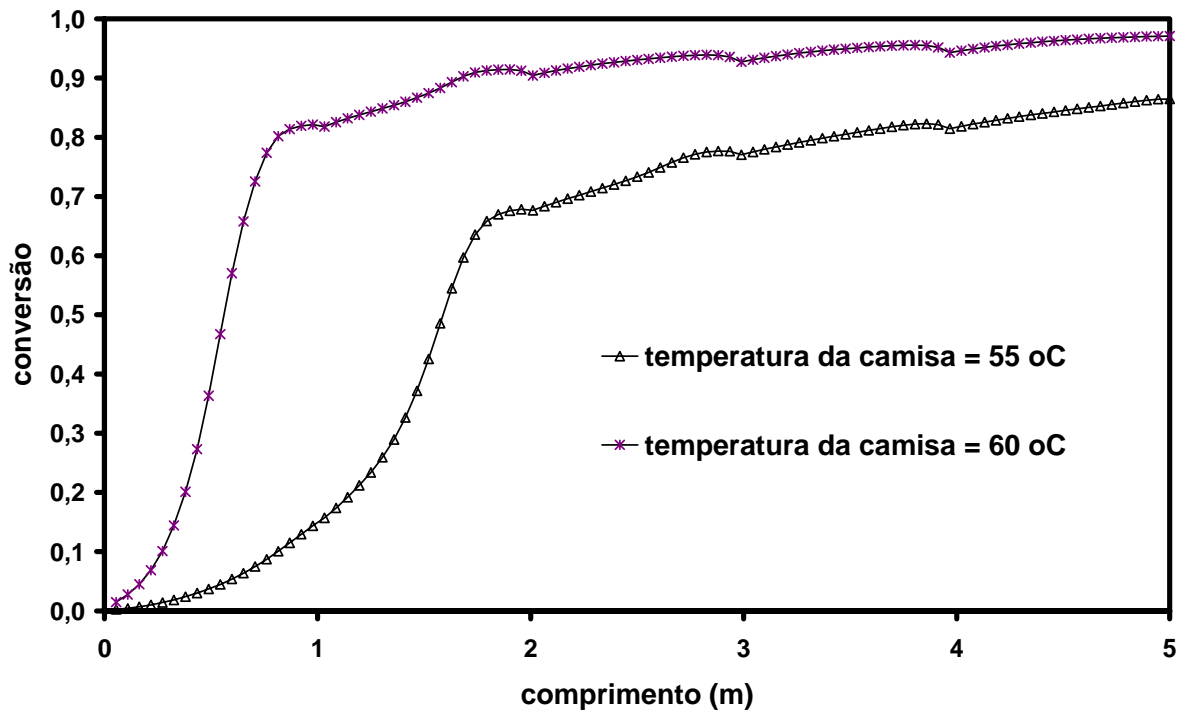

Figura 5.5 Efeito da temperatura da água na camisa sobre o perfil de conversão em regime permanente, previsto pelo modelo. 


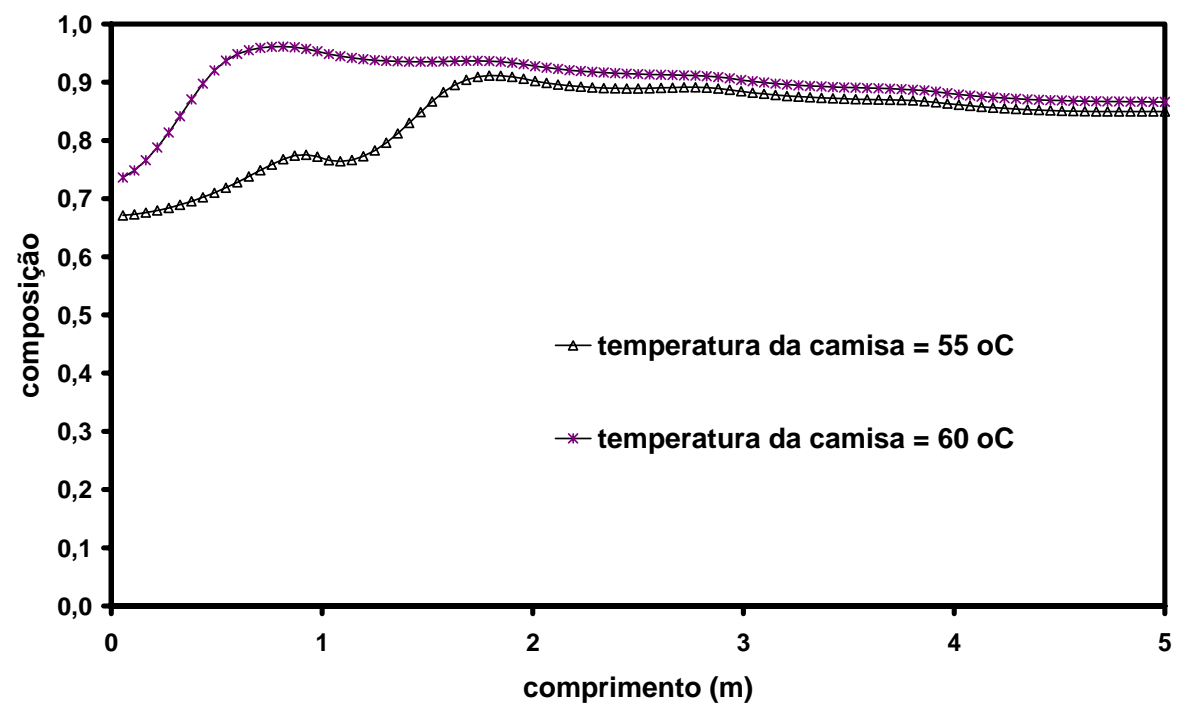

Figura 5.6 Efeito da temperatura da água na camisa sobre o perfil de composição do copolímero em regime permanente, previsto pelo modelo.

\subsubsection{Estudo do Efeito da Amplitude de Pulsação}

De acordo com equação (4.67) e Figura 4.1, a amplitude de pulsação afeta o coeficiente de dispersão axial. Pela análise das figuras 5.7, 5.8 e 5.9, verifica-se que o efeito da amplitude de pulsação sobre as variáveis representadas é pequeno, considerando a faixa de valores simulados (0 a $25 \mathrm{~mm}$ ). Os números de Peclet correspondentes a estas condições variaram entre 53 e 104, o que representa um intervalo relativamente estreito em termos de variação de dispersão axial. Outra possível forma de variar a dispersão axial seria através da mudança na freqüência de pulsação, e seu efeito seria análogo ao observado para a amplitude, como se pode verificar na equação (4.67). 


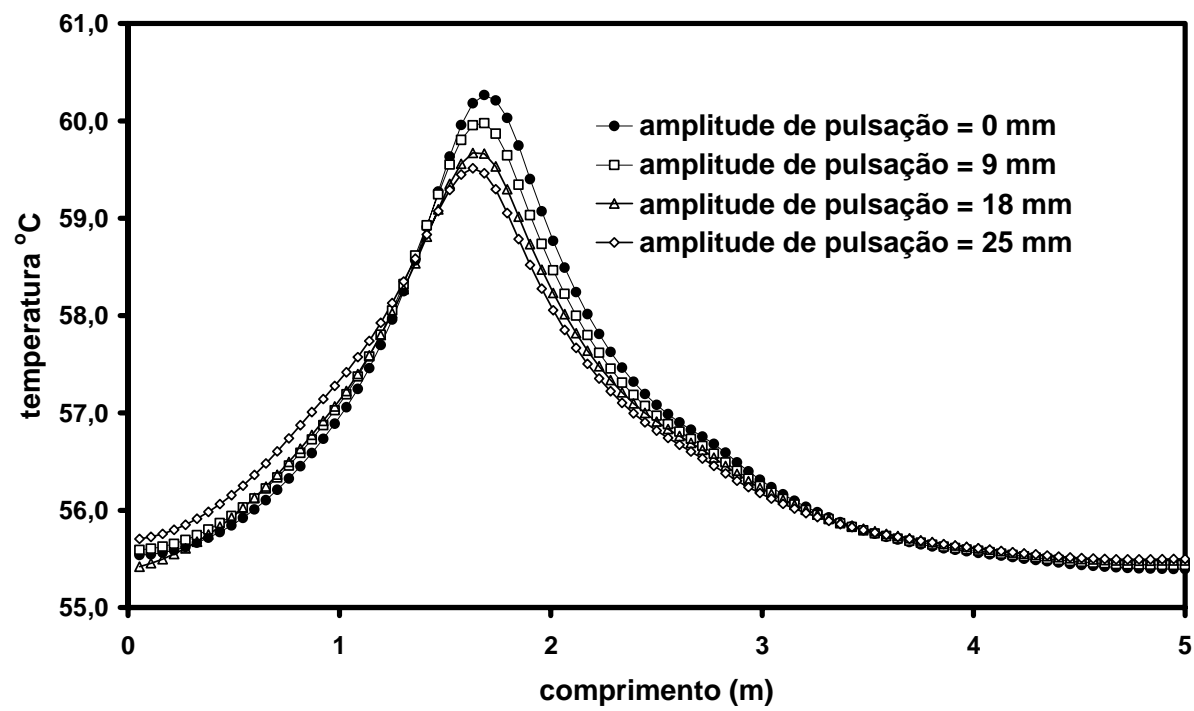

Figura 5.7. Efeito da amplitude de pulsação sobre o perfil de temperatura em regime permanente, previsto pelo modelo.

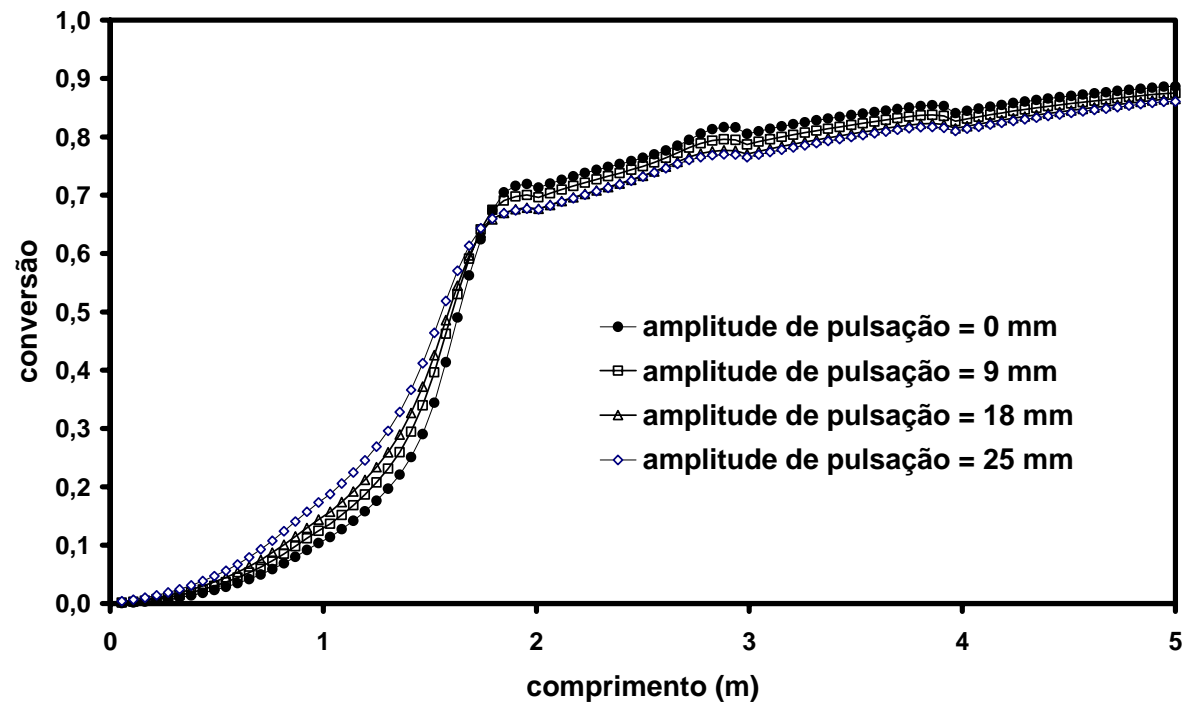

Figura 5.8 Efeito da amplitude de pulsação sobre o perfil de conversão em regime permanente, previsto pelo modelo. 


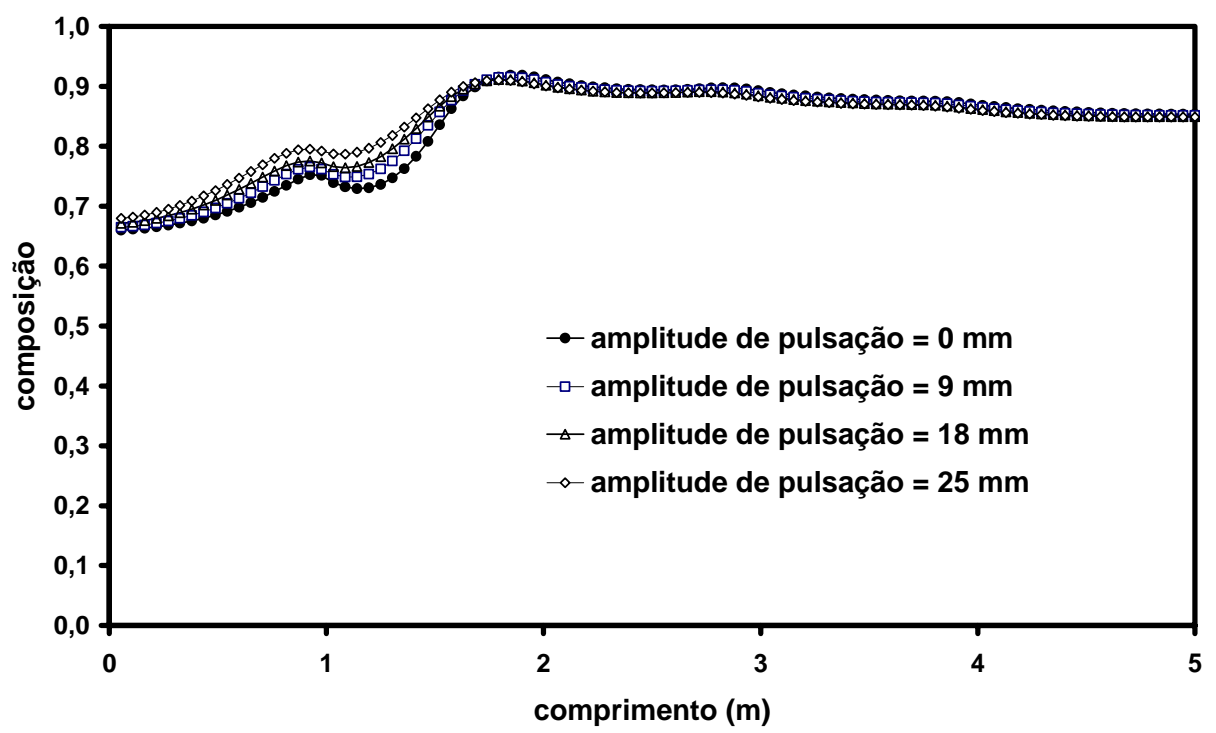

Figura 5.9 Efeito da amplitude de pulsação sobre o perfil de composição do copolímero em regime permanente, previsto pelo modelo.

Os resultados mostram também que com o aumento na amplitude de pulsação, os gradientes de concentração axiais são reduzidos, já que este efeito é equivante a aumentar o grau de mistura axial (e alargar a distribuição dos tempos de residência). Como consequência, também a deriva de composição do copolímero ao longo da coluna fica ligeiramente reduzida, distribuindo ligeiramente melhor a taxa de conversão e a liberação de calor pela reação ao longo da coluna. 


\subsubsection{Estudo do Efeito do Tempo de Residência}

Os resultados representados nas figuras $5.10,5.11$ e 5.12 mostram uma sensibilidade muito alta do desempenho do processo em função da mudança no tempo de residência, como seria esperado. A variação do tempo de residência afeta não só o grau de dispersão axial como também, principalmente, a velocidade média de escoamento convectivo do fluido através do reator, e a combinação entre estes dois efeitos determina o número de Peclet.

Verifica-se pela figura 5.12 a possibilidade do controle da composição ao longo das primeiras seções da coluna através do controle do tempo de residência. O perfil de conversão também é fortemente determinado pelo tempo de residência.

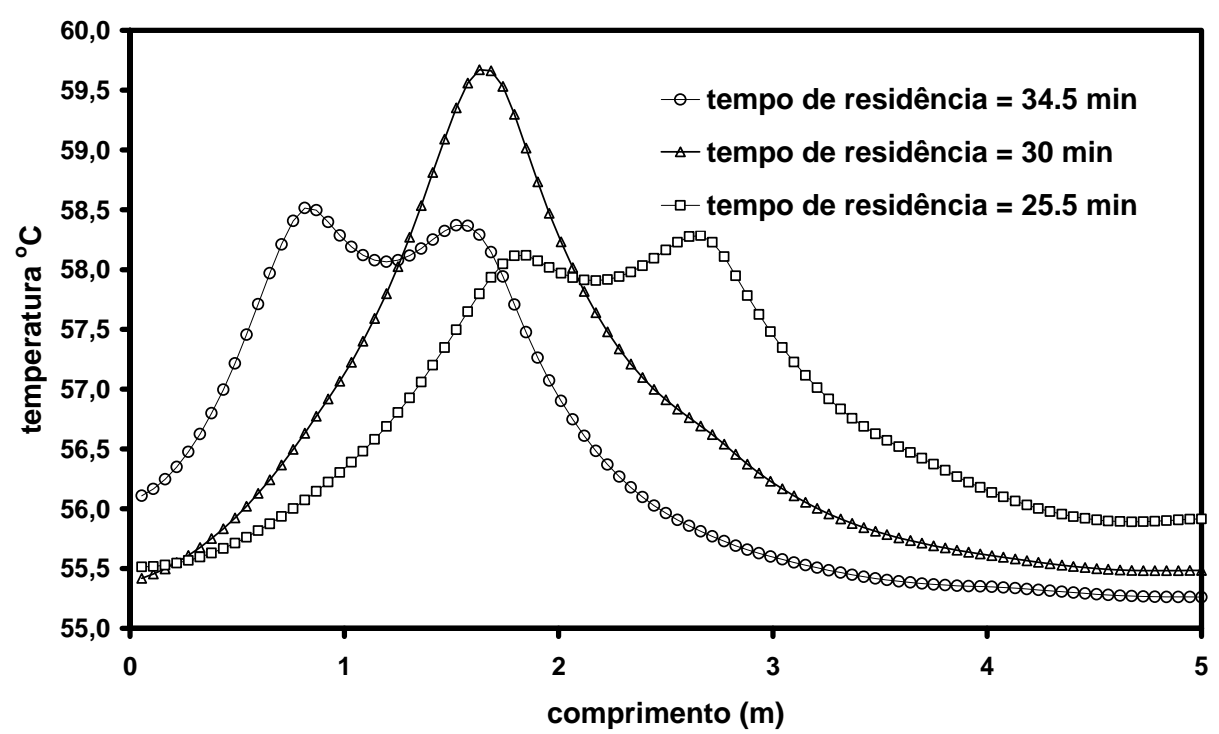

Figura 5.10 Efeito do tempo de residência do fluido no reator sobre o perfil de temperatura em regime permanente, previsto pelo modelo. 


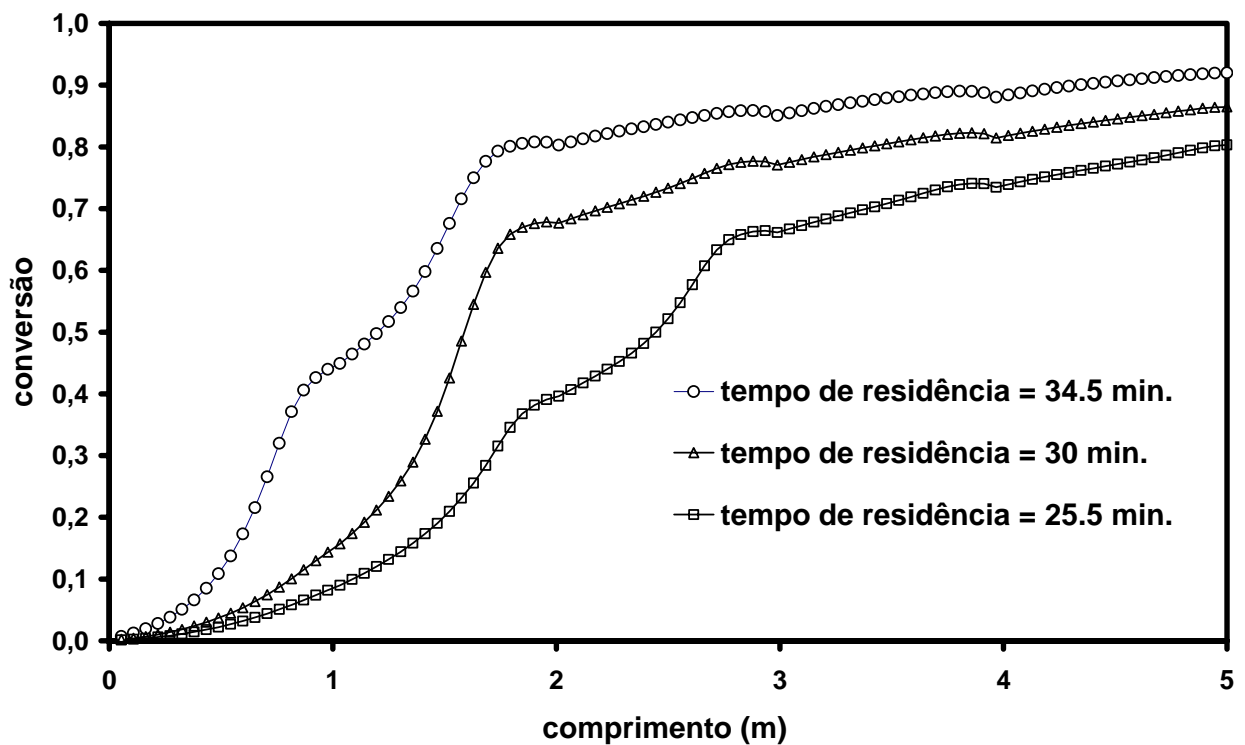

Figura 5.11 Efeito do tempo de residência do fluido no reator sobre o perfil de conversão em regime permanente, previsto pelo modelo.

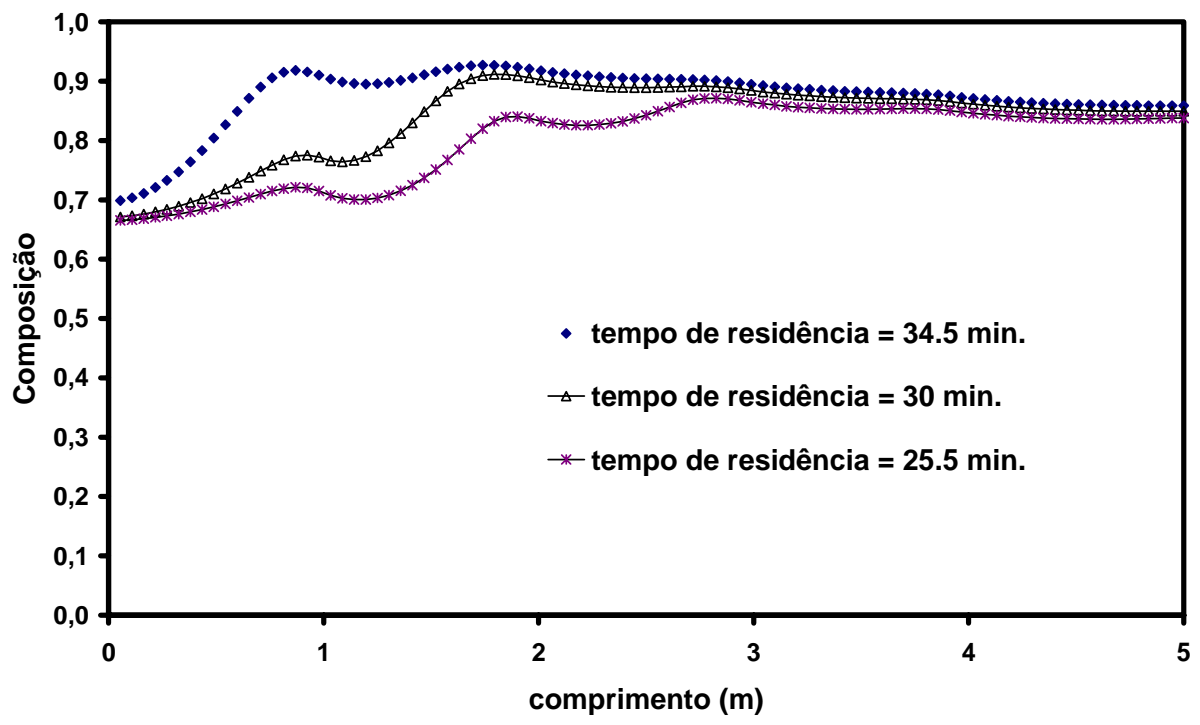

Figura 5.12 Efeito do tempo de residência do fluido no reator sobre o perfil de composição do copolímero em regime permanente, previsto pelo modelo. 


\subsection{Resultados Experimentais e Comparação com as Simulações.}

Nesta seção são apresentados os resultados de 10 ensaios experimentais da coluna operando em regime permanente, realizados em diversas condições de alimentação lateral de BuA e diferentes temperaturas na água de resfriamento que circula pelas camisas. Em cada ensaio, foi mantida a temperatura da água da camisa igual para cada seção ao longo da coluna, tal como nos casos simulados já apresentados. Em todos os casos, a temperatura das camisas das diferentes seções era praticamente a mesma durante cada ensaio. A variação de temperatura de reação decorrente destas condições permitiu uma melhor possibilidade de ajuste dos parâmetros do modelo relacionados ao balanço de energia do processo. Finalmente, foram validadas experimentalmente as condições operacionais ótimas previamente determinadas mediante a simulação matemática do processo.

Exceto pelo perfil de alimentação lateral e pela temperatura da água na camisa de resfriamento, as demais condições operacionais aplicadas a todos os ensaios são as mesmas que foram consideradas nas simulações na seção anterior e estão descritas na Tabela 5.2. A formulação empregada para o meio reacional é a mesma descrita na Tabela 5.1. A Tabela 5.3 descreve as condições operacionais que caracterizam cada um dos ensaios.

As pequenas diferenças no valor de temperatura das camisas nos diferentes ensaios $\left(56,5 \pm 1^{\circ} \mathrm{C}\right)$ decorrem de variações da caldeira que fornece água quente para as camisas. Os valores das temperaturas de entrada do meio reacional, na base da coluna, oscilaram entre 54 e $56{ }^{\circ} \mathrm{C}$ ao longo de todos os ensaios realizados. 
Tabela 5.3 Condições operacionais utilizadas nos ensaios experimentais.

\begin{tabular}{|c|c|c|}
\hline Ensaio & Temp. média das 5 camisas $\left({ }^{\circ} \mathrm{C}\right)$ & Perfil de alimentação lateral \\
\hline 1 & 57.5 & sem alimentação lateral \\
\hline 2 & 57.3 & 2 alimentações laterais (seções 2 e 3) \\
\hline 3 & 56.5 & 2 alimentações laterais (seções 2 e 3) \\
\hline 4 & 57.5 & 2 alimentações laterais (seções 3 e 4) \\
\hline 5 & 56.0 & 2 alimentações laterais (seções 3 e 4) \\
\hline 6 & 56.5 & 3 alimentações laterais iguais \\
\hline 7 & 57.2 & 4 alimentações laterais iguais \\
\hline 8 & 56.0 & 4 alimentações laterais iguais \\
\hline 9 & 55.6 & perfil otimizado de alimentação \\
\hline 10 & 56.0 & Perfil otimizado de alimentação \\
\hline
\end{tabular}

A repetição dos pares de ensaios (2 e 3), (4 e 5), (7 e 8), (9 e 10), que empregam o mesmo perfil de alimentação lateral, tem como objetivo a comprovação da reprodutibilidade dos resultados obtidos para diversas condições experimentais e, também, a verificação da validade do modelo para todos esses casos. Os resultados experimentais de cada ensaio estão apresentados graficamente (como pontos discretos) junto com os resultados obtidos pela simulação do modelo (como linhas) nas condições operacionais correspondentes.

\subsubsection{Ensaio 1}

O ensaio 1 foi realizado sem alimentação lateral de BuA e a alimentação total dos monômeros foi feita exclusivamente pela base da primeira seção da coluna.

Os gráficos da figura 5.13 mostram a evolução da conversão, da composição e da temperatura ao longo da coluna. Conforme esperado, os perfis das curvas simuladas e os dados experimentais revelam uma alta taxa de conversão nas duas primeiras seções da coluna, acompanhada de correspondentes aumentos de temperatura e de uma forte deriva de composição em função da posição na coluna. 
Na figura 5.14 é apresentada a evolução do diâmetro médio das partículas e do número de partículas por grama de emulsão tanto os valores calculados a partir dos dados experimentais bem como as curvas simuladas pelo modelo.

O gráfico superior da figura 5.15 mostra a evolução prevista pelo modelo do número médio de radicais por partícula de polímero com o decorrer da reação em cada ponto da coluna. Também conforme o esperado, os números obtidos seguem a tendência de dados verificados em trabalho anterior (KONG et al, 1992). O efeito da concentração de BuA na coluna sobre o número de radicais por partícula pode ser atribuído à solubilidade significativamente mais baixa deste monômero na fase aquosa do que a de VAc, o que resulta num aumento da taxa de entrada e numa redução da taxa de saída dos radicais das partículas de polímero o que, por sua vez, eleva o número de radicais por partícula. O gráfico inferior da mesma figura mostra também como a conversão de BuA ocorre quase que completamente logo na primeira seção, devido à sua maior razão de reatividade, aumentando simultaneamente o número médio de radicais por partícula. Este número passa a decrescer a partir do fim da primeira seção onde a conversão de VAc praticamente coincide com a conversão global da reação. 

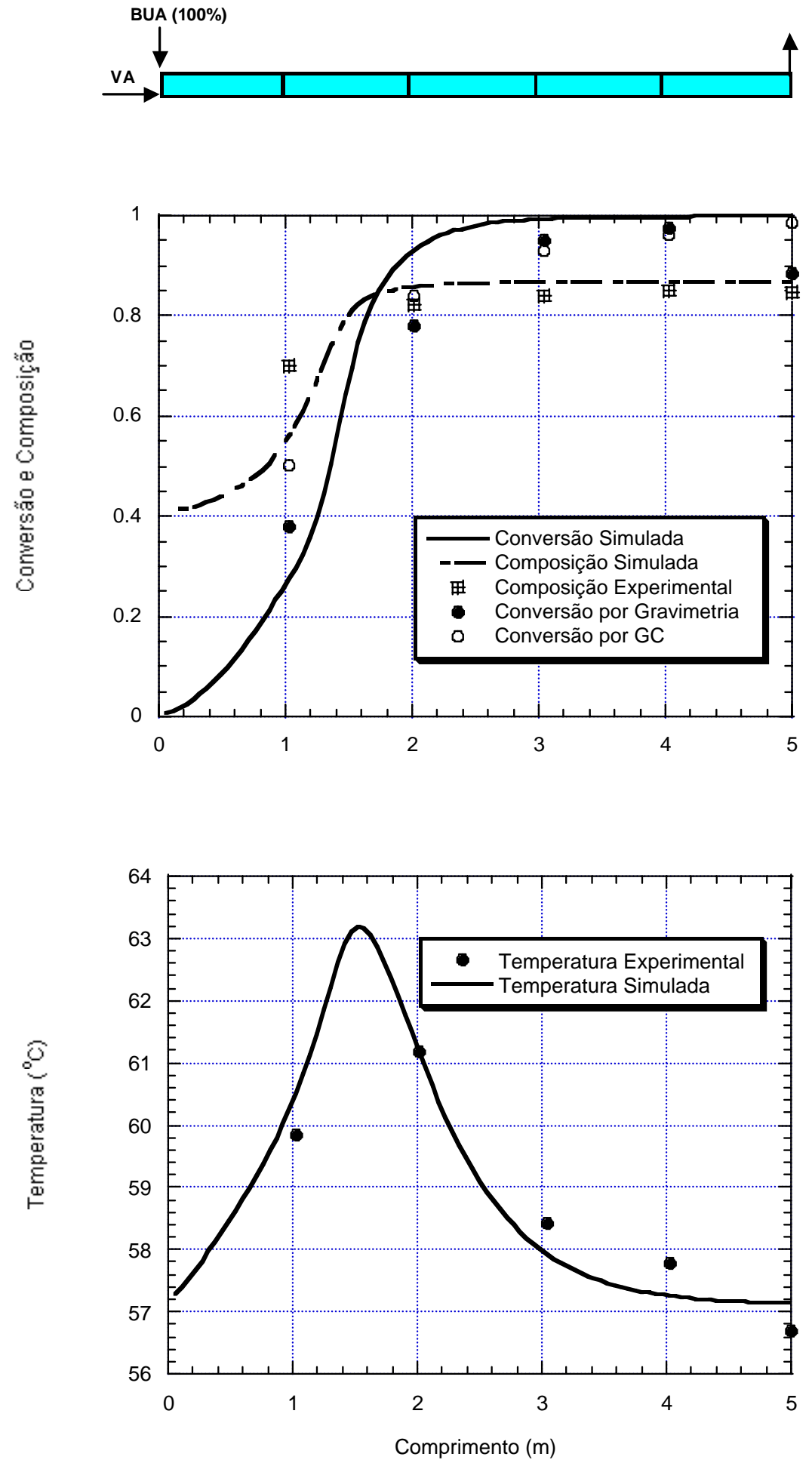

Figura 5.13 Dados experimentais e resultados da simulação para o ensaio 1. 

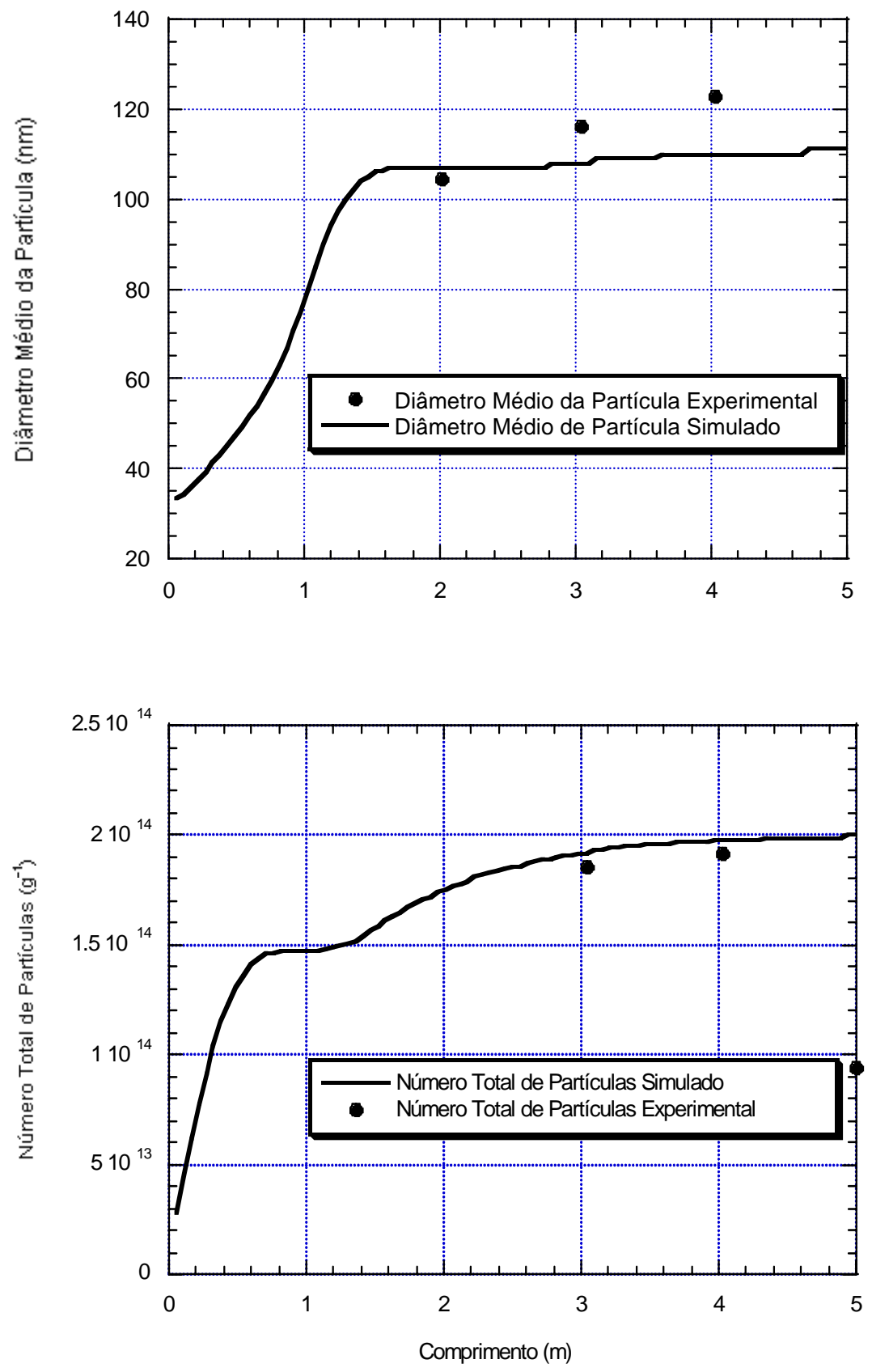

Figura 5.14 Dados experimentais e resultados da simulação para o ensaio 1. 

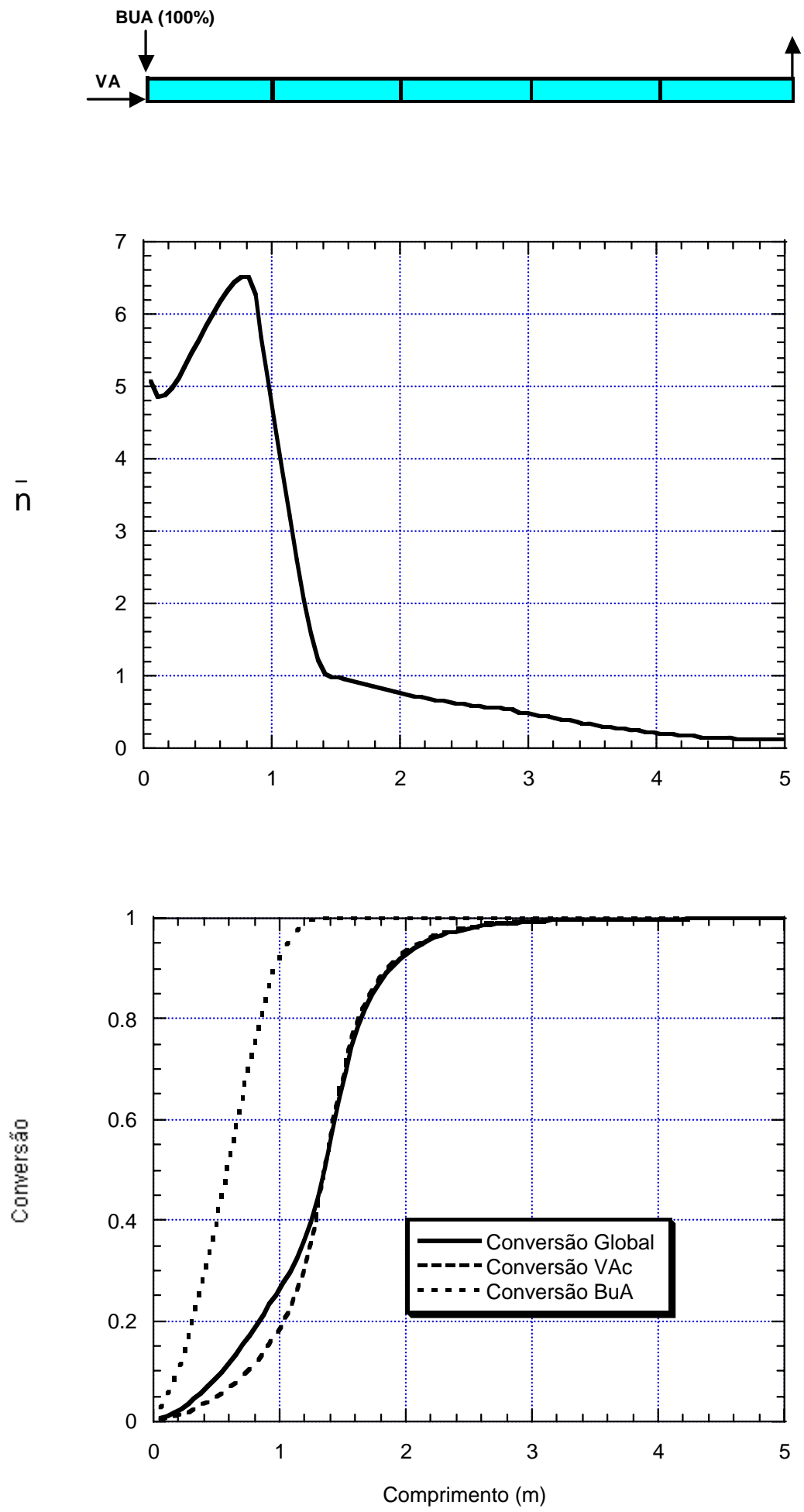

Figura 5.15. Resultados da simulação para o ensaio 1. 


\subsubsection{Ensaios 2 e 3.}

Os ensaios 2 e 3 foram realizados empregando-se a alimentação nos pontos representados na figura 5.16, ou seja, com a vazão de BuA distribuída equitativamente nas três primeiras seções. As vazões correspondentes estão representadas em forma de porcentagem em relação à quantidade global de BuA a ser alimentada durante a reação.

Neste ensaio verificou-se o aumento do número médio de radicais por partícula coincidindo com os pontos de adição lateral de BuA segundo os mesmos mecanismos já comentados anteriormente.

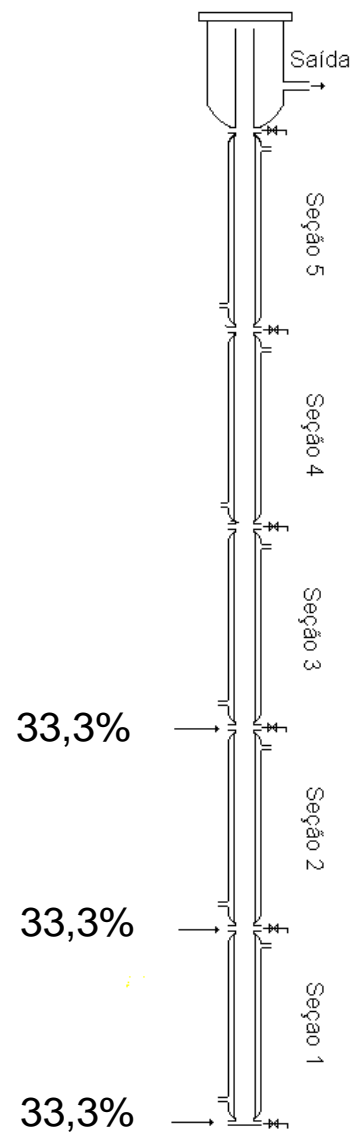

Figura 5.16. Distribuição das alimentações laterais de acrilato de butila usada nos ensaios 2 e 3. 

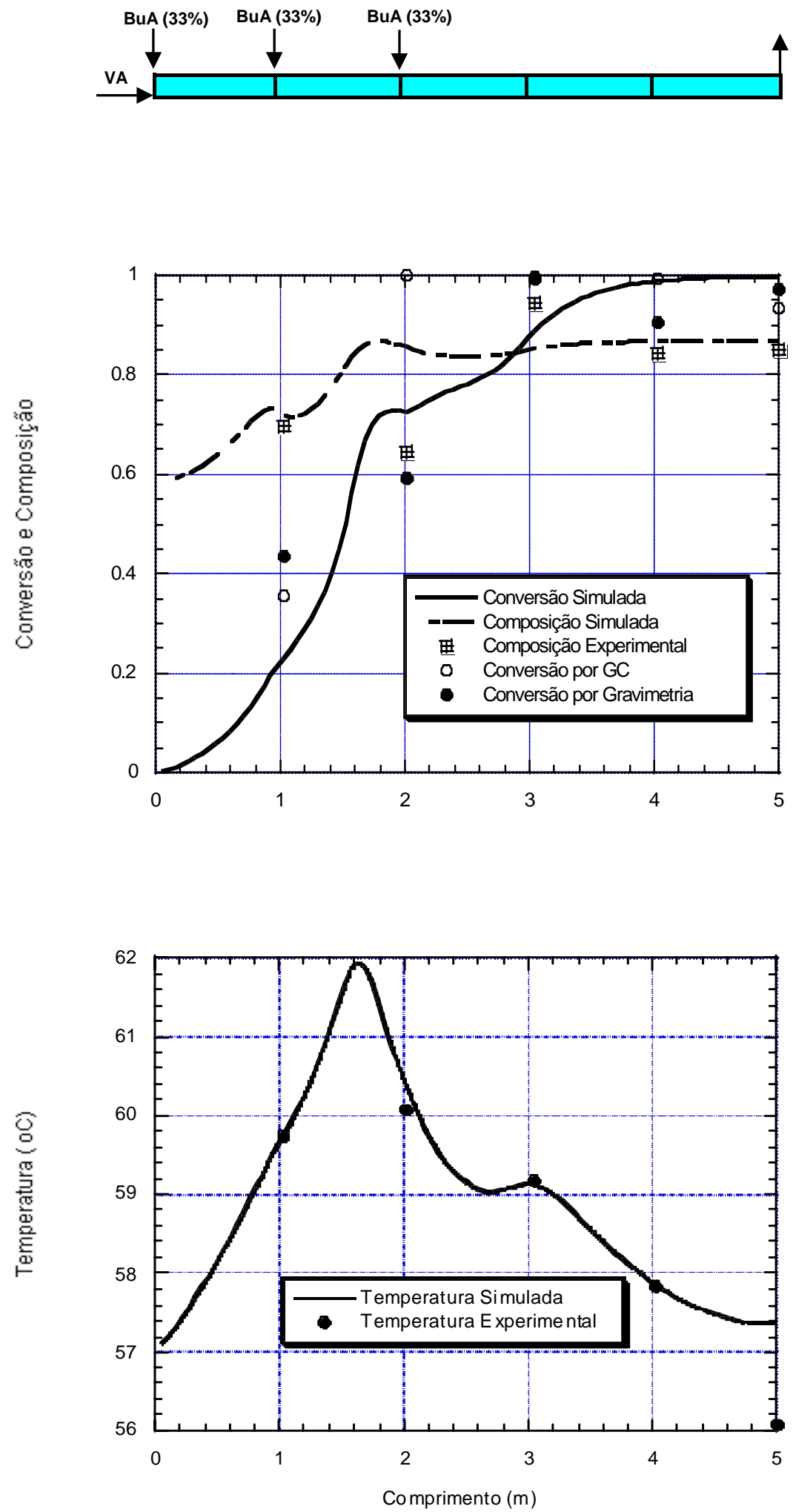

Figura 5.17 Composição, conversão e temperatura de reação em regime permanente - ensaio 2. 

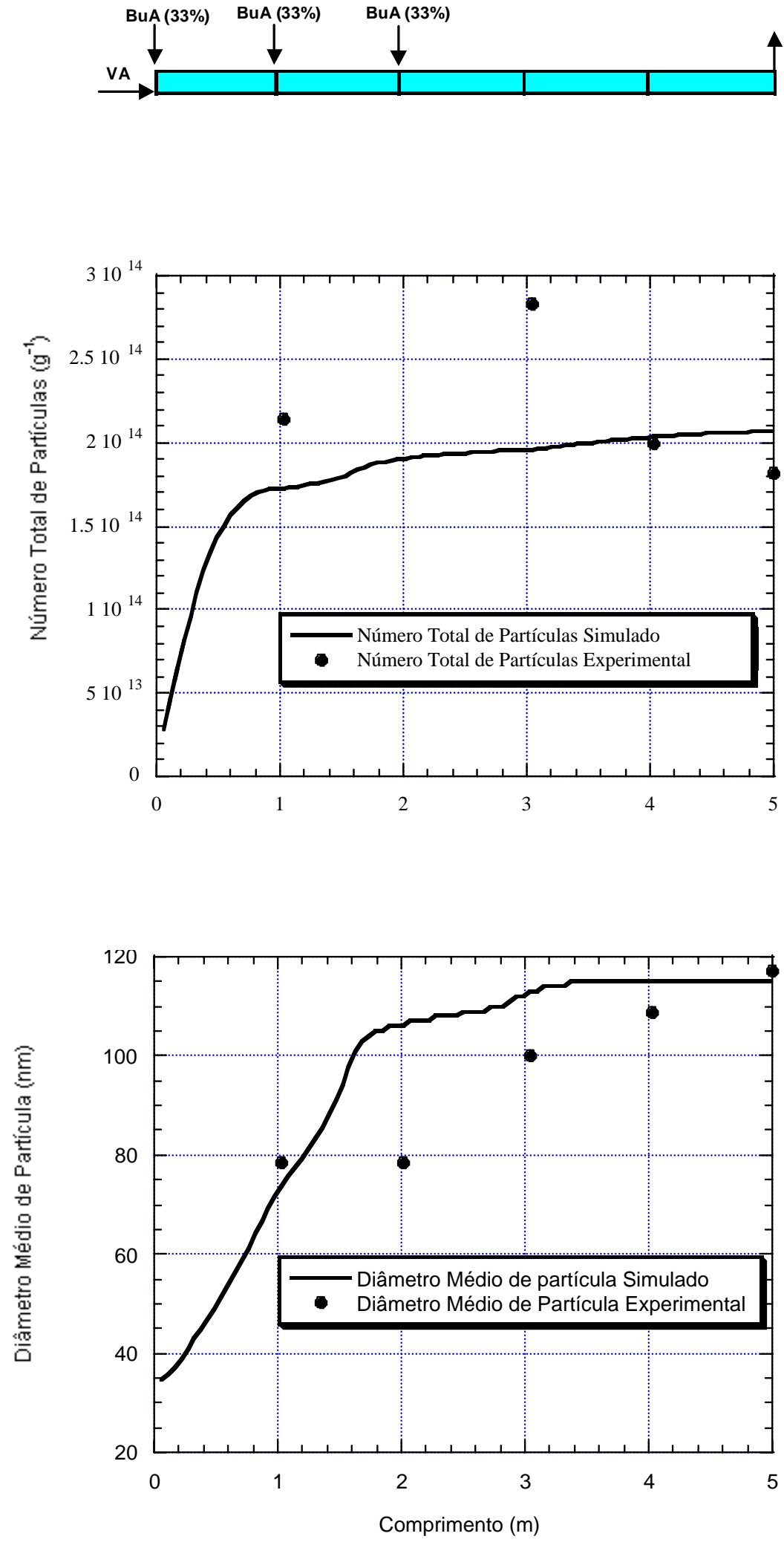

Figura 5.18 - Dados experimentais e resultados da simulação para o ensaio 2. 

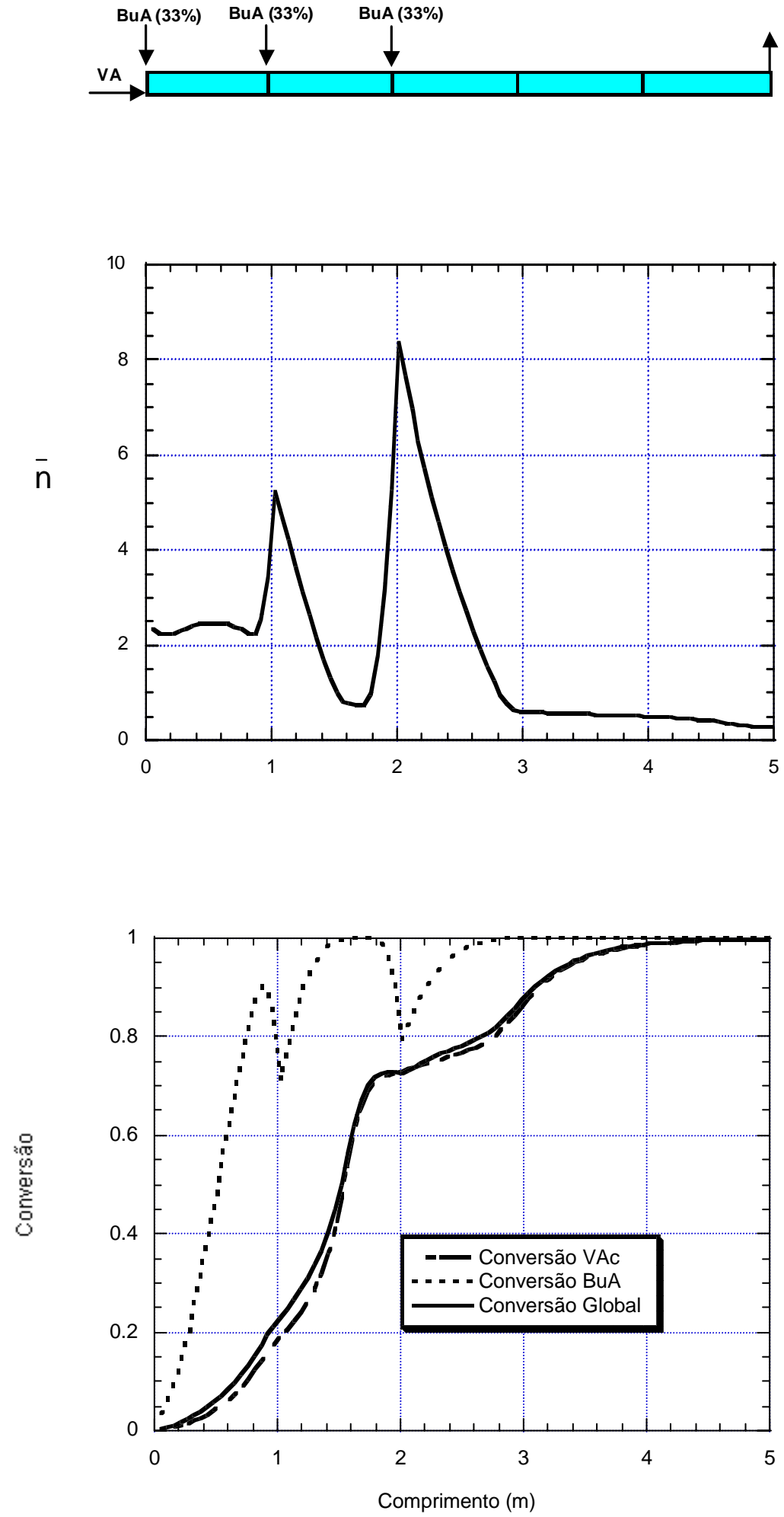

Figura 5.19 - Resultados da simulação para o ensaio 2. 

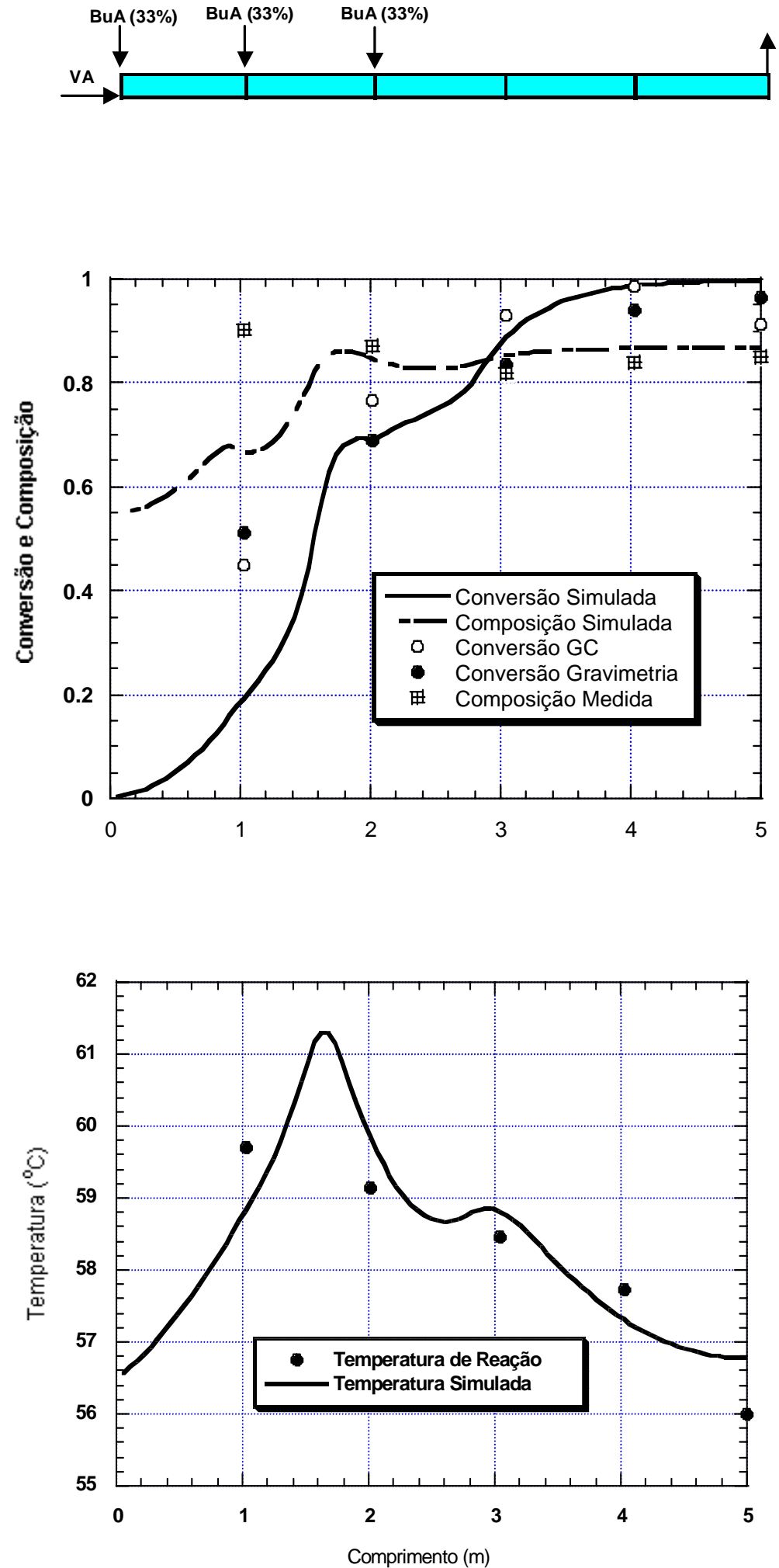

Figura 5.20 - Dados experimentais e resultados da simulação para o ensaio 3. 

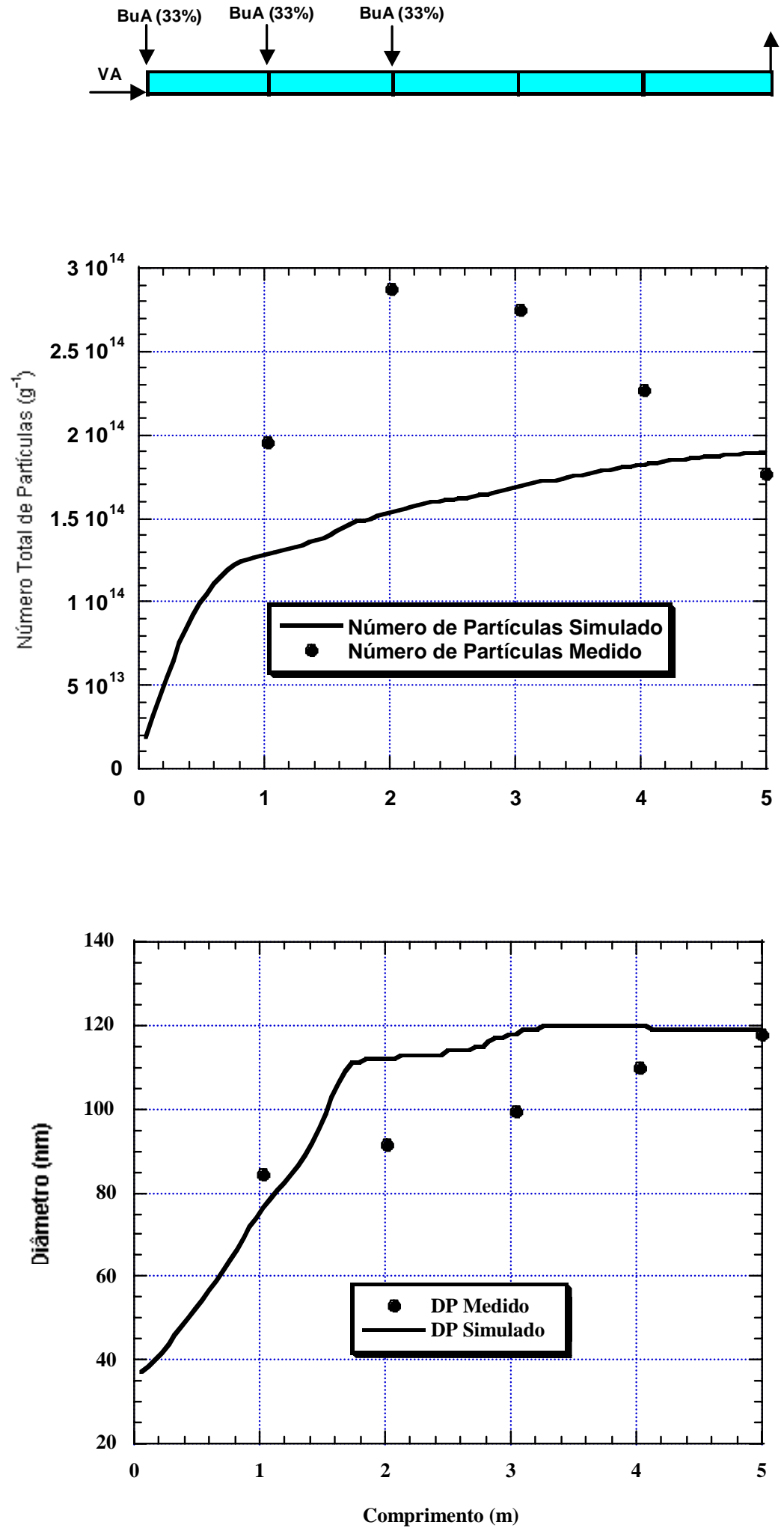

Figura 5.21 - Dados experimentais e resultados de simulação para o ensaio 3. 

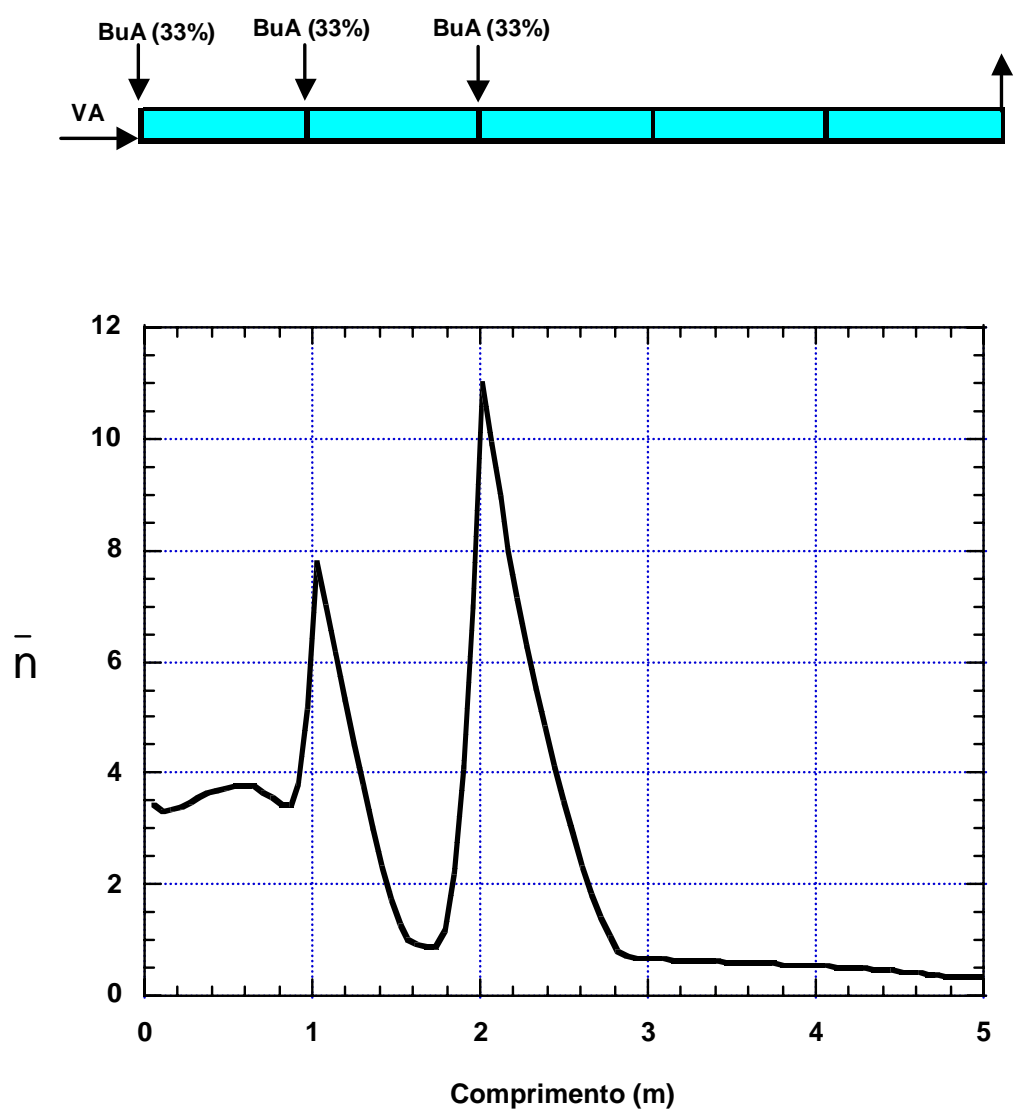

Figura 5.22- Resultados da simulação para o ensaio 3.

Os resultados desses ensaios demonstraram boa concordância com o modelo simulado principalmente em relação à temperatura da reação. Novamente verificou-se grande discrepância nos valores de conversão e composição no ponto de amostragem onde a velocidade de reação é mais alta (final da primeira seção). A maior diferença entre os valores experimentais e simulados foi verificada, no entanto, no caso dos valores obtidos para o número total de partículas por gramas de emulsão. Neste caso, pequenas variações nas condições experimentais relacionadas à concentração e ao desempenho do tensoativo podem afetar o diâmetro médio das partículas e conseqüentemente o número de partículas produzidas, cuja sensibilidade do próprio método de cálculo depende da medida do diâmetro médio da partícula e da conversão. Como o valor do diâmetro precisa ser elevado ao cubo na estimativa do número de partículas, a propagação do erro sobre o diâmetro se amplifica, gerando uma maior incerteza sobre o valor do número de partículas. 
Como se pode observar, a reprodutibilidade dos dois ensaios está melhor evidenciada nos respectivos perfis de temperatura. Para este caso, a diferença de somente $0,8{ }^{\circ} \mathrm{C}$ entre as temperaturas de entrada das camisas de resfriamento, empregadas em cada ensaio, foi insuficiente para ocasionar mudanças significativas nos perfis de conversão entre os dois ensaios. Verifica-se também, através da comparação entre as simulações dos dois ensaios, que existem diferenças significativas no número de radicais por partícula nos pontos onde estão localizadas as correntes laterais de alimentação de monômero mais reativo. Essa diferença no número médio de radicais por partícula (figura 5.19 (a) e figura 5.22) pode ser explicada pela influência da temperatura sobre as taxas de entrada e saída de radicais livres pelas partículas.

Devido à influência moderadora da alimentação lateral de acrilato de butila, as conversões alcançadas no final da segunda seção, nos ensaios 2 e 3, são inferiores à conversão obtida no ensaio 1, onde a alimentação de acrilato de butila é feita exclusivamente pela base da coluna. Para os ensaios com alimentação lateral, a quantidade de acrilato de butila incorporada ao produto na primeira seção passa ser menor devido à menor proporção deste monômero presente na corrente de alimentação feita na base da coluna. Desse modo, esse procedimento operacional contribui para a maior homogeneidade do produto e a composição inicial obtida é maior que a composição resultante do ensaio anterior, sem a adição lateral de monômero. 


\subsubsection{Ensaios 4 e 5.}

Os ensaios 4 e 5 foram realizados empregando-se a alimentação nos pontos representados na figura 5.23, ou seja, a vazão de alimentação de acrilato de butila foi dividida em um terço na primeira seção, um terço na terceira seção e um terço na quarta seção. Em relação aos ensaios 2 e 3, verifica-se que a maior taxa de conversão e o conseqüente aumento de temperatura se deslocam para locais mais próximos ao final da primeira seção da coluna onde as concentrações de BuA são mais baixas que nos ensaios anteriores.

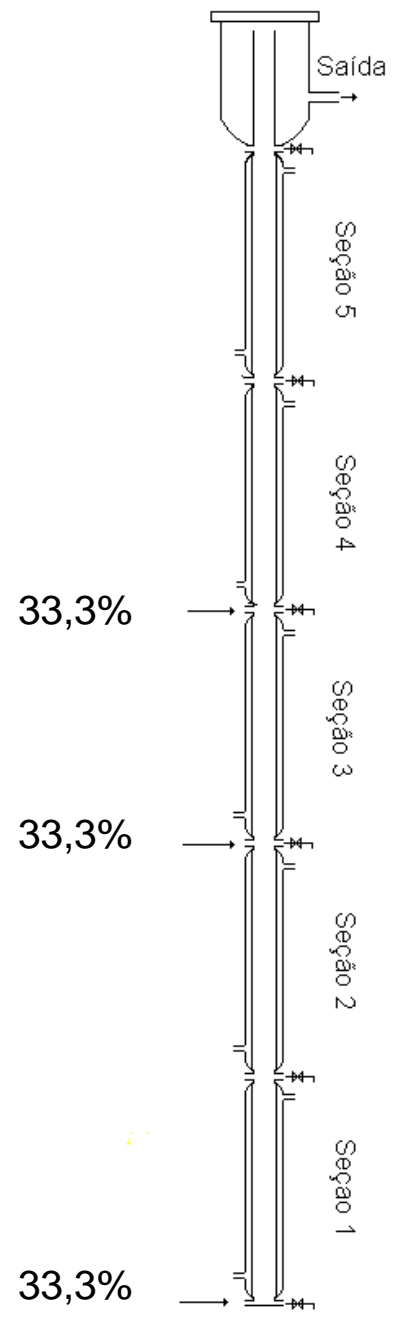

Figura 5.23 - Distribuição das alimentações laterais de acrilato de butila usada nos ensaios 4 e 5. 

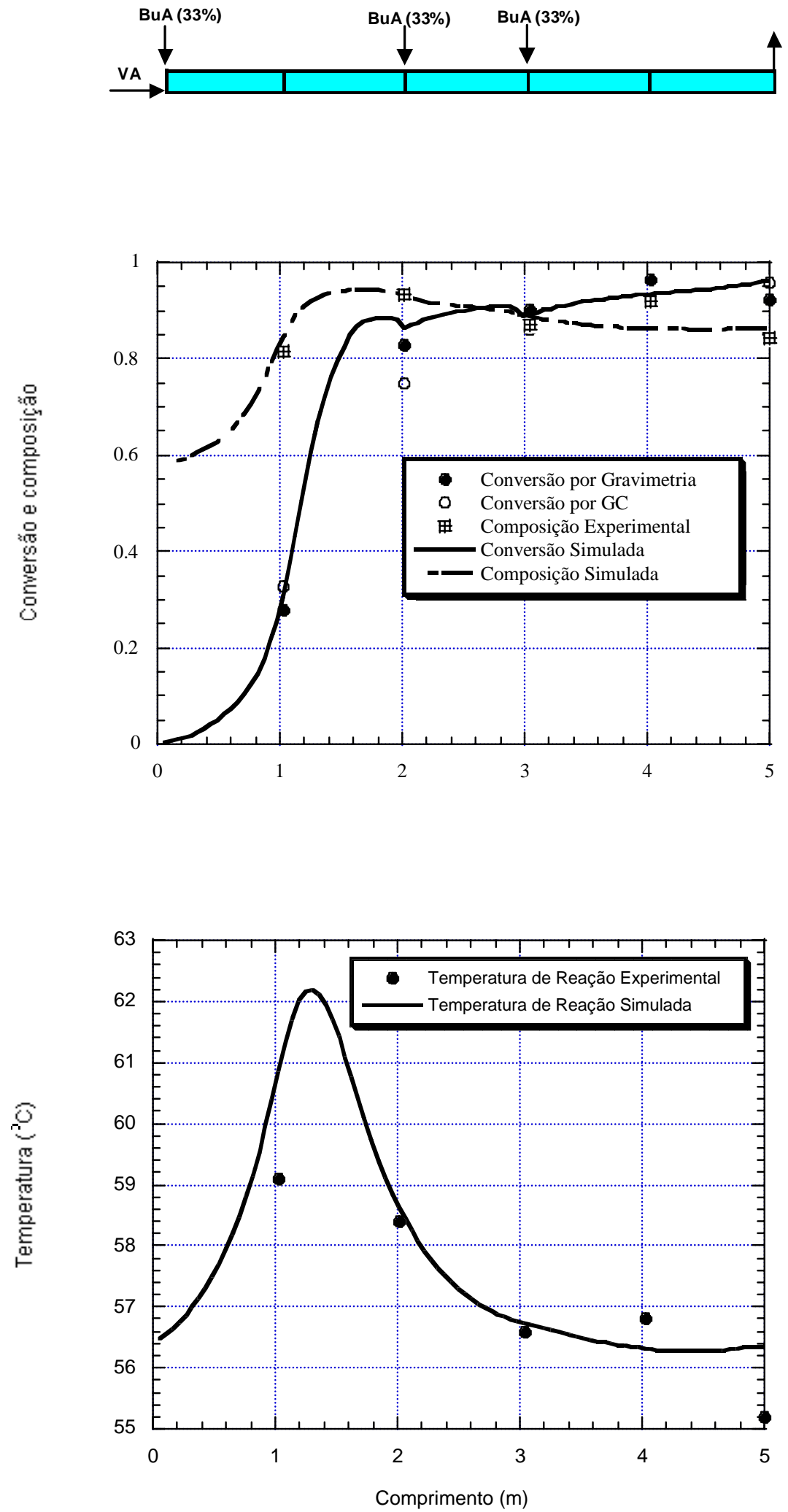

Figura 5.24 - Dados experimentais e resultados da simulação para o ensaio 4. 

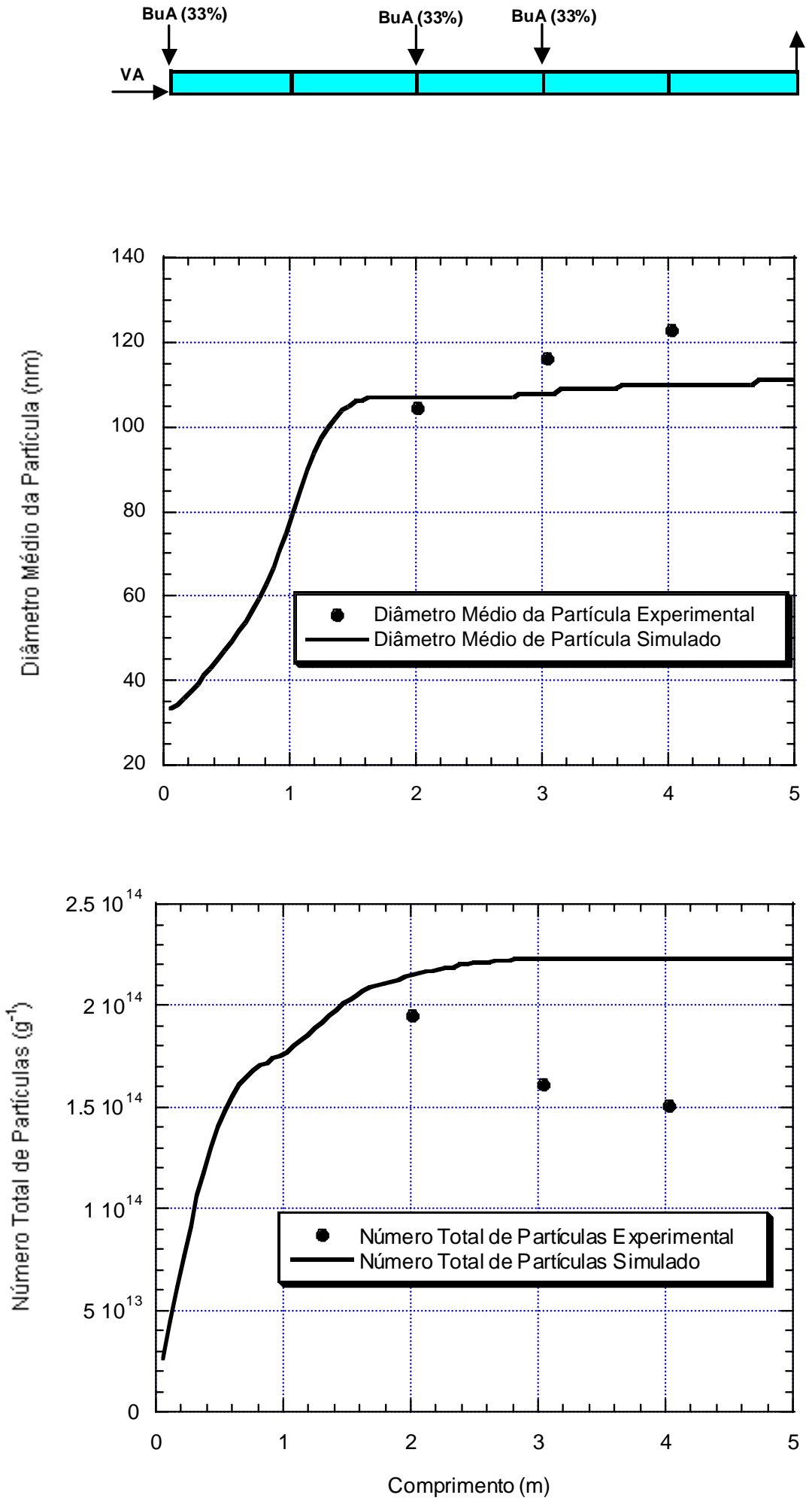

Figura 5.25 - Dados experimentais e resultados da simulação para o ensaio 4. 

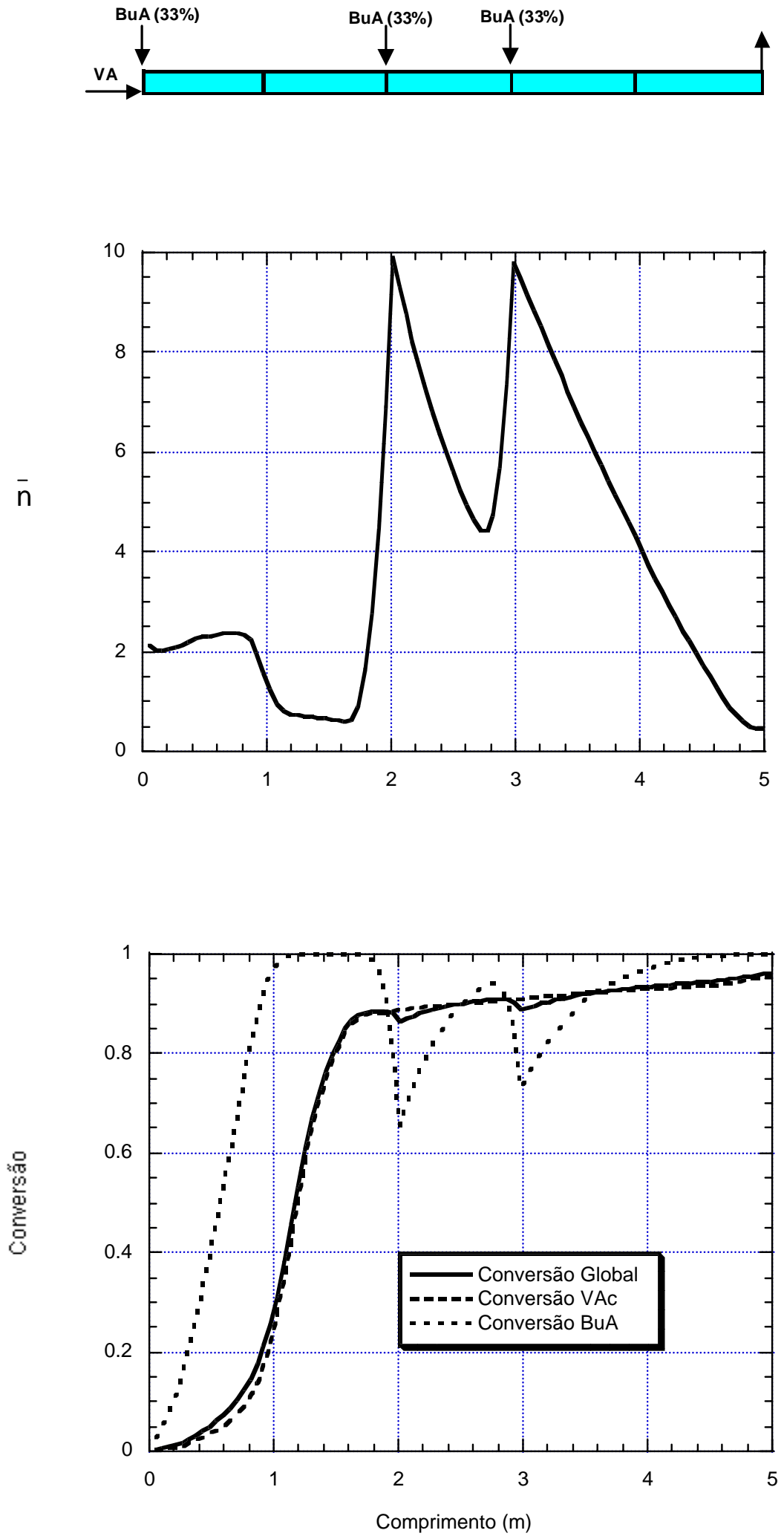

Figura 5.26 - Resultados da simulação para o ensaio 4. 

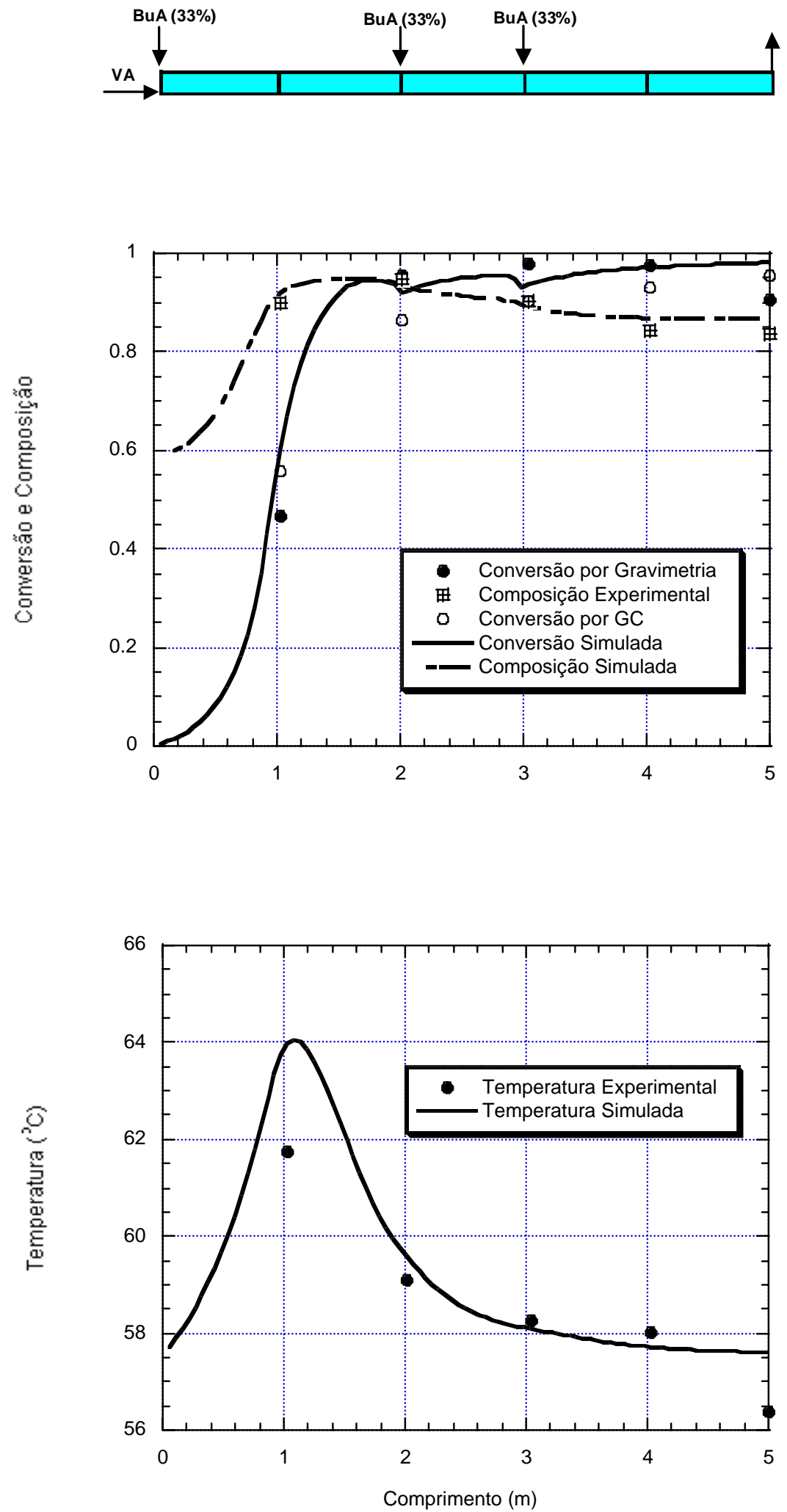

Figura 5.27 - Dados experimentais e resultados da simulação para o ensaio 5. 

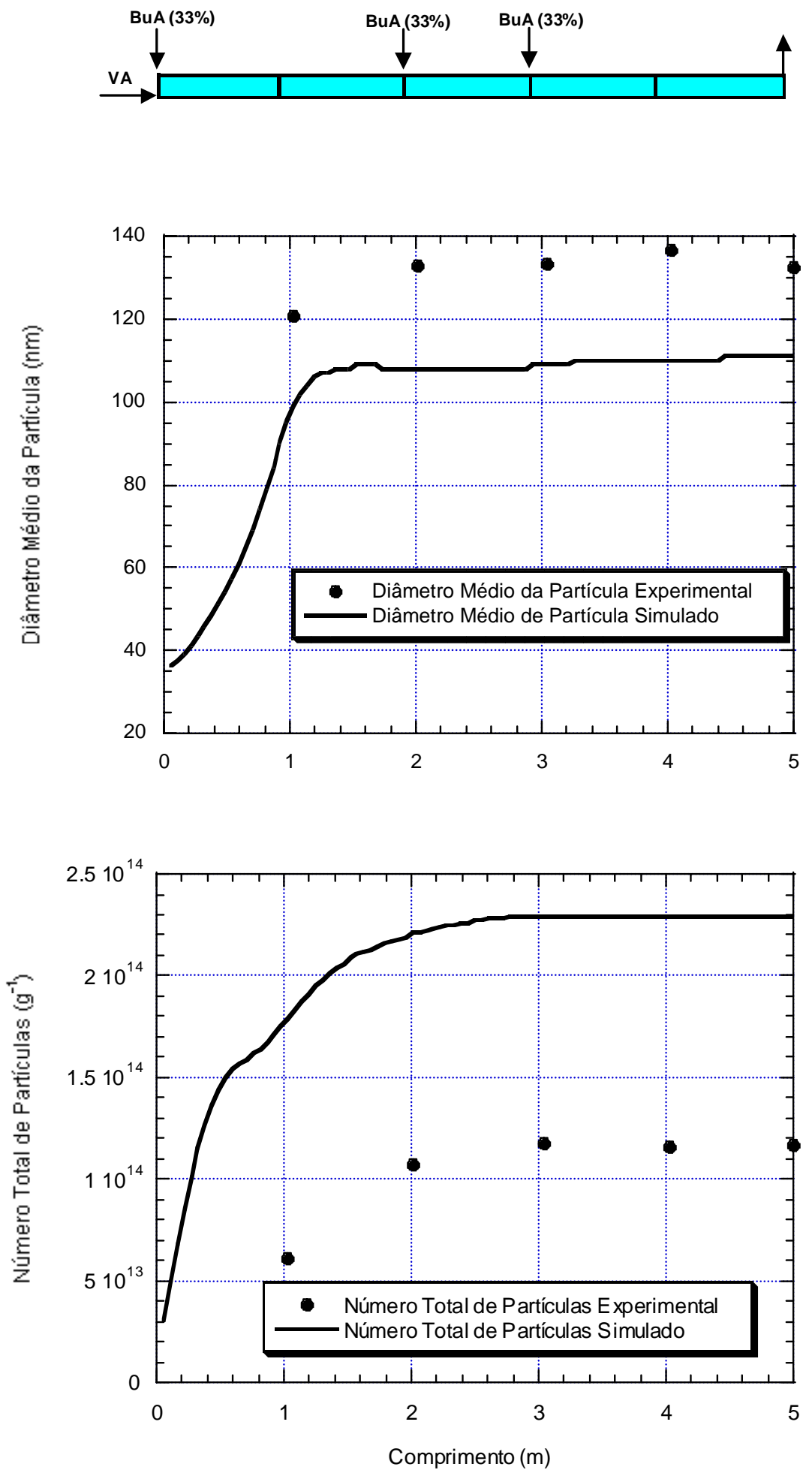

Figura 5.28 - Dados experimentais e resultados da simulação para o ensaio 5. 

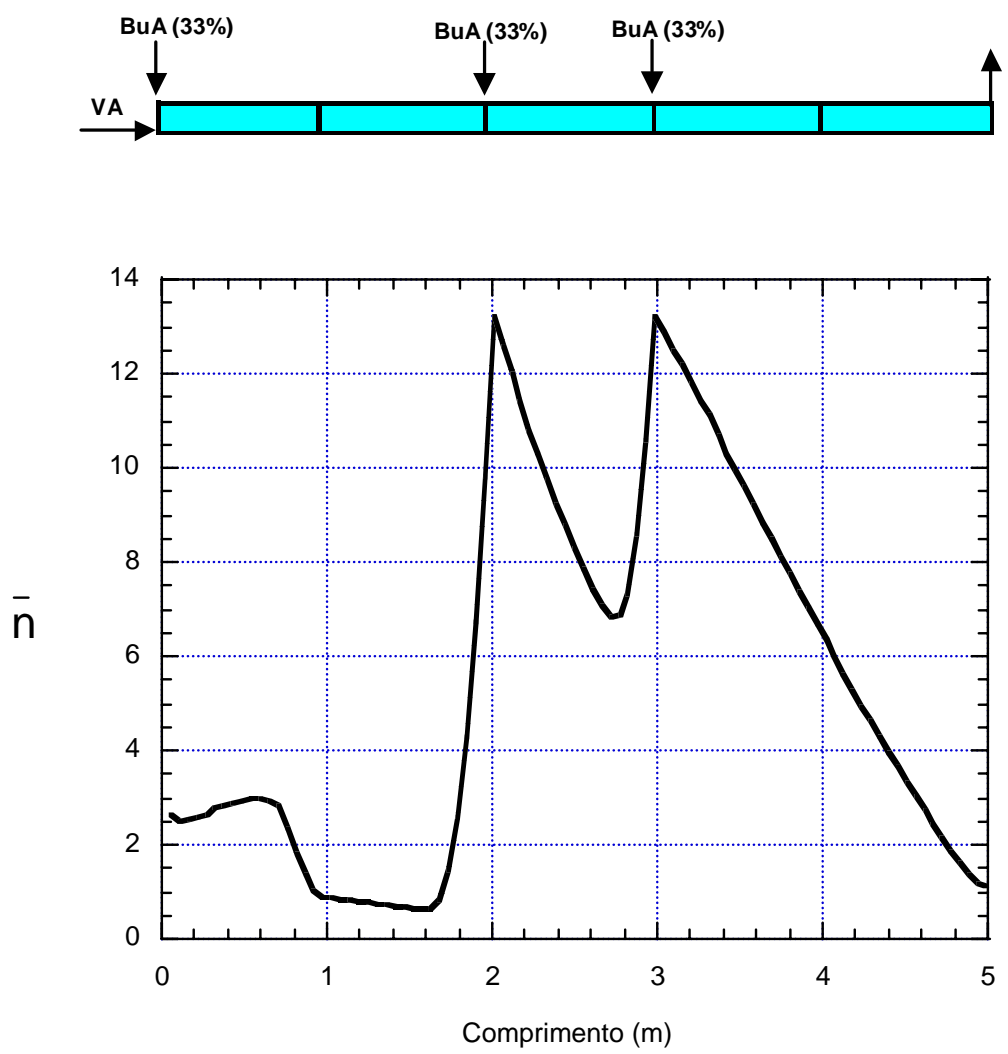

Figura 5.29 - Resultados da simulação para o ensaio 5.

A comparação entre estes dois ensaios mostra uma evidente influência da temperatura da reação sobre a taxa de reação obtida. No ensaio 5, uma pequena diferença de $1,5^{\circ} \mathrm{C}$ na temperatura da camisa do reator em relação ao ensaio anterior é o suficiente para elevar consideravelmente o consumo de monômero nas duas primeiras seções da coluna, alcançando valores de conversão no final da segunda seção próximos aos obtidos no topo da coluna. Este aumento na taxa de conversão devido ao incremento na temperatura das camisas ocorre principalmente na região onde a concentração de VAc é maior.

Os resultados simulados tiveram em geral boa concordância com os resultados experimentais com desvios maiores para o tamanho de partícula (e número de partículas) no ensaio 5. Os resultados obtidos de conversão, de composição e do número médio de radicais por partícula concordam com o comportamento esperado. As 
maiores concentrações de radicais livres por partícula ocorrem também nas regiões da coluna correspondentes à adição lateral de BuA. Verifica-se também a mesma sensibilidade dos resultados experimentais obtidos para o número de partículas por grama de látex da mesma forma que nos ensaios anteriores. Os valores obtidos de temperatura de reação, de conversão e composição acompanham a tendência prevista para o deslocamento dos pontos de alimentação de BuA.

Da mesma forma que nos ensaios 2 e 3, os resultados das simulações mostram que a diferença de temperatura do meio reacional entre os ensaios 3 e 4 também causou uma diferença acentuada no número de radicais livres por partícula nos pontos de adição lateral de monômero. Esse fato também indica que há uma influência diferenciada do aumento da temperatura sobre as taxas de entrada e saída dos radicais livres nas partículas. Também em relação aos ensaios 2 e 3, verifica-se que não há reprodutibilidade entre o número total de partículas medido entre os ensaios 4 e 5 , diferentemente dos resultados do modelo que, neste caso, fornece previsões similares para os ensaios 4 e 5 . Os motivos pelos quais isso acontece podem ser os mesmos que os dos ensaios 2 e 3. 


\subsubsection{Ensaio 6}

O ensaio 6 apresenta 3 alimentações laterais, tal como está descrito na figura 5.30. Nos resultados apresentados nas Figuras 5.31. a 5.33 pode-se verificar uma diminuição na deriva de composição em decorrência da maior distribuição de BuA ao longo da coluna.

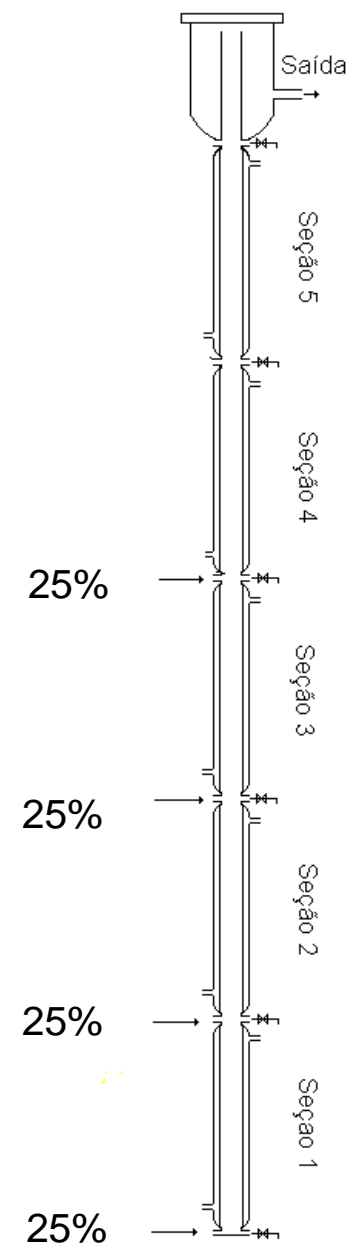

Figura 5.30 - Distribuição das alimentações laterais de acrilato de butila usada no ensaio 6. 

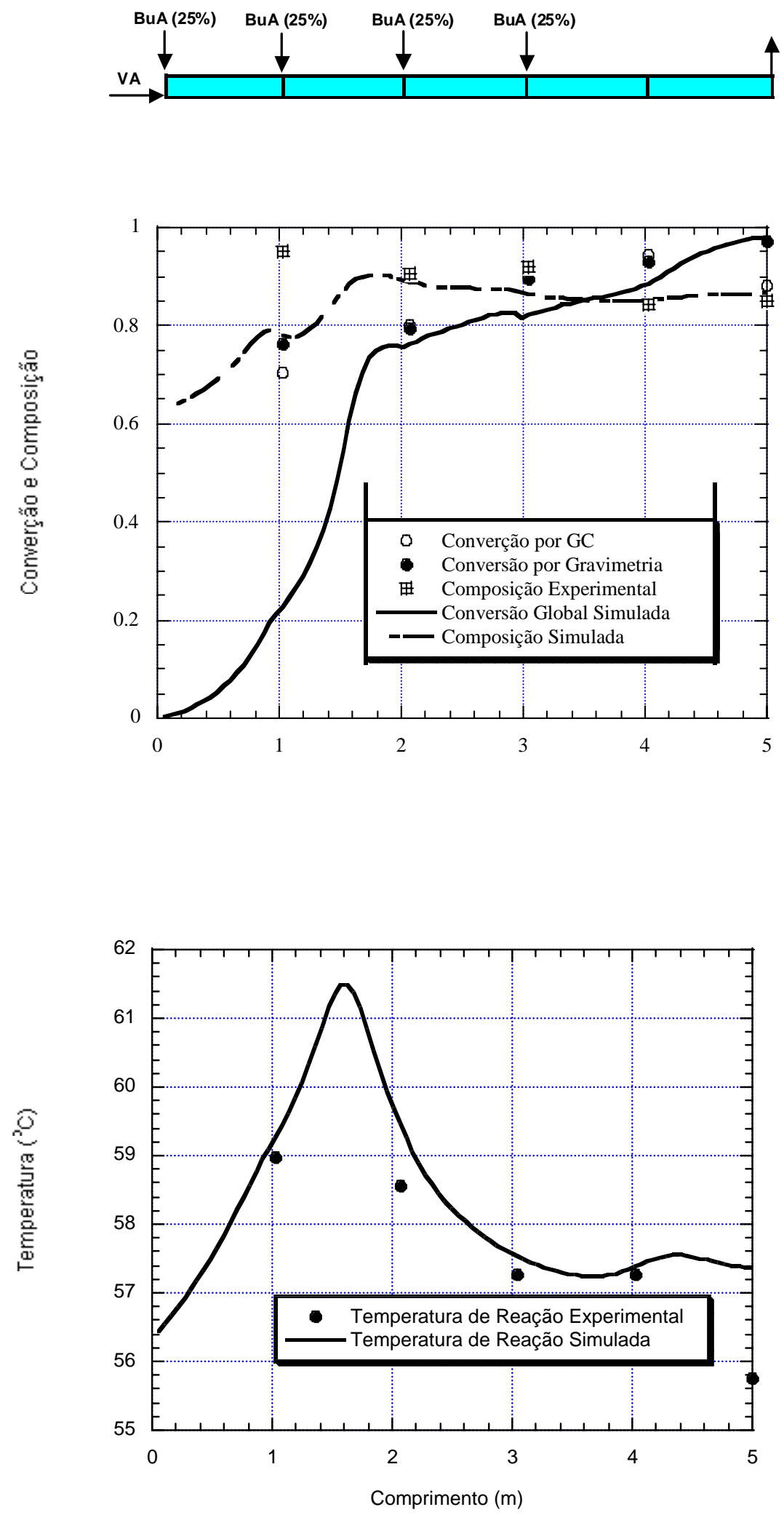

Figura 5.31 - Dados experimentais e resultados da simulação para o ensaio 6. 

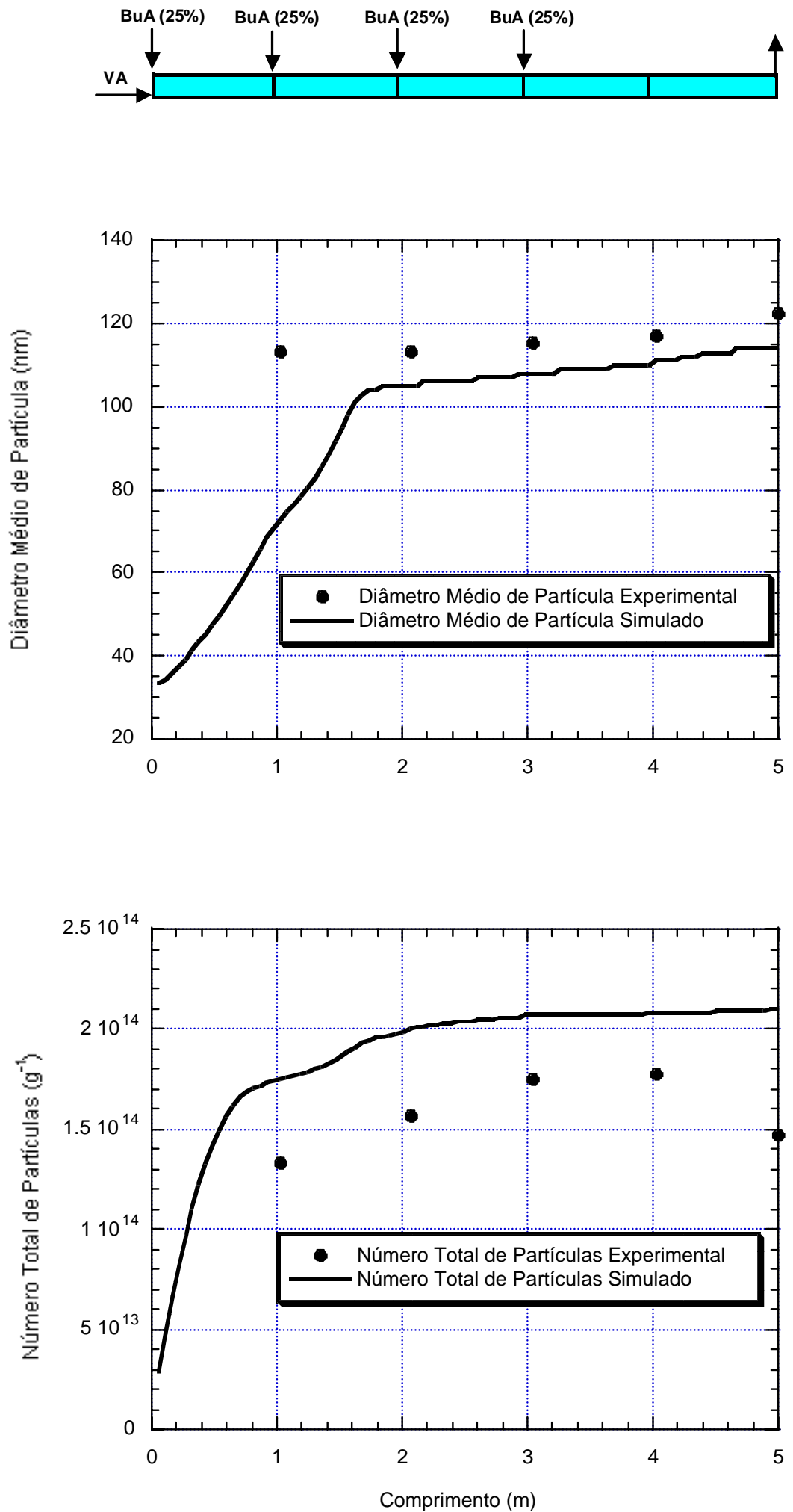

Figura 5.32 - Dados experimentais e resultados da simulação para o ensaio 6. 

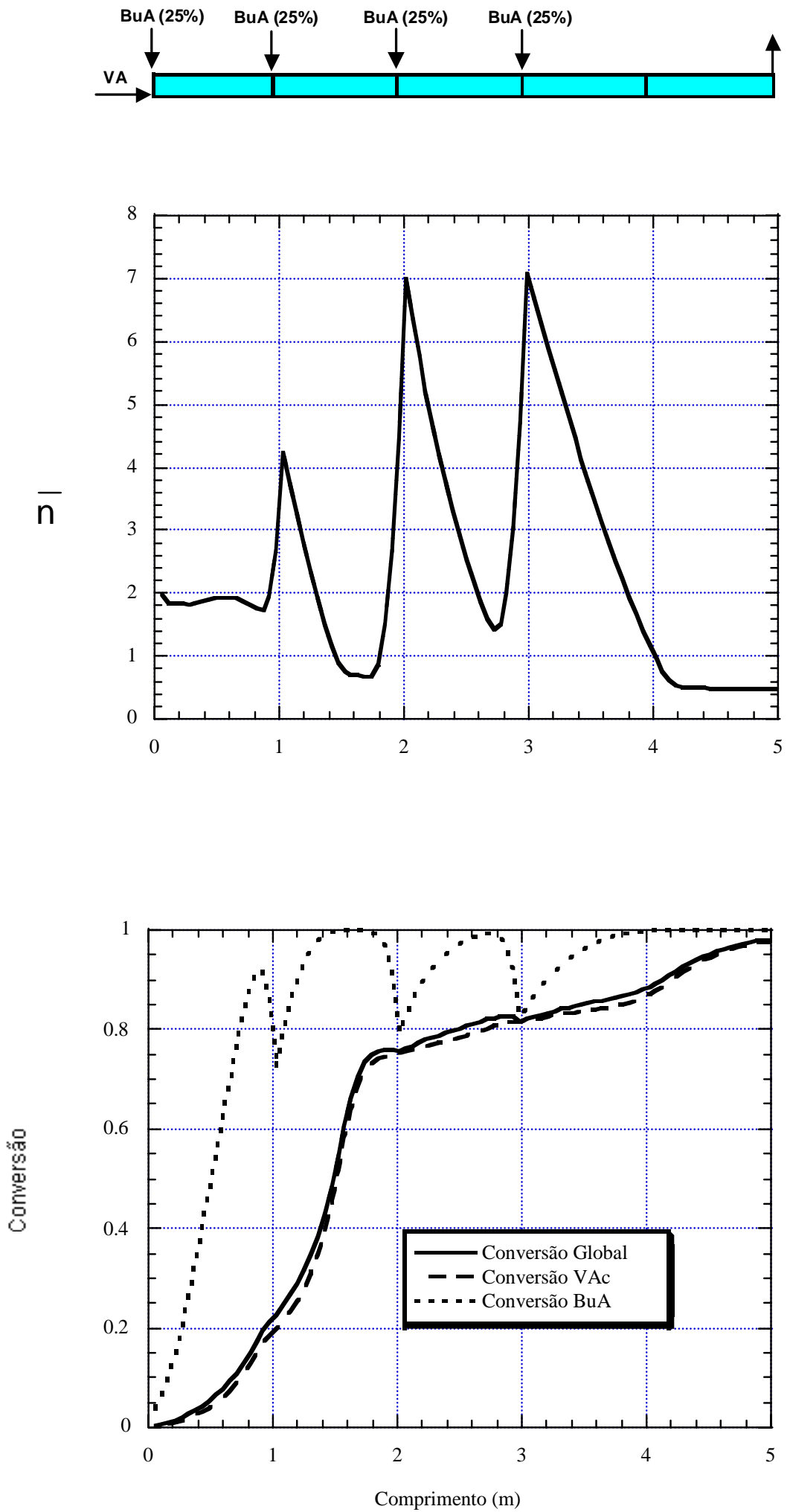

Figura 5.33 - Resultados da simulação para o ensaio 6 
Conforme a mesma tendência dos ensaios anteriores, no ensaio 6 há boa concordância entre os resultados experimentais e os resultados obtidos através da simulação do modelo, exceto pelos dados de conversão e composição medidos no final da primeira seção.

Neste ensaio, a diminuição da deriva na composição também segue acompanhada de uma diminuição na velocidade da reação nos pontos de adição de BuA. Por ser o comonômero mais reativo da reação, o acrilato de butila tende a reagir preferencialmente favorecendo a formação de radicais com terminal tipo BuA. Neste caso, a constante de homopolimerização do BuA é mais baixa que a constante de propagação de homopolimerização do acetato de vinila. Por isso, há uma diminuição da velocidade global de reação enquanto a maior parte de BuA não tiver sido consumida no meio reacional. Também pode-se notar pelos resultados da simulação que os efeitos da adição de acrilato de butila começam a ser verificados em pontos ligeiramente anteriores aos das alimentações laterais devido ao efeito da dispersão axial. Esse efeito causado pela dispersão axial pode ser verificado, por exemplo, no gráfico 5.33 que representa a evolução do número médio de radicais por partícula. 


\subsubsection{Ensaios 7 e 8.}

A alimentação lateral dos ensaios 7 e 8 está representada na figura 5.34. Os resultados demonstram a diminuição da deriva de composição com o aumento do número de alimentações equitativas de BuA confirmando a tendência dos resultados anteriores e as previsões das simulações apresentadas anteriormente.

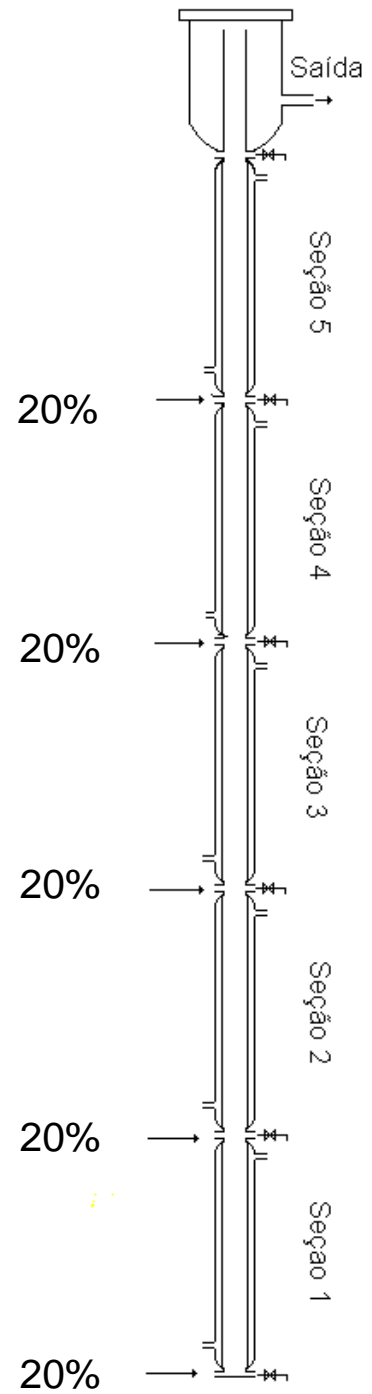

Figura 5.34 - Distribuição das alimentações laterais de acrilato de butila usada nos ensaios 7 e 8. 

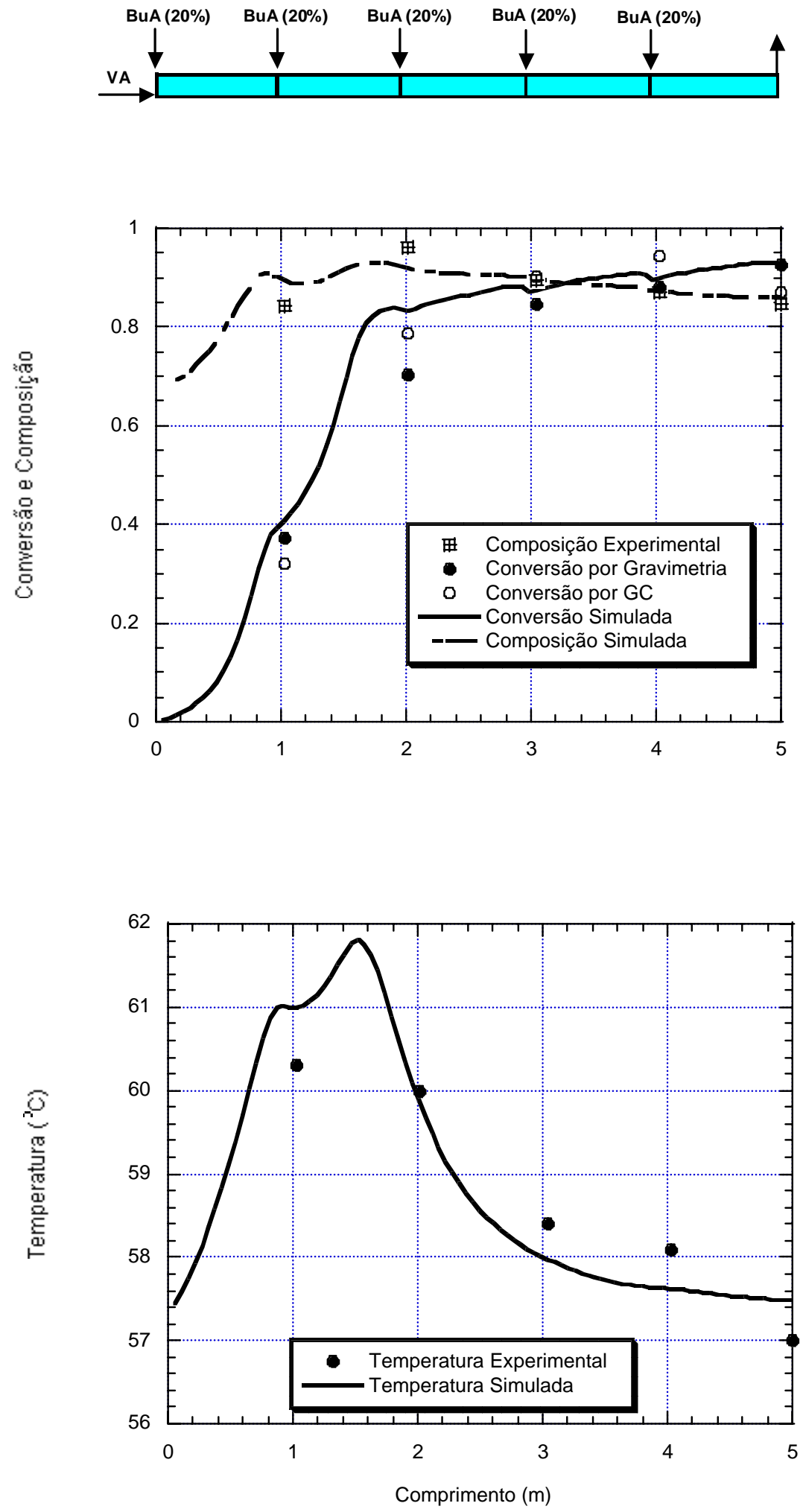

Figura 5.35 - Dados experimentais e resultados da simulação para o ensaio 7. 

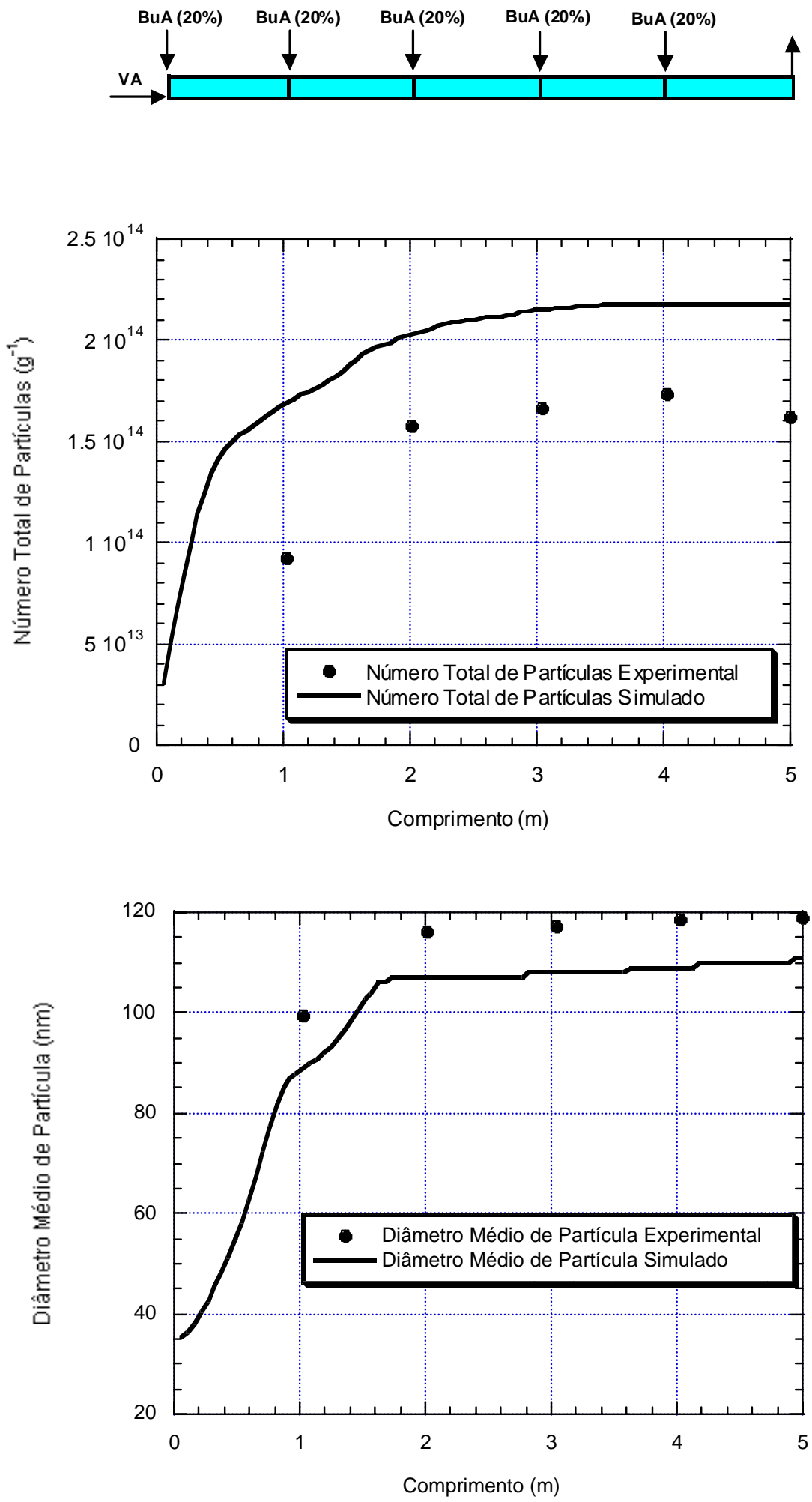

Figura 5.36 - Dados experimentais e resultados da simulação para o ensaio 7. 

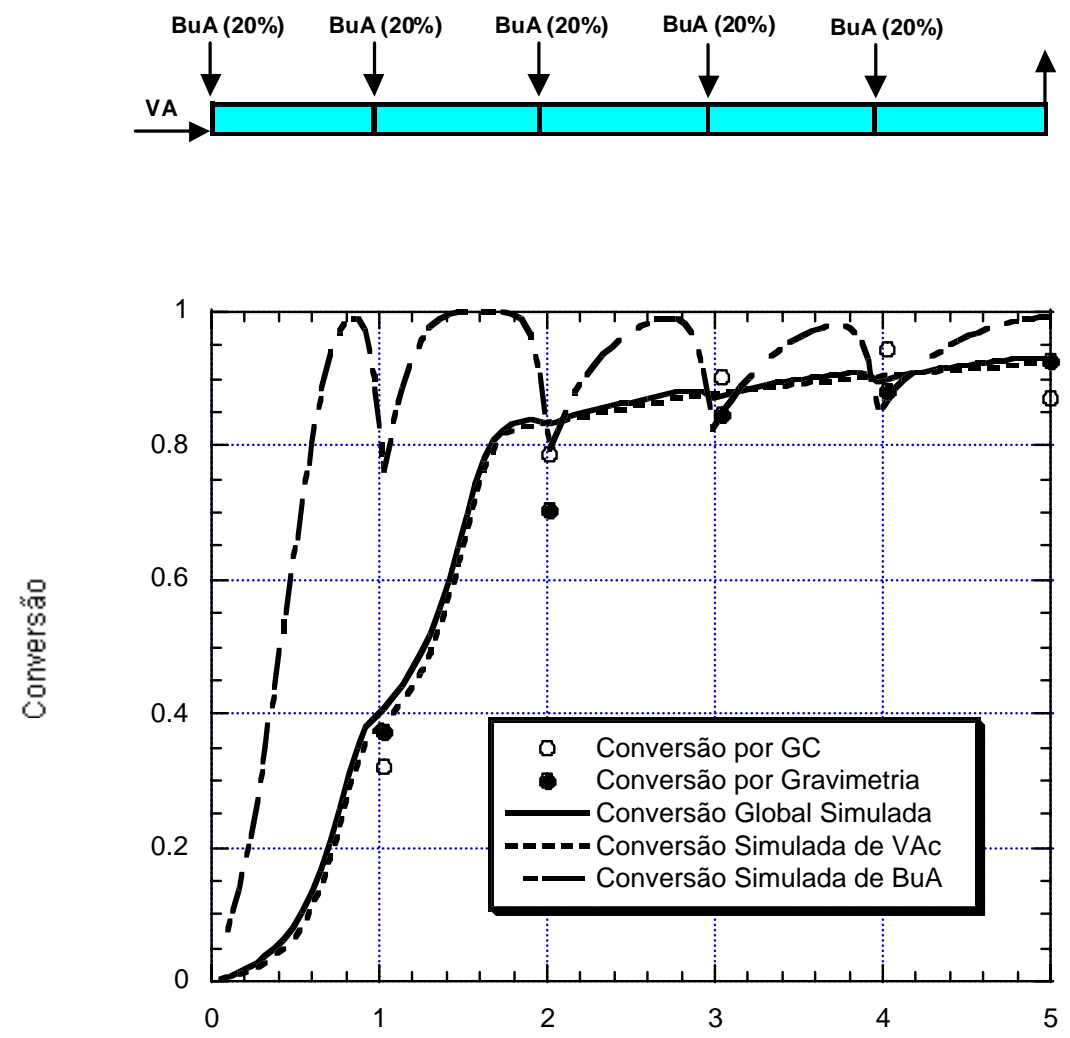

Figura 5.37 - Dados experimentais e resultados da simulação para o ensaio 7. 

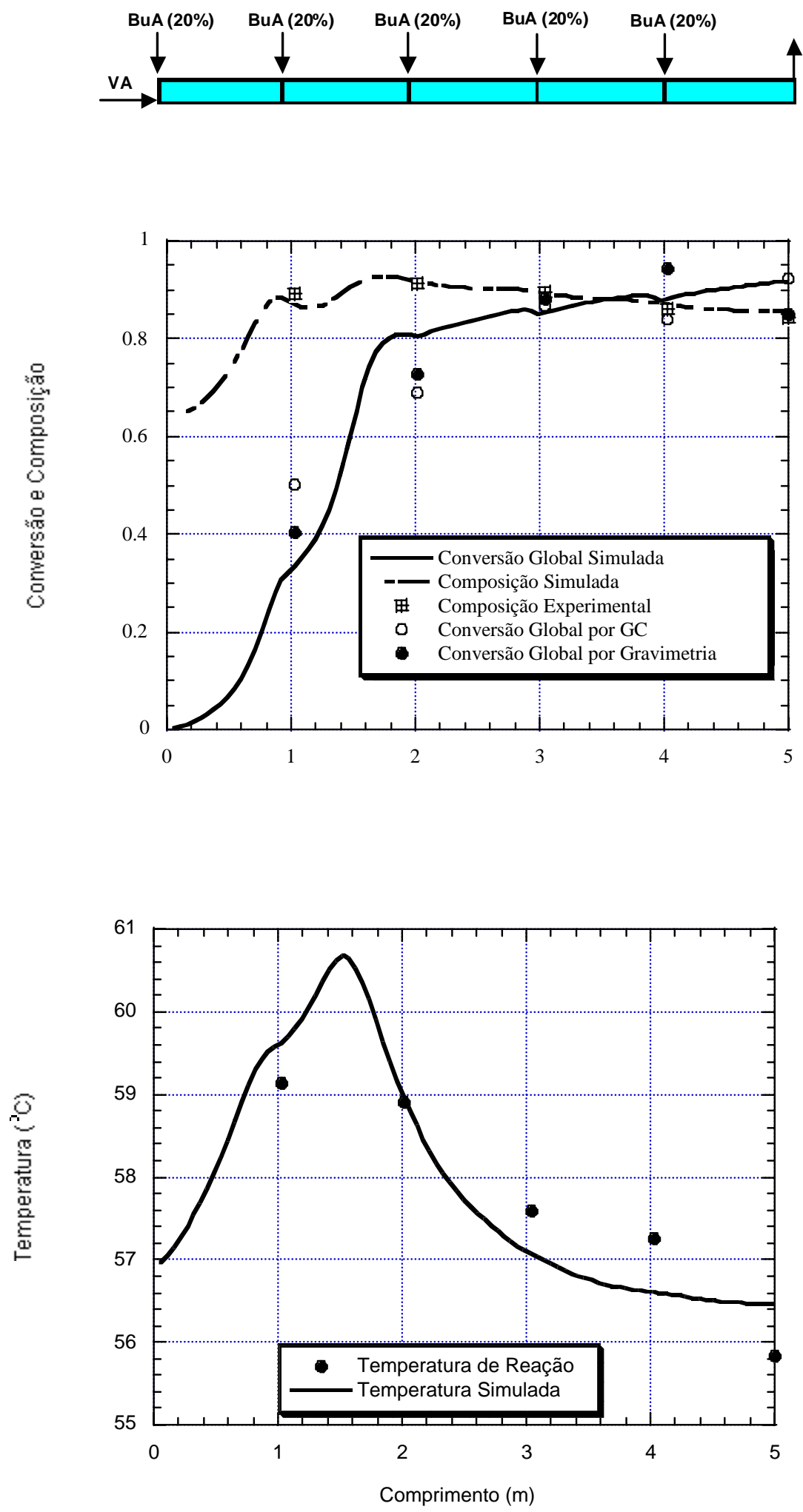

Figura 5.38 - Dados experimentais e resultados da simulação para o ensaio 8 

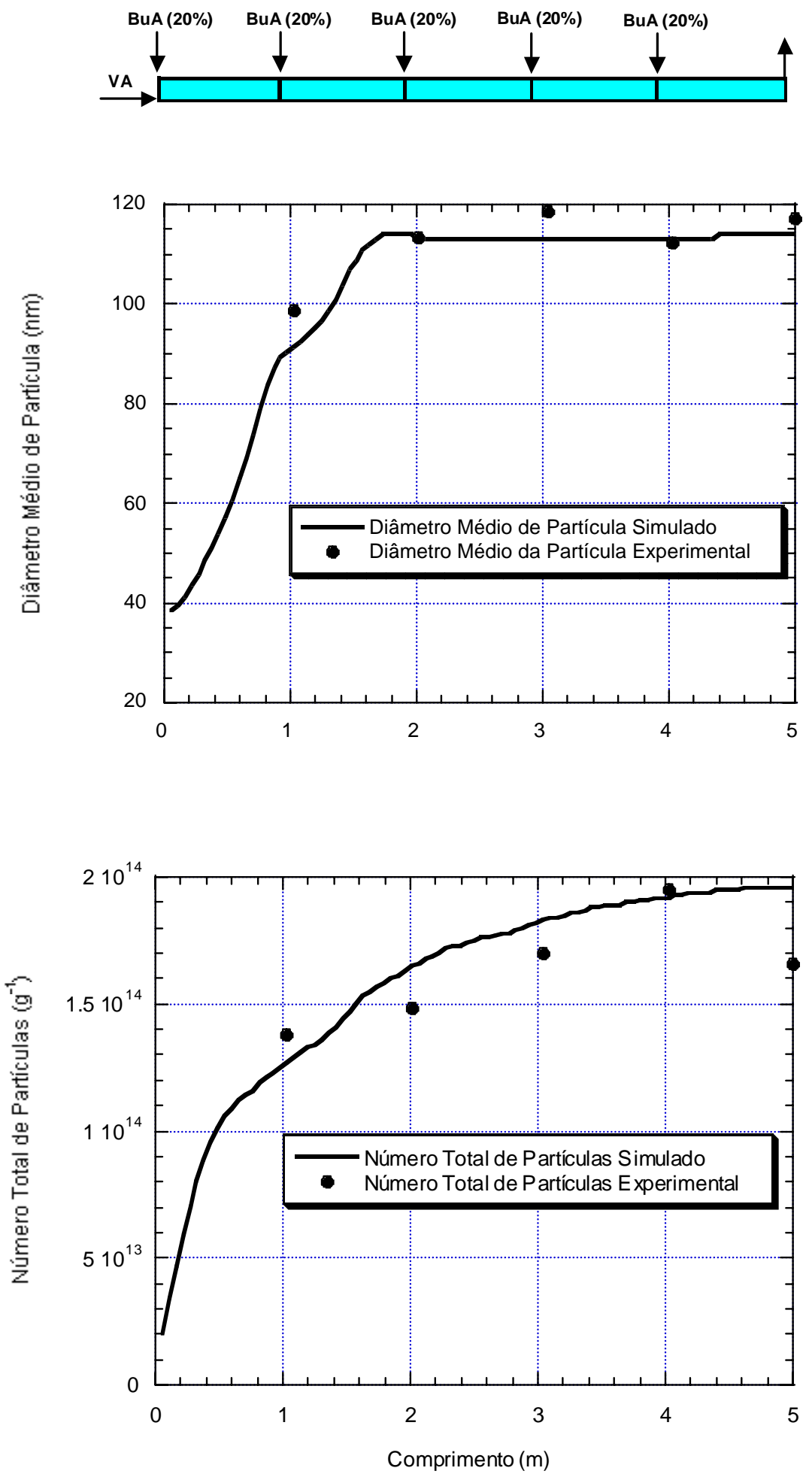

Figura 5.39 - Dados experimentais e resultados da simulação para o ensaio 8. 

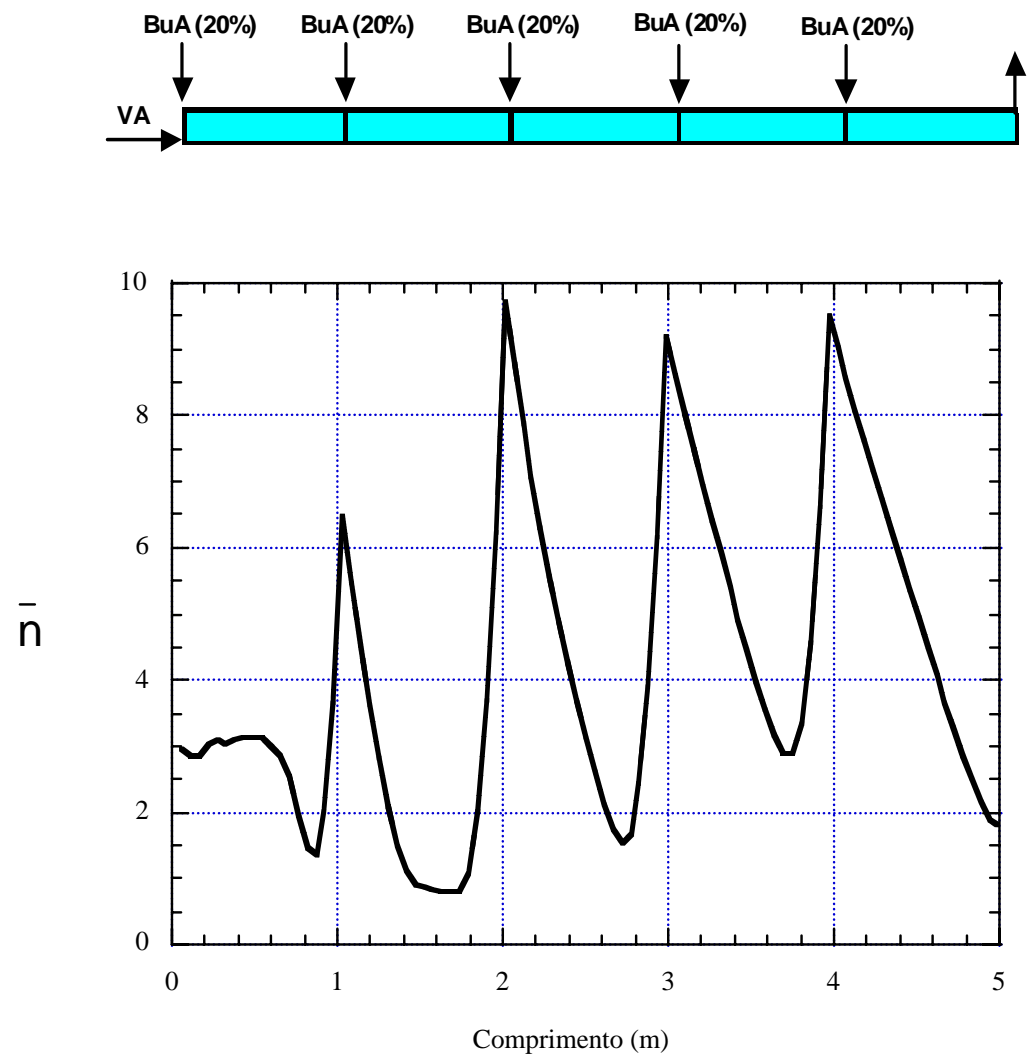

Figura 5.40 - Resultados da simulação para o ensaio 8.

Para estes ensaios foram utilizadas quatro alimentações laterais com vazões iguais e equivalentes a $20 \%$ do total de acrilato de butila alimentado no processo. Conforme esperado, a evolução do diâmetro das partículas acompanha o aumento da conversão da reação. Além disso, verifica-se também a reprodutibilidade dos resultados obtidos em ambos ensaios. Ao contrário do par de ensaios 4 e 5, o efeito da pequena diferença de temperatura da camisa $\left(1,2{ }^{\circ} \mathrm{C}\right)$ entre os dois ensaios 7 e 8 afetou um pouco menos a velocidade da reação. Neste último caso, a concentração de BuA nas duas primeiras seções foi maior que nos ensaios 4 e 5 . Essas condições reduziram a velocidade da reação e amorteceram o efeito da temperatura da camisa sobre a cinética da reação nestas mesmas seções. 


\subsubsection{Ensaios 9 e 10}

Os ensaios 9 e 10 apresentam o perfil ótimo de alimentações laterais, tal como está descrito na figura 5.41. Nos resultados apresentados a seguir são verificadas as previsões das condições ótimas determinadas pela simulação do modelo matemático.

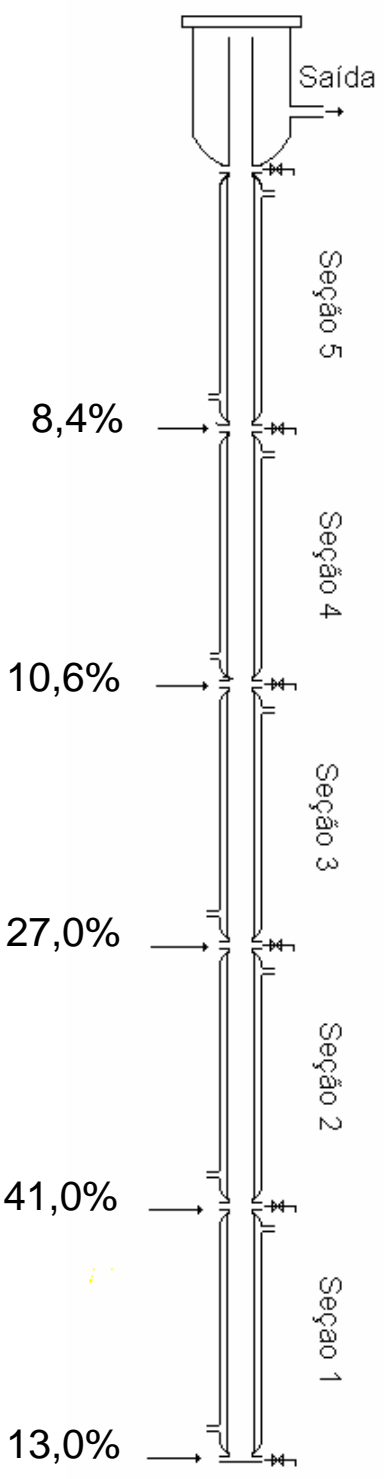

Figura 5.41 - Distribuição das alimentações laterais de acrilato de butila usada nos ensaios 9 e 10.

Para a determinação das condições "ótimas" de alimentação destes dois ensaios, a partir do modelo matemático, foram incluídas equações de um controlador PID ao 
modelo matemático que representa o processo na coluna. A finalidade deste controlador foi o de atuar sobre todas as vazões do monômero mais reativo. Para esse caso, a variável de controle é a composição do copolímero formado no final de cada seção e o set-point para os valores controlados equivale a 0,85 em fração mássica de VAc (que é a composição global da formulação).

Desse modo, as composições no final de cada seção da coluna devem ser praticamente iguais uma vez que as condições de controle tiverem sido alcançadas. $\mathrm{O}$ controle das vazões também atua de modo a manter a soma de todas as vazões igual ao valor da vazão total de acrilato de butila que foi estabelecido para o processo. A equação utilizada no modelo matemático do controlador são as seguintes:

$$
\Delta \mathrm{F}=\mathrm{kc}\left[\left(\mathrm{x}_{\mathrm{sp}}-\mathrm{x}_{\mathrm{BuA}}\right)+\frac{1}{\tau_{\mathrm{I}}} \int\left(\mathrm{x}_{\mathrm{sp}}-\mathrm{x}_{\mathrm{BuA}}\right) \mathrm{dt}+\tau_{\delta} \frac{\mathrm{d}\left(\mathrm{x}_{\mathrm{sp}}-\mathrm{x}_{\mathrm{BuA}}\right)}{\mathrm{dt}}\right]
$$

onde,

- $\Delta \mathrm{F}$ é a variação da vazão de monômero a cada passo de atuação do controlador para uma determinada seção da coluna;

- $\quad$ kc é a constante de proporcionalidade do controlador;

- $\quad \mathrm{X}_{\mathrm{BuA}}, \mathrm{X}_{\mathrm{sp}}$ são respectivamente o valor da composição de BuA medido a cada passo de atuação, no ponto de amostragem de uma dada seção, e o correspondente setpoint para ajuste dessa composição;

- $\tau_{\mathrm{I}}, \tau_{\delta}$ são respectivamente as constantes de tempo integral e derivativo do controlador.

Os dados das vazões ajustados quando a simulação do processo alcança o regime permanente, no qual as concentrações estabelecidas são alcançadas no final de cada seção, definem o perfil "ótimo" de alimentações laterais da coluna. Este procedimento força uma composição uniforme do copolímero ao longo da coluna (mais especificamente nos finais de cada seção), mas não garante uma conversão completa dos monômeros ao final do reator. 
O motivo de usar este procedimento simplificado para obter o perfil "ótimo" de alimentação foi o de evitar um problema convencional de otimização (composto por uma ou mais funções objetivo, restrições, etc.) em razão da carga computacional relativamente alta do modelo matemático. 

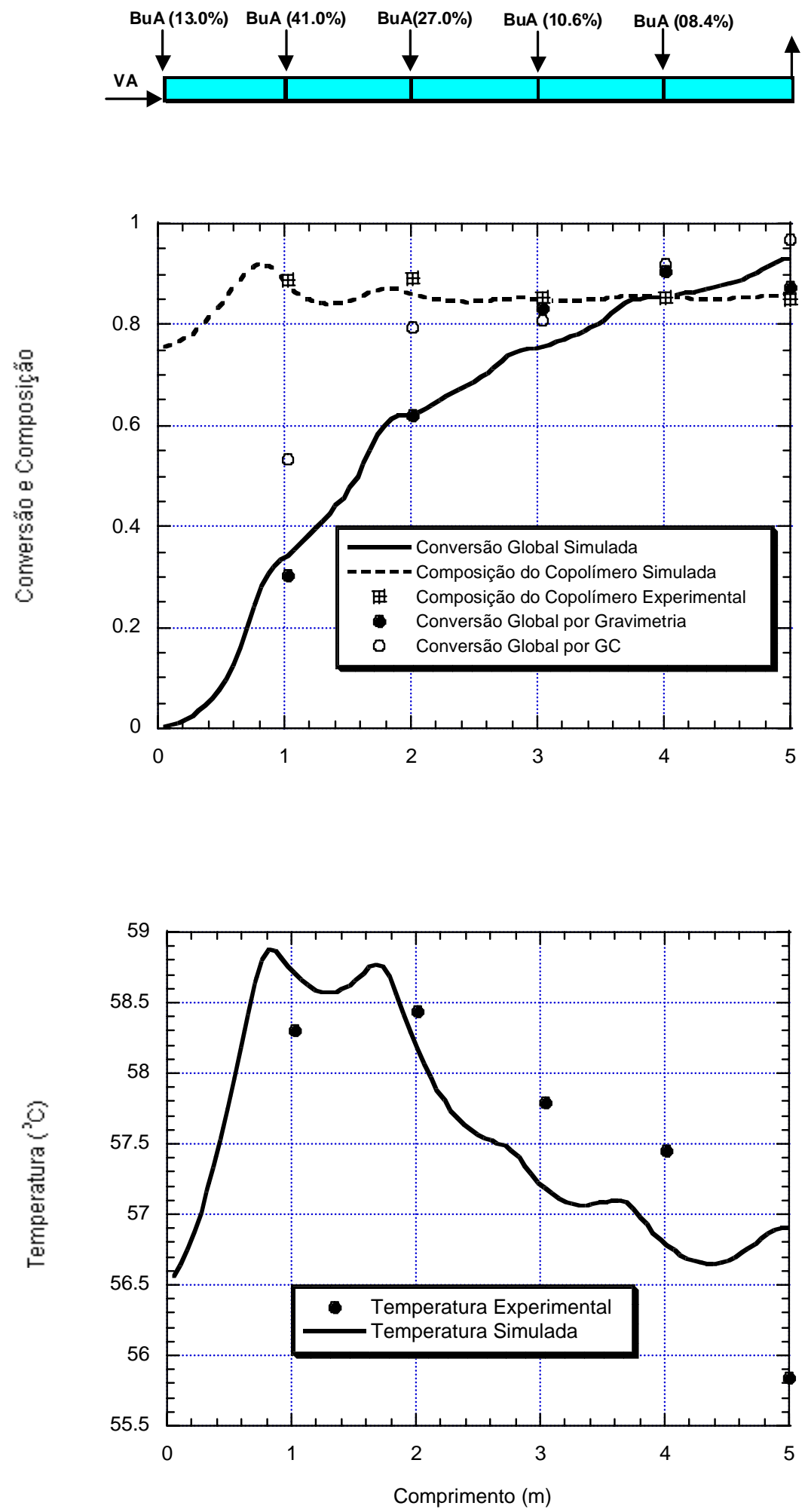

Figura 5.42 - Dados experimentais e resultados da simulação para o ensaio 9. 

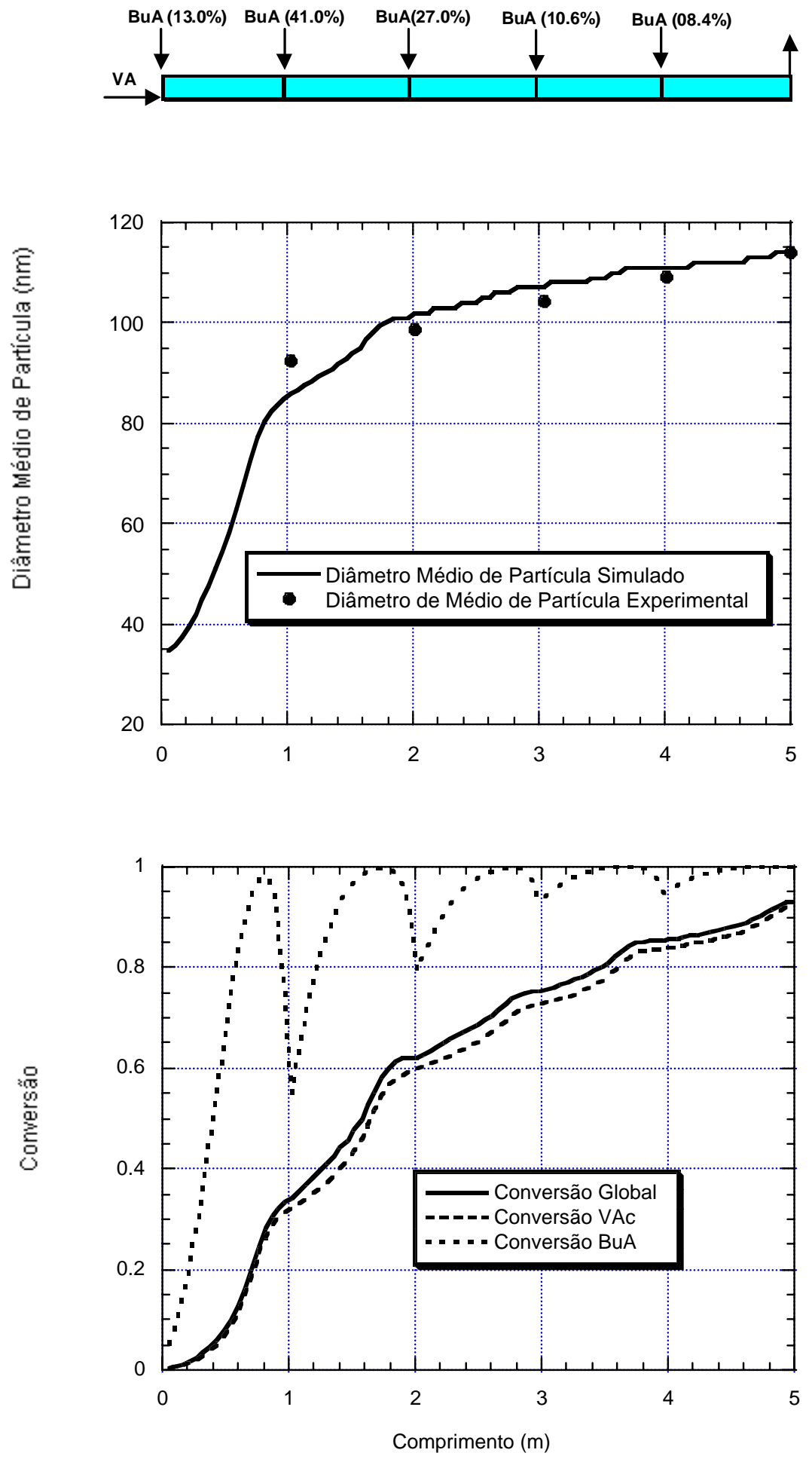

Figura 5.43 - Dados experimentais e resultados da simulação para o ensaio 9. 

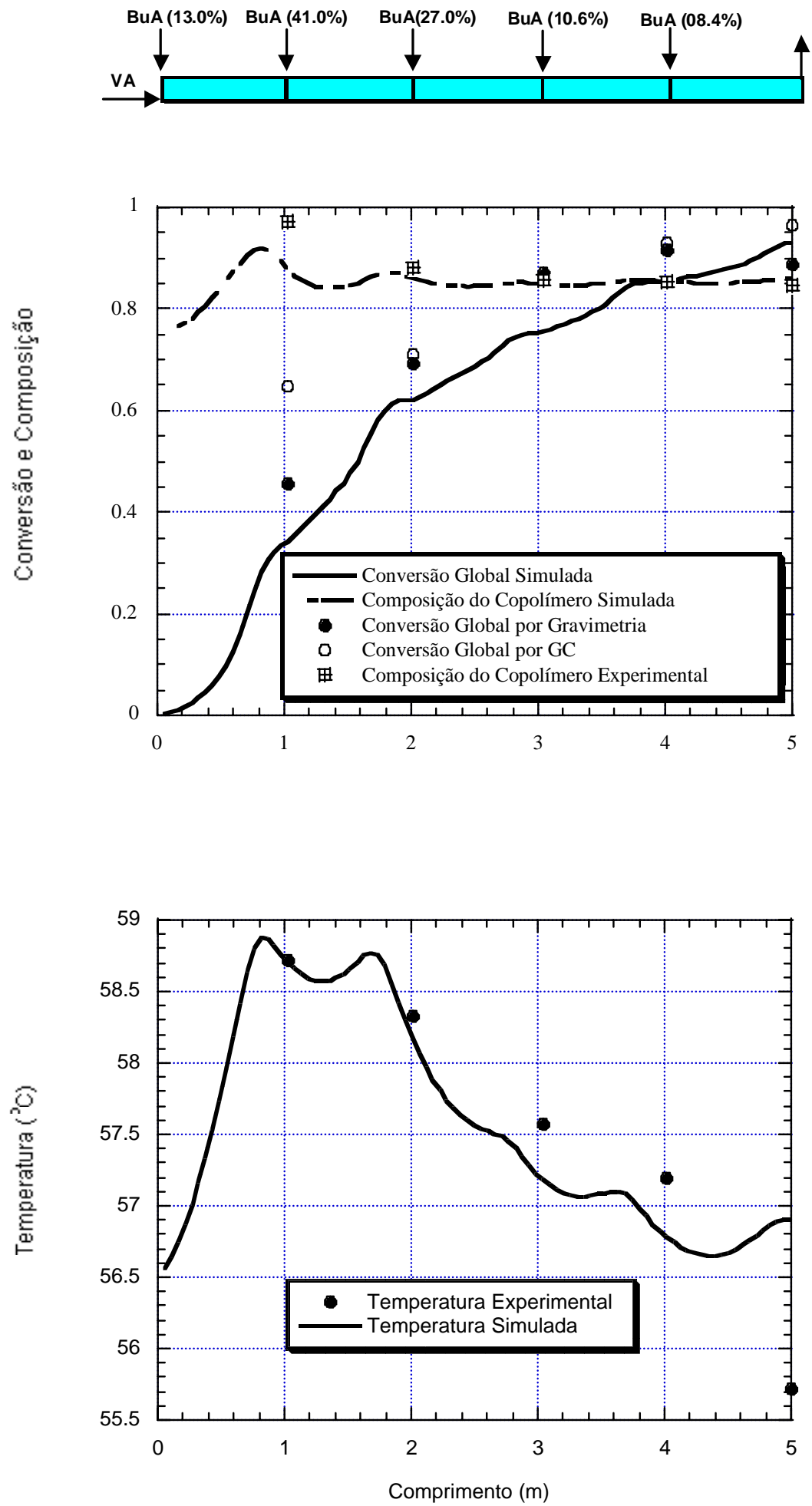

Figura 5.44 - Dados experimentais e resultados da simulação para o ensaio 10. 

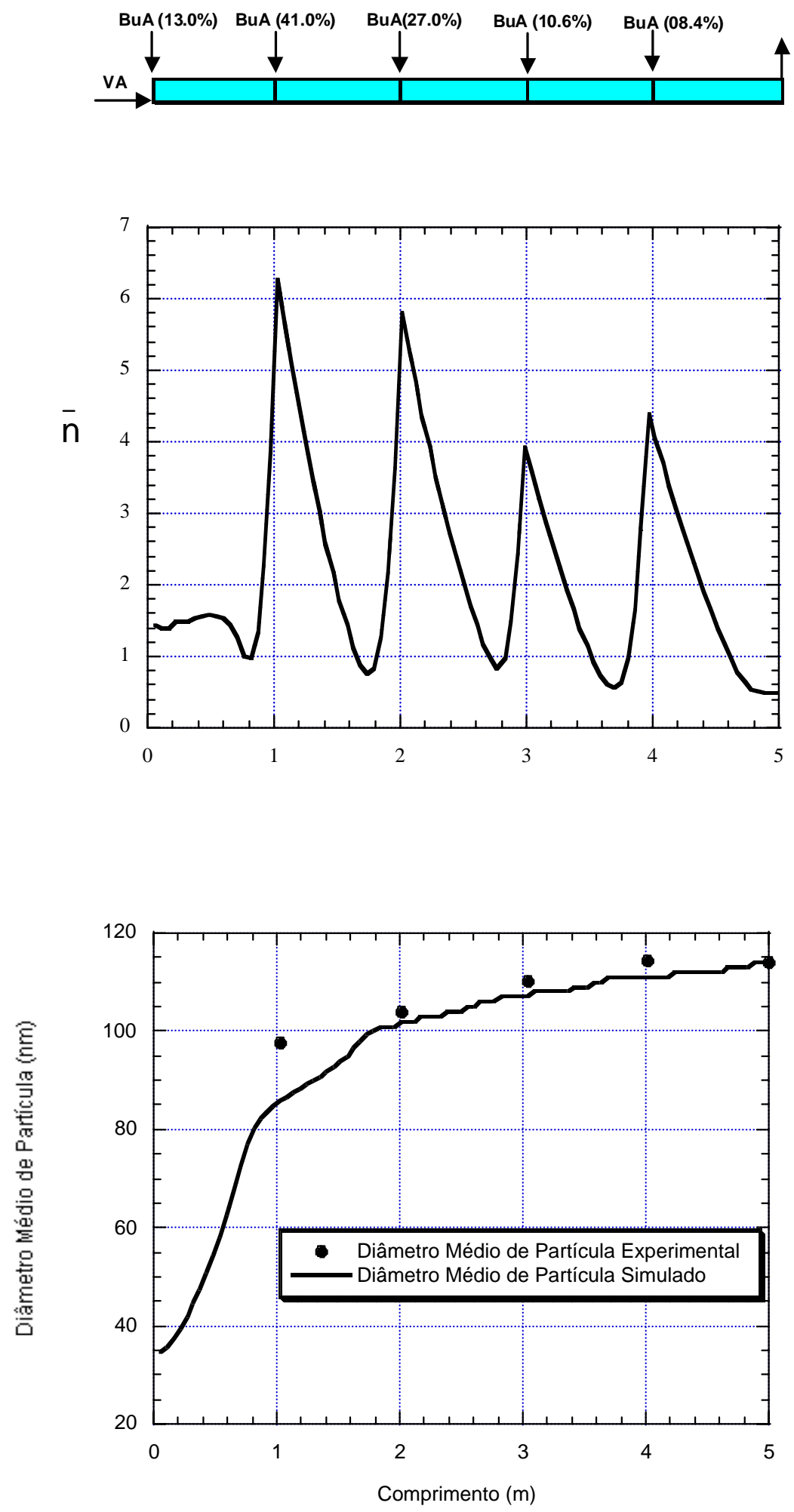

Figura 5.45 - Dados experimentais e resultados da simulação para o ensaio 10. 
As condições assim obtidas foram verificadas nestes dois últimos ensaios principalmente na composição do produto ao longo da coluna. Podemos observar a partir da comparação entre os ensaios 5, 8 e 10, que foram realizados com a mesma temperatura na camisa de resfriamento, que a conversão final do processo diminui ligeiramente com o grau de homogeneidade alcançado na composição do produto formado ao longo da altura da coluna em regime permanente. Portanto, existe um compromisso entre os objetivos estabelecidos para o grau de conversão e o grau de homogeneidade da composição a serem alcançados. Além disso, pode-se observar que a distribuição da alimentação do monômero mais reativo ao longo da coluna, não só constitui um fator de controle da homogeneidade do produto formado, como também pode ser uma importante variável operacional a ser utilizada para o controle da temperatura de reação.

Em regime permanente, com a temperatura da camisa de resfriamento constante, as duas primeiras seções da coluna são os locais onde é mais acentuada a variação da composição com a posição axial. Também, nestas mesmas seções está o local onde há maior taxa de produção de calor pelo meio reacional. Nessas condições, nos pontos onde ocorre maior liberação de calor de reação, um incremento adequado na adição de BuA possibilita a formação de um copolímero mais homogêneo com menor acréscimo de calor ao meio reacional. Portanto, a existência de pontos intermediários de alimentação de monômero nestas duas seções permitiria que se alcançassem resultados ainda melhores. 


\subsection{Análise das Possíveis Fontes de Imprecisão dos Resultados}

De uma forma geral, o modelo representou satisfatoriamente os resultados experimentais. No entanto, em algumas situações observaram-se desvios mais acentuados. Neste item, é apresentada uma discussão sobre as possíveis fontes de imprecisão, sejam as de caráter experimental, sejam aquelas relacionadas ao modelo matemático, mais especialmente aqueles parâmetros que foram usados (ou que poderiam ser usados) para ajuste do modelo.

As imprecisões da gravimetria (método usado para medir conversão) podem ser devidas ao tempo ou à temperatura inadequados de secagem na estufa e na pesagem. Estas imprecisões devem ser pequenas, pois o tempo e temperatura de secagem da amostra na estufa para a análise gravimétrica foi previamente determinado, e a pesagem foi feita em balança analítica. Também, outra causa de erro pode ser a taxa de reação inibida insuficientemente na amostra, a partir do momento de sua tomada do reator (é adicionado inibidor hidroquinona nas amostras para parar a polimerização na amostra). Possivelmente esta seja a fonte de imprecisão mais provável, uma vez que é no final da primeira seção, onde as taxas de polimerização são mais altas, que normalmente se verificam as maiores discrepâncias entre os resultados experimentais e os simulados. No caso dos resultados obtidos por cromatografia gasosa, além deles poderem sofrer alguma distorção a partir da inibição ineficaz da reação na amostra, há também o problema da interferência causada pela presença de gotas de monômero dispersas no meio reacional. Na emulsão convencional as gotas de monômero não são estáveis. Portanto, na amostra coletada (devido à falta da agitação) pode ocorrer a formação de um sobrenadante monomérico. Adicionalmente, especificamente no calculo da composição do copolimero experimental, assume-se que todo o monomero está no locus de polimerização, ou seja, nas partículas de polimero. Na presença de gotas de monomero, o teor de monomero A medido pelo GC não é representativo do teor de monomero A nas partículas, mas sim do teor de monômero no reator (gotas, partículas e mais uma pequena fração na fase aquosa). Para corrigir isto seria necessário calcular a partição do monômero entre as fases no cálculo dos valores 
experimentais de composição e conversão via GC. Esta possível fonte de erro também tem a sua maior probabilidade de incidência no final da primeira seção.

A determinação experimental do número de partículas por grama de látex está sujeita a duas importantes fontes de erro. A primeira é referente à sensibilidade do próprio método de cálculo, que depende da medida do diâmetro médio da partícula e da conversão. Como o valor do diâmetro precisa ser elevado ao cubo na estimativa do número de partículas, a propagação do erro sobre o diâmetro se amplifica, gerando uma maior incerteza sobre o valor do número de partículas. A segunda fonte de erro pode vir da variação de desempenho entre lotes diferentes de tensoativo.

$\mathrm{Na}$ primeira seção, onde a velocidade de reação é maior, com um aumento consecutivo de temperatura, verifica-se uma diferença sistemática entre a conversão global de monômero medida e a simulada. Os fatores que podem explicar essas discrepâncias seriam a dificuldade do método analítico em interromper a taxa de reação instantaneamente e, também, a proximidade do ponto de adição de acrilato de butila ao ponto de tomada de amostra. Neste ponto, no qual uma quantidade relativamente grande de acrilato pode ser adicionada, a mistura radial da emulsão necessita ser perfeita, tal como é assumido pelo modelo matemático empregado, de modo que não haja diferenças entre as concentrações de BuA do meio reacional da coluna e das amostras coletadas. Portanto, a adição de acrilato de butila ao meio reacional tem um efeito inibidor sobre a taxa global de reação, conforme discutido anteriormente, e uma eventual falta de homogeneidade radial do escoamento do meio, onde a reação ocorre, pode conduzir a diferenças significativas nos valores medidos de conversão e composição. Uma maneira eficaz de verificar a influência desse efeito e poder eliminá-lo seria aumentar a distância entre os pontos de adição e de amostragem.

Outro motivo que afetaria a comparação entre os resultados obtidos e simulados é a própria precisão do modelo matemático cujo grau de ajuste também depende da qualidade dos dados experimentais coletados. Neste caso, foram considerados os dados de temperatura de reação, do diâmetro e número de partículas por grama de 
látex, da conversão global de monômeros e da composição acumulada do copolímero formado. Os parâmetros do modelo que foram ajustados a fim de adequar os resultados do modelo aos dados experimentais foram os seguintes:

- razões de reatividade;

- coeficientes de partição;

- área específica coberta por emulsificante;

- eficiências de entrada de radicais da fase aquosa pelas partículas e micelas;

- eficiência de nucleação micelar;

- coeficientes de coalescência das partículas;

- Coeficiente global de troca térmica;

- Número de Peclet térmico.

Os valores destes parâmetros estão representados na tabela 4.1. Esse mesmo conjunto de valores ajustados foi utilizado na obtenção dos resultados simulados de todos os ensaios, de modo a validar o modelo matemático para todas as condições experimentais em que todos os ensaios foram realizados. Poder-se-ia forçar o modelo a aproximar-se melhor dos dados experimentais ajustando-se alguns dos parâmetros para cada ensaio separadamente. No entanto, esta abordagem alternativa implicaria numa perda de generalidiade do modelo, e por isso não foi utilizada.

\subsubsection{Razões de Reatividade}

O ajuste dos valores das razões de reatividade esteve associado ao ajuste dos coeficientes de partição uma vez que ambos os parâmetros influenciam diretamente os valores da velocidade de reação dos monômeros e da composição do copolímero formado. Os valores ajustados se aproximam a valores reportados na literatura. A partir de valores de razões de reatividade de conjuntos de pares de monômeros, foram determinadas por ALFREY e PRICE (1947), duas constantes, "Q" e "e", correspondentes a cada monômero específico, de modo a poder estimar as razões de reatividade para outros pares. A constante "Q" representa a reatividade geral do monômero e está relacionada com a probabilidade de estabilização do radical 
acrescentado à cadeia polimérica. A constante "e" representa fatores polares que influenciam a copolimerização. A relação entre as razões de reatividade e estas constantes é dada por:

$$
\begin{aligned}
& r_{1}=\left(Q_{1} / Q_{2}\right) \exp \left[-e_{1}\left(e_{1}-e_{2}\right)\right] \\
& r_{2}=\left(Q_{2} / Q_{1}\right) \exp \left[-e_{2}\left(e_{2}-e_{1}\right)\right]
\end{aligned}
$$

Os valores destas constantes, obtidos na literatura (BRANDRUP \& IMMERGUT, 1967), assim como as respectivas razões de reatividade calculadas por esse método e as ajustadas no modelo, estão apresentados na tabela 5.4.

Tabela 5.4 Valores de razões de reatividade estimadas pelas equações (5.2) e (5.3) em comparação com os valores adotados no modelo.

\begin{tabular}{|c|c|c|c|c|c|c|}
\cline { 2 - 7 } \multicolumn{1}{c|}{} & $\mathrm{Q}$ & $\mathrm{e}$ & $\mathrm{r}_{1 \text { calc }}$ & $\mathrm{r}_{2 \text { calc }}$ & $\mathrm{r}_{1 \text { modelo }}$ & $\mathrm{r}_{2 \text { modelo }}$ \\
\hline VAc & 0.026 & -0.22 & 0.04 & ------ & 0.04 & ------ \\
BuA & 0.5 & 1.06 & ------ & 4.95 & ------ & 4.70 \\
\hline
\end{tabular}

BATAILLE e BOURASSA (1989) observaram que existe uma dificuldade inerente aos métodos de cálculo das razões de reatividade entre os comonômeros quando as diferenças entre estas razões são muito altas. Portanto, os dados de razão de reatividade ajustados pelo modelo matemático são compatíveis com a grande dispersão de valores experimentais, obtidos em diversos trabalhos publicados, por exemplo NIKOLAEV et al. (1969), CHUJO et al. (1969), PICHOT et al. (1981), DELGADO (1986), KONG et al. (1988), BATAILLE e BOURASSA (1989), e com a imprecisão da estimativa teórica do método acima apresentado. Os valores experimentais publicados nestes trabalhos estão apresentados na tabela 2.1 e reproduzidos na tabela 5.5: 
Tabela 5.5 Valores de razões de reatividade obtidos experimentalmente.

\begin{tabular}{|l|c|c|c|}
\hline referência & $\mathbf{r}_{\mathbf{B}}$ (BuA) & $\mathbf{r}_{\mathbf{A}}$ (VAc) & Temperatura $\left({ }^{\mathbf{0}} \mathbf{C}\right)$ \\
\hline NIKOLAEV et al. (1969) & 5,529 & 0,0388 & 50 \\
\hline CHUJO et al. (1969) & 8 & 0 & 68,4 \\
\hline PICHOT et al. (1981) & 5,5 & 0,04 & 60 \\
\hline DELGADO (1986) & 6,35 & 0,037 & ---- \\
\hline KONG et al. (1988) & 7,2 & 0,08 & 60 \\
\hline BATAILLE e BOURASSA (1989) & 10,67 & 0,024 & 60 \\
\hline
\end{tabular}

Reprodução da tabela 2.1

Os dados da tabela 5.5 demonstram o grau de dispersão entre os pares de valores obtidos experimentalmente por diferentes autores. Parte desta dispersão pode ser atribuída ao uso de dados de composição dos copolímeros em cálculos nos quais não tenha sido considerada a influência da partição dos monômeros, conforme discutido anteriormente. Além disso, diferentes metodologias usadas na estimação das razões de reatividade também podem ser responsáveis por introduzir diferenças entre os valores (BATAILLE e BOURASSA,1989).

\subsubsection{Coeficientes de Partição}

No caso dos coeficientes de partição, foi feito somente um pequeno ajuste no valor do coeficiente de partição do VAc entre a fase aquosa e a polimérica para o VAc $(28,0$ contra 29,5 representado por GARDON, 1969), supondo que o valor do parâmetro ajustado seja praticamente constante com a variação da temperatura. No entanto, para simulações onde são consideradas grandes diferenças de temperatura de reação, os coeficientes de partição deveriam ser corrigidos de acordo com a variação dos coeficientes de atividade. No entanto, como observado por SCHOLTENS (2002), para o sistema estireno - acrilato de metila, os efeitos da temperatura sobre o coeficiente de partição e sobre as razões de reatividade podem se compensar por efeitos contrários, resultando em pequena sensibilidade à temperatura da composição do copolímero. De qualquer modo, nos ensaios experimentais do presente trabalho as variações de temperatura não foram muito acentuadas (máximo de $9{ }^{\circ} \mathrm{C}$ ) ao longo da direção axial. 


\subsection{3 Área específica Coberta por Emulsificante}

A área coberta por mol de emulsificante, As, varia conforme a natureza do emulsificante (GILES and SMITH, 1974) a polaridade da superfície polimérica (VIJAYENDRAN, 1979), (VIJAYENDRAN et al, 1981), (VIJAYENDRAN, 1985) e a composição do copolímero formado (KONG et al,1987). No caso do sistema estudado, foi verificado por VIJAYENDRAN et al. (1981) que o lauril sulfato de sódio, SLS, interage de um modo diferente com a superfície polimérica cuja composição média corresponde à proporção de comonômeros adotado nos casos simulados neste trabalho (85/15 VAc/BuA). Estes autores verificaram que a adsorção do surfactante, SLS, segue uma isoterma com dois estágios distintos, diferente da isoterma de Langmuir. A isoterma obtida representa um caso típico de penetração da superfície do polímero pelo soluto, SLS. Além disso, segundo os mesmos autores, o SLS interage com certos polímeros, tais como o poli(acetato de vinila), PVAc, solubilizando polímero e, deste modo, aumentado a viscosidade do meio.

No estudo de KONG et al, 1987, verificaram-se variações da área coberta por SLS inversamente proporcionais ao aumento de BuA na composição do copolímero de BuA / VAc, obtido em modo batelada. Por outro lado, o mesmo estudo mostrou uma variação mais complexa da As em função da conversão e da composição instantânea de copolímero. Estas variações podem ser devidas, segundo os autores, aos seguintes fenômenos:

- rearranjo das macromoléculas nas partículas com a possibilidade de algumas unidades de BuA contribuirem ao decréscimo da polaridade na interface da partícula com o meio aquoso;

- comportamento anormal de adsorsão do SLS no copolímero com alta proporção de VAc na superfície, causando a penetração do surfatante na partícula e a solubilização de cadeias ricas em PVAc na camada externa da partícula;

- hidrólise de cadeias ricas em PVAc na superfície polimérica e que se extendem à fase aquosa, causando um aumento da área disponível para adsorção de 
emulsificante.

Finalmente, para o ajuste do modelo matemático e tendo em vista a complexidade dos mecanismos envolvidos, considerou-se uma simples variação linear da área coberta $a_{s}$ com a composição média do copolímero formado, de acordo com a equação (5.4) desenvolvida empiricamente:

$a_{s}=\left(39,3 w_{a}+26,5\left(1,0-w_{a}\right)\right) N a * 10^{-16}$

Onde:

- Na é o número de Avogadro;

- $w_{a}$ representa a composição média em termos de fração molar de VAc no copolímero;

- $a_{s}$ é a área de polímero coberta por um mol de emulsificante ( $\left.\mathrm{cm}^{2} / \mathrm{mol}\right)$.

Esta equação é semelhante à utilizada por UNZUETA e FORCADA (1997) para o cálculo da área coberta por uma molécula de emulsificante em uma micela.

\subsection{Comentários Finais}

Os resultados obtidos em todos os ensaios permitiram demonstrar a reprodutibilidade dos dados experimentais e a validação do ajuste do modelo matemático simulado. Além disso, ficou comprovada a validação do equipamento para o controle das propriedades finais do produto (composição do copolímero). Finalmente, a partir destes mesmos resultados, conseguiu-se verificar a adequação do modelo matemático simulado como ferramenta eficaz para o trabalho de determinação das condições operacionais ótimas da coluna pulsada com pratos perfurados. 


\section{Capítulo 6 - CONCLUSÕES E SUGESTÕES}

Neste trabalho foi alcançada (mediante ajuste de parâmetros) e verificada experimentalmente a conformidade dos resultados simulados pelo modelo matemático aos dados obtidos a partir do estudo de reações contínuas de copolimerização de acetato de vinila e acrilato de butila, realizadas no reator tubular tipo coluna pulsada com pratos perfurados.

Durante as reações foram coletadas amostras do reator na saída de cada uma das cinco seções do reator para avaliar o comportamento de diversas variáveis do processo ao longo do reator. Para isto foram realizadas análises de gravimetria, de cromatografia gasosa com head-space e difração dinâmica de luz para a determinação da conversão, composição do copolímero, diâmetro médio e número de partículas. Adicionalmente, foi feita aquisição dos dados de temperatura (meio reacional, entrada e saída da camisa em cada uma das cinco seções do reator) e das vazões alimentadas na base e ao longo do reator.

\subsection{Conclusões dos Resultados Obtidos.}

Os resultados dos ensaios e das simulações realizadas conduziram às seguintes conclusões:

- Os perfis de temperatura resultantes do meio reacional em estado estacionário concordam satisfatoriamente com os perfis correspondentes obtidos por simulação. Estes perfis são determinados pela distribuição das taxas de produção de calor ao longo da coluna a qual também é influenciada pelo perfil de alimentação do monômero mais reativo ao longo da coluna. Verifica-se também que o perfil de temperaturas do meio reacional é bastante influenciado por pequenas diferenças na temperatura de entrada das camisas de resfriamento. 
- Como a conversão final atingida na saída da coluna foi relativamente alta em todos os ensaios, a composição final na saída da coluna foi praticamente a mesma para todos os casos indicando que o tempo médio de residência adotado (30 minutos) é suficiente para as condições de reação usadas. Já o perfil de conversão obtido ao longo da coluna, operando em regime permanente, foi fortemente influenciado pelo perfil das alimentações laterais de monômero mais reativo.

- Conforme os resultados obtidos experimentalmente e os previstos nas simulações apresentadas, a distribuição da alimentação do monômero mais reativo ao longo da coluna resultou numa redução do desvio da composição do copolímero. Essa tendência já pode ser verificada com a diminuição da deriva de composição do copolímero obtida com apenas duas alimentações laterais adicionais, ambas no final das duas primeiras seções, em relação às reações sem alimentação lateral. Além da alimentação lateral da unidade experimental permitir o controle da composição do copolímero através da alimentação do monômero mais reativo, os pontos de alimentação ainda poderão ser utilizados para outros reagentes, dependendo da propriedade polimérica a ser controlada.

- Os resultados de conversão e de composição em regime permanente são adequadamente representados pelo modelo matemático previamente desenvolvido para este tipo de processo. O modelo também pode levar em consideração a influência dos diferentes perfis de temperatura da reação, obtidos em regime permanente, a fim de otimizar as propriedades do produto e determinar as melhores condições operacionais da unidade experimental.

\subsection{Sugestões para Continuidade.}

Os seguintes estudos são sugeridos para trabalhos futuros em continuidade ao presente trabalho: 
- Para melhorar o controle de temperatura, sugere-se testar o sistema de controle em cascata para o controle de temperatura e o emprego de válvulas de três vias para o ajuste da relação entre água fria e quente no sistema de controle de temperatura de cada seção da coluna.

- Utilizar valores diferenciados de temperatura de entrada das camisas de resfriamento das diversas seções do reator e verificar o seu perfil ótimo para o fim desejado (por exemplo, para aumento de conversão, para redução de monômero residual ou para manter a conversão com maior vazão).

- Estudar as condições ótimas derivadas da combinação entre outras variáveis operacionais tais como freqüência e amplitude de pulsação, perfil de temperaturas de reação, tempo de residência no estudo da maximização do desempenho da coluna.

- Otimização de propriedades do produto tais como distribuições de tamanhos de partícula e de pesos moleculares utilizando-se também dos pontos laterais para a alimentação de iniciador, agente de transferência de cadeia e emulsificante, dependendo da finalidade de estudo proposta (por exemplo, agente de transferência de cadeia que pode afetar a distribuição de pesos moleculares, emulsificante que pode afetar a distribuição do tamanho das partículas).

- Testar novas condições experimentais com o objetivo de aumentar o teor de sólidos na emulsão produzida.

- Analisar com técnicas de CFD (Fluido Dinâmica Computacional) o escoamento ao longo de elementos da CPPP, para obter informações mais detalhadas sobre o escoamento do meio reacional. 


\section{REFERÊNCIAS BIBLIOGRÁFICAS}

ABAD, C.; DE LA CAL, J.C. \& ASUA, J.M. Emulsion Copolymerization in Continuous Loop Reactors, Chem. Eng. Sci., v. 49(24b), p. 5025-5037, 1994.

ABAD, C.; DE LA CAL, J.C. \& ASUA, J.M. Emulsion Copolymerization of Vinyl Esters in Continuous Reactors: Comparison Between Loop and Continuous Stirred Tank Reactors, J. Appl. Polym. Sci., v. 56, p. 419 (1995a).

ABAD, C.; DE LA CAL, J.C. \& ASUA, J.M. Modeling Nucleation and Particle Growth in Emulsion Copolymerization in Continuous Loop Reactors. Makromol. Chem., Macromol. Symp., v. 92, p. 195 (1995b).

ABAD, C.; DE LA CAL, J.C. \& ASUA, J.M. Macromixing and Micromixing in Continuous Loop Reactors. DECHEMA Monogr., v. 131, p. 87 (1995c).

ALFREY, T.; PRICE, C. Relative Reactivities in Vinyl Copolymerization. J. Polym. Sci., v. $2, \mathrm{n}^{0} 1$, p. 101-106, 1947.

ARAÚJO, P.H.H., Distribuição dos Tamanhos de Partícula em Sistemas Heterogêneos de Polimerização. Tese de Doutorado, Programa de Engenharia Química/COPPE, Universidade Federal do Rio de Janeiro, 1999.

ARAÚJO P.H.H.; ABAD, C.; DE LA CAL, J.C.; ASUA, J.M. \& PINTO, J.C. Performance of Continuous Loop Reactors in Emulsion Polymerization. DECHEMA Monogr., 134, 439-447, 1998.

ARAÚJO, P. H. H.; ABAD, C.; PINTO, J. C.; DE LA CAL, J. C.; ASUA, J. M. Emulsion Polymerization in a Loop Reactor: Effect of the Operation Conditions. Polym. React. Eng., v. 7, n. 3, p. 303-326, 1999.

ARAUJO, P. H. H.; DE LA CAL, J. C.; ASUA, J. M.; PINTO, J. C. Modeling Particle Size Distribution (PSD) in Emulsion Copolymerization Reactions in a continuous Loop Reactor. In: European Symposium on Computer Aided Process Engineering - 10, 2000, Florença. Computer-Aided Chemical Engineering. Amsterdam: ELSEVIER Science, 2000. v. 8. p. 565-570. (Apud. SAYER et al., 2002b).

ARAÚJO, P.H.H.; ABAD, C.; DE LA CAL, J.C.; PINTO, J. C.; ASUA, J.M. Using Multiplicity to Improve Reactor Performance and Product Quality in Emulsion Polymerization in Continuous Loop Reactors. Polym. React. Eng., v. 9(1), 1, 2001. 
ARMITAGE, P. D.; DE LA CAL, J.; ASUA, J.M. Improved Methods for Solving Monomer Partitioning in Emulsion Copolymer Systems. J. Polym. Sci., v. 51, p. 1985-1990, 1994.

BAAD, W.; MORITZ, H.U.; REICHERT, K.H. Kinetics of High Conversion Polymerization of Vinyl Acetate Effects of Mixing and Reactor Type on Polymer Properties, J. Appl. Polym. Sci., v. 27, p. 2249-2268, 1982. (Apud. SAYER et al., 2002b).

BASF S/A. Acrilato de Butila - Folheto Técnico, edição 01 [2003], 2 p.

BATAILLE, P. \& BOURASSA, H. Determination of the Reactivity Parameters for the Copolymerization of Butyl Acrylate with Vinyl Acetate. J. Polym. Sci., Polym. Chem. ed., v. 27, p. 357-365, 1989.

BRANDRUP, J.; IMMERGUT, E.H. Polymer Handbook, $3^{\text {rd }}$ ed., Wiley, New York, 1989.

BRITON, D.; HEATLEY, F.; LOVELL, P.A, 13C NMR Spectroscopy Studies of Branching and Sequence Distribution in Copolymers of Vinyl acetate and n-Butyl Acrylate Prepared by Semibatch Emulsion Copolymerization, Macromolecules, v. 34, p. 817-829, 2001.

BURAC, C. Étude de la Copolymerisation en Émulsion de l'Acetate de Vinyle et de l'Acrylate de Butyle. Tese de Master, Département de Génie Chimique - École Polytechnique de Montréal, 1998.

CARVALHO, A. C. S. M.; SAYER, C.; GIUDICI, R.. Development of a Continuous Emulsion Copolymerization Process in a Tubular Reactor. In: Macro 2006 World Polymer Congress $41^{\text {st }}$ International Symposium on Macromolecules, 2006, Rio de Janeiro. Proceedings, 2006c.

CARVALHO, A.C.S.M.; CHICOMA, D.L.; SAYER, C.; GIUDICI, R. Comparison of Vinyl Acetate - Butyl Acrylate Emulsion Copolymerizations Conducted in a Continuous Pulsed Sieve Plate Column Reactor and in a Batch Stirred Tank Reactor, Macromol. Symp., v. 243, Issue 1, p. 147-158, 2006b.

CARVALHO, A.C.S.M.; SAYER, C.; GIUDICI, R. Desenvolvimento de processo contínuo de copolimerização em emulsão em reator tubular. In: $8^{\circ}$ Congresso Brasileiro de Polímeros, Águas de Lindóia. anais, 2005.

CARVALHO, A.C.S.M.; SAYER, C.; GIUDICI, R.. Processo Contínuo de Copolimerização em Emulsão em Reator Tubular. Efeito do Número de Alimentações Laterais sobre as Propriedades do Polímero. In: XVI Congresso Brasileiro de Engenharia Química COBEQ-2006, 2006a, Santos. Anais, 2006. p. 5649-5654.

CHATTERJEE, A.; PARK, W.S.; GRAESSLEY, W.W. Free Radical Polymerization with Long Chain Branching: Continuous Polymerization of Vinyl Acetate in t-Butanol. Chem. Eng. Sci., v. 32, p. 167-178. 1977. (Apud. SAYER et al., 2002b). 
CHUJO, K.; HARADA, Y.; TONOMURA, S.; TANAKA, K., The Effects of Various Monomer Adition Methods on the Emulsion Copolymerization of Vinyl Acetate and Butyl Acrylate, J. Polym. Sci., C 27, p. 321-334,1969.

CHERN, C.S. Emulsion Polymerization Mechanisms and Kinetics. Prog. Polym. Sci., v. 31, p. 443-486, 2006.

DANCKWERTS, P.V. Continuous Flow Systems. Distribution of Residence Times, Chem. Eng. Sci., v. 2, p. 1-13, 1953. (Apud. SAYER et al., 2002b).

DELGADO J., Tese de Doutorado, Lehigh University, 1986. (Apud. GUGLIOTTA et al., 1995).

DELGADO, J.; EL-AASSER, M. S. \& VANDERHOOFF, J.W. Miniemulsion Copolymerization of Vinyl Acetate and Butyl Acrylate. I. Differences between the Miniemulsion Copolymerization and the Emulsion Copolymerization Processes. $\mathbf{J}$. Polym. Sci., Polym. Chem. ed., v. 24, p. 861-874, 1986.

DELGADO, J.; EL-AASSER, M. S.; SILEBI, C.A.; VANDERHOOFF, J.W. Miniemulsion Copolymerization of Vinyl Acetate and Butyl Acrylate. III. Experimental Evidence for the Role of the Cosurfactant. J. Polym. Sci., Polym. Chem. ed., v. 27, p. 193-202, 1989.

DELGADO, J.; EL-AASSER, M. S.; SILEBI, C.A.; VANDERHOOFF, J.W., 1990, Miniemulsion Copolymerization of Vinyl Acetate and Butyl Acrylate. IV. Kinetics of the Copolymerization, J. Polym. Sci., Polym. Chem. ed., v. 28, p. 777-794.

DELGADO, J.; EL-AASSER, M. S.; SILEBI, C.A., VANDERHOOFF; J.W., GUILLOT, J. Miniemulsion Copolymerization of Vinyl Acetate and Butyl Acrylate. II. Mathematical Model for the Monomer Transport. J. Polym. Sci., Polym. Phys. ed., v. 26, p. 14951517, 1988.

DIMITRATOS, J.; GEORGAKIS, C.; EL ASSER; M.S. \& KLEIN; A., Pseudosteady States in Semicontinuous Emulsion Copolymerization. J. Appl. Polym. Sci., v. 40, 5-6, p. 1005-1021, 1989.

DUBÉ, M.A. \& PENLIDIS, A. A Systematic Approach to the Study of Multicomponent Polymerization Kinetics - The Butyl Acrylate/Methyl Methacrylate/Vinyl Acetate Example: 1. Bulk Copolymerization. Polymer, v. 36, nº 3, p. 587-598, 1995.

EL-AASSER, M. S.; MAKGAWINATA, T., \& VANDERHOOFF, J.W. Batch and Semicontinuous Emulsion Copolymerization of Vinyl Acetate-Butyl Acrylate I. Bulk, Surface, and Colloidal Properties of Copolymer Latexes. J. Polym. Sci., Polym. Chem. ed. v. 21, p. 2363-2382, 1983. 
ERBIL, H. Y. Surface Energetics of Films of Poly(Vinyl Acetate-Butyl Acrylate) Emulsion Copolymers. Polymer, Vol. 37, n² 24, p. 5483-5491, 1996.

FAN, S.; STEINKE, J.H.G.; ALPAY, E. Emulsion Polymerizations in a Pilot-scale Loop Reactor with Inline Static Mixers. Ind. Eng. Chem. Res., v. 44 (15), p. 5483-5490, Jul 20 2005.

FAN, S.; GRETTON-WATSON, S.P.; STEINKE, J.H.G.; ALPAY, E. Polymerization of Methyl Methacrylate in a Pilot-scale Tubular Reactor: Moddelling and Experimental Studies. Chem. Eng. Sci., v. 58, p. 2479-2490, 2003.

FELDON, M.; McCANN, R. F.; LAUNDRIE, R. W. Continuous Emulsion Polymerization in a Tubular Reactor. India Rubber World, v. 128 (1), 51 - 63 (1955) (Apud. PAQUET, D.A. \& RAY, W.H., 1994a).

GARDON, J.L. Emulsion Polymerization . II. Review of Experimental Data in the Context of the Revised Smith-Ewart Theory. J. Pol. Sci. A, v. 6, p. 643-664, 1968.

GILBERT, R.G., Emulsion Polymerization: A Mechanistic Approach, $1^{\text {st }}$ ed. London, Academic Press; 1995.

GILES, C.H..; SMITH, D. A General Treatment and Classification of the Solute Adsorption Isotherm I. Theoretical, J. Colloid Interface Sci., 47, No 3, 755-765, 1974.

GUGLIOTTA, L.M.; ARZAMENDI, G.; ASUA, J.M. Choice of Monomer Partition Model in Mathematical Modeling of emulsion copolymerization System. J. Polym. Sci., v. 55, p. 1017-1039, 1995.

HARKINS, W.D., "A General Theory of Emulsion Polymerisation", 1947. J. Am. Chem. Soc., Vol.69, 1428 (Apud. VAN HERK, 2005).

HILLER S., "Monomerverteilung in Latexsystemen". Tese de Doutorado, Technische Fakultät der Universität Erlangen-Nürnberg, 2004.

HOEDEMAKERS, G.F.M., "Continuous Emulsion Polymerization in a Pulsed Packed Column", PhD. Thesis., Eindhoven University of Technology, 1990.

HOEDEMAKERS, G.F.M.; THEONES, D.; VAN DER LOOS, J.L.M. Process for Polymerization in a Packed Pulsating Column, Eur. Patent EP336469, 11.10.1989, Neth. Patent NL8800658 (1988)

HUTCHINSON, R.A.; PAQUET, D.A.; MCMINN, J.H.; BEUERMANN, S.; FULLER, R.E.; JACKSON, C. DECHEMA-Monogr., v. 131, p.467, 1995. (Apud. SAYER et al., 2002b). 
KIPARISSIDES C.; MACGREGOR J.F.; HAMIELEC A.E. Continuous Emulsion Polymerization of Vinyl Acetate. Part. I: Experimental Studies. Can J. Chem. Eng., V. 58 p. 48-55, 1980.

KONG, X.Z.; PICHOT, C., \& GUILLOT, J. Kinetics of Emulsion Copolymerization of Vinyl Acetate with Butyl Acrylate. Eur. Polym. J., v. 24, nº 5, p. 485-492, 1988.

KONG, X.Z..; PICHOT, C.; GUILLOT, J. Characterization of Particle Surface and Morphology in Vinyl Acetate - Butyl Acrylate Emulsion Copolymers - Influence of the Copolymerization Pathway. Colloid Polym. Sci., v. 265, p. 791-802, 1987.

LEE, D.Y.; KUO, J.F.; WANG, J.H.; CHEN, CHUH-YUNG, Study on the Continuous Loop Tubular Reactor for Emulsion Polymerization of Styrene. Polym. Eng. Sci., v. 30, p. 187-192, Feb 1990.

LICHTI, G.; GILBERT, R.G.; NAPPER, D.H. The Mechanisms of Latex Particle Formation and Growth in the Emulsion Polymerization of Styrene Using the Surfactant Sodium Dodecyl Sulfate. J. Polym. Sci., Polym. Chem. Ed., v. 21, p. 269 -291, 1983.

LOVELL, P. A.; EL AASSER, M.S. Emulsion Polymerization and Emulsion Polymers. $4^{\text {th }}$ edition, John Wiley and Sons Ltd., West Sussex - England, 1997.

MCKENNA, T.F.; GRAILLAT, C.; GUILLOT, J. Contributions to defining the rate constants for the copolymerization of butyl acrylate and vinyl acetate. Pol. Bul. v. 34, p. 361-368, 1995. (Apud. SAYER et al., 2002b).

MACKLEY M.R.; STONESTREET P.; ROBERTS E.P.L.; NI, X. Residence Time Distribution Enhancement in Reactors Using Oscillatory Flow. Trans IchemE, v. 74 (A5), p. 541-545, Jul 1996.

MARIN, F.L.M.; LONA, L.M.F.; MACIEL, M.R.W.; MACIEL FILHO, R. Finite volume method as the numerical method for new emulsion polymerization tubular reactor with internal angle baffles. J. Appl. Polym. Sci., v. 02 (6), p. 6037-6048, Dec 152006.

MARIN, F.L.M.; LONA, L.M.F.; MACIEL, M.R.W.; MACIEL FILHO, R., New emulsion polymerization tubular reactor with internal angular baffles: Reaction temperature effect. J. Appl. Polym. Sci., v. 100 (4): p. 2572-2581, May 152006.

MAYER, M.J.J.; MEULDIJK, J. \& THOENES, D. Emulsion Polymerization in Various Reactor Types: Recipes with High Monomer Contents. Chem. Eng. Sci., v. 49, $n^{\circ} 24 B$, p. 4971-4980, 1994. 
MAYER, M.J.J.; MEULDIJK, J.; THOENES, J., D. Application of the Plug Flow with Axial Dispersion for Continuous Emulsion Polymerization in a Pulsed Packed Column. Chem. Eng. Sci., v. 51, p. 3441-3448, 1996.

MAYO, F.R; LEWIS, F.M. J. Am. Chem. Soc., v. 66, p. 1594, 1944 (Apud VAN HERK, 2005).

MELIS, S.; KEMMERE, M.; MEULDIJK, J.; STORTI, G.; MORBIDELLI, M. A Model for the Coagulation of the Polyvinyl Acetate Particles in Emulsion. Chem. Eng. Sci., v. 55, p. 3101-3111, 2000. (Apud. SAYER et al., 2002b).

MEULDIJK, J.; VAN STREIN, C.J.G.; VAN DOORMALEN, F.A.H.C.; THOENES, D.; A Novel Reactor for Continuous Emulsion Polymerization. Chem. Eng. Sci., v. 47, p. 2603-2608, 1992.

MEULDIJK, J.; SCHOLTENS, C.A.; REYNHOUT, X.E.E.; DRINKENBURG, A.A.H. Polymer Latex Production: from (Semi-)Batchwise to Continuous Operation. DECHEMA Monogr., v. 137, p. 633-639, 2001.

MEULDIJK, J. \& GERMAN, L., Emulsion Polymerization in a Pulsed Packed Column Stability, Reaction Performance and Scale-Up. Polym. React. Eng., v. 7 (2), p. 207-230, 1999.

MIN, K.W.; RAY, W.H. The Computer Simulation of Batch Emulsion Polymerization Reactors Through a Detailed Mathematical Model. J.Appl.Polym. Sci., v.22, p. 89$112,1978$.

MISRA, S.C.; PICHOT, C.; EL-AASSER, M. S. \& VANDERHOOFF, J.W. Batch and Semicontinuous Emulsion Copolymerization of Vinyl Acetate-Butyl Acrylate. II. Morphological and Mechanical Properties of Copolymer Latex Films. J. Polym. Sci., Polym. Chem., v. 21, p. 2383-2396, 1983.

MISRA, S.C.; PICHOT, C.; EL-AASSER, M. S. \& VANDERHOOFF, J.W. Effect of Emulsion Polymerization Process on the Morphology of Vinyl Acetate-Butyl Acrylate Copolymer Latex Films. J. Polym. Sci., Polym. Lett., v. 17, p. 567-572, 1979.

NI, X.; PEREIRA, N.E. Parameters affecting fluid dispersion in a continuous oscillatory baffled tube. AIChE J., v. 46, p. 37, 2000.

NI, X.; JIAN, H.; FITCH, A.W. Computational fluid dynamic modelling of flow patterns in an oscillatory baffled column. Chem. Eng. Sci., v. 57, p. 2849, 2002.

NIKOLAEV, A.F.; VISHNEVETSKAYA, L.P.; GROMOVA, O.A.; GRIGOR'EVA, M.M.; KLESHCHEVA, M.S. Vysokomol. Soedin. Ser A, v. 11, p. 2418, 1969 (Apud. PICHOT et al., 1981). 
OHMURA, N.; KATAOKA, K.; WATANABE, S.; OKUBO, M. Controlling Particle Size by Self-sustained Oscillations in Continuous Emulsion Polymerization of Vinyl Acetate. Chem. Eng. Sci., v. 53, 12, p. 2129-2135, 1998.

OLAYIWOLA, B.O.; WALZEL, P. Flow Pulsation and Modified Duct Surface for Process Heat Transfer Intensification. Int. J. Chem. React. Eng., Vol. 5, A71, pp. 1-9, 2007.

OMI, S.; KUSHIBIKI, K.; NEGISHI, M.; ISO, M. Generalized Computer Modeling of Semi-Batch, n-Component Emulsion Copolymerization Systems and Its Applications. Zairyo Gijutsu. v.3, p. 426, 1985. (Apud. SAYER et al., 2002b)

OUZINEB, K.; GRAILLAT C.; MCKENNA, T. Continuous Tubular Reactors for Latex Production: Convencional Emulsion and Miniemulsion Polymerizations. J. Appl. Polym. Sci., v. 91, p. 2195-2207, 2004.

PALMA, M.; MIRANDA, S.C.F.; GIUDICI, R. 2001b, "Comparação entre Reações Contínuas de Polimerização em Emulsão em uma Coluna Pulsada de Pratos Perfurados com reações em Batelada", 6 CBPOL, Gramado, novembro, 2001.

PALMA M. "Polimerização de acetato de vinila em emulsão de modo contínuo em coluna pulsada de pratos perfurados". Tese de Doutorado, Escola Politécnica da USP, 2002.

PALMA, M. \& GIUDICl, R., 2001, "A New Reactor for Continuous Emulsion Polymerization. Characterization of Flow Non-Ideality", AIChE 2001 - Spring National Meeting. Houston, USA, 22-26th April 2001.

PALMA, M. e GIUDICI, R. Analysis of axial dispersion in an oscillatory-flow continuous reactor. Chem. Eng. J., v. 94(3), p. 189-198, 2003.

PALMA, M.; SAYER, C. \& GIUDICI, R. A New Continuous Reactor for Emulsion Polymerization: Effect of Operational Conditions on Conversion and Particle Number. DECHEMA-Monogr., v. 137, p. 625-631, 2001a.

PAQUET, D.A. \& RAY, W.H. Tubular Reactors for Emulsion Polymerization: I. Experimental Investigation. AIChE J., v. 40, $n^{0} 1$, p. 73-87, 1994a.

PAQUET, D.A. \& RAY, W.H., 1994b, Tubular Reactors for Emulsion Polymerization: II. Model Comparisons with Experiments, AIChE J., 40. No 1, 88-96.

PERRY, R.H.; CHILTON, C.H. Manual de Engenharia Química, $5^{a}$ Ed., Guanabara Dois, Rio de Janeiro, 1980. 
PETZOLD, L.R., A Description of DASSL: A Differential Algebraic System Solver, Sandia National Laboratories, Report \# SAD82-8637 (1982). (Apud. SAYER et al., 2002b).

PICHOT, C.; LLAURO, M.-F., \& PHAM, Q.-T. Microstruture of Vinyl Acetate-Butyl Acrylate Copolymers Studied by 13C-NMR Spectroscopy: Influence of Emulsion Polymerization Process, J. Polym. Sci., Polym. Chem., v. 19, p. 2619-2633, 1981.

PIIRMA, I., Emulsion Polymerization, Academic Press, New York; $1^{\text {st }}$ ed. 1982.

POORMAHDIAN, S.; BATAILLE, P., Emulsion Copolymerization in a Tubular Reactor. J. Appl. Polym. Sci., v. 75, p. 883-842, 2000.

RAWLINGS, J. B., \& RAY, W.H., Stability of Continuous Emulsion Polymerization Reactors: A Detailed Model Analysis, Chem. Engng. Sci., v. 42, p. 2767-2777, 1987.

RAWLINGS, J.B.; RAY, W.R. The Modelling of Batch and Continuous Emulsion Polymerization Reactors: II. Comparison with Experimental Data from Continuous Stirred Tank Reactors, Polym. Eng. Sci., v. 28, p. 257-274, 1988. (Apud. SAYER et al., 2002b).

ROLLIN AL, PATTERSON I, HUNEAULT R, HUNEAULT, R., BATAILLE, P. The Effect of Flow Regime on Continuous Emulsion Polymerization of Styrene in a Tubular Reactor, Can. J. Chem. Eng., v. 55 (5), p. 565-571, 1977.

SALLARÉS, A.C.; SAYER, C.; GIUDICI, R., Copolymer composition control during vinyl acetate - butyl acrylate emulsion polymerization reactions in a continuous pulsed sieve plate column reactor, DECHEMA-Monogr., Frankfurt, v. 138, p. 231-237, 2004.

SAYER C. \& GIUDICI R., 2002a, "Simulação do Processo de Copolimerização em Emulsão num Reator tipo Coluna Pulsada de Pratos Perfurados", $14^{\circ}$ COBEQ Congresso Brasileiro de Engenharia Química, Natal, 2002.

SAYER C. \& GIUDICI R., A Comparison of Different Modeling Aproaches for the Simulation of Transient and Steady-State Behaviors of Continuous Emulsion Polymerizations in Pulsed Tubular Reactors, Braz. J. Chem. Eng., v. 19, $n^{0} 1$, p. 89103, 2002b.

SAYER, C., PALMA, M. \& GIUDICI, R., Kinetics of Vinil Acetate Emulsion Polymerizations in a Pulsed Tubular Reactor. Comparison between Experimental and Simulation Results, Braz. J. Chem. Eng., v. 19, $\mathrm{n}^{\circ}$ 4, p. 425-431, 2002a. (3rd ENPROMER).

SAYER, C.; PALMA, M. \& GIUDICI, R., Modeling Continuous Vinyl Acetate Emulsion Polymerization Reactions in a Pulsed Sieve Plate Column, Ind. Eng. Chem. Res., v. 41, p. 1733-1744, 2002b. 
SCHOLTENS, C.A.; MEULDIJK, J.; DRINKENBURG, A.A.H., Production of copolymers with a Predefined Intermolecular Chemical composition Distribution by Emulsion Polymerization in a Continuously Operated Reactor, Chem. Eng. Sci., v. 56, p. 955-965, 2001a.

SCHOLTENS, C.A.; MEULDIJK, J.; DRINKENBURG, I.B., 2001b, "Seed Latex Production Polymerization in a Pulsed Packed Column", 6th World Congress of Chemical Engineering, Melburn.

SCHOLTENS, C.A.; MEULDIJK, J.; DRINKENBURG, I.B., 2001c, ", "Emulsion Copolymerization in a Pulsed Packed Column", 6th World Congress of Chemical Engineering, Melburn.

SHOLTENS, C.A.; "Process Development for continuous Emulsion Copolymerization", Eindhoven, 2002. Tese de Doutorado. Eindhoven Technical University.

SMITH W.V., EWART R.H. Kinetics Of Emulsion Polymerisation. J. Chem. Phys. Vol. 16 (6), pp. 592-599, 1948.

STONESTREET, P., VAN DER VEEKEN, P.M.J., The Effects of Oscillatory Flow and Bulk Flow Components on Residence Time Distribution in Baffled Tube Reactors, Trans IchemE, v. 77, A, p. 671-684, Nov. 1999.

TAUER, K.; KÜHN, I. Modeling Particle Formation in Emulsion Polymerization: An Approach by Means of the Classical Nucleation Theory. Macromolecules, v. 28, p. 2236 - 2239, 1995.

UGELSTAD, J.; MOEK, P.C.; AASEN, J.O. Kinetics of Emulsion Polimerization, J. Polym. Sci, v. 5, p. 2281-2287, 1967. (Apud. SAYER et al., 2002b).

UNZUETA, E.; FORCADA, J, Modeling the Effect of Mixed Emulsifier System in Emulsion Copolymerization, J. Appl. Polym. Sci., v. 66, p. 445-458, 1997.

VAN DEN BOOMEN, F.H.A.M.; MEULDIJK, J. \& THOENES, D., Continuous Emulsion Copolymerization of Styrene and Methyl Acrylate, Chem. Eng. Sci., v. 51, $n^{\circ}$. 11, 27872792, 1996.

VAN DEN BOOMEN, F.H.A.M.; M.J.J.; MEULDIJK, J. \& THOENES, D., Emulsion Copolymerization in a Flexible Continuously Operated Reactor, Chem. Eng. Sci., v. 54, p. 3283-3290, 1999.

VAN HERK, A. M. Chemistry and Technology of Emulsion Polymerization, $1^{\text {st }}$ ed.; Blackwell Publishing, 2005. 
VANDERHOOFF, J.W., Mechanism of Emulsion Polymerization, J. Polym. Sci., Polym. Symp., v. 72, p. 161-198, 1985.

VIJAYENDRAN, B.R., Polymer Polarity and Surfactant Adsorption, J. Appl. Polym., Sci., v. 23, p. 733-742, 1979.

VIJAYENDRAN, B.R., Some Studies on the Physico-Chemical Aspects of Vinyl-Acrylic Copolymer Latexes, Makromol. Chem., Suppl. ed., 10/11, p. 271-295, 1985.

VIJAYENDRAN, B.R.; BONE, T.; GAJRIA, C., Surfactant Interactions in Poly(Vinyl Acetate-Butyl Acrylate) Latexes, J. Appl. Polym. Sci., v. 26, p. 1351-1359, 1981.

WICKS JR., Z.W.; JONES, F.N.; and PAPPAS, S.P., Organic Coatings, Science and Technology, $2^{\text {nd }}$ ed. New York, John Wiley and Sons Ltd; 1999. 


\section{APÊNDICE A1 - Caracterização do Produto Final.}

\section{Medidas de Ressonância Magnética Nuclear.}

Em alguns trabalhos publicados sobre a copolimerização em emulsão de VAc e BuA, foi empregada a técnica da ressonância nuclear magnética NMR para a determinação da composição do copolímero formado (PICHOT et al, 1981; BATAILLE e BOURASSA, 1989; BRITTON et al, 2001). A principal vantagem desta técnica é a sua alta sensibilidade ao efeito da micro-estrutura molecular, permitindo determinar quantitativamente as diferentes seqüências de unidades de monômeros na cadeia polimérica.

No presente trabalho, tal técnica foi testada para avaliar sua utilidade e a informação adicional que poderia ser obtida na análise da microestrutura da cadeia de copolímero. Em razão dos custos envolvidos, foi realizada a análise apenas de uma amostra, a do copolímero produzido no ensaio 10, com o objetivo de verificar a homogeneidade da composição do copolímero.

Os espectros de Ressonância Magnética Nuclear de Carbono (RMN C ${ }^{13}$ ) do polímero foram obtidos em um espectrômetro Bruker DRX500, operando a 125,8MHz. Amostras do copolímero (100mg) foram dissolvidas em $1 \mathrm{ml}$ de clorofórmio deuterado ( $\mathrm{CDCl}_{3}, 99,9 \% \mathrm{D}$, Tedia), contendo 0,03\% v.v. de TMS (padrão interno), através de agitação por pelo menos $72 \mathrm{~h}$. Após esse período, as soluções foram filtradas e transferidas para tubos de RMN (Wilmad, modelo 537PP), que foram selados com tampas apropriadas.

Os espectros foram obtidos a $25^{\circ} \mathrm{C}$, usando a seqüência de pulsos adequada (normal, DEPT45 ou DEPT135, conforme o caso), desacoplamento contínuo de $\mathrm{H}^{1}$, intervalo entre os pulsos de 0,5 s com ângulo de $70^{\circ}$. A precisão quantitativa dos espectros foi verificada conforme descrito na literatura (BRITTON et al., 2001). Os deslocamentos químicos foram referenciados pelo TMS na amostra (0ppm).

Os subespectros de $\mathrm{CH}_{2}$ e $\mathrm{CH}$ foram obtidos através da subtração e da adição, respectivamente, dos espectros dos experimentos de DEPT45 e DEPT135 (BRITTON et al., 2001). 
Resultados e Discussão

A figura A-1 apresenta o espectro quantitativo da amostra analisada no qual estão atribuídos os átomos de carbono (indicados e codificados na figura A-2) a seus respectivos picos. A figura $A 2$ apresenta a ampliação do espectro quantitativo. Nas figuras A-4 e A-5 estão apresentados respectivamente os espectros DEPT45 e DEPT135. Nas figuras A-1 a A-9, as unidades monoméricas de VAc e de BuA estão representadas pelas letras $\mathrm{V}$ e $\mathrm{B}$ respectivamente.

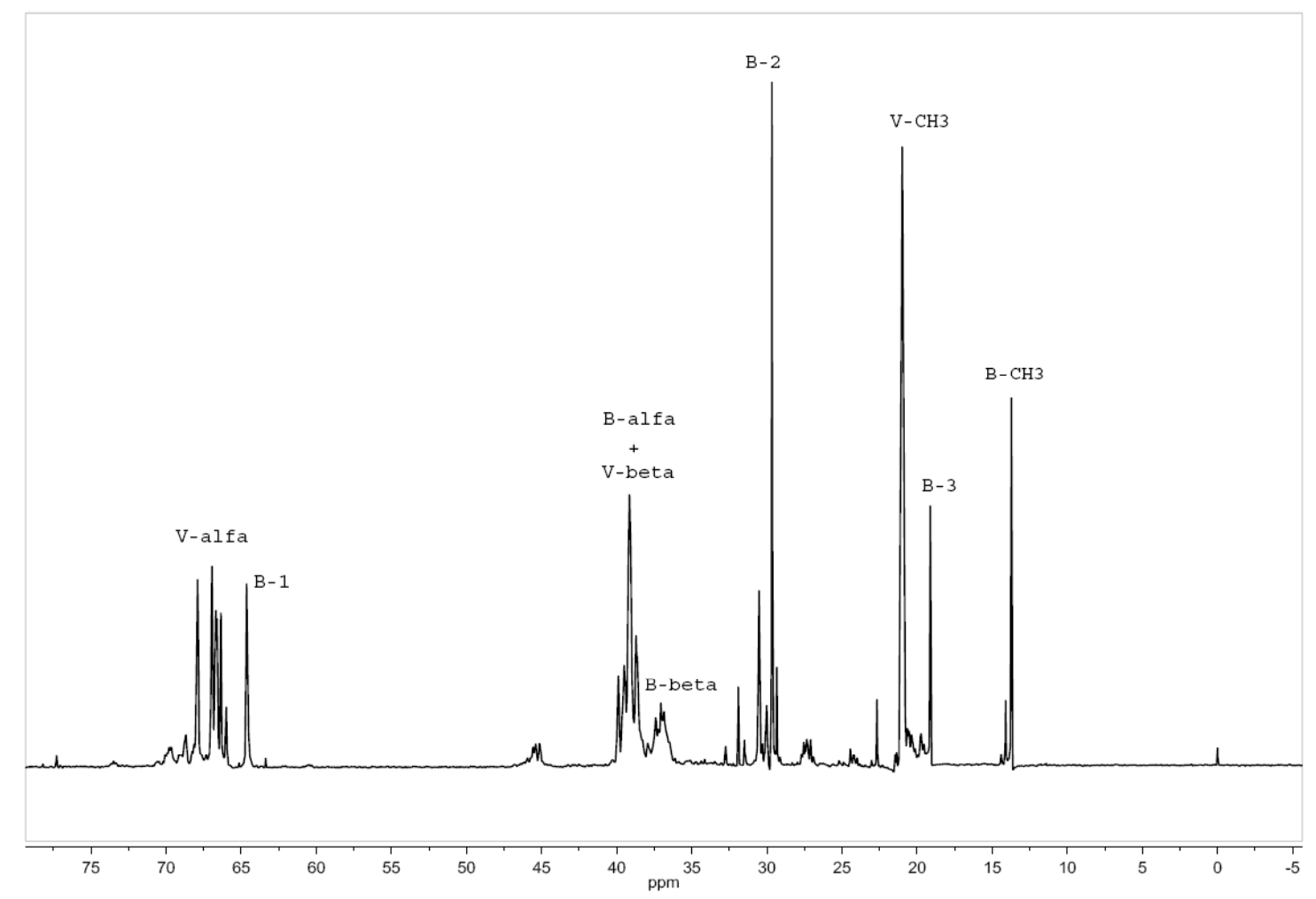

Figura A-1 - Espectro de RMN-C ${ }^{13}$ do copolímero com atribuição dos picos (baseado em BRITTON et al., 2001). 


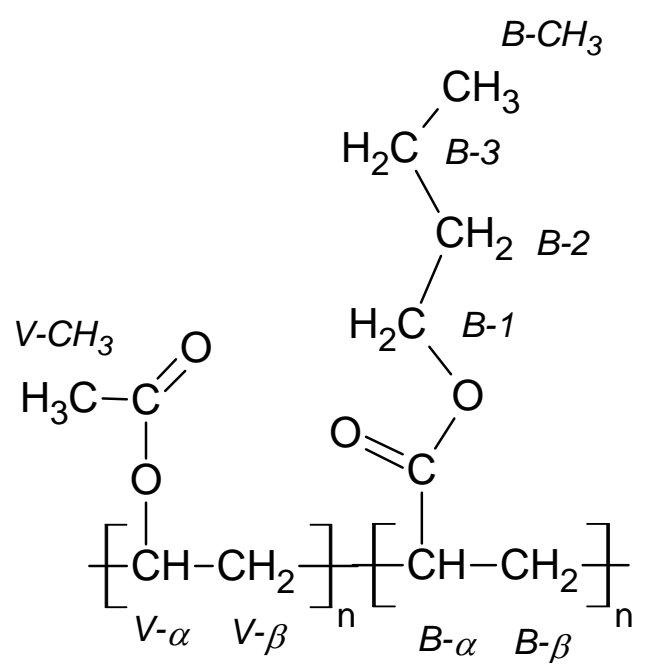

Figura A-2 - Esquema do copolímero, indicando a codificação dos átomos de carbono.

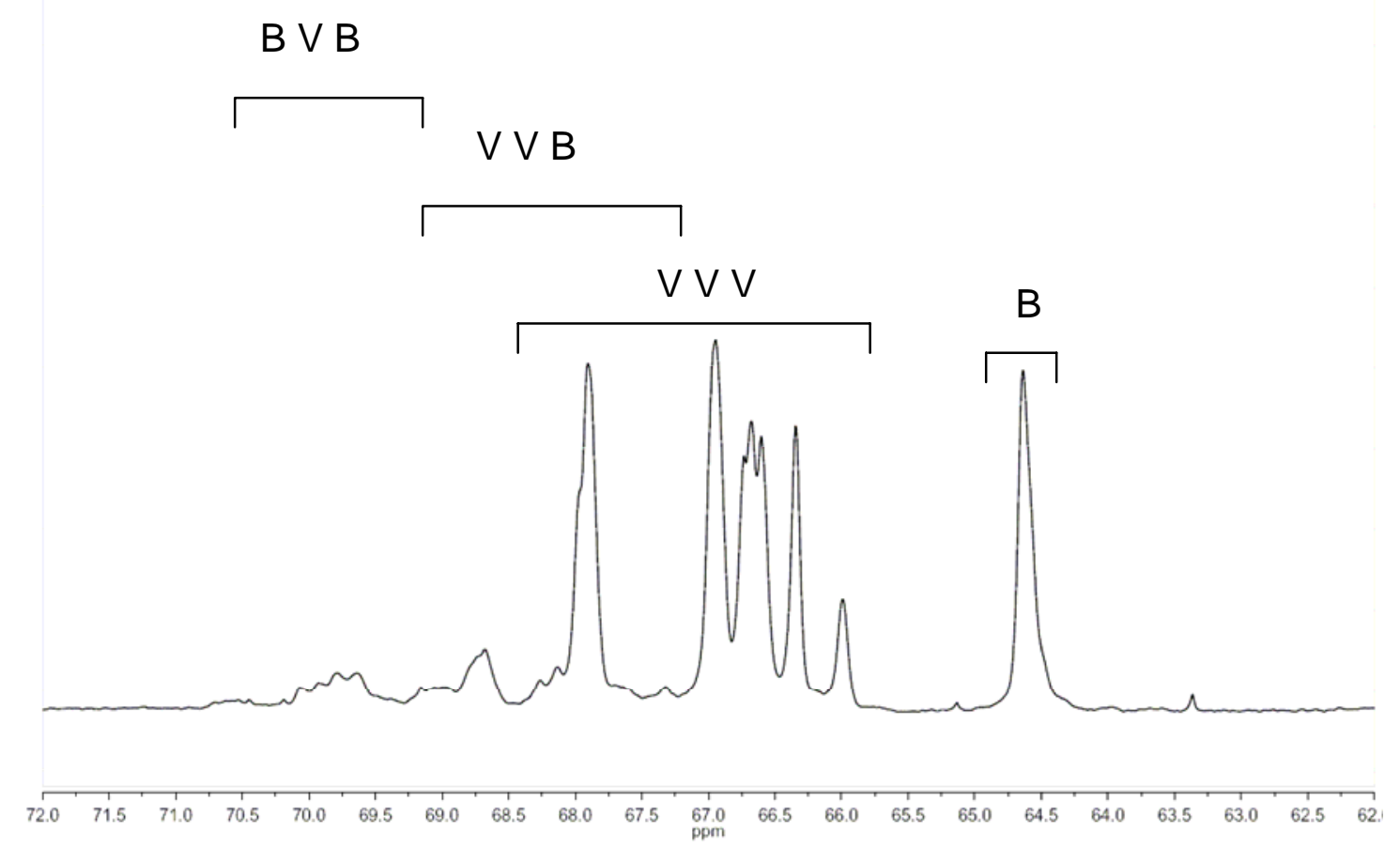

Figura A-3 - Ampliação do espectro de $\mathrm{RMN}-\mathrm{C}^{13}$. 
DEPT4 5

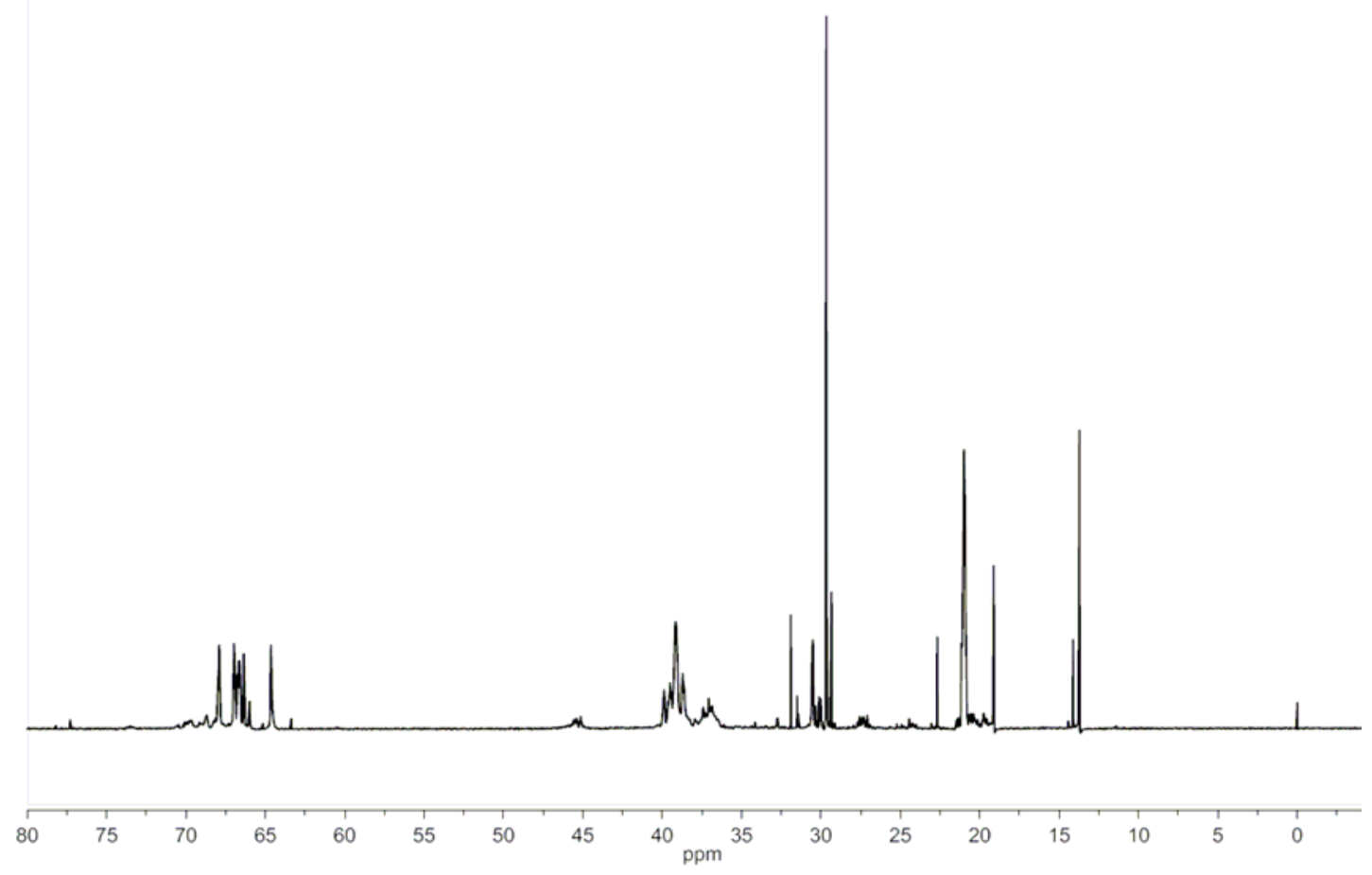

Figura A-4 - Espectro DEPT45.
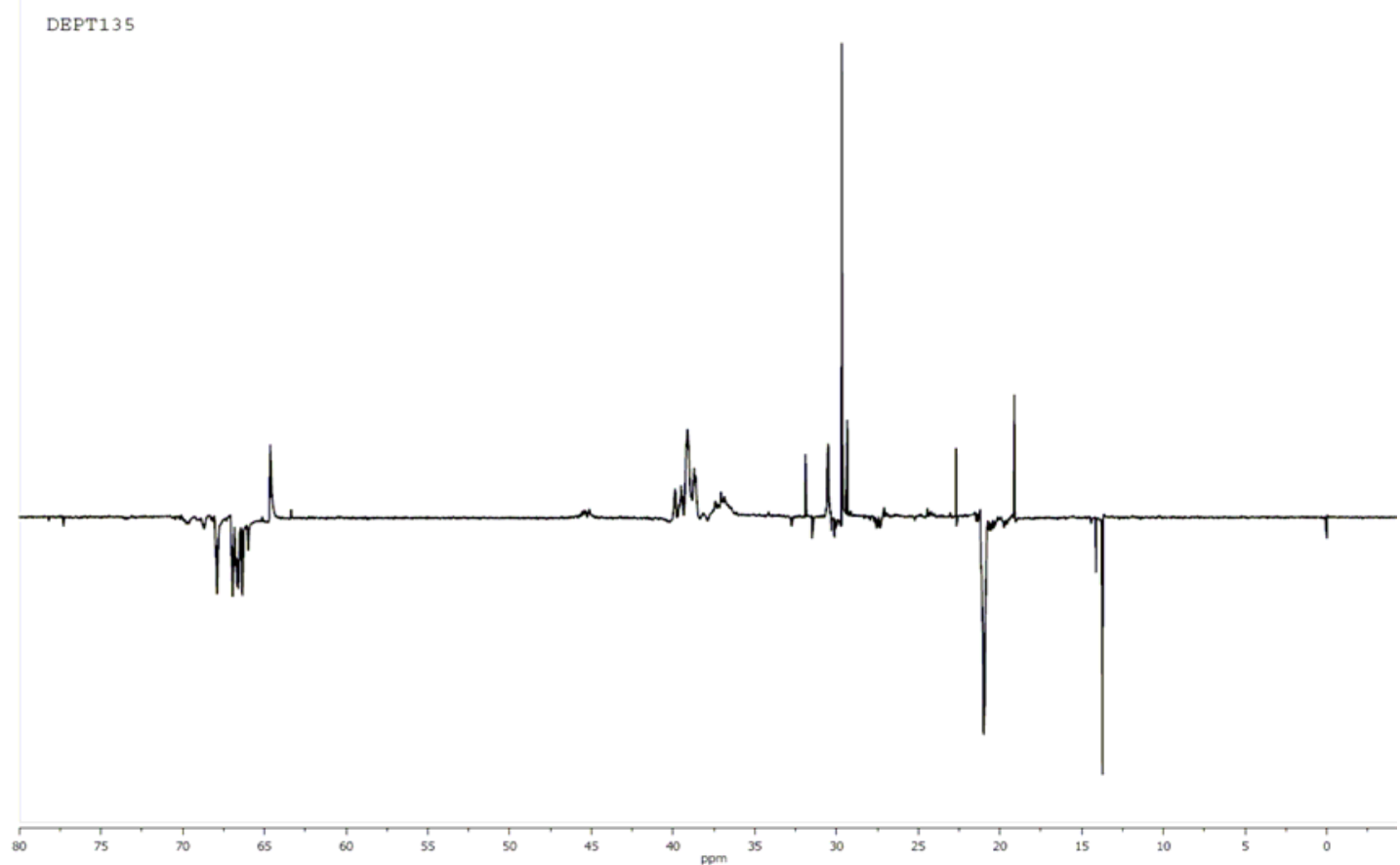

Figura A-5 - Espectro DEPT135. 

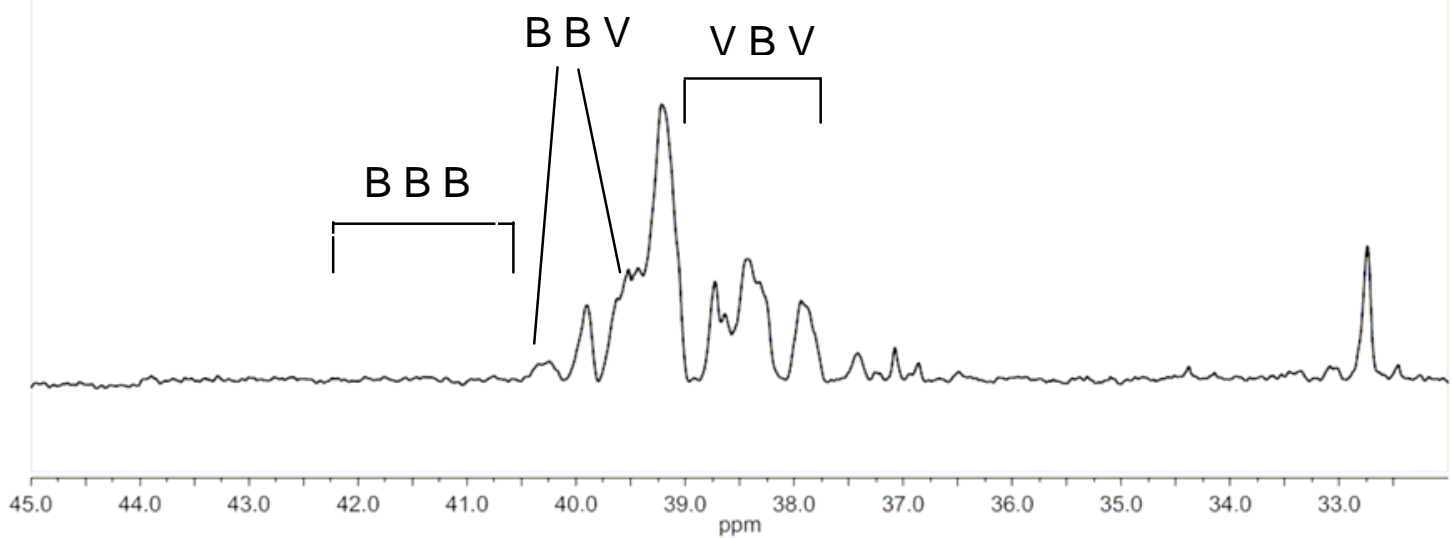

Figura A-6 - Subespectro de $\mathrm{CH}$.

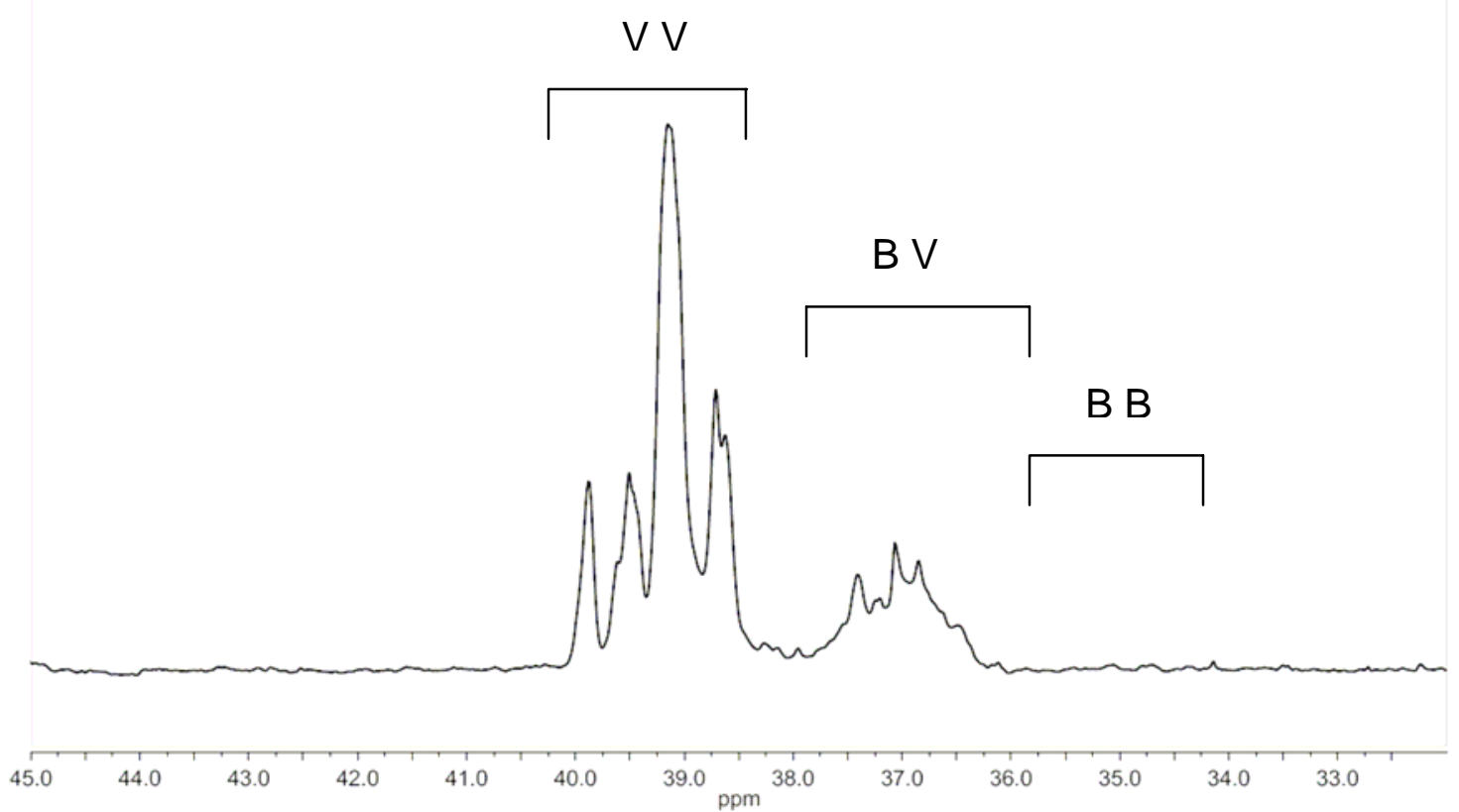

Figura A-7 - Subespectro de $\mathrm{CH}_{2}$. 
A partir das áreas obtidas nos subespectros representados nas figuras A-6 e A-7, foram obtidas as probabilidades de incidência na cadeia polimérica das possíveis seqüências de díades conforme o balanço calculado com as seguintes equações:

$$
\begin{aligned}
& (B)=(B B B)+(B B V)+(V B V) \\
& (B B)=(B B B)+1 / 2 \cdot(B B V) \\
& (V V)=(V V V)+1 / 2 .(V V B) \\
& (V)=1-(B)=(V V)+1 / 2 .(B V) \\
& (B)=(B B)+1 / 2 \cdot(B V) \\
& (B V)=1-(V V)-(B B)
\end{aligned}
$$

Onde $\mathrm{V}$ e $\mathrm{B}$ representam respectivamente as unidades monoméricas correspondentes ao acetato de vinila e ao acrilato de butila. As probabilidades de ocorrência das possíveis díades estão apresentadas na tabela A.1.

Tabela A.1 - Probabilidades de incidência das possíveis díades na cadeia polimérica.

\begin{tabular}{|c|c|c|}
\hline BV & VV & BB \\
0,216 & 0,770 & 0,014 \\
\hline
\end{tabular}

As probabilidades (B) e (V) equivalem às composições molares dos dois comonômeros correspondentes no polímero formado. De acordo com BRITTON et al.(2001), um fator $\mathrm{R}$ de randomicidade pode ser calculado a partir das probabilidades das díades conforme a equação A.7:

$$
\mathrm{R}=4(\mathrm{VV})(\mathrm{BB}) /(\mathrm{BV})^{2}
$$

Quando a seqüência de comonômeros segue uma distribuição de Bernoulli, o valor de $\mathrm{R}$ corresponde a 1 , enquanto que para tendências à formação de blocos 0 valor de R é maior 1 ou menor que 1 para seqüências mais alternadas. Para este caso, o valor calculado equivale a 0,94 , o que indica uma ligeira tendência à formação alternada do copolímero. 
Medidas de DSC.

A determinação da temperatura de transição vítrea, $T g$, de um copolímero permite verificar o seu grau de homogeneidade mediante a sua comparação com o valor da $\mathrm{Tg}$ do copolímero perfeitamente homogêneo.

Uma análise de DSC (calorimetria exploratória diferencial) foi realizada com o copolímero resultante do ensaio 10 e o correspondente diagrama de DSC está apresentado na figura A-8. A análise foi realizada em um equipamento Shimadzu DSC-50.

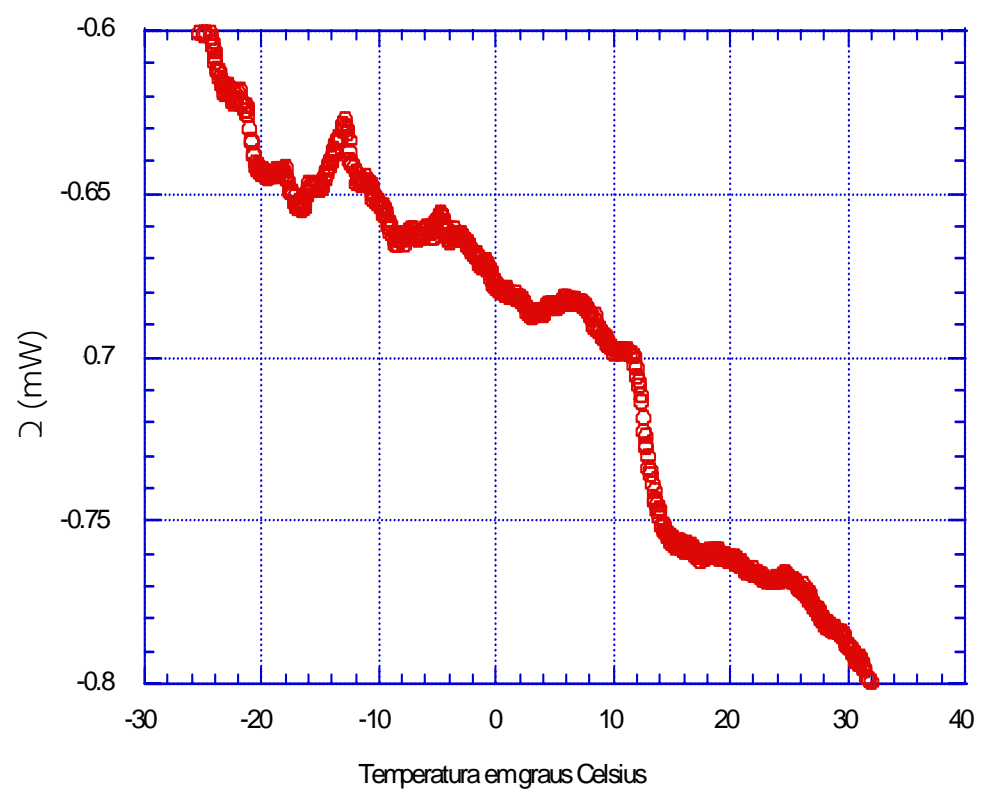

Figura A-8 - Diagrama de Calorimetria Exploratória Diferencial.

A determinação da temperatura de transição vítrea de um copolímero pode ser feita por medidas de DSC (Calorimetria Exploratória Diferencial), conforme mostrado na figura A.8, ou através das equações A.8 e A.9.

$$
\begin{aligned}
& \frac{1}{T g}=\frac{w_{1}}{T g_{1}}+\frac{w_{2}}{T g_{2}} \\
& T g=v_{1} T g_{1}+v_{2} T g_{2}
\end{aligned}
$$


A equação A8 é conhecida como a equação de Fox onde $T g, T g_{1}$ e $T g_{2}$ são respectivamente as temperaturas de transição vítrea do copolímero, do homopolímero do monômero 1 e do homopolímero do monômero 2 em $\mathrm{K}$. As variáveis $w_{1}$ e $w_{2}$ representam as frações molares dos dois monômeros.

No caso da amostra analisada, que corresponde ao produto final do ensaio 10 , as frações molares do acetato de vinila e do acrilato de butila são 0.894 e 0,106 respectivamente, e suas temperaturas de transição vítrea correspondentes são $301,15 \mathrm{~K}$ e $218,15 \mathrm{~K}$.

Aproximações melhores da $T g$ podem ser calculadas pela equação A9, também elaborada por Fox, a qual considera os fatores $v_{1}$ e $v_{2}$ que são as frações volumétricas dos monômeros no copolímero. Esta equação não é amplamente utilizada uma vez que algumas das densidades dos homopolímeros, necessárias para calcular os fatores $v_{1}$ e $v_{2}$, nem sempre são facilmente encontradas (WICKS, 1999). Para o par de monômeros VAc e BuA, nas concentrações mássicas empregadas neste trabalho, os valores dos fatores $v_{1}$ e $v_{2}$ são respectivamente 0,824 e 0,176 .

O valor previsto pela equação A8 da temperatura de transição vítrea $T g$ é 18,16 ${ }^{\circ} \mathrm{C}$ enquanto que pela equação $\mathrm{A} 9$ o valor calculado de $\mathrm{Tg}$ é $13,4{ }^{\circ} \mathrm{C}$. Pela análise da figura A.8 este valor estaria localizado no intervalo entre $12{ }^{\circ} \mathrm{C}$ e $14{ }^{\circ} \mathrm{C}$, confirmando, para este caso, a melhor precisão da equação A.9. 


\section{APÊNDICE A2 - Trabalhos Publicados Publicados pelo Autor, Relacionados com a Presente Tese.}

\section{Trabalhos em periódicos indexados internacionais}

(1) A.C.SALLARES, C. SAYER \& R.GIUDICI (2004) "Copolymer composition control during vinyl acetate - butyl acrylate emulsion polymerization reactions in a continuous pulsed sieve plate column reactor", DECHEMA Monographs Series Vol. 138, p. 231-237, WileyVCH Verlag GmbH, 2004. (ISBN 3-527-10232-9, ISSN 0070-315X).

(2) A.C.S.M. CARVALHO, D.CHICOMA, C.SAYER, R. GIUDICI (2006) "Comparison of Vinyl Acetate - Butyl Acrylate Emulsion Copolymerizations Conducted in a Continuous Pulsed Sieve Plate Column Reactor and in a Batch Stirred Tank Reactor", Macromolecular Symposia, 243(1), 147-158, Nov 2006.

(3) A.C.S.M. CARVALHO, C.SAYER, R. GIUDICI "Emulsion copolymerization process in a continuous sieve plate tubular reactor: mathematical modeling and experimental validation." (em preparação)

\section{Trabalhos em congressos internacionais}

(1) A.C.SALLARES, C. SAYER \& R.GIUDICI (2004) "Copolymer composition control during vinyl acetate - butyl acrylate emulsion polymerization reactions in a continuous pulsed sieve plate column reactor", $8^{\mathrm{TH}}$ International Workshop on Polymer Reaction Engineering, 3-6 October 2004, Hamburg/Germany.

(2) A..C.S.M. CARVALHO ; C. SAYER; R. GIUDICI (2006) "Development of a Continuous Emulsion Copolymerization Process in a Tubular Reactor". Macro 2006 World Polymer Congress 41th International Symposium on Macromolecules, Rio de Janeiro, 16-21 Julho 2006.

(3) A.C.S.M. CARVALHO, D.CHICOMA, C.SAYER, R. GIUDICI "Comparison of Vinyl Acetate - Butyl Acrylate Emulsion Copolymerizations Conducted in a Continuous Pulsed Sieve Plate Column Reactor and in a Batch Stirred Tank Reactor", PRE-VI, Polymer Reaction Engineering IV - Halifax, Canadá, 21-26 Maio 2006.

(4) A.C.S.M. CARVALHO, C.SAYER, R. GIUDICI (2007) "Development of a Continuous Emulsion Copolymerization Process in a Tubular Reactor. Copolymer Composition Optimization Employing Mathematical Model Simulation" Vingtièmes Entretiens du Centre Jacques Cartier Modeling, Monitoring and Control of Polymer Properties, Lyon, França, 1 December - 5 December 2007. 


\section{Trabalhos em congressos nacionais}

(1) A. C. S. M. CARVALHO, C. SAYER, R. GIUDICI (2005) "Desenvolvimento de processo contínuo de copolimerização em emulsão em reator tubular". $8^{\circ}$ Congresso Brasileiro de Polímeros, Águas de Lindóia, 6-10 Novembro 2005. Anais em CD-ROM. Trabalho 550.

(2) A.C.S.M. CARVALHO ; C. SAYER; R. GIUDICI (2006) "Processo Contínuo de Copolimerização em Emulsão em Reator Tubular. Efeito do Número de Alimentações Laterais sobre as Propriedades do Polímero" XVI Congresso Brasileiro de Engenharia Química COBEQ-2006, Santos, 24-27 Setembro 2006, Anais (em CD-ROM), trabalho 0910, pp. 5649-5654. 